THE INTERNATIONAL

REVIIEW OF RESEARCH IN

OPEN AND DISTANCE LEARNING

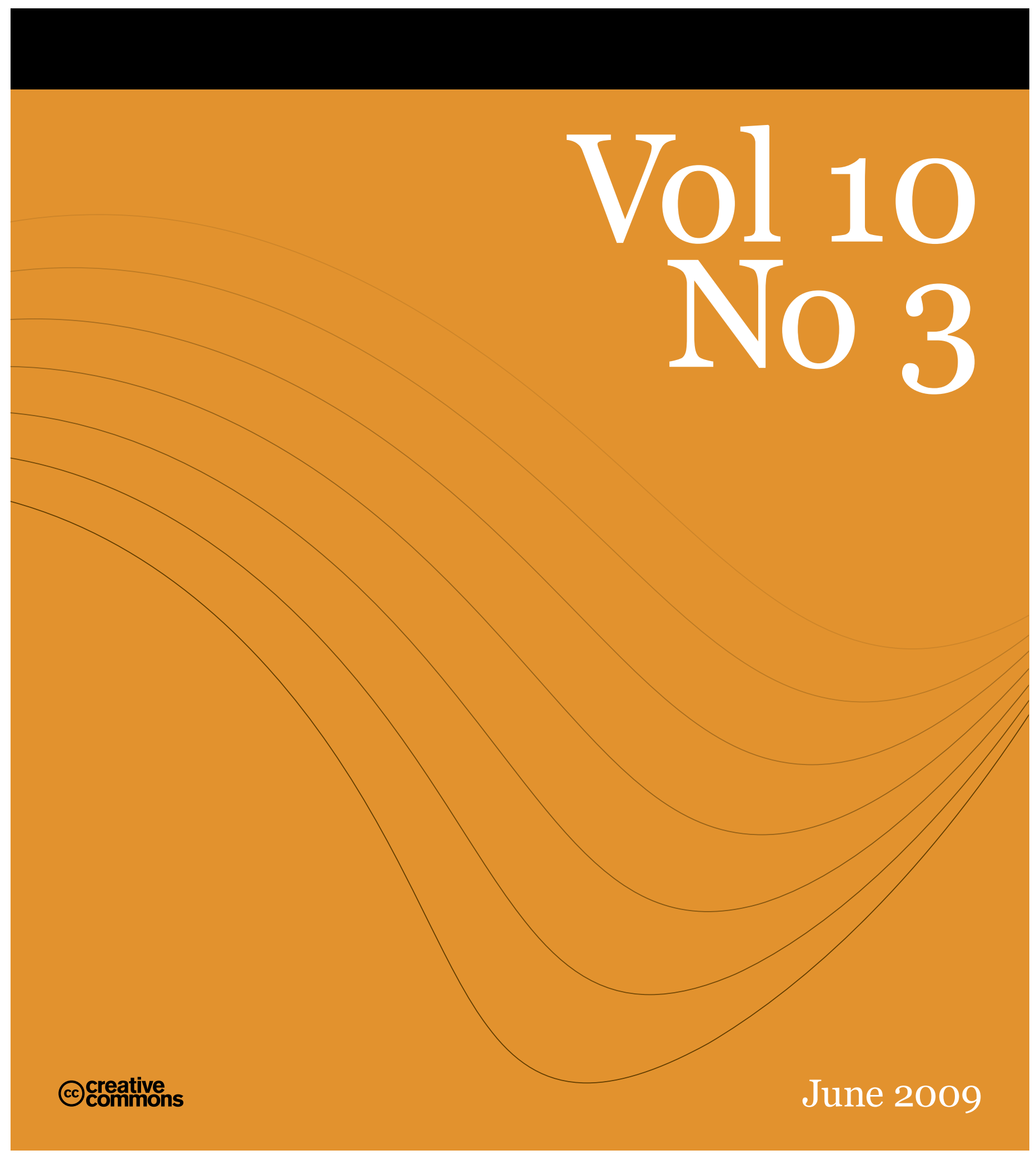


June - 2009

\title{
Editorial
}

\section{The Ratings Game}

\author{
Terry Anderson \\ Editor, IRRODL
}

This issue is notable as it is the largest single issue ever published by IRRODL! The issue contains fourteen peer-reviewed research articles, two technical reports, and links to five recordings and PowerPoint slides from research presentations to IRRODL's sister organization, the Canadian Institute for Distance Education Research (CIDER). It also contains two articles formatted for mobile devices (EPUB), and we welcome feedback, particularly from Amazon Kindle and Stanza users.

As usual, the subject and research methods employed in the articles are heterogeneous, though all content has a focus on distance education. Ten of the articles relate to innovations in teaching and learning in distance contexts. Issues covered include synchronous technologies, multimedia training in industry contexts, web conferencing in high schools, strategies to create online group collaboration, and effective and ineffective instructor behaviours. We also have two very interesting conceptual pieces, one on the role of culture in online learning and the other highlighting the effect of transparency on cooperative learning. The issue begins with two excellent articles relating directly to distance education research. The first presents the results of a Delhi study in which international experts prioritized distance education research issues and trends. The second is an article that provides a ranking system and the results when it is used to assess computer-mediated learning journals. I confess that I cannot resist bringing to your attention that IRRODL rates as the top-ranked journal amongst 46 contenders!!

The ratings game, while potentially both ego boosting and deflating for editors and authors, has very serious implications in academia. Enormous attention is placed in tenure and promotion hearings on not only the number of publications a scholar produces but also on the quality of the journals in which this work appears. Unfortunately, like many other measures of quality, determining the quality (often referred to as 'impact factor') of scholarly journals raises many issues including the validity of the results, the reliability of the measurement scales, and the effect of regional, linguistic, and pecuniary bias. Much work has been done to create valid indexes of journal quality, and Elbeck's and Mandernach's (this issue) innovative assessment strategies add to this literature. The digitization of articles and their accessibility on the web (either through subscription to databases of commercial publications or through open access) creates opportunity for new metrics to calculate impact. These include the number of downloads and links from other 
sources. However, citation of the work by one's peers remains the most credible measurement of impact.

Thus, I was very pleased to bump into the work of Australian researcher Anne-Wil Harzing and the interesting tool she has developed and released freely for non-commercial use. The downloadable tool, "Publish or Perish," uses the Google Scholar database to aggregate the number of articles and the number of times they have been cited by others. These citation numbers are then used to calculate an "impact factor" of both individual authors and journals. The tool also provides a number of algorithms that attempt to resolve the problem of multiple authors and also allow one to restrict publications used in the calculations by date or subject matter. Although Google Scholar's data collection methods remain clouded in commercial obscurity, Harzing's tool is at worst very entertaining and at best a very informative means by which researchers can select appropriate journals for publication and quantitatively measure the impact of their own and their colleagues' work. I won't give the results away (yet), but please feel free to spend a few entertaining minutes comparing the 12 distance education journals currently publishing or calculate your own and your colleagues' impact factors! 
June - 2009

\title{
Research Areas in Distance Education: A Delphi Study
}

\author{
Olaf Zawacki-Richter \\ FernUniversität in Hagen, Germany
}

\begin{abstract}
This study had three purposes: Firstly, to develop a categorization of research areas in distance education; secondly, to identify the most important research areas in distance education; and thirdly, to identify the most neglected research areas in distance education. Based on a literature review and a Delphi study, three broad levels or perspectives with 15 research areas were derived to organize the body of knowledge in distance education. Prospective researchers can use the results to identify gaps and priority areas and to explore potential research directions.
\end{abstract}

Keywords: Distance education research areas; literature reviews; Delphi study

\section{Introduction}

Research on distance education has been subject to consistent critique (Bernard et al., 2004; Moore, 1985; Perraton, 2000; Saba, 2000). It has even been characterized as "atheoretical and predominantly descriptive" (Perraton, 2000, p. 1). Research questions should be posed within a theoretical framework and embedded in a holistic structure of research areas within a discipline. However, in the field of distance education, a validated meta-structure of research topics is lacking, i.e., a map of research areas that would help to organize the body of knowledge in the field. Furthermore, the structure of a research discipline forms the foundation for identifying gaps and priority areas for researchers. With regard to distance education, Mishra (1998) makes a plea for "a comprehensive and cohesive structure internationally to provide a strong foundation to the discipline" (p. 281).

Many reviews of the distance education literature have been conducted in which authors developed categorization schemes that were mapped onto publications under review. By and large, there is general agreement on the basic research topics in distance education, such as student support, instructional design, educational technologies, or interactivity through media. However, the various attempts to describe the broad and interdisciplinary field of distance education show a disparate picture. 
The aim of this paper is to posit a validated classification of research areas in distance education through the systematic analysis of expert responses in a Delphi study, seeking to clarify the following questions:

(1) What are the research areas in distance education, and how can they be categorized?

(2) What are the most important distance education research areas?

(3) What are the most neglected areas of distance education research?

The results are used to explore potential research directions and priority areas based on a solid classification of existing research areas in distance education.

\section{Literature Review}

The first attempt to describe the structure of the distance education discipline was proposed by Holmberg (1985). In the second edition of his book Status and Trends of Distance Education, he provides a systematic bibliography. His categorization system includes the following areas:

1. philosophy and theory of distance education;

2. distance students, their milieu, conditions, and study motivations;

3. subject matter presentation;

4. communication and interaction between students and their supporting organization (tutors, counsellors, administrators, other students);

5. administration and organization;

6. economics;

7. systems (comparative distance education, typologies, evaluation, etc.); and

8. history of distance education.

Over the years a number of reviews of distance education literature have been published in which the authors developed categorization schemes of research areas that they mapped onto the articles under review:

- Scriven (1991, p. 141) used the following nine headings to classify articles that were published in the first ten years of the journal Distance Education: (1) students and their characteristics; (2) specific programmes and courses; (3) telecommunications and media; (4) specific countries - practices and procedures; (5) theory; (6) course design and development; (7) economics and management; (8) counselling and student support; and (9) tutors, staff development, staff involvement.

- Panda (1992) reviewed 142 studies on distance education conducted in India under nine broad themes (p. 314): (1) concept, growth, and development; (2) curriculum, course planning, and development; (3) instruction and teaching; (4) 
media and technology; (5) learners and learning; (6) institutional policy and management; (7) economics; (8) evaluation and programme evaluation; and (9) staff development. Panda (1992) furthermore provided a conceptual framework for distance education research based on the model of systems philosophy, distinguishing between input (e.g. courses, students, staff development), process (e.g. two-way communication, student support services, evaluation) and output variables (e.g., student achievement and satisfaction, effectiveness and efficiency of the entire system).

- A similar study was conducted by Koble and Bunker (1997) for The American Journal of Distance Education (1987-1995) with the following classification: (1) theory, policy, and development; (2) media and delivery systems (effectiveness, evaluation, methods); (3) institution, staff, and management; (4) student psychology, motivation, and characteristics; (5) faculty participation and instructional process; (6) course design and curriculum development; and (7) student administration and support.

- In the same year, Mishra (1997) published an analysis of periodical literature in distance education (1991-1996) with seven major groups and 34 sub-groups of research topics (p. 49). The major groups in this classification are as follows: (1) distance education in perspective (including open learning, growth and development, equity and access); (2) students and their learning (including learner characteristics, drop out, cognition, student support, interaction, and feedback); (3) learning materials and related issues (including design and development of study materials, learning from media); (4) technology issues; (5) management issues (including planning, economics, evaluation, and quality assurance); (6) distance education theory, research and training/professional development; and (7) distance education in practice (including distance education institutions and teacher education).

- Berge and Mrozowski (2001, p. 7) adopted Sherry's ten issues in distance education (Sherry, 1996) for their review of research in distance education between 1990 and 1999, with the following outcome: (1) redefining roles of key participants with focus on training (teachers, students, and site facilitators); (2) technology selection and adaptation; (3) design issues; (4) strategies to increase interactivity and active learning; (5) learner characteristics; (6) learner support; (7) operational issues (planning, administration, management, and economics); (8) policy and management; (9) equity and accessibility; and (10) cost/benefit trade-offs. 
- Rourke and Szabo (2002) applied nine categories for a content analysis of the Canadian Journal of Distance Education (1986-2001): (1) administration: budgeting, change, inter-institutional cooperation, staffing; (2) evaluation: judgment of the worth, value, success of a course, program, or courseware; (3) foundations: semantics, definitions, history, models; (4) instructional design: course, program, or product design, development, and delivery; (5) instructor characteristics: satisfaction, motivation, attitude, perceptions, teaching style, gender, demographics; (6) international perspectives: practices, procedures, role of distance education in specific countries; (7) learner characteristics: satisfaction, motivation, attitude, perceptions, learning styles, cognitive styles, attrition, gender, demographics; (8) technology and media: educational radio, educational TV, video, audio, computer conferencing; and (9) trends: discussion of the general direction or inclination of issues and topics in the field.

- Lee, Driscoll, and Nelson (2004, p. 227) developed a system consisting of six categories for grouping distance education literature: (1) design-related topics: needs assessment, course scheduling, course design, instructional strategy development, course material design, and visual design; (2) development-related topics: course support system and material development, web-based learning management system building, online tools development, and online testing system development; (3) management-related topics: learning resource management, troubleshooting, attrition rate, faculty and staff support, learner support, and technical support; (4) evaluation-related topics: program quality control, assessment of learning outcomes, benefits and cost analysis, return on investment, evaluation of supporting system; (5) institutional and operational-related topics: administration, academic affairs, accreditation, certification, policy, payment, and budgeting; and (6) theory and research-related topics: distance education theory building, review of literature, introduction to new research methods, culture and gender issues, learning style, history of distance education, and copyright law.

In order to identify distance education research priorities for Australia, Jegede (1994) developed a questionnaire that was validated by a group of 36 Australian distance education researchers and practitioners. The questionnaire contained 22 broad groupings of research areas: (1) theory and philosophy; (2) learner characteristics; (3) equity and access; (4) design and development of study materials; (5) instructional and communications technology; (6) tele-teaching and learning; (7) management and planning; (8) student support services; (9) development of students' study skills; (10) systems for the provision of feedback to students; (11) interactive multimedia; (12) discipline based context; (13) cognition and metacognition; (14) cost benefit analysis; (15) relationship between open learning and distance education; (16) industrial and business training context; (17) research methodology; (18) evaluation; (19) expert learning systems; (20) role of 
distance education in national development; (21) teacher education; and (22) professional development of distance educators.

In contrast to the listings of research topics described above, this paper reports on an attempt to structure the broad and interdisciplinary research areas in the field of distance education based on a systematic analysis of expert responses in a Delphi study.

\section{Methodology}

The Delphi technique was selected to develop a consensus among a group of experts on common areas that are or should be covered in distance education research: "It is important that participants be, in some sense, 'experts' for valid results to be reached, and there should be sufficient participants that the extreme views of a few do not influence the results for the group disproportionately" (Charlton, 2004, p. 245). The essential element in the Delphi process is anonymity of participants when giving their opinion. The Delphi, then, alleviates problems that could be caused by domination of the group by a few prestigious or powerful individuals. According to Isaac and Michael (1995), the Delphi method of group interaction avoids the following disadvantages of face-to-face discussions: the bandwagon tendency, the vulnerability to manipulation, and the reticence on the part of individuals to change their minds in front of others.

A careful process was followed that resulted in three criteria for selecting experts, from which the eventual expert panel emerged. The three criteria were that the expert has achieved the following:

- a significant contribution to the distance education literature;

- at least 10 years of professional experience in the field of distance education; and

- a willingness to contribute.

All current members of the editorial boards of four major distance education journals were invited to participate. Furthermore, the invitation was sent to current and former faculty members in a master's of distance education program in which the author of this paper is also teaching, among them Tony Bates, Börje Holmberg, Som Naidu, and Otto Peters. A personal interview was carried out with Professor Peters at the FernUniversität in Hagen.

The final expert panel comprised 25 individuals from 11 countries (Australia, Brazil, Canada, China, Fiji, Germany, Ireland, New Zealand, South Africa, UK, and USA). Nineteen of the 25 experts participated in both rounds of the Delphi study. The required time to collect the data was four months from September to December 2008.

The respondents $(N=19)$ reported an average of 27 years of professional experience in distance education, ranging from 10 to 40 years. Twelve of them (63\%) sit on editorial boards, and two are editors of prominent distance education journals. Six (32\%) of the experts were women and $13(68 \%)$ were men. The panel consisted of eight directors, ten professors, four senior researchers, one instructional designer, and one manager. Five panellists reported dual titles of professor and director or researcher and manager resulting in 24 professional titles. 
In the first round of the Delphi study, the experts were asked via e-mail to list at least 10 issues or research areas that are most important for the development of theory and practice in distance education. Based on a qualitative text analysis of the responses using ATLAS.ti and a literature review on the topic, a categorization of research areas was developed. In order to identify priority areas, the second round of online questionnaire required participants to rate the research areas on a scale of importance ranging from 1 to 10, with 1 labeled "very low importance" and 10 labeled "very high importance." They were also asked to identify the most neglected research areas. This questionnaire was completed by 19 of 25 experts ( $76 \%$ response rate).

The study is limited to English-speaking experts in distance education with access to the Internet. Therefore, the results may not be generalizable to certain non-English speaking settings or where the technical infrastructure does not allow access to the Internet. Due to the small group size complex statistical analysis cannot be done. The reported results are therefore descriptive and the median is chosen as the measure of central tendency to depict experts' ratings.

\section{Results}

Three research questions were addressed in this study.

Question 1: What are the research areas in distance education, and how can they be classified?

This question was addressed in round one of the Delphi study. The experts were asked via e-mail to list 10 research areas in distance education (DE). Table 1 shows a list of the most common research themes and their frequency when analysing the responses $(N=25)$.

Table 1

Frequency $(f)$ of Codes

\begin{tabular}{|l|l|}
\hline Code & f \\
\hline $\begin{array}{l}\text { Educational } \\
\text { technology }\end{array}$ & 21 \\
\hline Instructional design & 20 \\
\hline Costs and benefits & 15 \\
\hline Quality assurance & 14 \\
\hline Access \& equity & 12 \\
\hline Pedagogy & 12 \\
\hline Learner support & 11 \\
\hline Management & 11 \\
\hline
\end{tabular}

\begin{tabular}{|l|l|}
\hline Code & f \\
\hline Interaction/communication & 7 \\
\hline DE in developing areas & 6 \\
\hline DE Systems & 6 \\
\hline Mobile learning & 6 \\
\hline Open ed. resources & 6 \\
\hline Tutoring & 6 \\
\hline Change management & 5 \\
\hline Changing roles & \\
\hline
\end{tabular}

\begin{tabular}{|l|l|}
\hline Code & f \\
\hline Globalisation & 4 \\
\hline $\begin{array}{l}\text { Learner } \\
\text { characteristics }\end{array}$ & 4 \\
\hline Learning styles & 4 \\
\hline Online communities & 4 \\
\hline Policy of & 3 \\
\hline $\begin{array}{l}\text { Competencies } \\
\text { learners }\end{array}$ & 3 \\
\hline $\begin{array}{l}\text { Curriculum } \\
\text { development }\end{array}$ & 3 \\
\hline Enrollments
\end{tabular}




\begin{tabular}{|l|l|}
\hline Assessment & 8 \\
\hline Cross-cultural aspects & 8 \\
\hline Theories and models & 8 \\
\hline Web 2.0 & 8 \\
\hline Course evaluation & 7 \\
\hline $\begin{array}{l}\text { Professional } \\
\text { development }\end{array}$ & 7 \\
\hline Innovation & 7 \\
\hline
\end{tabular}

\begin{tabular}{|l|l|}
\hline Drop-out & 5 \\
\hline Incentives & 5 \\
\hline Knowledge transfer & 5 \\
& \\
\hline Leadership and strategy & 5 \\
\hline Continuing education & 4 \\
\hline DE institutions & 4 \\
\hline Effectiveness of DE & 4 \\
\hline
\end{tabular}

\begin{tabular}{|l|l|}
\hline Ethics & 3 \\
\hline Future trends & 3 \\
\hline $\begin{array}{l}\text { Institutional } \\
\text { partnerships }\end{array}$ & 3 \\
\hline Media selection & 3 \\
\hline Multimedia & 3 \\
\hline $\begin{array}{l}\text { Prior learning } \\
\text { assessm. }\end{array}$ & 3 \\
\hline Reputation of DE & 3 \\
\hline
\end{tabular}

Based on a literature review on the topic and a qualitative analysis of the responses from the panellists, three broad meta-levels of distance education research were derived:

1. macro level: distance education systems and theories;

2. meso level: management, organization, and technology;

3. micro level: teaching and learning in distance education.

Under these three levels, the research issues that are considered important by the experts can be categorized into 15 research areas that are briefly characterized in the following table.

Table 2

Classification of Research Areas in Distance Education

\begin{tabular}{|l|l|}
\hline Macro level: Distance education systems and theories \\
\hline Access, equity, and ethics & $\begin{array}{l}\text { The democratization of access to distance education } \\
\text { afforded by new media and finding ways to deliver high } \\
\text { quality education to those who have limited resources and } \\
\text { poor infrastructure. Issues that refer to the (sustainable) } \\
\text { provision of distance education in developing areas. What is } \\
\text { the impact of distance education (e.g. via mobile learning) } \\
\text { on narrowing the digital divide and what is the role of ICT } \\
\text { (information and communication technologies) and/or OER } \\
\text { (open educational resources) on access to education? }\end{array}$ \\
\hline $\begin{array}{l}\text { Globalization of education } \\
\text { and cross-cultural aspects }\end{array}$ & $\begin{array}{l}\text { Aspects that refer to the global external environment and } \\
\text { drivers, the development of the global distance education } \\
\text { market, teaching and learning in mediated global } \\
\text { environments and its implications for professional } \\
\text { development. }\end{array}$ \\
\hline $\begin{array}{l}\text { Distance teaching systems } \\
\text { and institutions }\end{array}$ & $\begin{array}{l}\text { Distance education delivery systems, the role of institutional } \\
\text { partnerships in developing transnational programmes, and }\end{array}$ \\
\hline
\end{tabular}




\begin{tabular}{|c|c|}
\hline & $\begin{array}{l}\text { the impact of ICT on the convergence of conventional } \\
\text { education and distance education institutions (hybrid or } \\
\text { mixed-mode). }\end{array}$ \\
\hline Theories and models & $\begin{array}{l}\text { Theoretical frameworks for and foundations of distance } \\
\text { education, e. g. the theoretical basis of instructional models, } \\
\text { knowledge construction, interaction between learners, or the } \\
\text { impact of social constructivism learning theories on distance } \\
\text { education practice. }\end{array}$ \\
\hline $\begin{array}{l}\text { Research methods in } \\
\text { distance education and } \\
\text { knowledge transfer }\end{array}$ & $\begin{array}{l}\text { Methodological considerations, the impact of distance } \\
\text { education research and writing on practice and the role of } \\
\text { professional associations in improving practice. Literature } \\
\text { reviews and works on the history of distance education are } \\
\text { subsumed under this area. }\end{array}$ \\
\hline \multicolumn{2}{|c|}{ Meso level: Management, organization, and technology } \\
\hline $\begin{array}{l}\text { Management and } \\
\text { organization }\end{array}$ & $\begin{array}{l}\text { Strategies, administration, and organizational infrastructures } \\
\text { and frameworks for the development, implementation, and } \\
\text { sustainable delivery of distance education programmes. } \\
\text { What is required for successful leadership in distance } \\
\text { education? Distance education and policies relating to } \\
\text { continuing education and lifelong learning and the impact of } \\
\text { online learning on institutional policies, as well as legal } \\
\text { issues (copyright and intellectual property). }\end{array}$ \\
\hline Costs and benefits & $\begin{array}{l}\text { Aspects that refer to financial management, costing, pricing, } \\
\text { and business models in distance education. Efficiency: What } \\
\text { is the return on investment or impact of distance education } \\
\text { programmes? What is the impact of ICT on the costing } \\
\text { models and the scalability of distance education delivery? } \\
\text { How to provide cost effective but meaningful learner } \\
\text { support. }\end{array}$ \\
\hline Educational technology & $\begin{array}{l}\text { New trends in educational technology for distance education } \\
\text { (e.g. Web } 2.0 \text { applications or mobile learning) and the } \\
\text { benefits and challenges of using OERs, media selection (e.g. } \\
\text { synchronous vs. asynchronous media), technical } \\
\text { infrastructure and equipment for online learning } \\
\text { environments and their opportunities for teaching and } \\
\text { learning. }\end{array}$ \\
\hline Innovation and change & $\begin{array}{l}\text { Issues that refer to educational innovation with new media } \\
\text { and measures to support and facilitate change in institutions } \\
\text { (e.g. incentive systems for faculty, aspects referring to staff } \\
\text { workloads, promotion and tenure). }\end{array}$ \\
\hline
\end{tabular}




\begin{tabular}{|c|c|}
\hline $\begin{array}{l}\text { Professional development } \\
\text { and faculty support }\end{array}$ & $\begin{array}{l}\text { Professional development and faculty support services as a } \\
\text { prerequisite for innovation and change. What are the } \\
\text { competencies of online teachers and how can they be } \\
\text { developed? }\end{array}$ \\
\hline Learner support services & $\begin{array}{l}\text { The infrastructure for and the organization of learner } \\
\text { support systems (from information and counselling for } \\
\text { prospective students through library services and technical } \\
\text { support to career services and alumni networks). }\end{array}$ \\
\hline Quality assurance & $\begin{array}{l}\text { Issues that refer to accreditation and quality standards in } \\
\text { distance education. The impact of quality assurance and } \\
\text { high quality learner support on enrolments and drop- } \\
\text { out/retention, as well as reputation and acceptance of } \\
\text { distance education as a valid form of educational provision. }\end{array}$ \\
\hline \multicolumn{2}{|c|}{ Micro level: Teaching and learning in distance education } \\
\hline Instructional design & $\begin{array}{l}\text { Issues that refer to the stages of the instructional design } \\
\text { process for curriculum and course development. Special } \\
\text { emphasis is placed on pedagogical approaches for tutoring } \\
\text { online (scaffolding), the design of (culturally appropriate) } \\
\text { study material, opportunities of new developments in } \\
\text { educational technology for teaching and learning (e.g. Web } \\
2.0 \text { applications and mobile devices), as well as assessment } \\
\text { practices in distance education. }\end{array}$ \\
\hline $\begin{array}{l}\text { Interaction and } \\
\text { communication in } \\
\text { learning communities }\end{array}$ & $\begin{array}{l}\text { Closely related to instructional design considerations is } \\
\text { course design that fosters (online) articulation, interaction, } \\
\text { reflection, and collaboration throughout the learning and } \\
\text { teaching process. Special areas include the development of } \\
\text { online communities and gender differences and cross- } \\
\text { cultural aspects in online communication. }\end{array}$ \\
\hline Learner characteristics & $\begin{array}{l}\text { The aims and goals of adult learners, the socio-economic } \\
\text { background of distance education students, their different } \\
\text { learning styles, critical thinking dispositions, and special } \\
\text { needs. How do students learn online (learner behavior } \\
\text { patterns, learning styles) and what competencies are needed } \\
\text { for distance learning (e.g. 'digital literacy')? }\end{array}$ \\
\hline
\end{tabular}

A clear and non-ambiguous separation of research areas into categories is not easy in all cases. Some areas are considered on different levels. Cross-sectional fields are concerned with issues that refer to quality assurance and evaluation, educational technologies, and cross-cultural aspects. 
If the focus is placed on the evaluation or accreditation of whole institutions or programmes or, for example, the research is about the development of a general, institution-wide instrument to measure learner satisfaction, the issues are classified on the meso level: management, organization, and technology. However, if emphasis is placed on the evaluation of single courses, learning groups, or courseware (e.g., print-based study materials or multimedia applications), the topics are subsumed under the micro level: teaching and learning in distance education (evaluation as a step in the instructional design process).

The same applies to cross-cultural issues between the macro, meso, and micro levels. Crosscultural aspects have to be considered in international cooperation in the global education market (macro level) and in the planning, implementation, and management of transnational programmes to address the needs of an internationally dispersed student body, or 'target group' to use the terms of management and marketing (meso level). Intercultural communication plays an important role in classes with mixed cohorts of students from all over the world. Of course this also has implications for competencies required by distance educators on the meso level (professional development and faculty support).

Finally, the application of educational technologies has implications on all three dimensions. Issues that refer to access to educational technologies and infrastructure have to be considered on the global macro level. The introduction of new media for learning and teaching in institutions has a strong impact on educational management on the meso level, e.g., issues that refer to the organizational support and infrastructure for educational technologies, their costs, quality assurance, implications for organizational change, and the resulting need for professional development. Research that emphasizes the pedagogical opportunities that new media afford for teaching and learning falls into categories on the micro level (e.g., instructional design and mediated interaction and communication).

\section{Question 2: What are the most important distance education research areas?}

In the second round of the Delphi study the experts were asked to rate the 15 research areas described above on a scale of importance ranging from 1 to 10 , with 1 labeled "very low importance" and 10 labeled "very high importance."

The distribution of the experts' ratings on the importance of research areas in distance education is depicted in Figure 1. The box plot shows the median, which is less sensitive to extreme ratings by the small group of experts $(N=19)$ and the corresponding inter-quartile range (IQR). The IQR is defined as the difference between the twenty-fifth and the seventy-fifth quartiles, i.e., the tinted boxes in Figure 1 show the middle $50 \%$ of scores (Field, 2005, p. 75). 


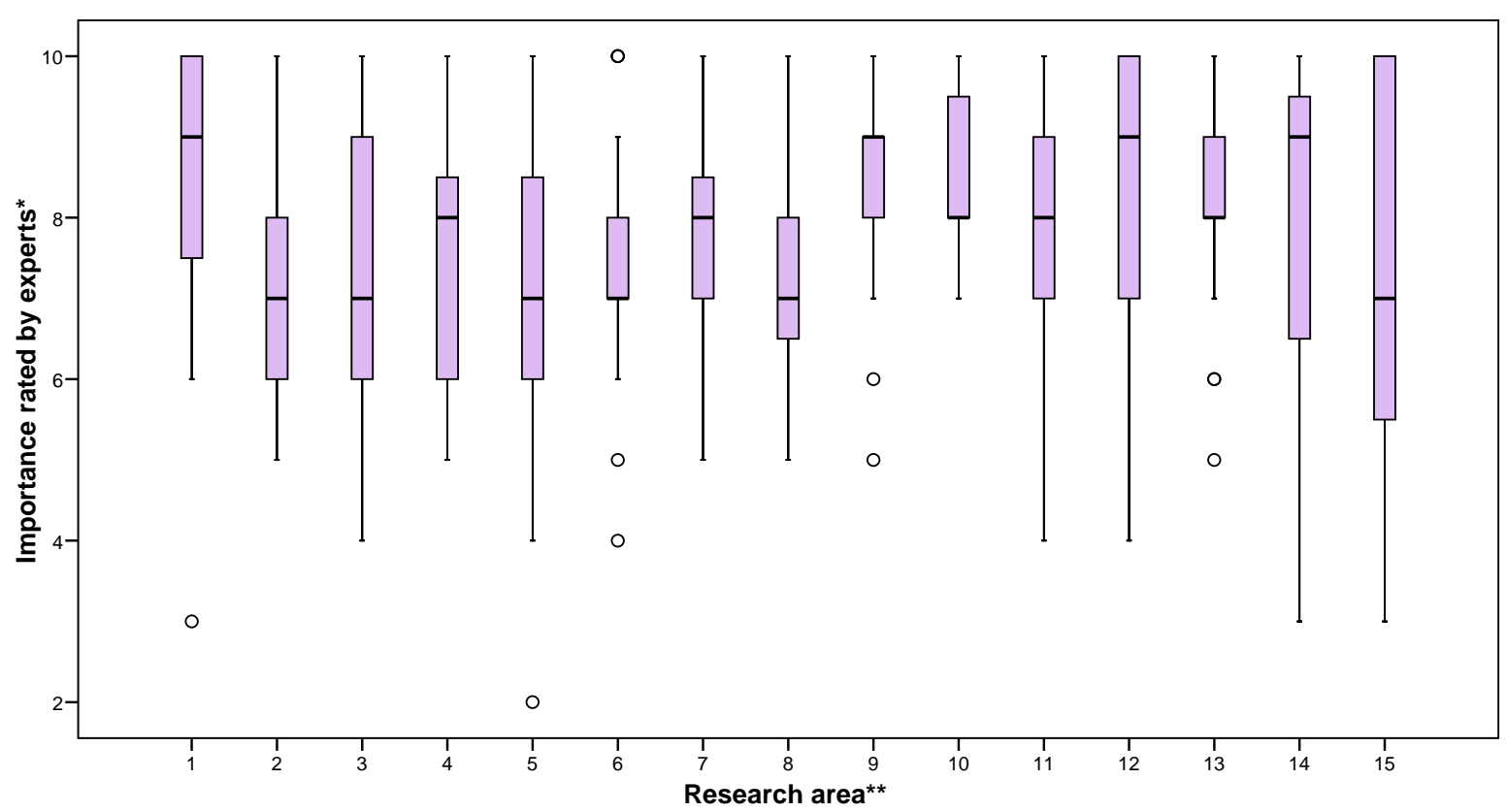

Figure. 1: Distribution of experts' ratings on the importance of research areas in distance education.

* scale ranges from $1=$ very low importance to $10=$ very high importance

** 1 =Access, equity and ethics; $2=$ Globalisation of education and cross-cultural aspects; $3=$ Distance teaching systems and institutions; 4=Theories and models; 5=Research methods in distance education and knowledge transfer; 6=Management and organization; 7=Costs and benefits; 8=Educational technology; 9=Innovation and change; $10=$ Professional development and faculty support; 11=Learner support services; 12=Quality assurance; 13=Instructional design; 14=Interaction and communication in learning communities; 15=Learner characteristics

A high level of agreement on the importance of a research area can be observed for management (6), innovation and change issues (9), professional development and faculty support (10), and instructional design (13); whereas, the widest range of ratings can be reported for issues that refer to learner characteristics (15).

The areas most frequently mentioned as being of high or very high importance ( 9 or 10 on the scale) are the following: Interaction and communication in learning communities (14) (57.9\%); access, equity, and ethics (1), innovation and change (9), quality assurance (12) (52.6\%); and learner support services (11) (47.4\%). These are followed by professional development and faculty support (10), instructional design (13), and learner characteristics (15) (42.1\%).

Table 3 presents the frequency tabulation of the responses to all items $(N=19)$, with the percentage frequencies in parentheses. 
Table 3

Frequency Tabulation of Responses Regarding the Importance of Research Areas in Distance Education

\begin{tabular}{|c|c|c|c|c|c|c|c|c|c|c|}
\hline & \multicolumn{10}{|c|}{ Scale of importance** } \\
\hline $\begin{array}{l}\text { Researc } \\
\text { h area* }\end{array}$ & 1 & 2 & 3 & 4 & 5 & 6 & 7 & 8 & 9 & 10 \\
\hline 1 & $\begin{array}{l}0 \\
(0.0)\end{array}$ & $\begin{array}{l}0 \\
(0.0)\end{array}$ & $\begin{array}{l}1 \\
(5.3)\end{array}$ & $\begin{array}{l}0 \\
(0.0)\end{array}$ & $\begin{array}{l}0 \\
(0.0)\end{array}$ & $\begin{array}{l}1 \\
(5.3)\end{array}$ & $\begin{array}{l}3 \\
(15.8)\end{array}$ & $\begin{array}{l}4 \\
(21.1)\end{array}$ & $\begin{array}{l}3 \\
(15.8)\end{array}$ & $\begin{array}{l}7 \\
(36.8)\end{array}$ \\
\hline 2 & $\begin{array}{l}0 \\
(0.0)\end{array}$ & $\begin{array}{l}0 \\
(0.0)\end{array}$ & $\begin{array}{l}0 \\
(0.0)\end{array}$ & $\begin{array}{l}1 \\
(5.3)\end{array}$ & $\begin{array}{l}1 \\
(5.3)\end{array}$ & $\begin{array}{l}7 \\
(36.8)\end{array}$ & $\begin{array}{l}1 \\
(5.3)\end{array}$ & $\begin{array}{l}3 \\
(15.8)\end{array}$ & $\begin{array}{l}4 \\
(21.1)\end{array}$ & $\begin{array}{l}2 \\
(10.5)\end{array}$ \\
\hline 3 & $\begin{array}{l}0 \\
(0.0)\end{array}$ & $\begin{array}{l}0 \\
(0.0)\end{array}$ & $\begin{array}{l}0 \\
(0.0)\end{array}$ & $\begin{array}{l}0 \\
(0.0)\end{array}$ & $\begin{array}{l}2 \\
(10.5)\end{array}$ & $\begin{array}{l}5 \\
(26.3)\end{array}$ & $\begin{array}{l}3 \\
(15.8)\end{array}$ & $\begin{array}{l}7 \\
(36.8)\end{array}$ & $\begin{array}{l}1 \\
(5.3)\end{array}$ & $\begin{array}{l}1 \\
(5.3)\end{array}$ \\
\hline 4 & $\begin{array}{l}0 \\
(0.0)\end{array}$ & $\begin{array}{l}0 \\
(0.0)\end{array}$ & $\begin{array}{l}0 \\
(0.0)\end{array}$ & $\begin{array}{l}0 \\
(0.0)\end{array}$ & $\begin{array}{l}2 \\
(10.5)\end{array}$ & $\begin{array}{l}6 \\
(31.6)\end{array}$ & $\begin{array}{l}1 \\
(5.3)\end{array}$ & $\begin{array}{l}5 \\
(26.3)\end{array}$ & $\begin{array}{l}2 \\
(10.5)\end{array}$ & $\begin{array}{l}3 \\
(15.8)\end{array}$ \\
\hline 5 & $\begin{array}{l}0 \\
(0.0)\end{array}$ & $\begin{array}{l}1 \\
(5.3)\end{array}$ & $\begin{array}{l}0 \\
(0.0)\end{array}$ & $\begin{array}{l}1 \\
(5.3)\end{array}$ & $\begin{array}{l}2 \\
(10.5)\end{array}$ & $\begin{array}{l}4 \\
(21.1)\end{array}$ & $\begin{array}{l}4 \\
(21.1)\end{array}$ & $\begin{array}{l}2 \\
(10.5)\end{array}$ & $\begin{array}{l}3 \\
(15.8)\end{array}$ & $\begin{array}{l}2 \\
(10.5)\end{array}$ \\
\hline 6 & $\begin{array}{l}0 \\
(0.0)\end{array}$ & $\begin{array}{l}0 \\
(0.0)\end{array}$ & $\begin{array}{l}0 \\
(0.0)\end{array}$ & $\begin{array}{l}1 \\
(5.3)\end{array}$ & $\begin{array}{l}1 \\
(5.3)\end{array}$ & $\begin{array}{l}2 \\
(10.5)\end{array}$ & $\begin{array}{l}9 \\
(47.4)\end{array}$ & $\begin{array}{l}2 \\
(10.5)\end{array}$ & $\begin{array}{l}1 \\
(5.3)\end{array}$ & $\begin{array}{l}3 \\
(15.8)\end{array}$ \\
\hline 7 & $\begin{array}{l}0 \\
(0.0)\end{array}$ & $\begin{array}{l}0 \\
(0.0)\end{array}$ & $\begin{array}{l}0 \\
(0.0)\end{array}$ & $\begin{array}{l}0 \\
(0.0)\end{array}$ & $\begin{array}{l}1 \\
(5.3)\end{array}$ & $\begin{array}{l}1 \\
(5.3)\end{array}$ & $\begin{array}{l}5 \\
(26.3)\end{array}$ & $\begin{array}{l}7 \\
(36.8)\end{array}$ & $\begin{array}{l}3 \\
(15.8)\end{array}$ & $\begin{array}{l}2 \\
(10.5)\end{array}$ \\
\hline 8 & $\begin{array}{l}0 \\
(0.0)\end{array}$ & $\begin{array}{l}0 \\
(0.0)\end{array}$ & $\begin{array}{l}0 \\
(0.0)\end{array}$ & $\begin{array}{l}0 \\
(0.0)\end{array}$ & $\begin{array}{l}5 \\
(26.3)\end{array}$ & $\begin{array}{l}2 \\
(10.5)\end{array}$ & $\begin{array}{l}6 \\
(31.6)\end{array}$ & $\begin{array}{l}4 \\
(21.1)\end{array}$ & $\begin{array}{l}1 \\
(5.3)\end{array}$ & $\begin{array}{l}5 \\
(26.3)\end{array}$ \\
\hline 9 & $\begin{array}{l}0 \\
(0.0)\end{array}$ & $\begin{array}{l}0 \\
(0.0)\end{array}$ & $\begin{array}{l}0 \\
(0.0)\end{array}$ & $\begin{array}{l}0 \\
(0.0)\end{array}$ & $\begin{array}{l}1 \\
(5.3)\end{array}$ & $\begin{array}{l}1 \\
(5.3)\end{array}$ & $\begin{array}{l}1 \\
(5.3)\end{array}$ & $\begin{array}{l}6 \\
(31.6)\end{array}$ & $\begin{array}{l}6 \\
(31.6)\end{array}$ & $\begin{array}{l}4 \\
(21.1)\end{array}$ \\
\hline 10 & $\begin{array}{l}0 \\
(0.0)\end{array}$ & $\begin{array}{l}0 \\
(0.0)\end{array}$ & $\begin{array}{l}0 \\
(0.0)\end{array}$ & $\begin{array}{l}0 \\
(0.0)\end{array}$ & $\begin{array}{l}0 \\
(0.0)\end{array}$ & $\begin{array}{l}0 \\
(0.0)\end{array}$ & $\begin{array}{l}4 \\
(21.1)\end{array}$ & $\begin{array}{l}7 \\
(36.8)\end{array}$ & $\begin{array}{l}3 \\
(15.8)\end{array}$ & $\begin{array}{l}5 \\
(26.3)\end{array}$ \\
\hline 11 & $\begin{array}{l}0 \\
(0.0)\end{array}$ & $\begin{array}{l}0 \\
(0.0)\end{array}$ & $\begin{array}{l}0 \\
(0.0)\end{array}$ & $\begin{array}{l}1 \\
(5.3)\end{array}$ & $\begin{array}{l}1 \\
(5.3)\end{array}$ & $\begin{array}{l}1 \\
(5.3)\end{array}$ & $\begin{array}{l}3 \\
(15.8)\end{array}$ & $\begin{array}{l}4 \\
(21.1)\end{array}$ & $\begin{array}{l}5 \\
(26.3)\end{array}$ & $\begin{array}{l}4 \\
(21.1)\end{array}$ \\
\hline 12 & $\begin{array}{l}0 \\
(0.0)\end{array}$ & $\begin{array}{l}0 \\
(0.0)\end{array}$ & $\begin{array}{l}0 \\
(0.0)\end{array}$ & $\begin{array}{l}1 \\
(5.3)\end{array}$ & $\begin{array}{l}1 \\
(5.3)\end{array}$ & $\begin{array}{l}1 \\
(5.3)\end{array}$ & $\begin{array}{l}5 \\
(26.3)\end{array}$ & $\begin{array}{l}1 \\
(5.3)\end{array}$ & $\begin{array}{l}3 \\
(15.8)\end{array}$ & $\begin{array}{l}7 \\
(36.8)\end{array}$ \\
\hline 13 & $\begin{array}{l}0 \\
(0.0)\end{array}$ & $\begin{array}{l}0 \\
(0.0)\end{array}$ & $\begin{array}{l}0 \\
(0.0)\end{array}$ & $\begin{array}{l}0 \\
(0.0)\end{array}$ & $\begin{array}{l}1 \\
(5.3)\end{array}$ & $\begin{array}{l}2 \\
(10.5)\end{array}$ & $\begin{array}{l}1 \\
(5.3)\end{array}$ & $\begin{array}{l}7 \\
(36.8)\end{array}$ & $\begin{array}{l}5 \\
(26.3)\end{array}$ & $\begin{array}{l}3 \\
(15.8)\end{array}$ \\
\hline 14 & $\begin{array}{l}0 \\
(0.0)\end{array}$ & $\begin{array}{l}0 \\
(0.0)\end{array}$ & $\begin{array}{l}1 \\
(5.3)\end{array}$ & $\begin{array}{l}1 \\
(5.3)\end{array}$ & $\begin{array}{l}2 \\
(10.5)\end{array}$ & $\begin{array}{l}1 \\
(5.3)\end{array}$ & $\begin{array}{l}1 \\
(5.3)\end{array}$ & $\begin{array}{l}2 \\
(10.5)\end{array}$ & $\begin{array}{l}6 \\
(31.6)\end{array}$ & $\begin{array}{l}5 \\
(26.3)\end{array}$ \\
\hline 15 & $\begin{array}{l}0 \\
(0.0)\end{array}$ & $\begin{array}{l}0 \\
(0.0)\end{array}$ & $\begin{array}{l}2 \\
(10.5)\end{array}$ & $\begin{array}{l}0 \\
(0.0)\end{array}$ & $\begin{array}{l}3 \\
(15.8)\end{array}$ & $\begin{array}{l}2 \\
(10.5)\end{array}$ & $\begin{array}{l}4 \\
(21.1)\end{array}$ & $\begin{array}{l}0 \\
(0.0)\end{array}$ & $\begin{array}{l}2 \\
(10.5)\end{array}$ & $\begin{array}{l}6 \\
(31.6)\end{array}$ \\
\hline
\end{tabular}


* 1=Access, equity and ethics; $2=$ Globalisation of education and cross-cultural aspects; $3=$ Distance teaching systems and institutions; 4=Theories and models; 5=Research methods in distance education and knowledge transfer; 6=Management and organization; 7=Costs and benefits; 8=Educational technology; 9=Innovation and change; $10=$ Professional development and faculty support; 11=Learner support services; 12=Quality assurance; 13=Instructional design; 14=Interaction and communication in learning communities; 15=Learner characteristics ** scale ranges from $1=$ very low importance to $10=$ very high importance

Table 4 ranks the importance of the research areas on the three levels. Due to the small group size $(N=19)$, the measure of central tendency chosen is the median.

Table 4

Importance of Research Areas in Distance Education Assigned by Panel Members

\begin{tabular}{|l|l|l|l|}
\hline Rank & Research area & Mdn & SD \\
\hline Macro level: Distance education systems and theories & & \\
\hline 1 & Access, equity and ethics & 9 & 1.8 \\
\hline 2 & Theories and models & 8 & 1.6 \\
\hline 3 & Globalisation of education and cross-cultural aspects & 7 & 1.8 \\
\hline 3 & Distance education systems and institutions & 7 & 1.3 \\
\hline 3 & $\begin{array}{l}\text { Research methods in distance education and knowledge } \\
\text { transfer }\end{array}$ & 7 & 2.1 \\
\hline Meso level: & Management, organization, and technology & & \\
\hline 1 & Innovation and change & 9 & 1.3 \\
\hline 1 & Quality assurance & 9 & 1.9 \\
\hline 2 & Costs and benefits & 8 & 1.3 \\
\hline 2 & Professional development and faculty support & 8 & 1.1 \\
\hline 2 & Learner support services & 8 & 1.7 \\
\hline 3 & Educational technology & 7 & 1.6 \\
\hline 3 & Management and organization & 7 & 1.6 \\
\hline Micro level: & Teaching and learning in distance education & & \\
\hline 1 & Interaction and communication in learning communities & 9 & 2.2 \\
\hline 2 & Instructional design & 8 & 1.4 \\
\hline 3 & Learner characteristics & 7 & 2.4 \\
\hline
\end{tabular}

Question 3: What are the most neglected fields of distance education research?

This question was addressed in the second round survey by means of an open-ended question.

On the macro level (distance education systems and theories), the experts claim that the role of culture and cultural differences in global distance learning programmes and cooperation should receive much more attention. This includes the impact of cultural differences on leadership and 
culturally complex student support systems. There is a great need for international comparative research on distance learning systems. One respondent pointed out that the history of distance education and the lessons learnt previously should not be forgotten.

Additional work needs to be done on the meso level (management, organization, and technology). Experts on the panel see considerable gaps here: Issues that refer to the management of change and innovation, costs, organizational development and infrastructure for online student and faculty support, professional development, and quality assurance are of growing importance. In particular, they highlighted aspects that refer to leadership in distance education and strategy.

According to the experts, there is a need for more research on the pedagogical opportunities that Web 2.0 applications, mobile devices, and synchronous tools afford for teaching, learning, and assessment (micro level: teaching and learning in distance education).

\section{Conclusions and Implications}

This study examined the opinion of distance education experts with regard to (1) categorization of research areas in distance education, (2) their importance, and (3) the most neglected areas of distance education research.

With specific reference to Australia, Jegede (1994) listed eight broad groupings of research areas that require priority attention:

1. instructional and communications technology;

2. industrial and business training context;

3. role of distance education in national development;

4. student support services;

5. evaluation;

6. equity and access;

7. design and development of study materials; and

8. interactive multimedia.

The research areas identified in the present study as requiring a concentration of research activities seem to agree in the main with what Jegede (1994) recommended for Australia. Issues that refer to access and equity, the role of distance education in developing areas, student support services, evaluation, educational technologies, and instructional design are still important. The field has been dominated by research in the areas of technology, increased interactivity through new media, and instructional design issues (Berge \& Mrozowski, 2001). However, there are also new fields or key areas that are, or should be, on top of the research agenda.

Many institutions are moving into the global education market to reach new target groups using online learning to 'export' their knowledge. Therefore, globalization of education, cross-cultural aspects, and access, equity, and ethics are research areas that should receive more attention. This 
is supported by the fact that the whole first section in the new International Handbook of Distance Education is devoted to "Diversity in Distance Education" (Evans, Haughey, \& Murphy, 2008).

The results suggest that there is a shift from technology-centered research to areas that focus on management and change in distance education institutions. The emergence of online distance learning highlights a pressing need for educational institutions to embrace innovation and change. It can be concluded that all aspects related to educational management are growing in importance (strategy and leadership, change management, quality assurance, costs etc.). In order to guide practice we should not rely on under-informed trial and error, but on sound research on the effectiveness of managerial interventions for education innovation. Distance educators ranked the areas of innovation and change and quality assurance as the research areas to be given priority attention on the meso level. There was a high level of agreement on the importance of faculty support and professional development of those who are involved in the process of education innovation. This process should be driven by people and pedagogical concepts that apply new technological developments in a meaningful way for the purpose of adding value to teaching and learning. Technology is not an end in itself. Interestingly, the area of educational technology emerged on only the third rank.

As revealed in Tables 3 and 4, interaction and communication in learning communities was ranked the highest on the micro level. Future research emphasis should be on the pedagogical impact of educational technologies on teaching and learning and on the capacity of social software, Web 2.0 applications, and mobile devices to foster social interaction and to support flexible learning.

Based on the classification of research areas and the priority areas identified in this study, it would be interesting to carry out a new large-scale literature review to investigate research trends and gaps, methods, and authorship patterns in distance education research. 


\section{References}

Berge, Z., \& Mrozowski, S. (2001). Review of research in distance education. American Journal of Distance Education, 15(3), 5-19.

Bernard, R. M., Abrami, P. C., Lou, Y., \& Borokhovski, E. (2004). A methodological morass? How we can improve quantitative research in distance education. Distance Education, 25(2), 175-198.

Charlton, J. R. H. (2004). Delphi technique. In M. S. Lewis-Beck, A. Bryman, \& T. F. Liao (Eds.), The SAGE encyclopedia of social science research methods (Vol. 1). Thousand Oaks: Sage.

Evans, T., Haughey, M., \& Murphy, D. (Eds.). (2008). International handbook of distance education. Bingley, UK: Emerald Publishing.

Field, A. (2005). Discovering statistics using SPSS. London: Sage.

Holmberg, B. (1985). Status and trends of distance education. Lund: Lector Publishing.

Isaac, S., \& Michael, W. (1995). Handbook in research and evaluation. San Diego: Educational and Industrial Testing Services.

Jegede, O. J. (1994). Distance education research priorities for Australia: A study of the opinions of distance educators and practitioners. Distance Education, 15(2), 234-253.

Koble, M. A., \& Bunker, E. L. (1997). Trends in research and practice: An examination of The American Journal of Distance Education 1987-1995. American Journal of Distance Education, 11(2), 19-38.

Lee, Y., Driscoll, M. P., \& Nelson, D. W. (2004). The past, present, and future of research in distance education: Results of a content analysis. American Journal of Distance Education, 18(4), 225-241.

Mishra, S. (1997). A critical analysis of periodical literature in distance education. Indian Journal of Open Learning, 6(1\&2), 39-54.

Mishra, S. (1998). Distance education research: a review of its structure, methodological issues and priority areas. Indian Journal of Open Learning, 7(3), 267-282.

Moore, M. G. (1985). Some observations on current research in distance education. Epistolodidaktika,1,35-62. 
Panda, S. (1992). Distance educational research in India: Stock-taking, concerns and prospects. Distance Education, 13(2), 309-326.

Perraton, H. (2000). Rethinking the research agenda. International Review of Research in Open and Distance Learning, 1(1).

Rourke, L., \& Szabo, M. (2002). A content analysis of the Journal of Distance Education 19862001. Journal of Distance Education, 17(1), 63-74.

Saba, F. (2000). Research in distance education: A status report. International Review of Research in Open and Distance Learning, 1(1).

Scriven, B. (1991). Ten years of 'Distance Education'. Distance Education, 12(1), 137-153.

Sherry, L. (1996). Issues in distance learning. International Journal of Educational Telecommunications, 1(4), 337-365. 
June - 2009

\title{
Journals for Computer-Mediated Learning: Publications of Value for the Online Educator
}

\author{
Matt Elbeck \\ Troy University, USA \\ B. Jean Mandernach \\ Park University, USA
}

\begin{abstract}
In contrast with traditional academic disciplines, online educators do not have a generally accepted list of scholarly journals, which is in part a result of the multidisciplinary nature of the field, the relative infancy of online learning, and the view of online pedagogy as an instructional modality rather than a discrete academic discipline. The purpose of this study is to determine a comprehensive listing and relative value ranking of scholarly journals whose content informs online educators and motivates scholarship. After defining the scope of investigation to target peer-reviewed, scholarly journals with an explicit focus on computer-mediated learning (e.g., virtual, electronic, distance, distributive, mobile, and blended learning), 46 scholarly journals were identified as advancing the knowledge base in computer-mediated learning. Popularity, importance, prestige, and overall rankings for each journal are presented. The results inform online educators about the range of scholarly journals available and provide insight into the relative value of journals devoted to computer-mediated learning.
\end{abstract}

Keywords: Journal Ranking; computer-mediated learning; online educators; e-learning; distance learning; distributed learning, virtual learning; mobile learning; open learning; blended learning.

\section{Introduction}

The exponential growth of online learning has sparked widespread scholarly interest in issues related to online teaching and learning. This has produced a host of scholarly journals exploring issues such as best practices in online teaching, learning theories relevant to online education, and the interaction between technology and education. Nonetheless, little is scientifically known about the consistency of these publications and their relative worth to online teachers, learners, and scholars. Unlike established academic disciplines, there is neither a definitive list nor a value ranking of such journals. 
Identifying journals relevant to educators involved in online learning together with value rankings of the journals critically advances the knowledge base for online educators by offering an efficient way to identify journals for their particular instructional and/or scholarly activities. The purposes of this study are outlined as follows: (a) define the scope of computer-mediated learning; (b) identify scholarly journals devoted to computer-mediated learning; and (c) rank the journals independently and collectively based upon popularity, importance, and prestige.

\section{Journal Ranking}

Scholarly journal bibliometric assessment seems a never ending search to definitively rank journals. According to Mason et al. (1997) and Kim (1991), there are two general approaches to journal ranking. The first is based on citations, which have been found to return inconsistent results (Baumgartner \& Pieters, 2003; Jobber \& Simpson, 1988). For example, Hascall, Bollen, and Hanson (2007) report that the Journal of Biological Chemistry was ranked first by PageRank, developed by Brin and Page (1998), and 180th using the impact factor, which is based on the Institute of Scientific Information's (ISI) citation database. Also, review articles (versus original research) inflate a journal's impact factor (Bollen et al., 2006), an issue that challenges the validity of the ranking. The second approach to journal ranking examines perceptions of style or content (e.g. Mylonopoulos \& Theoharakis, 2001; Nisonger, 1999; Hult, Neese, \& Bashaw, 1997; Luke \& Doke, 1987). This form of journal ranking may be inaccurate due to the limited geographic scope of survey respondents, personal publication history, exposure, and other nonrelevant perceptual biases.

To date, most ranking schemas align strictly with either a citation or perception approach. Alternative ranking options suggest utility in combining citation and perception data into an integrated system. For example, Rice and Stankus (1983) suggest a combination to include impact factor, manuscript acceptance rate, journal sponsorship, mission, and audience. Parnell (1997) limits journal quality to expert opinion surveys, citation counts, and a combination of both variables. Other studies have considered complex variables, such as accessibility (Polonsky et al., 1999), ethnocentricity (Czinkota, 2000), international involvement of editorial boards and article content (Rosenstreich \& Wooliscroft, 2006), global dispersion of authorship (Polonsky et al., 2006), and inadequacy of ranking schemas for open access publications (Elbeck \& Mandernach, 2008).

\section{Methods}

\section{Defining the Scope of Investigation}

Online education reflects a highly diversified growth industry that represents all academic disciplines and uses a relatively recent set of technologies, which makes classification of the discipline a challenge. There are ten general categories relevant to online education, which are listed below: 


\section{Blended learning}

Serving many different learning styles by offering a combination of virtual and physical resources

2. Hybrid learning

Often used interchangeably with blended learning; more explicit in the combination of face-to-face classroom instruction with online instructional delivery

3. Flexible learning (a term from Australia and New Zealand)

Generic term that highlights learners choices about where, when, and how learning occurs; often used synonymously with open learning

4. Distance education/learning

Pedagogy, adult learning strategies (andragogy), and instructional systems delivering education to students who are not physically on site

5. Distributed learning

People educate themselves by engaging in learning activities at their own pace and at a self-selected time

6. E-learning

Planned teaching/learning experience using a wide spectrum of technologies, mainly Internet or computer-based, to reach learners

7. Online learning

Using the Internet to disseminate and manage classroom instruction

8. M-learning

Learning with mobile devices, such as iPods and cell phones

9. Virtual learning

A learning environment where teacher and student are separated by time or space, or both, and

\section{Open learning}

An educational approach (typically involving e-learning) that highlights flexibility and students' choice concerning the timing, pace, structure, and content of learning activities; often used synonymously with flexible learning

The various terms represent nuanced perspectives of the multi-disciplinary nature and relatively recent evolution of online learning as a discipline. To help consolidate the various interdependent terms, we offer the term computer-mediated learning (CML), which we define in the following way: Computer-mediated learning occurs when an individual interactively learns (formally or informally, synchronously or asynchronously) about material via computer means where the learning materials and pedagogy are developed to take advantage of the available technologies.

The fundamental goal of CML is to remove the barriers of time and place in the facilitation of learning. The interactive learning relationship empowers students with control over (a) when and what they view, hear, or read, (b) the pace of their learning, and (c) requests for additional information from other student(s) or instructor(s) via the same or other media. Further, the medium to learn is any technology-based conduit connecting instructors and/or educational materials with students, which may (a) change in nature over time (e.g., from personal computer to podcast), (b) include non-electronic interventions (blended learning), and (c) facilitate 
instructor-student interaction both in real time (synchronously) and in different times (asynchronously). The extent of formality ranges from formal learning in a class setting to informal learning (browsing, surfing), such as lifetime learning, which may be incidental to, or a complementary feature of, formal learning.

\section{Journals Devoted to CML}

As indicated by the definition of CML, a wide array of instructional strategies, pedagogies, and approaches are relevant to this study. A comprehensive list of potentially relevant computermediated learning journals was compiled using the following sources:

- Google and Yahoo search engines (key terms: journal, with e-learning, distance learning, distributed learning, virtual education, online learning, m-learning, virtual learning and blended learning);

- Lists available from professional organizations (such as the Higher Education Academy [http://www.english.heacademy.ac.uk/explore/resources/technology/journals.php], American Educational Research Association [http://aera-cr.asu.edu/ejournals/], and Association for Educational Communications and Technology [http://www.aect.org/Intranet/Publications/index.asp]); and

- University reading lists (such as the University of Wisconsin - Madison [http://www.wisc.edu/depd/html/mags3.htm]).

This search generated 154 publications. To be eligible for inclusion, the publication had to be a scholarly journal. A search for various definitions of scholarly journal from Wikipedia (http://en.wikipedia.org/wiki/Scholarly_journal), Cal Poly Pomona Library (2009), and Cornell University Library (2009) resulted in the following definition: To be considered a scholarly journal, the publication must be peer-reviewed, cite all source material, return manuscript acceptance rates below $100 \%$, and solicit original work; as well, manuscripts may include original research articles, literature reviews, and book reviews. We further refined the definition by limiting journal selection to peer review journals that contained original articles.

As such, the following types of publications were not included in the final list of journals: (a) practitioner non-scholarly magazines (e.g., eLearn Magazine); (b) review only journals as they are limited to previously published material (e.g., eLearning Reviews); (c) newsletters (e.g., eLearning Newsletter, Online Classroom); (d) blogs (e.g., The e-Learning Review); (e) journals no longer in publication (e.g., International Journal of Educational Technology); (f) publications limited in scope (e.g., Teaching with Technology Today is limited to University of Georgia system faculty and students); and (g) peer-reviewed conference proceedings (e.g., Annual Instructional Technology Conference at Middle Tennessee State University).

Based on the preceding exclusions, a content evaluation of each of the remaining 73 publications was conducted by examining a sample of articles (two from 2008 and two from 2007) and journal descriptions to screen for peer-reviewed journals containing original research articles. This 
process resulted in a list of 46 scholarly journals, of which 26 (56\%) are journals from outside the US, reflecting the discipline's world-wide scope in terms of readership and scholarship.

\section{Value Ranking Journals}

To refine the journal collection of 46 publications, we developed four ranking schemas to help online educators make informed judgments about each journal. The schemas reflect journal popularity, importance, prestige, and an overall ranking.

\section{Journal popularity.}

A useful metric to assess the popularity of a journal's website is links from other websites. This metric is known as in-links, which are links from other websites to at least one page inside a journal's website. Work comparing citations with URLs started with Larson (1996), followed by studies dismissing (Harter \& Ford, 2000; Meric et al., 2002) and supporting (Vaughan \& Hysen, 2002; An \& Qiu, 2003) a relationship between impact factor and a site's in-link count. A reasonable position implied by Vaughan and Thelwall (2003) is that in-link counts measure impact beyond scholarly impact to a wider audience of students, practitioners, and other interested parties. In-link counts are provided by various commercial search engines. As of December 2008, the most popular search engines and their shares of searches (R\&R Web design, 2008) are Google (78.99\%), Yahoo (11.46\%) and MSN (3.15\%). In-link counts from Google, AlltheWeb, AltaVista and MSN for the home page URL of each CML journal were supplied by the online links counter service, CheckSEO (2009).

\section{Journal importance.}

Google's PageRank algorithm is used to define a web page's relevance or importance (Rogers, 2002) such that a link to a page represents support for that page. Chen, Xie, Maslov, and Redner et al. (2007) suggest that the PageRank result favors more important links and devalues unimportant links. The online service Top25Web (2009) generated the PageRank values, which range from 0 to 10 . According to Rogers (2002, p.2), each PageRank value is a logarithmic scale $(0=0$ to $10 ; 1=10$ to 100 ; etc $)$. It is therefore prudent to consider each journal's PageRank score representing a cohort of similarly scored journals.

\section{Journal prestige.}

The final construct we measured is prestige based on the perceptions of peers. The resulting experience survey (also known as a key informant survey) taps the knowledge and experience of scholarly CML journal editors familiar with the relative prestige among scholarly CML journals. Using e-mail, each of the $46 \mathrm{CML}$ journal editors was invited to answer the question, "which are the top 5 scholarly journals in the field of online education?" 


\section{Overall ranking.}

The final ranking schema uses indexes for each of the popularity, importance, and prestige ranking to combine them into a single world-wide ranking of all 46 journals.

\section{Results}

\section{Journal Popularity}

The number of links from other sites to each journal's home page is not a stable metric (Jacso, 2005, McCown \& Nelson, 2007). Experimentation with in-links data returned valuation fluctuations of up to $10 \%$ over a 48 -hour period, together with remarkable in-link differences for journals with more than one home page URL. For these reasons, data collection was conducted on January 28, 2009, in a constrained time period from 14:00 to 15:00 EST. For some journals, a 'home page' with the highest in-link counts was selected whenever the journal had a home page provided by the publisher and one provided by the journal's sponsor.

For each search engine, the total number of in-link counts for each of the 46 journals was tabulated. Given that Yahoo owns AlltheWeb and AltaVista (Search Engine Watch.com, 2007) percentages for each search engine were computed and then averaged to represent each journal's relative share of the Yahoo in-link counts. Each journal's percentage share of in-link counts by search engine was calculated. To arrive at a realistic overall multi-search engine in-link, the overall ranking was calculated using each search engine's percentage of global searches (R\&R Web design, 2008) resulting in weights of 25.0 for a Google in-link score, 3.6 for a Yahoo in-link score, and 1.0 for a MSN in-link score. These results in Table 1 show each journal's website's relative popularity, as measured by links from both scholarly and non-scholarly websites.

Table 1

Ranking of Journals Based on Home Page In-Link Percentage Share $(N=46)$

\begin{tabular}{lllll}
\hline Journal & $\begin{array}{l}\text { Weighted } \\
\text { share* }\end{array}$ & $\begin{array}{l}\text { Yahoo } \\
\text { share** }\end{array}$ & Google share & $\begin{array}{l}\text { MSN } \\
\text { share }\end{array}$ \\
\hline $\begin{array}{l}\text { eLearning Papers } \\
\text { International Review of Research in Open and Distance }\end{array}$ & $17.81 \%$ & $43.47 \%$ & $14.83 \%$ & $0.00 \%$ \\
Learning & $8.04 \%$ & $0.74 \%$ & $9.41 \%$ & $0.05 \%$ \\
Journal for Asynchronous Learning Networks & $6.97 \%$ & $0.67 \%$ & $8.11 \%$ & $1.13 \%$ \\
Educause Quarterly & $5.55 \%$ & $1.26 \%$ & $6.39 \%$ & $0.00 \%$ \\
Online Journal of Distance Learning Administration & $5.23 \%$ & $0.94 \%$ & $5.56 \%$ & $12.39 \%$ \\
Journal of Interactive Media in Education & $4.47 \%$ & $0.34 \%$ & $4.13 \%$ & $27.77 \%$ \\
Electronic Journal of e-Learning & $3.42 \%$ & $0.45 \%$ & $3.96 \%$ & $0.63 \%$ \\
European Journal of Open, Distance and E-Learning & $3.35 \%$ & $0.29 \%$ & $3.74 \%$ & $4.49 \%$ \\
International Journal of Instructional Technology $\&$ & $3.32 \%$ & $0.09 \%$ & $3.92 \%$ & $0.03 \%$
\end{tabular}


Distance Learning

Australasian Journal of Educational Technology

E-Learning and Education

$0.54 \%$

$3.46 \%$

$7.27 \%$

Journal of Educational Technology \& Society

$2.61 \%$

$0.19 \%$

$3.02 \%$

$1.22 \%$

Journal of Distance Education

$2.59 \%$

$0.24 \%$

$2.49 \%$

$13.43 \%$

Canadian Journal of Learning and Technology

$2.45 \%$

$0.02 \%$

$2.89 \%$

$0.32 \%$

The Turkish Online Journal of Distance Education

$2.26 \%$

$0.04 \%$

$2.67 \%$

$0.19 \%$

Journal of Online Learning and Teaching

$2.25 \%$

$0.17 \%$

$2.17 \%$

$11.73 \%$

Interdisciplinary Journal of E-Learning and Learning

Objects

$2.22 \%$

$0.29 \%$

$2.45 \%$

$3.45 \%$

$1.92 \%$

$0.45 \%$

$2.14 \%$

$1.63 \%$

Journal of Computer-Assisted Learning

$1.71 \%$

$0.56 \%$

$1.95 \%$

$0.15 \%$

$1.90 \%$

$0.01 \%$

E-Learning

$1.67 \%$

$0.12 \%$

$1.86 \%$

$1.46 \%$

Journal of Distance Learning

$1.59 \%$

$7.60 \%$

$0.57 \%$

$0.03 \%$

Computers and Education

$1.42 \%$

$0.12 \%$

$1.55 \%$

$0.51 \%$

American Journal of Distance Education

$1.40 \%$

$0.14 \%$

$1.64 \%$

$2.30 \%$

International Journal of Interactive Mobile Technologies

$1.40 \%$

$0.53 \%$

$1.44 \%$

$0.00 \%$

International Journal on E-Learning

$1.31 \%$

$7.51 \%$

$0.28 \%$

$0.67 \%$

The Internet and Higher Education

$1.16 \%$

$0.41 \%$

$1.20 \%$

$0.16 \%$

AACE Journal

$1.09 \%$

$8.42 \%$

$0.00 \%$

$0.84 \%$

Education and Information Technologies

$1.02 \%$

$2.45 \%$

$0.74 \%$

$0.01 \%$

Distance Education

$0.94 \%$

$0.22 \%$

$0.96 \%$

$0.48 \%$

Asian Journal of Distance Education

$0.87 \%$

$2.40 \%$

$0.63 \%$

$0.78 \%$

Learning, Media and Technology

$0.85 \%$

$3.71 \%$

$0.46 \%$

$0.57 \%$

British Journal of Educational Technology

$0.84 \%$

$0.07 \%$

$0.79 \%$

$0.00 \%$

Journal of Interactive Online Learning

$0.78 \%$

$2.40 \%$

$0.50 \%$

$3.16 \%$

Educational Media International

$0.72 \%$

$0.03 \%$

$0.79 \%$

$0.22 \%$

The Turkish Online Journal of Educational Technology

$0.70 \%$

$2.41 \%$

$0.46 \%$

$0.81 \%$

Open Learning: The Journal of Open and Distance Learning

$0.69 \%$

$4.63 \%$

$0.00 \%$

$0.22 \%$

Educational Technology Research and Development

$0.57 \%$

$0.12 \%$

$0.59 \%$

$0.21 \%$

Journal of Educators Online

$0.56 \%$

$0.10 \%$

$0.35 \%$

$1.28 \%$

International Journal of Distance Education Technologies

$0.31 \%$

$2.39 \%$

$0.00 \%$

$0.01 \%$

Association for Learning Technology Journal

$0.30 \%$

$2.39 \%$

$0.00 \%$

$0.32 \%$

Technology, Pedagogy, and Education

$0.29 \%$

$0.66 \%$

$0.00 \%$

$0.00 \%$

Innovate: Journal of Online Education

$0.08 \%$

$0.08 \%$

$0.00 \%$

$0.00 \%$

International Journal of Instructional Media

$0.02 \%$

$0.12 \%$

$0.00 \%$

$0.19 \%$

Informatics in Education

$0.02 \%$

$0.03 \%$

$0.00 \%$

$0.03 \%$

Quarterly Review of Distance Education

$0.00 \%$

$0.02 \%$

$0.00 \%$

$0.01 \%$

The International Journal of Excellence in e-Learning

$0.00 \%$

$0.01 \%$

$0.00 \%$

$0.00 \%$

Journal of the Research Center for Educational Technology

$0.00 \%$

] $/ 29.2$

The denominator 29.2 is the sum of percentage weights which results in the sum of all percent weighted scores $=100 \%$.

$* *$ Yahoo percent score $=[($ AltaVista percentage $)+($ AlltheWeb percentage $)] / 2$. 
To test the similarity of the search engine in-link counts, Table 2 presents a correlation matrix reporting highly uncorrelated relationships among the various search engine in-link counts with the exception of a strong relationship between Google and AlltheWeb $(r=.678, p<.01)$. Clearly, each search engine computes in-link counts in differing ways with respect to the magnitude of the counts and the source of the incoming links.

Table 2

Correlation Matrix among Search Engine In-Link Counts $(N=46)$

\begin{tabular}{lllll} 
Search Engine & AlltheWeb & AltaVista & Google & MSN \\
\hline AlltheWeb & 1.000 & & & \\
AltaVista & -.052 & 1.000 & & \\
Google & $.678 * *$ & -.270 & 1.000 & \\
MSN & -.060 & -.177 & .170 & 1.000 \\
\hline
\end{tabular}

** Correlation is significant at the $p<0.01$ level (2-tailed).

\section{Journal Importance}

PageRank scores in Table 3 refine the in-link count ranks shown in Table 1 by emphasizing the quality of the link sources, analogous to an emphasis on links from scholarly websites (PageRank) versus all websites (in-link count). Unlike the reported volatility of in-links data used to rank journals by popularity, PageRank values seemed to be stable, as observed over a five-day period. Data collection took place on January 28, 2009.

Table 3

Alphabetical Ranking of Scholarly CML Journal Cohort Web Sites by Google PageRank Score (N $=46)$

\begin{tabular}{ll}
\hline Journal & $\begin{array}{l}\text { Google } \\
\text { PageRank } \\
\text { score }\end{array}$ \\
\hline E-Learning & 7 \\
Electronic Journal of e-Learning & 7 \\
Innovate: Journal of Online Education & 7 \\
International Review of Research in Open and Distance Learning & 7
\end{tabular}


Journal of Educational Technology \& Society $\quad 7$

Online Journal of Distance Learning Administration 7

$\begin{array}{ll}\text { AACE Journal } & 6\end{array}$

American Journal of Distance Education 6

$\begin{array}{ll}\text { Asian Journal of Distance Education } & 6\end{array}$

$\begin{array}{ll}\text { Australasian Journal of Educational Technology } & 6\end{array}$

Canadian Journal of Learning and Technology 6

$\begin{array}{ll}\text { Educational Media International } & 6\end{array}$

Educause Quarterly $\quad 6$

E-Learning and Education $\quad 6$

eLearning Papers $\quad 6$

European Journal of Open, Distance and E-Learning 6

$\begin{array}{ll}\text { Informatics in Education } & 6\end{array}$

Interdisciplinary Journal of E-Learning and Learning Objects 6

$\begin{array}{ll}\text { International Journal of Distance Education Technologies } & 6\end{array}$

International Journal of Instructional Media 6

International Journal of Interactive Mobile Technologies 6

$\begin{array}{ll}\text { International Journal on E-Learning } & 6\end{array}$

$\begin{array}{ll}\text { Journal for Asynchronous Learning Networks } & 6\end{array}$

$\begin{array}{ll}\text { Journal of Distance Education } & 6\end{array}$

Journal of Interactive Media in Education $\quad 6$

$\begin{array}{ll}\text { Journal of Interactive Online Learning } & 6\end{array}$

$\begin{array}{ll}\text { Journal of Online Learning and Teaching } & 6\end{array}$

$\begin{array}{ll}\text { Learning, Media and Technology } & 6\end{array}$

$\begin{array}{ll}\text { Technology, Pedagogy, and Education } & 6\end{array}$

The Turkish Online Journal of Distance Education 6

$\begin{array}{ll}\text { The Turkish Online Journal of Educational Technology } & 6\end{array}$

Association for Learning Technology Journal 5

Distance Education $\quad 5$

Education and Information Technologies $\quad 5$

International Journal of Instructional Technology \& Distance Learning 5

Journal of Computer-Assisted Learning 5

Journal of Distance Learning 5

Journal of Educators Online 5

Open Learning: The Journal of Open and Distance Learning 5

Quarterly Review of Distance Education $\quad 5$

The International Journal of Excellence in e-Learning 3

British Journal of Educational Technology 0

$\begin{array}{ll}\text { Computers and Education } & 0\end{array}$

Educational Technology Research and Development 0

Journal of the Research Center for Educational Technology 0

$\begin{array}{ll}\text { The Internet and Higher Education } & 0\end{array}$ 


\section{Journal Prestige}

From a total of 46 journals, 31 editors responded (67\% response rate; 17 from the United States, two each from Australia, Canada, and the United Kingdom, and one each from Austria, Germany, Lithuania, New Zealand, Spain, Turkey, and United Arab Emirates) to the question "which are the top 5 scholarly journals in the field of online education?" Eight editors offered no opinion, leaving a useable response rate of 50\% from 23 editors whose total of 92 prestige votes (not all editors submitted five journal titles) make up the journal prestige rankings. This request was unguided given the editors did not know which journals made up the list for this study. The editors' total of 92 votes makes up the list of journals ranked by prestige as shown in Table 4.

Table 4

Journal Rankings by Editors' Perception of Prestige $(N=23)$

\begin{tabular}{|c|c|c|c|c|}
\hline $\begin{array}{l}\text { Country of } \\
\text { origin }\end{array}$ & Journal & $\begin{array}{l}\text { Total Votes } \\
(\%)\end{array}$ & $\begin{array}{l}\text { US } \\
\text { journal } \\
\text { editor } \\
\text { votes }\end{array}$ & $\begin{array}{l}\text { Non-US } \\
\text { journal } \\
\text { editor } \\
\text { votes }\end{array}$ \\
\hline Canada & $\begin{array}{l}\text { International Review of Research in Open and Distance } \\
\text { Learning }\end{array}$ & $10.87 \%$ & 5 & 5 \\
\hline USA & American Journal of Distance Education & $8.70 \%$ & 4 & 4 \\
\hline USA & Innovate: Journal of Online Education & $8.70 \%$ & 6 & 2 \\
\hline USA & Journal for Asynchronous Learning Networks & $8.70 \%$ & 4 & 4 \\
\hline Australia & Distance Education & $7.61 \%$ & 3 & 4 \\
\hline Canada & Journal of Distance Education & $6.52 \%$ & 3 & 3 \\
\hline Australia & Australasian Journal of Educational Technology & $4.35 \%$ & & 4 \\
\hline UK & European Journal of Open, Distance and E-Learning & $4.35 \%$ & 2 & 2 \\
\hline USA & Online Journal of Distance Learning Administration & $4.35 \%$ & 3 & 1 \\
\hline UK & British Journal of Educational Technology & $3.26 \%$ & & 3 \\
\hline USA & Educational Technology Research and Development & $3.26 \%$ & 2 & 1 \\
\hline USA & Journal of Online Learning and Teaching & $3.26 \%$ & 2 & 1 \\
\hline UK & Open Learning: The Journal of Open and Distance Learning & $3.26 \%$ & & 3 \\
\hline USA & The Internet and Higher Education & $3.26 \%$ & 1 & 2 \\
\hline Turkey & The Turkish Online Journal of Distance Education & $3.26 \%$ & 1 & 2 \\
\hline USA & AACE Journal & $2.17 \%$ & 2 & \\
\hline USA & Journal of Educators Online & $2.17 \%$ & 2 & \\
\hline USA & Quarterly Review of Distance Education & $2.17 \%$ & 2 & \\
\hline $\begin{array}{l}\text { China and } \\
\text { India }\end{array}$ & Asian Journal of Distance Education & $1.09 \%$ & & 1 \\
\hline UK & Association for Learning Technology Journal & $1.09 \%$ & & 1 \\
\hline USA & Computers and Education & $1.09 \%$ & 1 & \\
\hline UK & Journal of Computer-Assisted Learning & $1.09 \%$ & & 1 \\
\hline New & Journal of Distance Learning & $1.09 \%$ & 1 & \\
\hline
\end{tabular}




\begin{tabular}{|c|c|c|c|c|}
\hline Zealand & & & & \\
\hline USA & Journal of Interactive Online Learning & $1.09 \%$ & 1 & \\
\hline UK & Learning, Media and Technology & $1.09 \%$ & & 1 \\
\hline UK & Technology, Pedagogy, and Education & $1.09 \%$ & & 1 \\
\hline Turkey & The Turkish Online Journal of Educational Technology & $1.09 \%$ & & 1 \\
\hline Canada & Canadian Journal of Learning and Technology & $0.00 \%$ & & \\
\hline USA & Education and Information Technologies & $0.00 \%$ & & \\
\hline Austria & Educational Media International & $0.00 \%$ & & \\
\hline USA & Educause Quarterly & $0.00 \%$ & & \\
\hline UK & E-Learning & $0.00 \%$ & & \\
\hline Germany & E-Learning and Education & $0.00 \%$ & & \\
\hline Spain & eLearning Papers & $0.00 \%$ & & \\
\hline UK & Electronic Journal of e-Learning & $0.00 \%$ & & \\
\hline Lithuania & Informatics in Education & $0.00 \%$ & & \\
\hline USA & Interdisciplinary Journal of E-Learning and Learning Objects & $0.00 \%$ & & \\
\hline USA & International Journal of Distance Education Technologies & $0.00 \%$ & & \\
\hline USA & International Journal of Instructional Media & $0.00 \%$ & & \\
\hline USA & $\begin{array}{l}\text { International Journal of Instructional Technology \& Distance } \\
\text { Learning }\end{array}$ & $0.00 \%$ & & \\
\hline Austria & International Journal of Interactive Mobile Technologies & $0.00 \%$ & & \\
\hline USA & International Journal on E-Learning & $0.00 \%$ & & \\
\hline Canada & Journal of Educational Technology \& Society & $0.00 \%$ & & \\
\hline UK & Journal of Interactive Media in Education & $0.00 \%$ & & \\
\hline USA & Journal of the Research Center for Educational Technology & $0.00 \%$ & & \\
\hline UAE & The International Journal of Excellence in e-Learning & $0.00 \%$ & & \\
\hline & Total & $100 \%$ & 45 & 47 \\
\hline
\end{tabular}

\section{Overall Ranking}

Table 5 presents all three popularity, importance, and prestige rankings as indexes to produce a final overall journal ranking. The indexing was computed as the journal's score divided by the highest score for a particular ranking. For example, the prestige index for Distance Education = $7.61 / 10.87=0.70$.

Table 5

Overall Ranking of Scholarly CML Journals $(N=46)$

\begin{tabular}{llllll} 
Rank & Journal & $\begin{array}{l}\text { Summed } \\
\text { index }\end{array}$ & $\begin{array}{l}\text { Popularity } \\
\text { index }\end{array}$ & $\begin{array}{l}\text { Importance } \\
\text { index }\end{array}$ & $\begin{array}{l}\text { Prestige } \\
\text { index }\end{array}$ \\
\cline { 2 - 2 } & International Review of Research in Open and Distance & 2.45 & 0.45 & 1.00 & 1.00 \\
2 & Learning & & & & \\
3 & Journal for Asynchronous Learning Networks & 2.05 & 0.39 & 0.86 & 0.80 \\
eLearning Papers & 1.86 & 1.00 & 0.86 & 0.00
\end{tabular}




\begin{tabular}{|c|c|c|c|c|c|}
\hline 4 & Innovate: Journal of Online Education & 1.80 & 0.00 & 1.00 & 0.80 \\
\hline 5 & American Journal of Distance Education & 1.74 & 0.08 & 0.86 & 0.80 \\
\hline 6 & Online Journal of Distance Learning Administration & 1.69 & 0.29 & 1.00 & 0.40 \\
\hline 7 & Journal of Distance Education & 1.59 & 0.14 & 0.86 & 0.60 \\
\hline 8 & Distance Education & 1.47 & 0.05 & 0.71 & 0.70 \\
\hline 9 & European Journal of Open, Distance and E-Learning & 1.45 & 0.19 & 0.86 & 0.40 \\
\hline 10 & Australasian Journal of Educational Technology & 1.44 & 0.18 & 0.86 & 0.40 \\
\hline$=11$ & The Turkish Online Journal of Distance Education & 1.28 & 0.13 & 0.86 & 0.30 \\
\hline$=11$ & Journal of Online Learning and Teaching & 1.28 & 0.12 & 0.86 & 0.30 \\
\hline 13 & Electronic Journal of e-Learning & 1.19 & 0.19 & 1.00 & 0.00 \\
\hline 14 & Educause Quarterly & 1.17 & 0.31 & 0.86 & 0.00 \\
\hline 15 & Journal of Educational Technology \& Society & 1.15 & 0.15 & 1.00 & 0.00 \\
\hline 16 & AACE Journal & 1.12 & 0.06 & 0.86 & 0.20 \\
\hline 17 & Journal of Interactive Media in Education & 1.11 & 0.25 & 0.86 & 0.00 \\
\hline 18 & E-Learning & 1.09 & 0.09 & 1.00 & 0.00 \\
\hline 19 & $\begin{array}{l}\text { Open Learning: The Journal of Open and Distance } \\
\text { Learning }\end{array}$ & 1.05 & 0.04 & 0.71 & 0.30 \\
\hline 20 & Asian Journal of Distance Education & 1.01 & 0.05 & 0.86 & 0.10 \\
\hline$=21$ & Learning, Media and Technology & 1.00 & 0.05 & 0.86 & 0.10 \\
\hline$=21$ & E-Learning and Education & 1.00 & 0.15 & 0.86 & 0.00 \\
\hline$=21$ & Journal of Interactive Online Learning & 1.00 & 0.04 & 0.86 & 0.10 \\
\hline$=21$ & The Turkish Online Journal of Educational Technology & 1.00 & 0.04 & 0.86 & 0.10 \\
\hline 25 & Canadian Journal of Learning and Technology & 0.98 & 0.13 & 0.86 & 0.00 \\
\hline 26 & Technology, Pedagogy, and Education & 0.97 & 0.02 & 0.86 & 0.10 \\
\hline 27 & $\begin{array}{l}\text { Interdisciplinary Journal of E-Learning and Learning } \\
\text { Objects }\end{array}$ & 0.96 & 0.11 & 0.86 & 0.00 \\
\hline 28 & Journal of Educators Online & 0.95 & 0.03 & 0.71 & 0.20 \\
\hline 29 & International Journal of Interactive Mobile Technologies & 0.94 & 0.08 & 0.86 & 0.00 \\
\hline 30 & International Journal on E-Learning & 0.93 & 0.07 & 0.86 & 0.00 \\
\hline$=31$ & Quarterly Review of Distance Education & 0.91 & 0.00 & 0.71 & 0.20 \\
\hline$=31$ & Journal of Computer-Assisted Learning & 0.91 & 0.10 & 0.71 & 0.10 \\
\hline$=33$ & Journal of Distance Learning & 0.90 & 0.09 & 0.71 & 0.10 \\
\hline$=33$ & $\begin{array}{l}\text { International Journal of Instructional Technology \& } \\
\text { Distance Learning }\end{array}$ & 0.90 & 0.19 & 0.71 & 0.00 \\
\hline$=33$ & Educational Media International & 0.90 & 0.04 & 0.86 & 0.00 \\
\hline 36 & $\begin{array}{l}\text { International Journal of Distance Education } \\
\text { Technologies }\end{array}$ & 0.87 & 0.02 & 0.86 & 0.00 \\
\hline$=37$ & International Journal of Instructional Media & 0.86 & 0.00 & 0.86 & 0.00 \\
\hline$=37$ & Informatics in Education & 0.86 & 0.00 & 0.86 & 0.00 \\
\hline 39 & Association for Learning Technology Journal & 0.83 & 0.02 & 0.71 & 0.10 \\
\hline 40 & Education and Information Technologies & 0.77 & 0.06 & 0.71 & 0.00 \\
\hline
\end{tabular}




\begin{tabular}{|c|c|c|c|c|c|}
\hline 41 & The International Journal of Excellence in e-Learning & 0.43 & 0.00 & 0.43 & 0.00 \\
\hline 42 & The Internet and Higher Education & 0.37 & 0.07 & 0.00 & 0.30 \\
\hline 43 & British Journal of Educational Technology & 0.35 & 0.05 & 0.00 & 0.30 \\
\hline 44 & Educational Technology Research and Development & 0.33 & 0.03 & 0.00 & 0.30 \\
\hline 45 & Computers and Education & 0.18 & 0.08 & 0.00 & 0.10 \\
\hline & $\begin{array}{l}\text { Journal of the Research Center for Educational } \\
\text { Technology }\end{array}$ & 0.00 & 0.00 & 0.00 & 0.00 \\
\hline
\end{tabular}

The correlation matrix which tests the relationship between the various ranking indexes is presented in Table 6, showing significant correlations between the overall index and the other three, though stronger for importance $(r=.719, p<.01)$ and prestige $(r=.674, p<.01)$ indexes. There are no significant correlations between the three ranking indexes of popularity, importance, and prestige.

Table 6

Correlation Matrix of Indexes between Overall Rank and the Three Ranking Schemas $(N=46)$

Rank Scheme Overall Popularity Importance Prestige

\begin{tabular}{lllll}
\hline Overall & 1.000 & & \\
Popularity & $.580^{* *}$ & 1.000 & & \\
Importance & $.723^{* *}$ & .246 & 1.000 & \\
Prestige & $.653^{* *}$ & .145 & .072 & 1.000 \\
** Correlation is significant at $p<0.01$ level (2-tailed).
\end{tabular}

** Correlation is significant at $p<0.01$ level (2-tailed).

\section{Discussion}

\section{Journal Popularity}

Results in Table 1 rank eLearning Papers as the most popular journal with a $17.81 \%$ weighted share of in-link counts. The 90th percentile contains five journals, each with over $4.85 \%$ share of all CML journal links. Analogous to a journal's in-link count share is market share that offers insights from the application of a four-firm concentration ratio $(\mathrm{C} 4)$ representing the combined in-link count share of the top five journals, calculated as $43.59 \%$. According to Wikipedia (http://en.wikipedia.org/wiki/Concentration_ratio), this describes a monopolistic market structure (Grewal \& Levy, 2010) with a relatively large number of journals, many readers, and competition 
based on subtle product differentiation among the journals. The competitive response for journal publishers and editors is to focus on content quality and widespread availability (a benefit of open access journals) to strengthen the journal's popularity.

\section{Journal Importance}

The top ranked six journals in Table 3 show a PageRank score of 7; when compared to other commonly accepted quality journals, this metric indicates relative importance. For comparative purposes, the PageRank scores for Econometrica (http://www.econometricsociety.org/) and Harvard Law Review (http://www.harvardlawreview.org/) are 7 each. After two ranking iterations, two journals share upper ranks in both popularity and importance categories: the International Review of Research in Open and Distance Learning, and the Online Journal of Distance Learning Administration. Clearly, these are two very well known CML journals by virtue of the number and quality of links from other websites.

As with any set of computations, a caveat is in order. The two rankings of journal popularity and importance may be influenced positively by the age of the journal's website and the relative amount of online content (Vaughan \& Thelwall, 2003). With this consideration, one is cautioned to monitor these rankings over time.

\section{Journal Prestige}

As shown in Table 4, there are five journals in the 90th percentile, each with over $6 \%$ of the total number of editor votes, three from the US and one representing Canada and the UK respectively. The journal ranked first place for prestige is the International Review of Research in Open and Distance Learning.

\section{Overall Ranking}

The top five out of forty-six scholarly CML journals are the International Review of Research in Open and Distance Learning, Journal for Asynchronous Learning Networks, eLearning Papers, Innovate: Journal of Online Education, and American Journal of Distance Education. Based upon popularity, importance, and perceptions of prestige, these journals represent the gold standard of quality and utility for online educators.

Table 6 reports no significant correlations between the three ranking indexes of popularity, importance, and prestige, suggesting that each index presents a unique perspective, which contributes to the robustness of the overall ranking index and allows for a valuable overall ranking of journals. 


\section{Limitations of this Study}

A challenge we faced when creating a list of CML scholarly journals centered on finding enough information sources because each new source offered diminishing returns. The ranking of journals by prestige was based on a single-item perception from editors in the field. Whilst singleitem perceptual rankings do capture complex individual knowledge, we would be more comfortable with multiple variables to create multi-dimensional constructs for each ranking schema and so clearly delineate between popularity, importance, prestige, and other dimensions of journal criteria, as has been suggested by others (Baumgartner \& Pieters, 2003; Shugan, 2003). In addition, any study on journal ranking is fraught with opinions about face validity; specifically, one can challenge the operational definition of the constructs under investigation. This study will undoubtedly generate varying perspectives concerning the integrity of the selected journals, which, in itself, is a never ending task given the growth and change computer-mediated learning is experiencing. The challenge is evident as witnessed by the demise of over $5 \%$ of the journals listed in various scholarly and professional websites. For example, several international journals (e.g., Indian Journal of Open Learning, Brazilian Review of Open and Distance Learning, and the Malaysian Journal of Distance Education) have not published an issue in over 12 months.

\section{Conclusions}

The results of this study provide insight into current and emerging leaders in scholarly publishing for the field of computer-mediated learning. This information is essential to guide online educators seeking quality information concerning pedagogy, best practices, and scholarly developments in the field. Whether one is investigating CML journals for the purposes of advancing their teaching and course design or as an outlet to disseminate their own scholarly investigations, the results of this study serve as a heuristic for effective, efficient journal selection.

We hope this study will encourage like-minded scholars to design and publish rigorous studies addressing journal selection and ranking to arrive at a generally accepted list of CML journals, and, from this, to develop a citation database to complement in-link counts, PageRank, expert opinions, and other dimensions offering alternative approaches to rank the journals, consistent with positions held by Bollen et al., (2006). A generally accepted list and ranking of scholarly CML journals will evolve over time as convergence validity is established from a result of a critical mass of these studies. Naturally, the relative youth and remarkable growth of CML as a discipline makes any decision about absolute journal ranking somewhat tentative. That is, definitively suggesting one journal is 'better' than another is premature given that a universally applicable journal ranking may not be possible (Polonsky \& Whitelaw, 2005), and a review of 16 different ranking studies shows rank consistency limited to the top three to six journals and widely divergent results for the remaining set of journals (Hawes \& Keillor, 2002).

This study offers a platform from which to start a formal conversation about scholarly publishing opportunities for CML educators. Also, it illustrates the importance of CML journals as a scholarly outlet to communicate knowledge and to offer manuscript submission options. The 
apparent independence among the various journal rankings (popularity, importance, and prestige) highlights the contribution of various qualitative measures to rank journals. Advancing the field of computer-mediated learning by offering a list and ranking of the scholarly journals guides educators toward an informed selection of the journals they will read and, as importantly, offers the ever growing number of scholars a cohort of journals to consider when submitting high quality manuscripts. Over the medium term, studies examining various aspects of journal ranking will generate a definitive list and ranking of journals that will doubtlessly help faculty and administrators judge the relative value of publications for promotion and tenure purposes.

\section{Acknowledgements}

The authors are grateful for the valuable guidance from two anonymous reviewers. 


\section{References}

An, L., \& Qiu, J. (2003). Research on the relationships between Chinese journal impact factors and web impact factors and external web link counts. Journal of the China Society for Scientific and Technical Information, 22(4), 398-402.

Baumgartner, H., \& Pieters, R. (2003). The structural influence of marketing journals: A citation analysis of the discipline and its sub-areas over time. Journal of Marketing, 67(2), 12339.

Bollen, J., Rodriguez, M.A., \& Van de Sompel, H. (2006). Journal status. Scientometrics, 69(3), 669-687.

Brin, S., \& Page, L. (1998). The anatomy of large-scale hypertextual web search engine.

Computer Networks and ISDN Systems, 30, 107-17.

Cabell, D.W.E. (2006). Cabell's directory of publishing opportunities in marketing. Beaumont, CA: Cabell Publishing.

Cal Poly Pomona Library. (2009). Scholarly journals. Retrieved April 9, 2009, from http://www.csupomona.edu/ library/tutorials/scholarly_journals.html

Check SEO. (2009). Link popularity. Check Search Engine Optimization. Retrieved April 9, 2009, from http://www.check-seo.com/LinkPopularity.php

Chen, P., Xie, H., Maslov, S., \& Redner, S. (2007). Finding scientific gems with Google. Journal of Informetrics, 1(1), January, 8-15.

Cornell University Library. (2009). Distinguishing scholarly journals from other periodicals. $\begin{array}{llll}\text { Retrieved April 9, 2009, from } & \text { 9, }\end{array}$ http://www.library.cornell.edu/olinuris/ref/research/skill20.html

Czinkota, M.R. (2000). International information cross-fertilization in marketing. European Journal of Marketing, 34(11/12), 1305-14.

Elbeck, M., \& Mandernach, B. J. (2008). Expanding the value of scholarly, open access ejournals. Library and Information Science Research, 30(4), 237-241.

Grewal, D., \& Levy, M. (2010). Marketing (2nd ed.). New York, NY: McGraw-Hill Irwin.

Harter, S., \& Ford, C. (2000). Web-based analysis of e-journal impact: Approaches, problems and issues. Journal of the American Society for Information Science, 51(13) 1159-76.

Hascall, V.C., Bollen, J., \& Hanson, R. (2007). Impact factor page rankled. ASBMB Today, July, 
16-19.

Hawes, J.M., \& Keillor, B. (2002). Assessing marketing journals: A mission-based approach. Journal of the Academy of Business Education, 3(2) 70-86.

Hult, G.T.M., Neese, W.T., \& Bashaw, R.E. (1997). Faculty perceptions of marketing journals. Journal of Marketing Education, 19(1), 37-52.

Jacso, P. (2005). Visualizing overlap and rank differences among web-wide search engines: Some free tools and services. Online Information Review, 29(5), 554-560. Retrieved April 9, 2009, from http://www.jacso.info/PDFs/jacso-visualizing-overlap.pdf

Jobber, D., \& Simpson, P. (1988). A citation analysis of selected marketing journals, International Journal of Research in Marketing, 5(2), 137-42.

Kim, M.T. (1991). Ranking journals in library and information science: A comparison of perceptual and citation-based measures. College and Research Libraries, 52(1), 24-37.

Larson, R.R. (1996). Bibliometrics of the World Wide Web: An exploratory analysis of the intellectual structure of cyberspace. ASIS, 96. Retrieved on January 23, 2009, from http://sherlock.berkeley.edu/asis96/asis96.html

Luke, R.H., \& Doke, E.R. (1987). Marketing journal hierarchies: Faculty perceptions, 1986-1987. Journal of the Academy of Marketing Science, 15(2), 74-8.

Mason, P.M., Steagall, J.W., \& Fabritius, M.M. (1997). Economics journal rankings by the type of school: Perceptions versus citations. Quarterly Journal of Business \& Economics, 36(1), 60-79.

McCown, F., \& Nelson, M.L. (2007). Agreeing to disagree: Search engines and their public interfaces. Joint Conference on Digital Libraries (DCDL)'07, June 18-23, Vancouver, British Columbia, Canada. Retrieved April 9, 2009, from http://delivery.acm.org/10.1145/1260000/1255237/p309mccown.pdf?key1=1255237\&ke y2=1477939321\&coll $=$ GUIDE \&dl=GUIDE \&CFID=29810093\&CFTOKEN $=13911580$

Meric, F., Bernstam, E.V., Mirza, N.Q., Hunt, K.K., Ames, F.C., Ross, M.I., et al. (2002). Breast cancer on the World Wide Web: Cross sectional survey of quality of information and popularity of websites. British Medical Journal, 324, March, 577-81.

Mylonopoulos, N.A., \& Theoharakis, V. (2001). Global perceptions of IS journals. Communications of the ACM, 44(9), 29-37.

Nisonger, T.E. (1999). JASIS and library and information science journal rankings: A review and 
analysis of the last half century, Journal of the American Society for Information Science, 50(11), 1004-1020.

Parnell, J.A. (1997). Assessing management journal quality: A methodological critique and empirical analysis. The Mid-Atlantic Journal of Business, 33, March, 69-83.

Polonsky, M.J., Jones, G., \& Kearsley, M.J. (1999). Accessibility: An alternative method of ranking marketing journals? Journal of Marketing Education, 21(3), 181-93.

Polonsky, M.J., \& Whitelaw, P. (2005). What are we measuring when we evaluate journals? Journal of Marketing Education, 27(2) 189-201.

Polonsky, M.J., Garma, R., \& Mittelstaedt, J.D. (2006). An examination of the globalization of authorship in publishing in 20 leading marketing journals. European Business Review, 18(6), 437-56.

Rice, B.A., \& Stankus, T. (1983). Publication quality indicators for tenure or promotion decisions: What can the librarian ethically report? College and Research Libraries, 44, March, 173-8.

R\&R Web design. (2008). Top global search engines December 2008 - market share. Retrieved April 11, 2009, from http://r-rwebdesign.com/blog/?p=353

Rogers, I. (2002). The Google Pagerank algorithm and how it works. Retrieved on January 27, 2009 from http://www.ianrogers.net/google-page-rank/

Rosenstreich, D. \& Wooliscroft, B. (2006). How international are the top academic journals? The case of marketing. European Business Review, 18(6), 422-36.

Search Engine Watch.com (2007). Major search engines and directories. Retrieved January 29, 2009, from http://searchenginewatch.com/2156221

Shugan, S.M. (2003). Journal rankings: Save the outlets for your research. Marketing Science, 22(4), 437-41

Top25Web. (2009). Google PageRank report. Retrieved April 9, 2009, from http://www.top25web.com/pagerank.php

Vaughan, L., \& Hysen, K. ( 2002). Relationship between links to journal web sites and impact factors. Aslib Proceedings, 54(6), 356-61

Vaughan, L., \& Thelwall, M. (2003). Scholarly use of the web: What are the key inducers of links to journal web sites? Journal of the American Society for Information Science, 54(1), 2938. 
(c)

SORERIGHISRESERVED
Athabasca University 
June - 2009

\title{
Cognitive, Instructional, and Social Presence as Factors in Learners' Negotiation of Planned Absences from Online Study
}

\author{
Dianne Conrad \\ Athabasca University, Canada
}

\begin{abstract}
Adult learners value the flexibility and convenience offered to them as online learners, and many learners are required to absent themselves from their online classes during courses in order to accommodate demanding schedules. What factors and tensions contribute to learners' decisionmaking at these times? This qualitative study considered the planned absences of learners engaged in an online graduate course at a large university. Working within the framework provided by cognitive, instructional, and social presences, findings showed the following: (1) learners understood and accommodated the relationship and importance of the affective domain to their cognitive successes in learning, (2) successful learners demonstrated insightful selfknowledge in using meta-cognitive strategies, and (3) learners' external support systems were fundamental to their ability to continue to learn when absences occurred. The study's findings corroborate other recent research that similarly stresses the complexity and interrelated nature of the adult learning process.
\end{abstract}

Keywords: Online learning; pedagogy; social presence; cognitive presence

\section{Introduction}

In our 21 st century technology-enhanced lives, the advanced state of technological access that we enjoy presents a mixed blessing. It is true that we can establish near-instant contact with anyone or any type of information anywhere in the world. At the same time, however, we are overwhelmed with connectivity. We struggle to establish new boundaries that will bring balance to our lives by permitting us to escape the omnipresence of technology and its many devices.

Online learning presents a similar dichotomy. Touted as making learning more accessible and more flexible, it does indeed provide learners with countless and never-ending opportunities to access courses, programs, and educational credentials. On the other hand, the constant availability of learning technology platforms doubles our workload when we are called away to attend to "the business of life" by work commitments, illness, family trauma, or the need for travel or family 
vacations. How do adult learners negotiate with themselves their "time-out" from online learning? How does their time-out affect their perceptions of their learning and the learning domains characterized by social, cognitive, and teaching presence? This paper reports the findings of a participatory action research project in which a small group of adult learners who were engaged in master's level study in a distance education program at a large American university worked together with the researcher to consider the issues underlying the reality of absenting themselves from their learning community and disrupting the regularity of process that they had developed to maintain their learning progress.

\section{The Study}

The qualitative research study that is reported here evolved with a participatory action intention in that the research question arose in conversation among participants, who were the learners, and a curiosity-driven researcher, who was the instructor. To observe the integrity of the learner-teacher relationship, the researcher did not initiate the research project until after the class had ended. Given this timeframe, there was no possibility to enact the findings of the research or to implement any kind of change based on our collective discoveries or wisdom (Wadsworth, 1997). Motivated by the spirit of participatory research, however, the research questions were derived from a collective, shared experience, and a number of data-gathering occasions reflected an iterative and interactive design.

\section{Genesis of the Study}

During the 16-week duration of a master's course offered by distance at an American university, many of the adult learners, who were engaged in rigorous online interactions with course material, the instructor, and their classmates (Moore, 1989), had to leave the course for periods of up to two weeks' duration. These absences arose from typical adult-learner circumstances: parental illness/death, family vacation, work assignments, work-travel assignments. When extensive class dialogue resulted from learners' announcing their impending absences, the instructor took note of the ensuing dynamic and became intrigued as to its impact on the group's learning, specifically in the areas of affective domain, social presence, and community.

\section{Participants}

In a class of 18 learners, fully $50 \%$ of the group took a leave of some sort $(N=9)$. Several learners indicated the need to absent themselves more than once and for different reasons. The reasons presented for extended absences included work demands (4), family pressures/demands, including child and health issues (3), work-related travel (5), and family vacations (3). The six learners who eventually responded to the post-course invitation to participate in a research project on "travel learning" were male and female middle-class adult learners, who were employed fulltime. Geographically, they were located in three countries on two continents. Beyond these facts, no attempt was made to gather more specific socio-economic data. All participants were English speakers. 


\section{Research Questions}

The overarching research question driving this study was the following: "How do learners experience extended absence from their learning communities?" Because of the evolutionary and participatory nature of the research design, the initial issues that would work themselves into subquestions were identified by the study's participants and formed the framework for four rounds of data collection, described below.

\section{Methodology}

Unlike other research projects in which the writer has been involved, this study generated a gentle and iterative knowledge-building type of data gathering. Each round of questioning and exchange expanded on and delved further into the issues. The door was always open for participants and researchers to exchange thoughts, clarify questions, and probe the data. Various combinations of the six participants interacted with the researcher and each other at all times in conversational exchanges. Each round of data gathering is described below.

\section{Round one.}

Data collection began with the distribution by email of this question: "What issues are raised for you when you contemplate an extended absence from an online course?" Participants reflected on this question and responded with various degrees of commentary on their lists of issues. Participants also opened up a Google site for discussion that arose from their responses.

\section{Round two.}

Working from participants' initial responses, the researcher extrapolated nine common issues and approached the participants a second time with this request: "Please reflect on these issues. Do they make sense to you? Do you think this captures the 'deal about having an absence from your regular learning routine"'? Then two more requests were made of participants: 1) "Moving to a next level, think in terms of learning domains (cognitive, affective [social], psycho-motor). Does any one of these domains stand out as the one that is most affected by the actions needed to enable an absence?" and 2) "If you were an online instructor (and some of you are...) and a student came to you to tell you about a proposed fairly lengthy absence from class (how long would that be?), what question(s) would you put to the student to ensure that he/she had everything under control?" Responses from seven participants to these enquiries were returned by email and posted to the Google site. 


\section{Round three.}

From the data received, the researcher refined several seed questions to initiate a real-time online focus group among those participants who could attend. The usual type of circumstances that hinder synchronous conferencing prevented many of the participants from attending the session, which was held by mutual agreement on a Saturday; one participant was travelling and two had family commitments. As a result, only two participants and the researcher chatted online for an hour. The transcript was recorded and sent to the participants for their validation and responses. Concomitantly, the researcher constructed a learning style inventory instrument for distribution by email to all participants and explained that she would use it as a categorizing tool for the study's data. The inventory that was used combined Kolb's (1984) categories of learning styles (AR, AS, CS, and $\mathrm{CR}$, where $\mathrm{A}=$ abstract, $\mathrm{C}=$ concrete, $\mathrm{R}=$ random, and $\mathrm{S}=$ sequential) with Grasha's (1996) similar inventory of styles. Its purpose was to allow participants to self-identify their learning styles in order to provide a categorizing mechanism for analyzing their behaviours when dealing with absence. Four participants completed and returned the inventory.

\section{Round four.}

During the next month, the researcher continued to analyze, categorize, and thematize the data. During this time, she engaged in several one-on-one question-and-answer exchanges with participants as she sought to clarify data. Some discussion evolved within the Google site in response to postings, but the group's energy level was dissipating. A final question went out to participants three months after the initial data gathering. Five participants responded to these questions:

1. Looking back, what aspect of your being away from your online class do you recall causing you the most grief/anxiety? (or substitute another noun here, depending...)

2. As a learner, did you learn anything about yourself and your ability to be a good learner from that episode?

3. Would you feel comfortable taking a lengthy absence again from online study? (Or, have you, since then?)

\section{Limitations of the Study}

There was an obvious limitation to this study that superseded the normal limitations of small, qualitative studies that are not able to be generalized to a larger population. Several more learners from the group were invited to participate in the study from its inception - invited to contribute ideas, questions, and issues - based on the fact that they had also experienced absences from the class. Some of these learners performed less well than others; some of these learners in fact suffered from their absences to the extent that they were not able to maintain an adequate level of commitment to the course and fell by the wayside, either immediately following an absence or a little later on, as it became more difficult for them to attempt to catch up. All told, the participants that engaged in the study were strong and successful learners; repeated efforts to engage some of 
the other learners were not successful. There is, therefore, an element of self-selection here that is recognized by the researcher but deemed unavoidable.

\section{Literature Review and Theoretical Framework}

The complex individual and social nature of online learning has been well researched and documented in recent years. This research draws on two bodies of literature, the most fundamental being the implicit understanding of adult education principles that underpin most discussions of online learning. From the adult education literature come notions of self-direction, autonomy, respect, and independent learning (Brookfield, 1990; Knowles, 1970; Renner, 2005) as well as notions of the value of adults' experiential learning and the role that learning plays in their engagement in occasions of formal learning (Dewey, 1938). Additionally, the study is framed both by Garrison and Anderson's (2003) community of inquiry work and by learning style theory, most notably Kolb (1984). Initiated by Garrison, Anderson, Archer, and Rourke's seminal "presences" research almost a decade ago, constructivist thinkers in the field of distance education have focused on "webs of significance" (Geertz, 1973) that constitute the online learning dynamic. From myriad research studies, our perception of what was once thought to be a technology-enhanced communication has developed into an understanding of a very layered enterprise (Blanton, Moorman, \& Trathen, 1998). To understand and discuss the research findings, this study uses Garrison and Anderson's (2003) community of learning framework and adds to this framework distance education's understanding of the concept of community in learning and among learners and also builds on two notions of learning style. Kolb's (1984) experiential learning model is juxtaposed with Grasha's (1996) online learners' typology and used as a foundational categorization strategy.

Garrison, Anderson, and Archer's (2000) articulation of cognitive, instructional, and social presence gave online theorists and researchers a useful schema through which to conceptualize the complex interaction of online learners' learning processes. From this solid starting point, subsequent and related research has investigated more deeply the various factors that define and connect online learners. Whereas the interrelated nature of the online learning dynamic is recognized by this writer, the nature of this study invited a closer look at cognitive and social presence constructs than at teaching presence, and the analysis of the findings and the subsequent discussion highlight the key roles of learners' sense of cognition and their devotion to maintaining their cognitive presence when absent from their learning group. Interestingly, recent quantitative data on the progression and integration of online social, cognitive, and teaching presence over time (Akyol \& Garrison, 2008) support the predominance of cognitive presence among learners, while at the same time acknowledging the intricate intermeshing of all three presences. Akyol and Garrison's (2008) study, while reporting on changes in the delicate balance of an online course over time, did not raise the issue of learners' prolonged absences from the community dynamic; however, the researchers did recognize the complexity of online learning's "constituting elements and categories" within the "dynamic nature of a community of enquiry" in calling for further investigation into the nature of that community. Coming at the concept of community from its perspective as a substantive factor in the makeup of online learners' affective domain, Conrad's research (2005) demonstrated a robust, vital sense of group cohesiveness that 
responded to many stimuli, including the length of the study period of the course or program, the integration of distance study with face-to-face meetings, and patterns of community evolution over time.

In a quantitative study involving 135 participants, Wang et al. (2008) investigated the psychological characteristics of distance learners to determine the relationship between learners' levels of motivation, their self-efficacy, and their learning results, determining that "learning motivation and learning strategies are clearly associated with positive and predictable effects on learning results" (p. 17). Building on Ausubel's theory of learning motivation, Wang et al. gathered their data from a questionnaire that explored the three dimensions of learners' intrinsic motivation. For the purposes of this study, however, Wang et al.'s (2008) findings were most relevant in their support of Shih and Gamon's (2001) work, which concluded that "the level of learning strategy is one of the most important factors in determining learning results" (p. 25).

Where do learners' learning strategies come from? Motivation theory is one place that provides background against which to think about the connection between online learners' learning success and learning strategies. Raymond Wlodkowski, arguably one of the strongest voices on adult motivation, suggests that the highest level of adult motivation arises when "the adult has experienced learning as pleasurable and intrinsically motivating” (2008, p. 101). Wlodkowski's third edition of Enhancing Adult Motivation to Learn (2008) is valuable to this study because of its detailed attention to the cognitive aspects of adult learning but also because of the author's emphasis on cultural - broadly speaking - inclusiveness and social relevance as important parts of the learner's landscape. Wlodkowski ties motivation-to-learn to "our acute awareness of the degree of our inclusion in a learning environment" (p. 126). Research into online community supports this view (Conrad, 2005; Kehrwald, 2008).

\section{Findings of the Study}

The results of this study confirm the fact that a network of strongly interconnected factors guides learners' decision-making when they are faced with the need to absent themselves from their regular online learning. Working in an adapted participatory style, as described above, the study's first round of data collection asked participants $(N=6)$ to respond to the following question: "What issues are raised for you when you contemplate an extended absence from an online course? What issues do we need to be aware of? Think not only in terms of study and learning areas, but also of the affective domain, and of any other peripheral factors that play into the arrangements or deals that you make with yourself in order to facilitate the absence and/or the learning." Participants' responses to this opening question brought forth many issues, which were placed by the researcher into the following categories (in no particular order): connection with other learners; connection with materials and resources; self-knowledge (learning style, learning needs, learning rhythm); making physical arrangements for technology and for connections with course; dealing with assignments; enhancing classroom learning through travel experiences (e.g., "giving back"); planning or setting priorities; family support or arrangements; and control of environment and of self. 
In the second round of data collection, learners were asked to reflect on these issues and to consider whether they captured the essence of "having an absence from your regular learning routine." They were also asked to "move to a next level" by "think [ing] in terms of learning domains (cognitive, affective (social), psycho-motor)" and noting whether any one of these domains stood out as the one that was the most affected by the actions needed to enable an absence. Finally, participants were asked this question: "If you were an online instructor, and a student came to you to tell you about a proposed fairly lengthy absence from class (how long would that be?), what question(s) would you put to the student to ensure that he/she had everything under control?"

Participants unanimously agreed that the issues extracted from the first round of data-gathering were indeed the salient ones. The second question generated responses that identified both the cognitive and affective domains as being impacted by absences, although most learners clearly indicated that the cognitive domain was of foremost importance to them. The most revealing outcome from this question was learners' connection of the cognitive domain to the affective domain, expressed in statements like this one: "I personally depend on other classmates to stimulate my thinking process." This finding supports research confirming not only significant relationships between cognitive presence and satisfaction and between cognitive presence and perceived learning but also that "social presence through group cohesion ... supports integration and higher levels of cognitive presence (e.g., integration)" (Akyol \& Garrison, 2008).

The third question asked learners to respond from a hypothetical or real instructional perspective. Only one participant had experience as an online instructor (although all had face-to-face instructional experience); that participant contributed two anecdotes to illustrate her responses. That said, all participants' responses, both theoretical and real, emphasized their concern that logistical arrangements should be well-confirmed for learners before embarking on a lengthy absence from the online experience. The following are some of the questions that they would ask of students:

- When will your assignments be submitted?

- Will you have access to a computer?

- Will you have Internet access?

- Which resources will you count on to help you stay on track?

- How do you plan to overcome any obstacles that you may face during your absence?

- Are you aware of the course syllabus?

Participants also indicated that in an instructional role they would give the following advice to students who were preparing for a lengthy absence:

- You must prepare for your absence by setting up a web-based repository for necessary documentation.

- Be sure to take the right resources. Don't get caught with the wrong readings or books!

- Look carefully at assignment due dates.

- Let your instructor and classmates know that you will be gone. 
- If you're involved in small group or collaborative work, let those classmates know up front that you will be absent or less available than usual.

Round three's data came from an hour-long online chat among two participants and the researcher. The exchange was recorded by a software program and a transcript was produced. Several of the same themes as had arisen in previous exchanges were reiterated, although in a more casual fashion given the conversational flavour of the chat function. The learners involved were also quite familiar with each other from repeated course contact. Themes that were repeated from prior data are outlined below:

- Absenting oneself from an online course required conscientious and diligent planning, which included the following: knowing when and where you would be driving or flying, so as to arrange work-time; knowing whether or not the destination would have reliable Internet access, wireless, or printers; and ensuring that the correct materials were packed, including course readings or textbooks. Such planning also included the choice of whether or not to enrol in a course when vacation or travel was looming on the horizon.

- Some absences may be more easily accommodated than others (due to location, type, length, etc.).

- Individuals who are not by nature "planners" needed to become planners in order to succeed in their absence.

- Regular routines had to be adapted in order to fit course work into absences.

- Assignment due dates were "red-letter" factors in planning absences.

- There was a perceived difference in importance between assignments and participation in discussions.

- It was considered important to have access to the course's syllabus well ahead of time and to know with confidence that the syllabus would not change.

- There was an expectation that instructors' demands would be flexible as well as a recognition that such flexibility was the norm in cases of emergencies, such as a death in the family or power outage due to a severe storm.

- Chatting with classmates maintained the level of connection and the feeling of connectedness.

Interestingly, two new themes emerged from this informal exchange. (The chat occurred on a Saturday, which also may have been a factor in the level of informality.) Firstly, anxiety levels rose according to the complexity of the travel plan and the number of logistical issues involved (e.g., whether or not there would be a reliable Internet connection in a hotel in another country). And secondly, these participants felt that some students would "always have excuses for not being [online]." One participant commented that as adults we suppose that we can manage our time and coordinate our activities so as to be able to fulfill the obligations of the course. The other, acknowledging that he had himself figured out how to do this, agreed: "There seem to be several folks who used travel as an excuse not to be there...because I've figured out how to do both, I wasn't overly sympathetic." Both participants couched their remarks by acknowledging that there were many extenuating factors at play in these types of situations. 
Round four's data collection asked learners to look back on their experience and to reflect after a four-month passage of time. Julia was clear and decisive in her reflection: "I had been 'absent' in a prior course and that experience made me unwilling to be absent again." Similarly, Don was not comfortable with the thought of another extended absence. He reflected on his current learning experience, comparing it with the course under study:

Right now I'm taking the capstone course. Next weekend I am going on a trip and don't expect to be able to check in at all; however, the capstone course is not set up for debates, discussions, etc. It is mostly work on your own - project and portfolio. So I don't think I'll feel like I'm missing out! At least, I hope not.

Hannah reflected that while three or four days might be alright, an absence of more than a week would be too disruptive for her. Carol came away with the exact opposite type of experience. Knowing that she had succeeded through her organizational measures to be successful in spite of a lengthy absence, she felt she could manage such an absence again. (No contrast is intended between Julia and Carol as students. Both were very successful learners.) For Carol, though, having experienced high anxiety around the question of whether or not she would be able to find convenient Internet access, knowing that she would be able to cope left her feeling completely at ease.

\section{Discussion}

As described above, the impetus for this study arose out of online class members' efforts to situate themselves properly - according to their perceptions - when they were going to be absent from the group for a long period of time. In most cases, this was about two weeks, constituting over a 15 week course approximately $13 \%$ of the length of the course. Translated to a traditional face-to-face 39-hour course, this length of absence equates to missing 5 hours of class time, or approximately two three-hour lectures. Absences expressed in those terms do not seem to be such a big deal! How many of us, in our own years of studentship, simply did not show up for lectures?

But there is a difference that cannot be interpreted quantitatively by comparing these numbers, and the difference lies in the now-understood notion "that meaningful and worthwhile learning is associated with collaborative communities of inquiry" (Akyol \& Garrison, 2008). This is true of online learning for several reasons: the connective heart of a learning community must exist in a distributed manner; online learning succeeds best using constructivist approaches that both foster and require collaborative input; and the asynchronous generation of knowledge on discussion boards is fluid and multi-faceted. At a practical level, online courses usually feature a participation grade that is awarded based not on quantitative measures but on a representative spread of participative activities by the learner throughout the course. Sustained absence from the course could potentially threaten participation grades. But a more severe and potentially disruptive result of sustained absence concerns learners' separation from other learners and from the sense of community that hallmarks Wlodkowski's (2008) desired state of inclusivity. For 
many learners (not all) engaged in constructivist learning environments, the binding-together and sharing of common purpose serves as a powerful learning device.

This study's participants all labelled themselves as "cooperative" learners on Grasha's (1996) scale. From among several choices, such as competitive (wants to be first), avoidant (nonparticipating), participant (eager to accomplish), dependent (looks to instructor for guidance), independent (thinks for self, likes to work alone), they chose the option "collaborative, shares ideas and information." The course's archival records support participants' self-selection in this regard. Interestingly, whereas round three participants who completed the learning styles inventory $(n=4)$ unanimously declared themselves as collaborative learners, they differed in their labelling of themselves on Kolb's scale. From this, the researcher surmised that they had thought carefully about their choices and that the task of self-categorization did not lend itself to an automatic pairing of categories. Ultimately, therefore, while the results of participants' selfcategorization confirms that they are indeed willing, constructive, and collaborative-minded learners, the results also reaffirm the limitation of the study: this handful of online learners who shared their concerns and insights about the nature of their online absences were already committed online learners, who both understood and had made their peace with what was being asked of them in an online course.

This study's findings break down into three major themes: the validation of the interconnectedness of cognitive, social, and instructional presence (Garrison \& Akyol, 2008); the importance of learners' self-knowledge, comparable to Wang et al.'s (2008) understanding of meta-learning; and the always-relevant impact of external and circumstantial life-situations on adult learners' ability to engage in learning. None of these themes can be distinctly separated from the other. In that sense, the Venn diagram used by Garrison and Anderson (2003) to capture the interrelated nature of the three presences could be used conceptually here to represent the meshed nature of all the learning factors named above; that is, the three presences would be set among and complemented by both internal and external factors contributing to learners' performances.

\section{Validation of the Interconnectedness of Cognitive, Social, and Instructional Presence}

The study's data spoke clearly to the fact that learners valued most strongly their ability to maintain a strong cognitive presence during their absences from online classes. One respondent described at length her decision-making process, which centred on assignment due dates in relation to the dates of a planned family vacation:

I knew that traveling with my [children] would mean that I would have zero "metime" let alone a chunk of time to research and write an assignment. My preferred way of writing assignments is to give myself at least two full days with no interruptions where I can work alone for at least 7 consecutive hours. I hate having to write assignments in small bits of time. It makes me feel really stressed and discombobulated. 
This student asked the instructor if she should withdraw from the course but was reassured that arrangements could be made to resolve the situation satisfactorily.

Don had been in the process of changing jobs and relocating during the course, and he commented that he was sorry to be away:

...there were good things going on there... discussion and/or debate... that I was missing. I like to get into the thick of things in my courses and check in a few times every day, so not being able to get internet access was frustrating. When I returned from my trips, I had to read through several days of postings in one sitting. Not only was it time-consuming, it was difficult to determine the sequence of the action: generally there are several conversations going on, and classmates tend to reference other ongoing discussions in other threads. If you are not reading them in real time, it's hard to recreate the flow.

Don was also aware that the finer logistics of timing contributed to the quality of interaction that permits constructive knowledge-building online. He described his attempts to catch up toward the end of a discussion forum: "Often, no one responds to a late post and it just hangs out there in space; they may not even be reading the late posts because they have already moved on."

Similarly, Hannah connected timing issues to her own cognitive functioning in the course, functions that she found were disrupted by her absence: "I wasn't able to ask questions of the other students and I was often a couple of days behind in reading the posts. By the time I could comment, the other students had moved on to the next issue."

When asked pointedly which domain they felt was most affected by absence, all participants indicated the cognitive domain. They also, however, appended to that statement subsequent statements explaining the ways that they felt that their activities in the cognitive domain slipped over into activities in the affective domain: "So, did my 10-day vacation have an impact on my online experience as I had sorted out the assignment problem? Yes. I hadn't reckoned on how much online learning depended on active participation in the conferences."

Other participants commented on the connection that existed for them between the quality of their learning and the interaction they experienced - and missed out on, when away - with their colleagues.

I personally depend on other classmates to stimulate my thinking process. I read and form an opinion or understanding and then compare what others have to say to my own thoughts. Sometimes I change my mind based on the arguments of others. The interaction helps me to reanalyze my position which enhances my learning process.

Not being able to check in when I wanted to did make me realize that I am a very social learner. I like to be where the action is, and being isolated from it was 
tough for me. I think that it challenged my ability to be a good learner. I learn by doing.... by reading and participating... and I felt as if I was not learning during the times I was away, even though I was reading articles or doing other work for my class.

Learners' perceptions of the interconnection of their own learning progress to the comfortable and collaborative learning milieu engendered by the presence of online colleagues indicated that they have realized a level of harmony and integration that has been upheld by educators and researchers as attrition-reducing and support-engendering (Conrad, 2005; Kehrwald, 2008; Moore \& Kearsley, 2005; Tinto, 1993). Accepting then that the sense of belonging, well-being, and connection that Garrison and Anderson (2003) depict as the overlapped centre in the "presences" model was understood and valued by these learners, the question arises: what strategies or factors are at work as they attempt to retain the necessary harmony when they prepare for a lengthy absence from the group's dynamic? This study's data, supported by the literature, maintain that both instructional presence and learners' own self-knowledge are important factors.

Participants indicated that the actions and attitudes of instructors were critically important in making absences possible. Carol became aware of her organizational capabilities after a lengthy absence traveling in Europe but credited her instructors with helping to make her absence palatable. As she contemplated another absence from the two online courses that she was enrolled in, she offered this comment:

Both my online instructors have already posted all the activities for the course. This gives me the opportunity to plan my readings in advance and organize my time while away from class. I already know what I have to do and how I have to do it, which gives me confidence during my absence.

In this sense, although the primary foci of learners' concerns could be labelled as cognitive and social, the impact of instructional presence was also important to absentee learners. They needed to be able to depend on supportive instructors with whom they could negotiate the terms of their absence. Additionally, learners needed to be able to count on dates and assignments remaining stable so that they could plan informed absences.

\section{Learners' Self Knowledge}

Contained within this category are two elements, maturity and learning styles. By learning styles, I refer to learning habits rather than to inventory-designed preferences, such as Kolb's abstract sequential (AS) or Grasha's "competitive" learning style. Rather, the example outlined previously that documented a learner's struggle to arrange her schedule to match her course's assignment due dates is an example of a learning habit: this learner is in the habit of checking assignment due dates and, in the case of upcoming travel, ensuring that the dates are feasible for her. This learner's demonstrated intrinsic motivational strategies also confirmed previous studies' data that highlighted the importance of learners' level of learning strategies (Shih \& Gamon, 2001; Wang et al., 2008). 
That same learner also realized that the "lurker" style of learning was not for her. Reading other learners' posts after-the-fact "did not really help me in the usual way that reading other students' postings do." Switching over to cognitively-based observations on her own style, she continued:

Usually when I read postings, I'm reading actively, i.e., as I read, I'm measuring up that response with what I have/will post on the same topic. I'm thinking about what I'm going to reply, what I'll say, do I need to go away and ponder this point? However, reading closed conferences [upon her return] in which I could not participate, I found that I read passively, counting how many posts I had to read and plodding through them without really interacting with the content in the usual way.

Learners expressed their individual nuggets of self-knowledge in various ways. One wrote, "For me, taking an online course means that I commit to being around a computer for the whole course. Another wrote, explaining the necessity for careful choices of what materials to take away with her while traveling, "I don't like to read on the screen so having the documents with me worked better."

Carol, a self-described organized learner, also commented that becoming a "witness learner" while away helped to reduce her anxiety level as she "kept informed about what was happening in my class during my absence." Carol also reported that her two week absence from class reinforced her own sense of being responsible and organized. "I had time to plan my trip and I made sure I took all my readings with me so I could read them while being at the airport, in the plane or even at nights." Carol organized her holiday time so that she could spend time with her family and enjoy her trip "while having my readings and assignments [done] on time."

Some learners revealed self-knowledge concerning the impact of timing and immediacy on the quality of their responses. The issue of immediacy is telling given that asynchronous learning, as in the course under study, is criticized by some for not offering learners a sense of immediacy. For Don, regular attendance during the course allowed him to feel involved and to contribute what he felt was meaningful and "honest." However, he added:

When you get there after the fact [after an absence], you really cannot naturally enter the conversation and add your thoughts and comments. It ends up being more artificial and more of an afterthought and your peers generally have already moved on to other topics and discussions.

The thoughtful reflections of learners on the nature of their own learning are indicative of levels of maturity and emotional intelligence. Research indicates that mature learners are better equipped for success in online learning (Berenson, Boyles, \& Weaver, 2008). Wlodkowski, referencing Goleman's seminal research on emotional intelligence, suggests that "intellectual capacity during adulthood is a combination of genetic expression, experience, and knowledge that displays continued growth and highest potential in culturally relevant, real-life situations" (2008, 
p. 41). Learners in this study clearly demonstrated the coalescence of these maturity-related factors while they constructed academic success amidst real-life situations that had the potential to affect their studies.

\section{Impact of External Factors on Adult Learners' Ability to Manage their Learning}

Traditional learners have always cited personal issues as a major reason for dropping out of courses (Moore et al., 2002; Wiesenberg, 2001). The notion of personal issues contains a cluster of factors: time, money, work, personality conflicts with others, and so on. Similarly, online learners cite personal issues as contributing to their inability to complete online study, but in addition online learners cite issues of "support" as critical to their success (Moore \& Kearsley, 2005; Moore et al., 2002; Zembylas, 2008). Augmenting any learner's need for support is the odd circumstance in which many online learners find themselves when they miscalculate the amount of time and challenge that online learning will demand of them (Stanford-Bowers, 2008).

The most carefully arranged study plans can be severely disrupted when online learners - for whatever reason - have to suddenly absent themselves from their routine and their commitment to their learning group. One learner made a clear distinction between her "regular" online load resulting from "just taking online courses in general" and "catching up on missed online work" resulting from an absence: "My husband takes on a lot more childcare duties when I am trying to catch up on work and I rely on him to 'free-me-up' on weekends so I can study." In the same vein, another female learner relied on her husband to "cut his work days shorter so that he could drop off and pick up our son at daycare and shuttle him to soccer practice and games." This family arranged and re-arranged their schedules and childcare routine for the learner's absence. She returned the favour when she returned to allow him "to catch up at work," and then her husband stepped to the plate again on a Saturday to allow the learner "a chance to catch up on a paper." "Logistics!" she commented.

\section{Conclusion}

Online instructors and administrators often need to explain to novice learners the meaning of flexibility as regards online learning. Too often, it is interpreted by learners as meaning, "Do your learning however and whenever it suits you." And although most online courses - with their deadlines and their due dates and fairly routine parameters - still permit more flexibility than traditional place-bound courses, absenting oneself from an online learning experience can take its toll on learners. The adult learners in this study were all strong learners who shared through four rounds of data collection their questions, insights, and reflections on how being absent from their online class for an extended amount of time affected their studentship. As committed and mature learners, they recognized that undertaking absences from their online studies during course-time would require planning and levels of decision-making that recognized the dynamic interplay of cognitive, instructional, and social presences on their learning. Although learners in this study were aware of and attentive to all three domains of learning, their cognitive presence - and the 
perceived need to maintain cognitive success while absent - proved to be the most important factor in their planning process. Learners also recognized the relationship between their cognitive success and both the social fabric of their online course, which supported them in a comfortable learning environment, and the nature of instructional presence that rendered their absence either easier or more difficult. Learners demonstrated a keen degree of self-knowledge, especially as regards their own learning patterns, and were also aware of their interrelationship with and dependence on external factors, such as family support. By melding responsibility with flexibility, this study's learners successfully negotiated additional degrees of "distance" into their distance learning. 


\section{References}

Akyol, Z., \& Garrison, D. R. (2008). The development of a community of inquiry over time in an online course: Understanding the progression and integration of social, cognitive and teaching presence. Journal of Asynchronous Learning Networks (JALN), 12(3).

Berenson, R., Boyles, G., \& Weaver, A. (2008). Emotional intelligence as a predictor for success in online learning. International Review of Research in Open and Distance Learning, 9(2). Retrieved on October 10, 2008, from http://www.irrodl.org/index.php/irrodl/article/view/385/1049.

Blanton, W. E., Moorman, G., \& Trathen, W. (1998). Telecommunications and teacher education: A social constructivist review. Review of Research in Education, 23, 235-275.

Brookfield, S. D. (1990). The skillful teacher. San Francisco: Jossey-Bass.

Cigognini, M. E., Pettenati, M. C., Paolette, G., \& Edirisingha, P. (2008). Guiding learners to become knowledgeable learners 2.0. Proceedings of EDEN Conference 2008, Portugal. Retrieved November 23, 2008, from http://www.edenonline.org/papers/publications/proceedings/Lisbon 08/papers/A2/199.html

Conrad, D. (2005). Building and maintaining community in cohort-based online learning. Journal of Distance Education, 20(1), 1-21.

Dewey, J. (1938). Experience and education. New York, NY: Macmillan.

Garrison, D. R., \& Anderson, T. (2003) E-learning in the 21 st century: A framework for research and practice. London: Routledge/Falmer.

Garrison, D. R., Anderson, T, \& Archer, W. (2000). Critical inquiry in a text-based environment: Computer conferencing in higher education. The Internet and Higher Education, 2(2/3), 87-105.

Geertz, C. (1973). Interpretation of cultures. New York, NY: Basic Books.

Grasha, A. F. (1996). Teaching with style. Pittsburgh, PA: Alliance.

Kehrwald, B. (2008). Understanding social presence in text-based online environments. Distance Education, 1(29), 89-102.

Knowles, M. (1970). The modern practice of adult education. Chicago, Ill: Follett.

Kolb, D. A. (1984). Experiential learning: Experience as the source of learning and development. 
Englewood Cliffs, NJ: Prentice-Hall.

Moore, M. G., \& Kearsley, G. (2005). Distance education: A systems view (2nd ed.). Belmont, CA: Thomas Wadsworth.

Moore, K., Bartkovich, J., Fetzner, M., \& Ison, S. (2003). Success in cyberspace: Student retention in online courses. Journal of Applied Research in the Community College, 10(2), 107-118.

Müller, T. (2008). Persistence of women in online degree-completion programs. International Review of Research in Open and Distance Learning, 9(2). Retrieved on September 21, 2008, from http://www.irrodl.org/index.php/irrodl/article/view/455/1042

Renner, P. (2005). The art of teaching adults: How to become an exceptional instructor and facilitator. Vancouver: Training Associates.

Rourke, L., Anderson, T., Garrison, D. R., \& Archer, W. (1999). Assessing social presence in asynchronized text-based computer conferencing. Journal of Distance Education, 14(2), 50-71.

Shih, C.- C., \& Gamon, J. (2001). Web-based learning: Relationships among student motivation, attitude, learning styles, and achievement. Journal of Agricultural Education, 42(4), 12 20 .

Stanford-Bowers, D. (2008). Persistence in online classes: A study of perceptions among community college stakeholders. Journal of Online Learning and Teaching, 4(1), 37-50.

Swan, K., \& Shih, L. (2005). On the nature and development of social presence in online course discussions. Journal of Asynchronous Learning Networks, 9(3). Available at http://www.sloan-c.org/publications/jalm/v9n3/v9n3_swan.asp

Tinto, V. (1993). Leaving college: Rethinking the causes and cures of student attrition (2nd ed.). Chicago: The University of Chicago Press.

Wadsworth, Y. (1997). Do it yourself social research (2nd ed.). Sydney, Australia: Allen \& Unwin.

Wang, Y., Peng, H., Huang, R., Hou, Y., \& Wang, J. (2008). Characteristics of distance learners: Research on relationships of learning motivation, learning strategy, self-efficacy, attribution and learning results. Open Learning, 23(1), 17-28.

Wiesenberg, F. (2001). The roller coaster life of the online learner: How distance educators can help students cope. Canadian Journal of University Continuing Education, 2(27), 33-59. 
Wlodkowski, R. (2008). Enhancing adult motivation to learn: A comprehensive guide for teaching all adults (3rd ed.). San Francisco: Jossey-Bass.

Zembylas, M. (2008). Adult learners' emotions in online learning. Distance Education, 1(29), 71-87. 
June - 2009

\title{
Effect of Instructor-Personalized Multimedia in the Online Classroom
}

\author{
B. Jean Mandernach \\ Park University, USA
}

\begin{abstract}
There is considerable evidence that well-designed multimedia resources can enhance learning outcomes, yet there is little information on the role of multimedia in influencing essential motivational variables, such as student engagement. The current study examines the impact of instructor-personalized multimedia supplements on student engagement in an introductory, college-level online course. A comparison of student engagement between courses that feature increasing numbers of instructor-personalized multimedia components reveals conflicting evidence. While qualitative student feedback indicates enhanced engagement as a function of instructor-generated multimedia supplements, quantitative data reports no significant differences in engagement or learning between the various levels of multimedia inclusion. Findings highlight the complexity surrounding the appropriate use of multimedia within an online course. University policy-makers and instructors are cautioned to examine carefully the cost-benefit ratio of multimedia inclusion for online learning environments.
\end{abstract}

Keywords: Multimedia; online learning; policy

\section{Introduction}

The increasing growth and popularity of online learning is forcing faculty to examine the role of multimedia within their online course content. Research indicates that effective online multimedia is content-relevant and pedagogically intentional; as such, appropriately integrated multimedia components become a valuable teaching tool for facilitating student learning. While there is considerable evidence supporting the cognitive value of multimedia in the online classroom (for a multitude of studies on this topic, see journals such as New Review of Hypermedia and Multimedia, Multimedia System, Journal of Multimedia, Advances in Multimedia, Journal of Interactive Media in Education or, the previously published, Interactive Multimedia Electronic Journal of Computer-Enhanced Learning), there is little information on the role of multimedia in influencing essential motivational variables such as student engagement. The purpose of the current study is to examine the impact of instructor-personalized multimedia supplements (i.e., 
multimedia that features the face and/or voice of the course instructor) on the self-reported level of student engagement and learning in an online course.

\section{Role of Multimedia}

The emphasis of multimedia design and development has been on the presentation of information in multiple formats (Hede \& Hede, 2002). There are a number of overlapping definitions of multimedia. According to Doolittle, "web-based multimedia represents the presentation of instruction that involves more than one delivery media, presentation mode, and/or sensory modality" (2001, p.3). Multimedia has also been defined as "the use of multiple forms of media presentation" (Schwartz \& Beichner, 1999, p. 8) and "text along with at least one of the following: audio or sophisticated sound, music, video, photographs, 3-D graphics, animation, or high-resolution graphics" (Maddux, Johnson, \& Willis, 2001, p. 253). Although numerous definitions exist to capture the essence and meaning of multimedia, "one commonality among all multi-media definitions involves the integration of more than one media" (Jonassen, 2000, p.207). Examples of multimedia include, but are not limited to, text in combination with graphics, audio, music, video, and/or animation.

The theoretical value of multimedia inclusion is supported by a range of basic learning principles. The cognitive theory of multimedia learning is based on the following: 1) constructivist learning theory in which meaningful learning occurs when a learner selects relevant information, organizes the information, and makes connections between corresponding representations; 2) cognitive load theory in which each working memory store has limited capacity; 3) and dual coding theory emphasizing that humans have separate systems for representing verbal and nonverbal information (Moreno \& Mayer, 2000). In supporting this inclusion of multimedia, the multimedia principle finds that "students learn better from words and pictures than from words alone" (Doolittle, 2001, p.3). Hede and Hede (2002) find that games and simulations afford goalbased challenges that trigger interest and increase user motivation, and they also suggest that providing tools for annotation and collation of notes promotes learner engagement. Moreno and Mayer (2000) provide additional information to suggest "active learning occurs when a learner engages in three cognitive processes - selecting relevant words for verbal processing and selecting relevant images for visual processing, organizing words into a coherent verbal model and organizing images into a coherent visual model, integrating corresponding components of the verbal and visual models" (p.3).

The need for diverse instructional strategies targeting a range of cognitive styles is echoed by the literature in learning styles, thinking styles, and individualized cognitive processes (Dunn, Dunn, $\&$ Price, 1984; Kolb, 1984; Mills, 2002). Learning styles theories emphasize the unique cognitive approaches favored by individual learners and highlight the importance of providing a range of instructional strategies to facilitate learning for all learners. The potential of multimedia applications has been theoretically favored in the learning styles models based on the ability of multimedia applications to efficiently target various learning styles (i.e., visual, auditory, reading/writing, kinesthetic, or tactile; see Fleming \& Mills, 1992 or Sternberg, 1997 for more information). However, the value of multimedia is dependent upon its appropriate use, selection, 
and placement (Mayer, 1997, 2001). Multimedia users are cautioned to ensure research-based principles are applied to the design and implementation of multimedia supplements.

Empirical results indicate and support the effectiveness of multimedia inclusion for online student learning. Clark and Mayer (2002) provide the following empirically-based principles based in cognitive psychology theory to guide multimedia inclusion as it applies to virtual learning environments:

\section{Multimedia principle}

Relevant, instructional graphics to supplement written text should be incorporated to improve learning through the dual coding of verbal and visual information.

\section{Contiguity principle}

Place graphics and text close together so that limited working memory is reserved for learning content rather than coordinating various visual components.

\section{Modality principle}

Include audio to explain graphics as audio enhances learning more than text by expanding cognitive resources to simultaneously tap both visual and phonetic memory.

\section{Redundancy principle}

Supplement graphics with audio alone rather than audio and redundant text to reduce cognitive overload.

\section{Coherence principle}

Avoid using visuals, text, and sounds that are not essential to instruction as unnecessary information impedes learning by interfering with the integration of information.

\section{Personalization principle}

Use a conversational tone and/or a personalized learning agent to enhance learning via social conventions to listen and respond meaningfully.

As reflected by these principles, the inclusion of multimedia into the online classroom cannot be summarized by either the less-is-more or the more-is-more approach to course design. The educational value of multimedia is dependent upon appropriate inclusion of multimedia supplements to enhance the cognitive impact of the text (Mayer \& Anderson, 1992).

These principles and guidelines provide a framework for incorporating multimedia to maximize student learning, but they do not address the impact of multimedia on non-cognitive variables, such as student engagement. While most of the principles (multimedia, contiguity, modality, redundancy, and coherence) are clearly and exclusively geared toward enhancing the learning 
process through an emphasis on reduced cognitive demands and maximal encoding in memory, the personalization principle goes beyond information-processing theories of learning to highlight the importance of personalized interaction in educational contexts. The value of personalizing the online learning experience is echoed in the research on instructor presence (Anderson, Rourke, Garrison, \& Archer, 2001). Instructor presence encompasses "the design, facilitation, and direction of cognitive and social processes for the realization of personally meaningful and educationally worthwhile learning outcomes" (Anderson et al., \ 13); key to this model is the importance of an instructor's social presence. Social presence includes the "degree of salience of the other person in the (mediated) interaction and the consequent salience of the interpersonal relationships" (Short, Williams, \& Christie, 1976). Research on instructors' social presence in the online classroom (Richardson \& Swan, 2003) found significant positive correlations between students' social presence scores and perceived learning as well as between students' social presence scores and perceptions of instructor presence. Extending the implications of the personalization principle and theory of instructor presence, it is possible that online courses that utilize multimedia to create a more personalized, intimate learning experience may increase student engagement.

\section{Importance of Student Engagement}

Student engagement is rooted in a combination of personality, affective, motivational, and persistence factors applied to the learning process; it "includes attributes like intrinsic motivation, positive affect, persistence, effort and self-confidence" (Ruhe, 2006, p. 1). Students with high levels of engagement enjoy the process of learning, persist in their scholarly work despite challenges and obstacles, and gain satisfaction from scholarly accomplishments (Schlecty, 1994). Student engagement goes beyond simple emphasis on cognitive outcomes and learning to highlight students' active role in the educational processes. Engagement rests upon 'students' willingness, need, desire and compulsion to participate in, and be successful in, the learning process" (Bomia, Beluzo, Demeester, Elander, Johnson, \& Sheldon, 1997, p. 294).

While these attributes are important in all learning environments, student engagement becomes imperative in the virtual classroom. Not only are online students navigating the typical learning challenges of the academic content, but they are learning in a physically isolated environment that is often void of the entertainment and social aspects of the traditional classroom. Research clearly supports the relationship between student engagement and student achievement in the face-toface classroom (Gutherie \& Anderson, 1999; Handelsman, Briggs, Sullivan, \& Towler, 2005; Skinner, Wellborn, \& Connell, 1990), yet existing literature is limited in its examination of the unique considerations of student engagement as applied to online learning environments. Generalizing the findings from traditional classrooms, one would assume that enhanced student engagement in the online classroom should increase interest and enthusiasm for the course, which, in turn, impacts retention, learning, and satisfaction. Moreover, one may assume that because of the isolated nature of virtual education, the value and impact of increased student engagement may be even more pronounced in the online classroom than in traditional educational settings. 


\section{Instructor-Generated Multimedia and Student Engagement}

Online faculty must ponder the inclusion of multimedia to make their course design pedagogically intentional (i.e., including course components with diligent attention to their educational impact, alignment with learning goals, relevance to assessments, etc.), while also balancing increasing demands to integrate multimedia as a "best practice" for effective online learning (Mandernach, 2006). The cognitive value of multimedia as a discrete interactive piece has been well-established (Harris, 2002; Hede \& Hede, 2002; Moreno \& Mayer, 2000; Burg, Wong \& McCoy, 2004) as has students' preferences for multimedia inclusion, but little research has examined the effect of multimedia on non-learning variables, such as student engagement. In addition, there is little empirical data on the relative impact of commercially-produced multimedia supplements compared to more personalized multimedia options featuring the face and/or voice of the course instructor.

Research at the college level reveals five components relevant to student engagement: academic challenge, active/collaborative learning, student-faculty interaction, enriching education experiences, and a supportive learning environment (Kenny, Kenny, \& Dumont, 1995). The current study examines the use of multimedia as a tool to enhance student engagement by facilitating active learning, personalizing student-faculty connections, and enriching learning experiences. Relying on the theory underlying the personalization principle of multimedia inclusion, this study focuses on the impact of instructor-personalized multimedia supplements as opposed to commercially-produced pieces. The personalization principle highlights that conversational tone and/or a personalized learning agent enhances learning due to the activation of social conventions to listen and respond meaningfully. Thus, multimedia featuring the course instructor discussing concepts, as one would do in a face-to-face course, has the potential of simultaneously enhancing learning and student engagement. This type of multimedia inclusion increases the visibility of the course instructor to promote a more tangible faculty-student connection in the "faceless" environment of online learning.

The purpose of the current study is to examine changes in student engagement and learning as a function of the inclusion of instructor-personalized multimedia supplements in an online course. It is hypothesized that student engagement will increase as a function of the number of instructorpersonalized multimedia supplements. Specifically, students completing a standard online course with no instructor-personalized multimedia will report lower levels of student engagement than students completing an identical course with the addition of instructor-personalized multimedia supplements; additionally, as a course has more instructor-personalized multimedia components, students will report increased course engagement. 


\section{Method}

\section{Participants}

The sample for this quasi-experimental study includes four sections of an introductory-level general psychology course taught across sequential terms; all sections are taught completely in an online format using the Blackboard course management system. All sections are taught by the same instructor and utilize identical course structure, assignments, and instructional material. The instructor for this course is an experienced online teacher and has taught the target course in an online format for three years. Table 1 provides an overview of the number of students per section and the number of students completing all required outcome measures.

Table 1

Total Students and Students Responding per Section

\begin{tabular}{|l|l|l|l|}
\hline Section & $\begin{array}{l}\text { Total } \\
\text { students in } \\
\text { class }\end{array}$ & $\begin{array}{l}\text { Number of students } \\
\text { completing all outcome } \\
\text { measures }\end{array}$ & Response rate \\
\hline Control & 20 & 14 & $70 \%$ \\
\hline Video & 18 & 6 & $33 \%$ \\
\hline $\begin{array}{l}\text { Audio } \\
\text { PowerPoint }\end{array}$ & 25 & 13 & $52 \%$ \\
\hline $\begin{array}{l}\text { Video } \\
\text { PowerPoint }\end{array}$ & 29 & 18 & $62 \%$ \\
\hline
\end{tabular}

\section{Procedure}

The study compares student engagement and learning outcomes between four quasi-experimental course conditions: control (no instructor-personalized multimedia), video (brief weekly videos of the instructor), video plus audio PowerPoint (weekly videos and PowerPoint that is narrated by the instructor), and video, audio PowerPoint plus video PowerPoint (weekly videos and narrated PowerPoints along with a PowerPoint that is video narrated). All sections of the course contain complete instructional content with basic multimedia supplements woven throughout the online lectures. The control condition examines student outcomes in response to a fully-designed, multimedia-supported course without the addition of instructor-personalized multimedia supplements. The other sections are identical to the control condition with the addition of a specific type of instructor-personalized multimedia supplement. Multimedia supplements were added in a cumulative, rather than comparative, fashion. As such, the study examines changes in student outcomes in response to the integration of additional instructor-personalized multimedia supplements, but it does not address the comparative impact of each type of multimedia. 
To ensure that students were aware of the instructor-personalized multimedia components, these pieces were highlighted in the course announcement area of the course. In the three sections containing instructor-personalized multimedia, supplements were added once per week for each of the 10 weeks of the term in the following ways:

- In the video condition, a video was added to the course announcements each Tuesday;

- In the video plus audio PowerPoint condition, a video was added each Tuesday and an audio PowerPoint was added on Wednesday; and

- In the video, audio PowerPoint plus video PowerPoint condition, a video was added on Tuesday, an audio PowerPoint was added on Wednesday, and a video PowerPoint was added on Thursday.

All supplements were available via a link from the course announcements area appearing on the initial screen of the course management system; in addition, students received an email notification that a new course announcement had been posted.

At the completion of the term, students were asked to complete an online version of the Student Course Engagement Questionnaire and final course exam (as dictated by the requirements of the course). While the final exam was required as a portion of the students' overall course grade, completion of the Student Course Engagement Questionnaire was completely voluntary. Those electing to complete the Student Course Engagement Questionnaire were directed to an anonymous online survey tool.

\section{Materials}

To examine the impact of the cumulative addition of instructor-personalized multimedia supplements, four conditions were created across sequential terms of the same course. The target course is structured in weekly modules across a ten-week term. Each weekly module contains an online lecture, threaded discussion assignment, written homework assignment, and online quiz. The information and assignments contained in each module are the same across all conditions of the study. The only difference between the conditions is the introduction of a specific type of instructor-personalized multimedia. The conditions are outlined below:

\section{Control}

The control section serves as a baseline measure to determine students' engagement in the basic course prior to the addition of instructor-personalized multimedia supplements. To avoid a simple comparison between a multimedia-supported course and a nonmultimedia-supported course, the control course was enhanced with an array of professionally-developed multimedia components. The basic version of the course contains 50 interactive review activities created via Respondus StudyMate, 30 publisherproduced videos, nine publisher-produced PowerPoint presentations, seven java-based, non-graded self-reviews, and 24 Flash-based animations. All of the multimedia components of the control section are professionally produced with no explicit connection to the course instructor. 
Video

The video condition contains all the components of the control section with the addition of 10 short videos in which the instructor highlights weekly topics that may be of particular interest to the students. The videos, called "My Favorite Things," were created using a digital video recorder and contain a simple head-shot of the instructor informally discussing the target topic. Each video was professionally edited to ensure quality appearance. Videos were one to three minutes in duration.

\section{Video plus audio PowerPoints}

The video plus audio PowerPoint condition contains all the material in the control and video conditions with the addition of an instructor-generated PowerPoint presentation with integrated audio narration. The audio PowerPoints, called "A Closer Look," were created using authorPoint software that combines the PowerPoint presentation and audio narration into a single, compressed Flash file. All audio Powerpoint presentations are based on an instructor-generated PowerPoint presentation and are narrated by the course instructor. All audio PowerPoints were reviewed and edited by an instructional designer to ensure quality presentation. Each weekly audio PowerPoint went into additional detail about a selected course topic beyond what was covered in the text or online lecture. Audio PowerPoint presentations were three to eight minutes in duration.

\section{Video, audio PowerPoint plus video PowerPoinT}

The final cumulative condition contained all the features of the three previous conditions with the addition of weekly video PowerPoint presentations. The video PowerPoint presentations were also created with authorPoint software. The authorPoint software coordinates webcam video of the instructor presenting the material with the instructorgenerated PowerPoint presentation; the integrated presentation is a single, compressed Flash file. Each weekly video PowerPoint, called "Digging Deeper," explored a selected course topic beyond what is covered in the text, online lecture, or other multimedia supplement. Each video PowerPoint was reviewed and edited by an instructional designer to ensure quality presentation. All video PowerPoint presentations were five to eight minutes in duration.

\section{Measures}

To allow for a comparative analysis of the impact of instructor-personalized multimedia inclusion on student engagement and cumulative learning, three outcome measures were implemented at the end of each term: a modified version of the Student Course Engagement Questionnaire (Handelsman, Briggs, Sullivan, \& Towler, 2005), a cumulative final exam, and final course grades.

\section{Student Course Engagement Questionnaire}

The Student Course Engagement Questionnaire (Handelsman, Briggs, Sullivan, \& Towler, 2005) is a 27-item measure designed explicitly to measure college students' 
engagement with course material. Respondents indicate their level of agreement on a 5point Likert-type scale $(1=$ not at all characteristic of me; $5=$ very characteristic of me) to various statements concerning course engagement (such as "staying up on the readings" and "finding ways to make the course interesting"). Engagement is scored according to four discrete factors: skill engagement (including general study strategies, such as note-taking and studying), emotional engagement (including personal involvement with class material, such as relating course material to one's own life), participation/interaction engagement (including participation in class activities with the instructor or other students, such as asking questions in class), and performance engagement (including levels of performance in class, such as getting a good grade). The Student Course Engagement Questionnaire was modified to target an online learning environment; specifically, the wording of eight questions was adjusted to be more reflective of an online classroom. For example, the statement "Raising my hand in class" was modified to read "Raising questions in the threaded discussions."

\section{Cumulative final exam}

The cumulative final exam is a portion of the course requirements; it includes 80 multiple-choice questions and four short essay questions targeting key concepts and theories from each of the 10 weekly modules. The final exam is worth 100 points and accounts for $20 \%$ of the final course grade.

\section{Final course grades}

Final course grades were based on criterion-based scoring of all required course components. Grades were based on weekly threaded discussions (30\%), weekly homework assignments (30\%), weekly quizzes (20\%), and final exam (20\%).

\section{Results and Discussion}

To examine potential differences in student engagement and learning as a function of instructorpersonalized multimedia inclusion, one-way ANOVAs were conducted for each student engagement factor (skills, emotional, participation, and performance) as well as for the final exam. The results of these comparisons, as listed in Table 2, indicated no significant differences in course engagement or learning between any of the various levels of instructor-generated multimedia inclusion.

\section{Table 2}

ANOVA Results for Course Engagement and Learning

\begin{tabular}{|l|l|l|l|l|}
\hline Outcome measures & df & F & $p$ \\
\hline Course engagement & Skill factor & 3,47 & .882 & .457 \\
\cline { 2 - 5 } & Emotional factor & 3,47 & .657 & .582 \\
\cline { 2 - 5 } & Participation factor & 3,47 & .526 & .666 \\
\cline { 2 - 5 } & Performance factor & 3,47 & .647 & .589 \\
\hline
\end{tabular}




\begin{tabular}{|l|l|l|l|l|}
\hline \multirow{2}{*}{ Learning } & Final exam & 3,88 & .700 & .555 \\
\cline { 2 - 5 } & Overall course grade & 3,88 & .839 & .476 \\
\hline
\end{tabular}

To further investigate potential differences in student engagement, follow-up questions were included with the Student Course Engagement Questionnaire. The follow-up questions were posed directly to students: "How engaged are you in this class?" and "How engaged are you in this class, compared to other classes you are taking this semester?" As shown in Table 3, analysis revealed no significant differences in students' responses to these engagement indicators as a function of the level of instructor-personalized multimedia they experienced.

Table 3

\section{ANOVA Results for Follow-Up Engagement Questions}

\begin{tabular}{|l|l|l|l|}
\hline Engagement questions & df & F & $p$ \\
\hline How engaged are you in this class? & 3,47 & 2.490 & .072 \\
\hline $\begin{array}{l}\text { How engaged are you in this class, compared to other } \\
\text { classes you are taking this semester? }\end{array}$ & 3,47 & 2.143 & .107 \\
\hline
\end{tabular}

While none of the statistical analysis revealed significant differences between the groups, it is interesting to note that mean scores on each of the student engagement factors do slightly increase in the direction hypothesized. As reported in Table 4, for all engagement factors, the mean engagement score is lowest in the control condition and increases slightly in the conditions including the instructor-personalized multimedia components. This pattern is also repeated in the follow-up engagement question asking students their self-reported engagement in the class; however, the pattern of responding is not found when examining students' self-reported engagement in this class compared to other classes they are taking at the same time.

Table 4

Mean Scores by Multimedia Condition

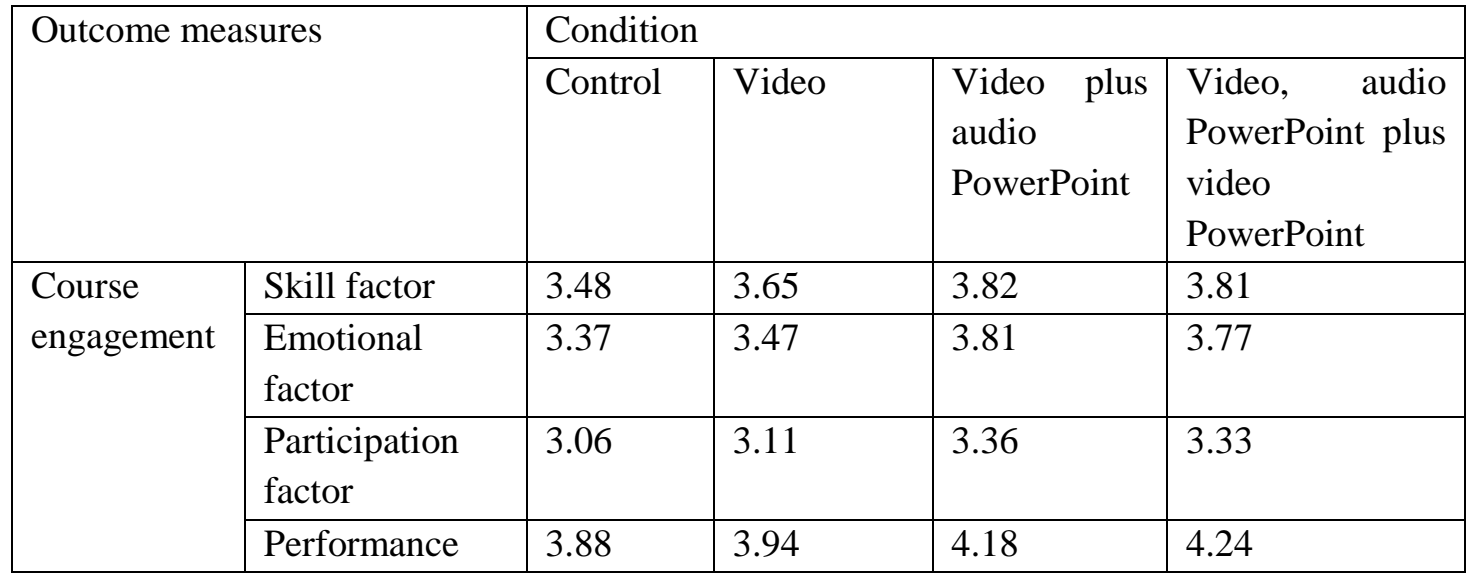




\begin{tabular}{|c|c|c|c|c|c|}
\hline & \multicolumn{5}{|l|}{ factor } \\
\hline & $\begin{array}{l}\text { Overall } \\
\text { engagement } \\
\text { from the } \\
\text { Student Course } \\
\text { Engagement } \\
\text { Questionnaire }\end{array}$ & 3.50 & 3.54 & 3.79 & 3.79 \\
\hline & $\begin{array}{l}\text { Engagement in } \\
\text { course }\end{array}$ & 3.14 & 3.33 & 3.23 & 3.94 \\
\hline & $\begin{array}{l}\text { Comparative } \\
\text { engagement }\end{array}$ & 3.14 & 3.50 & 2.54 & 3.67 \\
\hline & \multicolumn{5}{|c|}{$\begin{array}{l}\text { Note: Engagement measured on a 5-point scale ( } 1=\text { not engaged, } \\
5=\text { engaged }) \text {. }\end{array}$} \\
\hline \multirow[t]{3}{*}{ Learning } & Final exam & 65.55 & 62.61 & 66.56 & 68.00 \\
\hline & $\begin{array}{l}\text { Overall course } \\
\text { grade }\end{array}$ & 84.33 & 79.24 & 84.10 & 82.90 \\
\hline & \multicolumn{5}{|c|}{ Note: Learning measured on a 100-point scale. } \\
\hline
\end{tabular}

An examination of the mean scores also shows that overall, regardless of course section, students tend to be most focused on performance engagement (4.09) with less emphasis on skill engagement (3.70), emotional engagement (3.69), and participation engagement (3.24). This type of focus on performance and course grades may be attributed to the nature of this introductory course; most students in the class (regardless of section) take this course as a general studies elective. As such, because the course is not directly relevant to their major, minor, or career/educational goals, students may be less engaged in learning the material and more focused on the impact of this course as it serves to meet necessary requirements of the larger educational plan. This assumption is supported by a follow-up question that directly asks students, "If you had to choose between getting a good grade in this class or being challenged, which would you choose?"; in response to this question, $76 \%$ of students indicated that they would prioritize getting a good grade in the course over being challenged.

To further investigate potential differences in student engagement, unsolicited student feedback (received via email) and solicited student comments (received via open-ended course evaluation questions) were analyzed according to the theme of the message. Over the course of the four target courses, 27 qualitative feedback statements were available for analysis; the number of feedback statements by multimedia condition is shown in Table 5. An open coding qualitative analysis (Strauss \& Corbin, 1993) revealed six common themes: course/material interesting, interest in taking future psychology courses, interest in taking future courses with this online instructor, personalized nature of the online course, difficulty/amount of the course work, and organization of the course. Table 5 provides an analysis of student feedback according to themes and term; in many cases, feedback statements were analyzed and coded into multiple categories. 
Table 5

Theme of Student Feedback by Multimedia Condition

\begin{tabular}{|l|l|l|l|l|}
\hline Themes of student feedback & \multicolumn{3}{l}{$\begin{array}{l}\text { Number of occurrences } \\
\text { (\% of Occurrences) per Condition }\end{array}$} \\
\cline { 2 - 5 } & Control & Video & $\begin{array}{l}\text { Video plus } \\
\text { audio } \\
\text { PowerPoint }\end{array}$ & $\begin{array}{l}\text { Video, Audio } \\
\text { PowerPoint } \\
\text { plus video } \\
\text { PowerPoint }\end{array}$ \\
\hline Course/material interesting & $0(0 \%)$ & $3(50 \%)$ & $2(25 \%)$ & $3(27 \%)$ \\
\hline $\begin{array}{l}\text { Interest in taking future psychology } \\
\text { courses }\end{array}$ & $0(0 \%)$ & $1(17 \%)$ & $0(0 \%)$ & $2(18 \%)$ \\
\hline $\begin{array}{l}\text { Interest in taking future courses } \\
\text { with instructor }\end{array}$ & $0(0 \%)$ & $3(50 \%)$ & $2(25 \%)$ & $4(36 \%)$ \\
\hline $\begin{array}{l}\text { Personalized nature of online } \\
\text { course }\end{array}$ & $0(0 \%)$ & $3(50 \%)$ & $3(38 \%)$ & $5(45 \%)$ \\
\hline Difficulty/amount of course work & $1(50 \%)$ & $1(17 \%)$ & $2(25 \%)$ & $1(9 \%)$ \\
\hline Organization of course & $2(100 \%)$ & $4(67 \%)$ & $3(38 \%)$ & $4(36 \%)$ \\
\hline $\begin{array}{l}\text { Total number of feedback } \\
\text { occurrences }\end{array}$ & 2 & 6 & 8 & 11 \\
\hline
\end{tabular}

While there was minimal feedback available in the control condition (only two feedback statements from the 20 students in the course), the available feedback was reflective of the other conditions in expressing an appreciation for the organization of the course as well as a belief that the course was difficult and/or contained excessive work for an introductory level course. None of the feedback in the control condition mentioned a personal interest in the material, instructor, discipline, or online learning. The simple lack of student feedback in the control condition may be taken as an indicator of engagement; students who are less engaged in the course may be less likely to provide feedback about their experiences in the course.

Student feedback from the instructor-personalized multimedia conditions of the course included appreciation of the organization and difficulty/workload of the course and also acknowledgement that the course material was interesting and stimulated an increased interest in taking future psychology courses and/or future courses with this instructor. In addition, students in the instructor-personalized multimedia conditions were more likely to comment that the online course (or the online learning experience) was much more personal than they had expected or experienced in the past, as expressed, for example, by this student (in the video, audio PowerPoint plus video PowerPoint condition):

Honestly, I was very worried about this class when I decided to take it. I can't tell you how Dr. M pulled my interest to the point where I want to minor now in Psychology. The online class was organized PERFECTLY. The one that made me feel that I was actually part of her class was posting from her webcam of her 
actually explaining her favorite things each week in detail and also her slide presentations with her voice-overs.

These views were echoed by three other students (all in the video, audio PowerPoint plus video PowerPoint condition):

Thanks for a great class! This is the first online class I have taken where I actually feel like I KNOW the instructor. I loved your presentations each week that made me feel like I was sitting right in the front row of your class. Even though you made us do a lot of work, I hope to take another course from you in the future.

I just wanted you to know that I originally took General Psychology as an elective, but now I am thinking about changing my major. I used to think psychology was all about mental illness and therapy; I had no idea of all the other fun topics studied by psychologists. Thanks for taking the time to talk to us (with all your videos and stuff) about your experiences as a psychologist.

How did you make those lectures where we could see a video of you while listening to you explain the PowerPoint? I really liked those and think that all online teachers should use them. They really helped to grab my attention and make all the readings more interesting.

The impact was again highlighted in these comments from two students (both in the video plus audio PowerPoint condition):

I just wanted to ask you if you would be willing to serve as a reference for me. I take all online classes and it is hard to get to know the professors well enough to ask for a reference. I really feel like I know you as well as any of the face-to-face teachers I had in the past. I don't know if it is the videos or what, but your personality really came across in this class.

Loved your class (hated the final exam)! I never knew that psychology could be so interesting! I actually found myself yelling at my wife to come to the computer to watch the various little videos you made about your favorite topics in psychology.

As indicated by the open-ended student feedback (both solicited and unsolicited), students like the instructor-personalized multimedia components and believe they are an important component of their online learning experience. As such, the discrepancy between the lack of findings on the Student Course Engagement Questionnaire and the narrative student feedback brings up a number of unanswered issues. Specifically, it is unclear as to why student feedback indicates increased engagement, yet quantitative measures fail to detect differences in engagement as a function of 
instructor-generated multimedia inclusion. This discrepancy highlights various directions for future research:

1. As indicated in the methodology, the Student Course Engagement Questionnaire was designed for a traditional college environment and was modified in the current study for use in the online classroom. It is possible that the Student Course Engagement Questionnaire is not suitable for online learning environments and may not detect differences in engagement present in the unique confines of the virtual classroom. Future research on the validity of the Student Course Engagement Questionnaire as it applies to online learning environments is necessary.

2. As revealed by the mean scores of the present study, there may be subtle differences in student course engagement as a function of instructor-generated multimedia inclusion, but the present study may lack adequate sample size to effectively analyze potential differences. Future research should include additional participants to more closely determine the significance of the subtle differences in mean scores between conditions revealed in the current study.

3. As mentioned previously, the design of the current study did not provide a comparative analysis of the relative impact of various forms of instructor-generated multimedia inclusion. Future research should attempt to isolate the type of instructor-generated multimedia (audio versus video versus combined audio and video) to determine potential differences in the type and format of instructor-generated multimedia. An experimental analysis (as compared to the classroom-based nature of the current study) may help to isolate factors that are most influential for utilizing multimedia to enhance student course engagement.

4. As an introductory class, generally taken as an elective to meet general studies requirements, students may not view the instructor-student relationship as being as important as an upper-division course relevant to one's major. If students are generally less engaged in the course and do not see the value of establishing a personalized relationship with the instructor, it is possible that the impact of instructor-personalized multimedia may be less profound. Future research should examine the role of instructorpersonalized multimedia in upper-division online courses in which students may be seeking a more personalized relationship with the instructor for the purpose of advising and/or references.

5. Using the personalization principle of multimedia inclusion as a theoretical basis, the current study utilized instructor-personalized multimedia components to test their impact on student engagement. While the current study found no quantitative differences in student engagement as a function of the addition of instructor-generated multimedia, other research (Mandernach, 2008) finds that students report higher levels of engagement in response to instructor-generated video supplements than to professional, publisherproduced video supplements. As such, additional research is needed to examine the comparative value of instructor- versus commercial-generated multimedia supplements.

6. There are many subjective factors that impact the value and effectiveness of instructorgenerated material. Individual characteristics of the instructor (such as personality, creativity, communication ability, charisma, attractiveness, etc.) may affect the role of the 
multimedia as can the communicative characteristics of the multimedia resources. These were not considered in the current study and could account for differences in findings between various studies examining the role of personalized multimedia. Research is needed to gauge the extent to which subjective factors of the multimedia can mediate its impact on learning and/or student engagement.

7. Additionally, it can be theorized that online students are increasingly pragmatic in their educational endeavors (an assumption supported by the $76 \%$ of students in this study who reported that their priority was to "get a good grade"), and they may fail to invest their time or cognitive energy exploring instructor-personalized multimedia supplements that they do not perceive as essential to their learning goals. The current study did not monitor the extent to which the included supplements were, or were not, viewed by the students. Ongoing research should measure students' use of personalized multimedia and their perceived value of these supplements to gauge potential impact.

A final issue of concern when interpreting the results of this study, as is the case with much of the scholarship of teaching and learning, rests in its quasi-experimental design. Because this is classroom-based research and students were not randomly assigned to instructional conditions, there are many unmeasured factors that have the potential to influence outcomes. While there is nothing that would suggest systematic differences in the student characteristics between various terms, it is still an important consideration. Also, as the researcher was the instructor of investigation, one must be cautious about subtle bias or influence. To help monitor for potential bias, a disciplinary colleague reviewed all courses at the conclusion of the study, and no concerns were noted in this review.

The discrepancies between the quantitative and qualitative findings of this study highlight the complexity surrounding the appropriate use of multimedia within an online course. While the qualitative feedback indicates that students liked and benefitted from the instructor-personalized multimedia supplements, the quantitative data suggests that inclusion of instructor-personalized multimedia may have little impact on student engagement or learning in an online course.

Although there is a theoretical push for multimedia inclusion, the reality is that the integration of multimedia course enhancements can be extremely challenging. It is important to know if the time and monetary investment required to design, develop, and integrate multimedia is justified by the student outcomes. As indicated by the qualitative results of this study, instructors who create and integrate personalized multimedia components in their courses may benefit from increased student satisfaction with the course. But since the quantitative data finds that instructorgenerated multimedia components have little measurable impact on student engagement or learning, instructors should monitor the time and monetary investment necessary for personalized multimedia inclusion. As a general rule, online instructors can benefit from the development and inclusion of personalized multimedia only if the investment to do so is low.

The questions posed as a result of this study should serve as a springboard for future research into the impact of multimedia inclusion on student engagement and learning. Little is known about student engagement in online courses at the post-secondary level; additional data is needed to 
advance our understanding about best practices in designing online courses that promote student engagement. Research on the impact of instructor-personalized multimedia on both learning and student engagement is necessary to assist universities in developing policies surrounding course design expectations as well as to guide budget decisions concerning the investment of resources in the multimedia component of online course development (Simmons, 2004). 


\section{References}

Anderson, T., Rourke, L., Garrison, D. R., \& Archer, W. (2001). Assessing teaching presence in a computer conferencing context. Journal of Asynchronous Learning Networks, 5(2), 1-17.

Burg, J., Wong, Y., \& McCoy, L. (2004). Developing a strategy for creating and assessing digital media curriculum material. The Interactive Multimedia Electronic Journal of ComputerEnhanced Learning, 6(1).

Bomia, L., Beluzo, L., Demeester, D., Elander, K., Johnson, M., \& Sheldon, B. (1997). The impact of teaching strategies on intrinsic motivation. Champaign, IL: ERIC Clearinghouse on Elementary and Early Childhood Education. (ERIC Document Reproduction Service No. ED 418 925)

Clark, R.C., \& Mayer, R.E. (2002). E-Learning and the science of instruction: Proven guidelines for consumers and designers of multimedia learning. San Francisco: Jossey-Bass.

Doolittle, P. (2001). Multimedia learning: Empirical results and practical applications. Retrieved August 5, 2005, from http://blogs.usask.ca/multimedia_learning_theory/multimedia.pdf

Dunn, R., Dunn, K., \& Price, G. E. (1984). Learning style inventory. Lawrence, KS, USA: Price Systems.

Fleming, N.D., \& Mills, C. (1992). Not another inventory, rather a catalyst for reflection. To Improve the Academy, 11, 137-149.

Guthrie, J. T., \& Anderson, E. (1999). Engagement in reading: Processes of motivated, strategic, knowledgeable, social readers. In J. T. Guthrie \& D. E. Alvermann (Eds.), Engaged reading: Processes, practices, and policy implications (pp. 17-45). New York: Teachers College Press.

Handelsman, M. M., Briggs, W. L., Sullivan, N., \& Towler, A. (2005). A measure of college student course engagement. Journal of Educational Research, 98, 184-191.

Harris, C. (2002, Summer). Is multimedia-based instruction Hawthorne revisited? Is difference the difference? Education, 122(4).

Hede, T., \& Hede, A. (2002). Multimedia effects on learning: Design implications of an integrated model. In S. McNamara and E. Stacey (Eds), Untangling the web: Establishing learning links. Proceedings ASET Conference 2002, Melbourne, Australia. Retrieved July 22, 2008, from http://www.ascilite.org.au/aset-archives/confs/2002/hede-t.html

Jonassen, D.H. (2000). Computers as mindtools for schools: Engaging critical thinking. Upper Saddle River, NJ: Merrill/Prentice Hall. 
Kenny, G., Kenny, D., \& Dumont, R. (1995). Mission and place: Strengthening learning and community through campus design. Oryx/Greenwood.

Kolb, D. A. (1984). Experiential learning. Englewood Cliffs, NJ: Prentice Hall.

Maddux, C., Johnson, D., \& Willis, J. (2001). Educational computer: Learning with tomorrow's technologies. Boston: Allyn and Bacon.

Mandernach, B. J. (2006). Confessions of a faculty telecommuter: The freedom paradox. Online Classroom, 3, 7-8.

Mandernach, B. J. (2008). Comparative impact of commercially-produced and instructorgenerated videos on student engagement. Manuscript in preparation.

Mayer, R. E. (2001). Multimedia learning. Cambridge, UK: Cambridge University Press.

Mayer, R. (1997). Multimedia learning: Are we asking the right questions? Educational Psychology Review, 8, 357-371.

Mayer, R., \& Anderson, R. (1992). The instructive animation: Helping students build connections between words and pictures in multimedia learning. Journal of Educational Psychology, $88,64-73$.

Mills, D. W. (2002). Applying what we know: Student learning styles. Retrieved April 7, 2009, from http://www.csrnet.org/csrnet/articles/student-learning-styles.html

Moreno, R., \& Mayer, R. (2000). A learner-centered approach to multimedia explanations: Deriving instructional design principles from cognitive theory. Interactive Multimedia Journal of Computer Enhanced Learning, 2(2).

Richardson, J. C., \& Swan, K. (2003). Examining social presence in online courses in relation to students' perceived learning and satisfaction. Journal of Asynchronous Learning Networks, 7(1), 68-88.

Ruhe, V. (2006). A toolkit for writing surveys to measure student engagement, reflective and responsible learning. Retrieved July 22, 2008, from http://www1.umn.edu/innovate/toolkit.pdf

Schlecty, P. (1994). Increasing student engagement. Presentation at the Missouri Leadership Academy.

Schwartz, J.E., \& Beichner, R.J. (1999). Essentials of educational technology. Boston: Allyn and Bacon. 
Short, J., Williams, E., \& Christie, B. (1976). The social psychology of telecommunications. London: John Wiley and Sons.

Simons, T. (2004, September). The multimedia paradox. Presentations Magazine. Retrieved August 5, 2005, from http://www.presentations.com/presentations/trends/article display.jsp?vnu content $\mathrm{id}=1$ $\underline{000734183}$

Skinner, E. A., Wellborn, J. G., \& Connell, J. P. (1990). What it takes to do well in school and whether I've got it: The role of perceived control in children's engagement and school achievement. Journal of Educational Psychology, 82, 22-32.

Sternberg, R. J. (1997). Thinking styles. New York: Cambridge University Press.

Strauss, A., \& Corbin, J. (1990). Basics of qualitative research: Grounded theory procedures and techniques. Newbury Park, CA: Sage Publications.

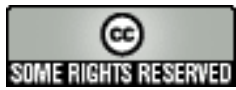


June - 2009

\title{
Virtual Spaces: Employing a Synchronous Online Classroom to Facilitate Student Engagement in Online Learning
}

\author{
J. Lynn McBrien and Phyllis Jones \\ University of South Florida \\ Rui Cheng \\ Nazareth College
}

\begin{abstract}
This research study is a collaborative project between faculty in social foundations, special education, and instructional technology in which we analyze student data from six undergraduate and graduate courses related to the use of a virtual classroom space. Transactional distance theory (Moore \& Kearsley, 1996) operates as our theoretical framework as we explore the role of a virtual classroom in distance education and analyze the ways in which a synchronous learning environment affects students' learning experiences. Elluminate Live! was the software employed in the virtual classroom. In this analysis, particular themes emerged related to dialogue, structure, and learner autonomy. In addition, students rated convenience, technical issues, and pedagogical preferences as important elements in their learning experiences. The article discusses these themes as a contribution to reducing the "distance" that students experience in online learning and to developing quality distance education experiences for students in higher education.
\end{abstract}

Keywords: Distance learning; synchronous online learning; transactional distance theory; virtual classroom

\section{Introduction}

Rapidly developing technology has facilitated distance education in all disciplines, and it has proven to be popular among students for various reasons, such as convenience and equal opportunity. As a result, many universities and colleges in the United States and around the world offer online degree programs and courses, which give students the opportunity to access higher education without leaving their homes (Butner, Murray, \& Smith, 1999). However, many students and researchers comment that distance learning courses lack interaction. Thus, improved teaching and learning strategies are needed to provide students not only the convenience of distance education but also the kind of access to real-time interaction with the instructor and class 
peers that simulates the traditional classroom setting. In fact, students have asked for more opportunities to interact with each other in synchronistic ways (West \& Jones, 2007).

The use of synchronous conferencing techniques can offer opportunities for social interaction in a virtual classroom space. Synchronous software popular in educational settings, such as Centra, HorizonLive, Elluminate Live!, and Interwise, share several interactive characteristics. They allow students and instructors to communicate orally, exchange messages through typing, upload PowerPoint presentations, transmit video, surf websites together, and more. However, because these synchronous systems are fairly new, they have not been studied extensively.

$\mathrm{Ng}$ (2007) reported the use of a synchronous e-learning system (Interwise) for online tutoring offered by Open University of Hong Kong. Interview data were collected from six tutors and eight students to examine teaching effectiveness and opportunities for interaction. The results indicated that both students and tutors were positive about using Interwise for online tutoring, and both student-teacher interaction and student-content interaction were perceived as successful through this platform. However, student-student interaction was minimal, several students cited technical difficulties that reduced their overall learning experience, and there was a mixed response regarding student preference (synchronous online versus traditional classroom). Both tutors and students regarded online tutorials as supplements to face-to-face tutorials.

Battin-Little, Passmore, and Schullo (2004) studied the use of Elluminate Live! (E!) by a group of nursing students, and the results showed that a majority of students rated E! in a positive way. It posed minor or no problems as long as student use of the technology was supported throughout the course. The study highlighted that students favored features such as emoticons, hand raising, a shared whiteboard, polling, and application sharing as points of personal engagement. Students talked about an enhanced learning experience, improved communication, high levels of satisfaction with the course, and strong group cohesion.

Although the student responses in these studies are positive to synchronic learning opportunities, more studies are needed to explore students' perceptions of the synchronous learning experience. The current study aims to make a contribution to the literature by analyzing qualitative student data that highlight pedagogical issues for higher education. Our research questions examined the following:

1. Do synchronous online platforms (specifically, Elluminate Live!) increase the social interaction that is missing in other, older forms of distance learning? Is this increase sufficient to create a positive learning experience for students?

2. What are the specific strengths and weaknesses of currently available synchronous online learning platforms, and what could be done to reduce the weaknesses?

This article discusses the insights gained from students about their experiences in a virtual classroom, which facilitates real-time interaction between learner-instructor, learner-learner, and learner-content. The intention of the research is to analyze distance by exploring the different elements of Moore's (1993) transactional distance theory, specifically dialogue, structure, and 
learner autonomy, through student responses to a survey about their experience with the synchronous online learning platform, Elluminate Live! (E!).

\section{Theoretical Framework}

One of the most prominent theories discussed in distance education is Moore's (1993) theory of transactional distance, which offers a framework for the current research into student perceptions of synchronous online learning. According to transactional distance theory, distance is considered a pedagogical phenomenon. The "sense of distance" a learner feels during the learning process transcends geography and is concerned with student interaction and engagement in the learning experience. This is particularly pertinent in an analysis of student perspectives of their own engagement in learning.

Transactional distance theory consists of three elements: dialogue, structure, and learner autonomy, all of which interrelate across learner-instructor, learner-learner, learner-content, and learner-interface interactions. Dialogue is defined as two-way communication and interaction in its many forms. Structure refers to course organization and the impact this has upon student engagement. Learner autonomy represents the learner's perception of both independent and interdependent participation in the course and is directly related to the student's level of selfdirected learning. For distance learning to be successful, Moore (1993) suggests that instructors need to pay attention to all three elements of transactional distance theory in order to reduce the "distance" experienced by the student.

Dialogue is an important element of all teaching and learning, but in distance education it presents a challenge. In online contexts, instructors must strive to optimize interaction between learner-instructor, learner-learner, and learner-content through effective modes of communication (Chen \& Willits, 1999; Jung, 2001; Moore, 1993). The facilitation of dialogue involves an evaluation of the opportunities for dialogue as well as an analysis of the quality of the dialogue that occurs.

All instructors adopt course structures and organization in their classrooms, both face-to-face and virtual; in transactional distance theory, "structure" represents the rigidity or flexibility of the course organization and course delivery. Moore (1993) asserts that the more rigid the course organization, structure, and delivery is, the higher the level of transaction distance experienced by the student.

Learner autonomy is a less obvious element of all teaching and learning but constitutes an essential element of transactional distance theory and student engagement in distance education. Online learning offers students the potential for more self-directed learning opportunities and flexible structures for engagement, which can increase student levels of autonomy, emotional independence, and self-direction (Belz \& Müller-Hartmann, 2003). Moore (1993) suggests that this is a crucial characteristic of student engagement in their learning, which naturally reduces their experience of "distance." 
Gorsky and Caspi (2005) asserted that Moore's theory is not a theory at all, but rather, a tautology that can be reduced to the following: "As understanding increases, misunderstanding decreases" (p. 8). They base their conclusion on a review of six quantitative studies that tested Moore's (1993) framework, and they found that each study supported the theory, but validity was poorly established. However, they also noted that the researchers involved in each study they reviewed suggested the need for qualitative measures in future studies.

In the current study, we are not so much attempting to validate Moore's theory as we are to discover what students identify as the strengths and weaknesses of this form of learning. However, we deemed the elements Moore references to be useful (and, at times, problematic, as we will discuss) in categorizing student responses.

E! is an example of synchronous software; it combines different tools into one interface creating a web-based classroom environment where a whole class or small groups of students, using headsets, can interact online in real-time. Such tools include text chat, two-way Voice-Over Internet Protocol (VOIP) audio, video, real-time presentation, breakout rooms for small group activities, white board presentations, class polling instruments, and application sharing. Synchronous online platforms offer instructors the potential for meaningful real-time interactions and improved opportunities for students to communicate at a geographical distance. Considering that dialogue requires two-way interaction, distance education tools involving virtual classrooms have the power to increase dialogue more than one-way methods of communication.

Synchronous online teaching supports careful planning and structuring of learning. For example, instructors can prepare a PowerPoint presentation to share during the live synchronous session. The technology is flexible enough to allow instructors to be responsive to students and to change teaching plans according to emerging student needs. This flexibility in structure is intended to decrease the transactional distance level between instructor and students.

The online platform that we adopted allowed us to provide immediate feedback to students and to facilitate constructive feedback between students themselves. Even with students who may not consider themselves self-directed or who may not have high learner autonomy, the friendly interface we adopted supported a range of various interactions to enable higher levels of student success.

\section{Research Design}

The authors, who are also the instructors, constructed a short, open-ended survey to collect student reflections about their experiences in our virtual classrooms. The survey was administered at the end of the course and was designed to capture succinct responses from students in a way that would highlight general themes to inform practice and future research (Cohen, Manion, \& Morrison, 2001). Our survey questions were the following:

1. What did you like about Elluminate?

2. What did you dislike about Elluminate? 
3. What worked? What didn't work?

4. Do you think I should use it again? Why? Why not?

The questions we chose to ask were intentionally broad as we did not want to lead students to answers that would directly correspond with Moore's (1993) theory. Rather, it was the process of analyzing emerging themes that caused us to address what Moore proposes as good practice in transactional distance theory.

\section{Context and Sample}

Participants in the project were enrolled in three undergraduate and three graduate courses in the College of Education at a regional campus of the University of South Florida. All of the courses were mandatory. We used opportunistic sampling to recruit participants (Silverman, 2000) from courses in social foundations and special education. Students were invited to voluntarily complete the survey as part of their evaluation of the course in addition to University-initiated evaluations. University evaluations do not include any reference to online learning. Table 1 illustrates the range of student and course information.

Table 1

Student and Course Information

\begin{tabular}{|l|l|l|l|}
\hline Department & Course & Academic level & $\begin{array}{l}\text { Number of } \\
\text { students }\end{array}$ \\
\hline Special Education & $\begin{array}{l}\text { Identification and } \\
\text { Assessment of Students with } \\
\text { Low Incidence Disabilities }\end{array}$ & Graduate & 14 \\
\hline Special Education & $\begin{array}{l}\text { Special Needs in the Early } \\
\text { Years }\end{array}$ & Undergraduate & 5 \\
\hline Special Education & Advanced Seminar & Graduate & 14 \\
\hline $\begin{array}{l}\text { Psychology/Social } \\
\text { Foundations }\end{array}$ & $\begin{array}{l}\text { Social Foundations of } \\
\text { Education }\end{array}$ & Undergraduate & 30 \\
\hline $\begin{array}{l}\text { Psychology/Social } \\
\text { Foundations }\end{array}$ & $\begin{array}{l}\text { Social Foundations of } \\
\text { Education }\end{array}$ & Undergraduate & 20 \\
\hline $\begin{array}{l}\text { Psychology/Social } \\
\text { Foundations }\end{array}$ & $\begin{array}{l}\text { Social and Economic } \\
\text { Foundations }\end{array}$ & Graduate & 7 \\
\hline
\end{tabular}

Each of the courses was web-enhanced and integrated virtual teaching and learning opportunities for the students. The number of synchronous online sessions in each course varied. Table 2 provides details about this variability and also illustrates the different delivery modes of each of the courses. From this table, it is clear that some students had more experience of virtual classrooms than other students. In fact, the majority of students in the social foundations courses who had only used E! twice responded that the course should either include more E! sessions or should not use the software because they felt that it took up to two class sessions to feel comfortable using it. 
Table 2

Mode of Delivery and Virtual Sessions per Course

\begin{tabular}{|l|l|l|}
\hline Course & Mode of delivery & Elluminate sessions \\
\hline $\begin{array}{l}\text { Identification and } \\
\text { Assessment of Students with }\end{array}$ & $\begin{array}{l}14 \text { week traditional schedule } \\
\text { Web-enhanced: } \\
\text { Asynchronous modules \& } \\
\text { Elluminate }\end{array}$ & 6 \\
\hline $\begin{array}{l}\text { Special Needs in the Early } \\
\text { Years }\end{array}$ & $\begin{array}{l}14 \text { week traditional schedule } \\
\text { Web-enhanced: } \\
\text { F2F \& } \\
\text { Elluminate }\end{array}$ & 3 \\
\hline Advanced Seminar & $\begin{array}{l}5 \text { full day and three evening non- } \\
\text { traditional schedule } \\
\text { Option: F2F and Elluminate for } \\
\text { each session }\end{array}$ & 6 \\
\hline $\begin{array}{l}\text { Undergraduate Social } \\
\text { Foundations courses }\end{array}$ & $\begin{array}{l}\text { Web enhanced: } \\
\text { Asynchronous, F2F, and Elluminate }\end{array}$ & 2 in each section \\
\hline $\begin{array}{l}\text { Social and Economic } \\
\text { Foundations }\end{array}$ & $\begin{array}{l}\text { Week summer session } \\
\text { Asynchronous, F2F, and Elluminate }\end{array}$ & \\
\hline
\end{tabular}

Every student participated in training for the adopted technology at the beginning of the course, and university instructional technology staff provided support at the beginning of each synchronous online session. Males were in the minority of students in all classes: three in the graduate foundations course and two each in the undergraduate foundations sections, plus one each in the Special Needs in the Early Years courses and the Advanced Seminar. We did not observe differences in answers by gender or by level (undergraduate or graduate).

\section{Process of Analysis}

Data was collected through paper surveys then typed into Microsoft Word documents so that each of us could code responses separately. This was initially completed per course and then across the data as a whole. Transactional distance theory (Moore \& Kearsley, 1996) offered a framework to make sense of the emerging data in relation to students' experiences of distance in the virtual classroom. Inter-rater reliability was developed through individual and collaborative coding and recoding of raw data, which is a process that has been applied effectively in collaborative research (Jones, West, \& Stevens, 2006). Through this process of inter-rater collaboration, other themes emerged in addition to those related to transactional distance theory that allow an added insight into student experiences of synchronous teaching and learning. 


\section{Results}

Ninety surveys were distributed and 62 were returned, showing a $69 \%$ return rate with variability across courses. Table 3 shows the return rates per course and it shows a good representation across courses.

Table 3

\section{Survey Return Rates per Course}

\begin{tabular}{|l|l|l|}
\hline Course & Surveys distributed & Surveys returned \\
\hline $\begin{array}{l}\text { Identification and Assessment } \\
\text { of Students with Low } \\
\text { Incidence Disabilities }\end{array}$ & 14 & 7 \\
\hline $\begin{array}{l}\text { Special Needs in the Early } \\
\text { years }\end{array}$ & 5 & 5 \\
\hline Advanced Seminar & 14 & 8 \\
\hline Social Foundations & 20 & 14 \\
\hline Social Foundations & 30 & 21 \\
\hline $\begin{array}{l}\text { Social and Economic } \\
\text { Foundations }\end{array}$ & 7 & 7 \\
\hline
\end{tabular}

Through the collaborative coding process, we highlighted transactional distance theory components - dialogue, structure, and learner autonomy - as we considered the ways in which E! might increase social interaction as well as the strengths and weaknesses of the learning experience. We then revisited the student responses to code any additional themes that emerged from the data independently of the theory. Table 4 illustrates the instances of each theme found by each of the authors.

Table 4

Rater Comparison

\begin{tabular}{|l|l|l|l|}
\hline Themes & Rater 1 & Rater 2 & Rater 3 \\
\hline Dialogue & 33 & 29 & 32 \\
\hline Structure & 43 & 39 & 43 \\
\hline Learner autonomy & 18 & 12 & 15 \\
\hline Technical difficulties & 53 & 51 & 55 \\
\hline Convenience & 43 & 46 & 49 \\
\hline Pedagogy & 43 & 48 & 40 \\
\hline
\end{tabular}

In discussions, we found that there is overlap between dialogue and pedagogy, structure and convenience, and learner autonomy and technical difficulties (with most of the reduced autonomy 
comments related to software and hardware issues). What follows is a discussion with examples of each theme.

\section{Dialogue}

Student comments about dialogue appear in remarks about comfort and student engagement. Only about 9\% (three comments) indicated a negative affect for dialogue. The majority of comments were positive (91\%), both in terms of quantity of dialogue from each student and the quality of dialogue experienced. Table 5 illustrates student data related to dialogue and demonstrates the range of responses, with the main thrust being positive.

Table 5

Example of Student Data for Theme of Dialogue

\begin{tabular}{|l|l|}
\hline Theme of dialogue & \multicolumn{1}{|c|}{ Student data } \\
\hline $\begin{array}{l}\text { Perceptions of comfort in the dialogue of the } \\
\text { virtual classroom }\end{array}$ & $\begin{array}{l}\text { "I felt comfortable talking to class members } \\
\text { and giving my presentation; it was like being in } \\
\text { a classroom." } \\
\text { "I learned a lot of information from the } \\
\text { sessions because I was so relaxed." }\end{array}$ \\
\hline $\begin{array}{l}\text { Student perceptions of engagement in dialogue } \\
\text { in the virtual classroom }\end{array}$ & $\begin{array}{l}\text { "I liked that everyone seemed to speak more." } \\
\text { "There seemed to be more participation from } \\
\text { classmates that are usually silent." } \\
\text { "I liked the way discussions were held since it } \\
\text { gave everyone an opportunity to talk." } \\
\text { "People express their points of view more } \\
\text { openly, and discussion becomes more } \\
\text { involved." } \\
\text { "Less people participated." } \\
\text { "Sometimes I felt disconnected to the rest of } \\
\text { the class." }\end{array}$ \\
\hline
\end{tabular}

Overall, most students rated E! positively as far as increasing dialogue and interaction between students and the instructor and increasing dialogue and interaction among students.

\section{Structure}

Within this theme, students shared their confusion about, for example, difficulties keeping up with simultaneous modes of communication and also the experience of being in a virtual classroom. Across the student data, we found a high number of comments related to convenience. Although not specifically discussed as structure by Moore (1993), we believe that this facet of 
synchronous online teaching best relates to his concept of structure, in this case physical structure. All of these comments focused on instructional ease due to the fact that students could remain at home for class, save on travel expenses, and attend class even when ill. Some students who had young children at home also commented that the online platform gave them the ability to attend to their families and still participate in class. Table 6 illustrates the different elements of structure with supporting student data.

Table 6

Example of Student Data for Theme of Structure

\begin{tabular}{|c|c|}
\hline Theme of structure & Student data \\
\hline Confusion experienced by students & $\begin{array}{l}\text { "Sometimes the chat got a little out of control. } \\
\text { People were typing so much at once that it was } \\
\text { hard to keep up." } \\
\text { "A bit confusing at times. Hard to always know } \\
\text { what the instructor was doing or when to speak, } \\
\text { answer questions." } \\
\text { "Once we were put into groups it was chaos. } \\
\text { We just did not know what to do." }\end{array}$ \\
\hline Experience of a virtual classroom & $\begin{array}{l}\text { "It gives you a break from the traditional } \\
\text { classroom experience. Sometimes you may sit } \\
\text { in the back of the room, but on E you have a } \\
\text { front row seat." } \\
\text { "It is nice to introduce to students being that it } \\
\text { is newer technology." } \\
\text { "It gives students an opportunity to learn in } \\
\text { different ways. Also it can give future online } \\
\text { teachers a feel of what they could be doing." }\end{array}$ \\
\hline Convenience & $\begin{array}{l}\text { "Since I would not have been able to take the } \\
\text { class if the majority of it was not offered } \\
\text { online, Elluminate offered a flexible classroom } \\
\text { option." } \\
\text { "It was easier for me because I have to be up at } \\
5 \text { a.m. for work and in class until } 9 \text { p.m." } \\
\text { "When I was sick I was able to stay in my PJ's } \\
\text { and still participate fully in class." } \\
\text { "It's so nice for parents/working students. I } \\
\text { cannot express how much I wish they offered } \\
\text { full-time classes on Elluminate." }\end{array}$ \\
\hline
\end{tabular}


Comments again indicate an increase of interaction, from simply being able to take the course to keeping up in spite of illness (which would prevent attendance in a traditional class). Positive pedagogy is indicated both by the idea that all students "have a front row seat" and that E! classes prepare future teachers to use new technologies.

\section{Learner Autonomy}

We found that the theme of learner autonomy was frequently double coded along with either convenience (thus, some independence in participation), student involvement (a sense of freedom in communication), or support of students processing concepts and content of the course. Thus, for us, this concept folded into structure and dialogue/pedagogy. Some students commented that the synchronous online system created opportunities for more advanced conversation and learning opportunities than might occur in a traditional classroom. Data related to technical issues that affected student involvement and engagement were mainly negative, with the majority detailing technical difficulties. These had to do with signing on to sessions, experiencing microphone problems, and occasionally being disconnected from the session. However, some students also discussed how the virtual classroom experience supported their engagement in the discussion. Convenience is detailed in Table 5 under structure but the other themes related to learner autonomy are illustrated in Table 7.

Table 7

Example of Student Data for Theme of Learner Autonomy

\begin{tabular}{|c|c|}
\hline Theme of learner autonomy & Student data \\
\hline Technical issues & $\begin{array}{l}\text { "Interactions with others were constrained by } \\
\text { technology. Frustrations signing on and getting } \\
\text { kicked off. Microphone troubles." } \\
\text { "TECHNICAL DIFFICULTIES. I personally } \\
\text { had audio issues but it was with my computer } \\
\text { and missing out on the classroom experience." }\end{array}$ \\
\hline Student involvement & $\begin{array}{l}\text { "It allows shy people to communicate their } \\
\text { opinions without being exploited. Takes the } \\
\text { pressure off giving opinions." } \\
\text { "I can make comments without feeling } \\
\text { awkward. Sometimes I do in class because I'm } \\
\text { shy." } \\
\text { "I felt like I could say anything without having } \\
\text { my answer judged. Sometimes I'm afraid to } \\
\text { answer in class." }\end{array}$ \\
\hline Supporting student processing of ideas & $\begin{array}{l}\text { "Talking through the microphone really helped } \\
\text { me to collect my thoughts, knowing that I } \\
\text { could only express myself verbally. It also }\end{array}$ \\
\hline
\end{tabular}




\begin{tabular}{|l|l|}
\hline & $\begin{array}{l}\text { made me feel more in control of how I } \\
\text { communicated my ideas because a large group } \\
\text { of people weren't staring at me, and this made } \\
\text { me more confident in how I expressed myself." } \\
\text { "I found that the class interacted more with the } \\
\text { topic than in class." } \\
\text { "Voting was great-great to see what everyone } \\
\text { else in class felt-you don't always get that } \\
\text { feedback." }\end{array}$ \\
\hline Negative impact on student involvement & $\begin{array}{l}\text { "So many things at once: PowerPoint, people } \\
\text { talking on the mike and people typing } \\
\text { messages. It was like CNN." } \\
\text { "Sometimes it was hard to keep up with the } \\
\text { messages, listening to commentators, and } \\
\text { reading the lesson." } \\
\text { "It was almost over-stimulating at times, which } \\
\text { caused me stress." } \\
\text { "Lack of interaction with peers and instructor." } \\
\text { "Lack of visual stimulation during lecture." } \\
\text { "We didn't do enough." }\end{array}$ \\
\hline
\end{tabular}

Clearly, the technical difficulties experienced by students, from poorly functioning microphones to the inability to $\log$ onto the site, constituted a major weakness. Additionally, students felt overwhelmed by the simultaneous methods of engagement. However, strengths of the platform were highlighted when students revealed that they felt more confident to comment when using an online platform and they recognized that the lack of non-verbal communication can stimulate students to reflect more and to be precise with their verbal responses.

In addition to the themes related to the framework of transactional distance theory, other themes emerged from the data. Similar to Ng (2007), we found that some students mentioned that they missed face-to-face classroom time:

Missing compadres.

I like to support others as they present by contributing verbally. Cannot do that on Elluminate and others could not support me when I was presenting.

I missed non verbal gestures.

These comments could, perhaps, be categorized with the element of dialogue, in this case nonverbal "dialogue" that results in a live social learning environment. It should be noted that more comments alluded to the comfort and sense of safety that resulted for some students who felt shy or "put on the spot" when commenting in a traditional classroom. 
In spite of numerous complaints about technological difficulties, 48 out of 62 responses indicated enthusiastic support for using a synchronous online environment again. Only five students said no, and nine were uncertain or gave qualifying responses. The affirmative data once again referred to convenience and the enhanced learning in terms of discussions, to pedagogical advantages such as increased interest, and to opportunities for familiarization with a new teaching/learning technology. The following comments are typical of these themes:

Yes, beneficial to students w/ kids and those w/ full-time jobs.

It was nice to have good discussions and to discuss materials.

Yes, use it again simply because of the interaction that takes place. You said last week that we had some good discussions - I most certainly agree.

Those students who were uncertain about using the technology again offered suggestions for implementation that would enhance learning, which were related to structure and organization. For example, one student wrote the following:

If used again, needs to be planned more carefully and maybe tried the first session with all of the students in the classroom, not home.

\section{Discussion}

In this study, one of our research questions was intended to address past concerns about insufficient social interaction in distance learning. Of course, it should be remembered that Moore's (1993) theory was formulated prior to the use of synchronous online learning platforms, and some of the past criticism can be attributed to the fact that early forms of distance learning (still in use today) did not include real-time meetings. Thus, we could expect that the use of technology that allows for real-time conversation, both audio and written, would be likely to decrease the "distance" incurred using asynchronous platforms. Beyond the issue of social interaction, we wanted to discover student-perceived strengths and weaknesses of using a platform such as Elluminate Live! with the hope that we could reduce perceived weaknesses and improve the learning experience.

Moore (1993) suggests that dialogue, structure, and learner autonomy form a triad of elements in transactional distance theory, which offers a way to understand notions of "distance" in online courses. Students' responses in this research provide insights into how participation in a virtual classroom using synchronous online classes affects these elements of transactional distance theory. In this section we reflect on each element separately. However, through the data analysis, we found many overlaps between the elements. This supports the notion that "distance" in online learning is a complex phenomenon that demands a holistic analysis. Here we concur with Gorsky and Caspi's (2005) criticism that Moore failed to offer operational definitions for the elements, with a result that it is sometimes difficult to clearly differentiate between them. 
Considering dialogue as communication and interaction, students shared their positive experiences of their time in a virtual classroom. The synchronous online system used at our university, Elluminate Live!, offers different modes of communication, which were perceived by most students to increase the amount of social interaction. Many students linked dialogue to important pedagogical considerations as well, such as increased participation and increased time to reflect before responding. Perhaps most importantly, the synchronous online platform allowed students, particularly shy students, to feel more comfortable expressing their opinions. This indicates the power of a synchronous online system to empower students in conversation and expression. Many of these students may never initiate comments in a traditional classroom. In such cases, the transaction distance enables such students to formulate their ideas and receive responses to them, thus increasing their learning potential.

Some students judged the screen interface, even with multiple transactions occurring at once, as inadequate. The activity that occurs on the screen is qualitatively different from the stimuli created by students and teachers in a traditional classroom. It may be that students making these comments perceive a lack of stimulus due to the loss of nonverbal communication and the lack of physical contact with their peers and instructor. Student responses in this project affirmed the work of Chen and Willits (1999) and Jung (2001), who show the value of supporting effective forms of interaction between learner-instructor, learner-learner, and learner-content. Student experiences in our virtual classrooms demonstrated that varied processes of real-time communication, which are sensitive to individual learning preferences, positively affected some student involvement in online learning. For example, we found that students who participated less in face-to-face $(\mathrm{F} 2 \mathrm{~F})$ classroom discussions participated more in synchronous online interactions, a change in their behavior that was noted by themselves and other students in their classes. However, we also heard from a smaller group of students (9\%) who felt that their interaction was negatively impacted and thus increased their "distance." Students in this group spoke of feeling "disconnected," and others talked about their frustration with technology glitches and how these glitches affected the quality of their interactions. Still other student comments suggested that the multitasking capability of the technology, including speaking, listening, writing, and viewing videos or PowerPoints, was often overwhelming. When multiple methods of communication occur simultaneously, it can be over-stimulating, with the result that some of the information transferred is overlooked by the students. Student data indicated that instructors must be vigilant and proactive regarding student interaction and communication throughout their time in the virtual classroom. Virtual classroom sessions can be recorded so that an instructor can go back and review student participation and interaction, and, if necessary, include additional supports for particular students in future classes. However, this level of instructor responsiveness can become a challenge when seats for online courses are increased.

Structure in transactional distance theory refers to course organization and the impact this has upon student participation (Moore, 1993). Structure is discussed on a continuum of flexibility to rigidity and Moore suggests that flexibility supports the reduction of distance between a learner and course material. Students in this research revealed the complexity of the issues related to rigidity and flexibility. They responded well to clear, tight, and transparent structures of organization, but some struggled when the virtual classroom features were employed in a less 
structured way. This suggests the need for clarity of understanding, or a clear operational definition, of what constitutes a flexible or rigid structure. Students revealed the need for clear and consistent structure, expectations, and roles in virtual classroom sessions to reduce their experience of distance. These responses seem to challenge Moore's (1993) contention that increased structure also increased transactional distance.

The final element of transactional distance theory is learner autonomy. Muller (2003) discusses student autonomy as being synonymous with notions of emotional independence and selfdirection. Students conveyed how the synchronous online classes offered them convenience, which increased their ability to participate in higher education. However, students also offered a strong insight into the impact of technical difficulties on their involvement and participation and thus on their capacity for emotional independence and self-direction. Clearly, in this study, we learned from students that technical issues have a strong impact on experiences of "distance" in online learning across all elements of the theory. The technical problems caused some students to feel that they had lost control, thus reducing their sense of autonomy. When technical problems arose, student learning was halted, and some students were shut out of entire classes because they could not fix the problem independently. In fact, in a couple instances, even help from Elluminate technicians was insufficient to solve immediate problems. As well, receiving technical help often prevented students from attending the entire class as they had to spend time with a technician to solve the problem.

As mentioned earlier, some students in this study discussed missing the face-to-face contact with peers, which points to the possibility that online learning is not their preferred form of learning and alludes to the qualitative difference between virtual and traditional classrooms. For some, the element of face-to-face human contact that is missing in the virtual classroom increases the transactional distance, reducing their sense of belonging and participation in class. This is an important lesson for instructors and calls for the need to build in technical training and support for students to reduce the negative impact of technical issues as well as to consider ways in which to include opportunities to simulate face-to-face interactions.

Our research is limited by the fact that we could only investigate the use of one synchronous online system. Additionally, it only reviews evaluations by a limited sample of students in education courses at one university. Further studies need to occur using larger samples, other subject courses, and other systems of synchronous online learning. Studies that compare several systems of synchronous online learning would also be beneficial to determine which platform components are most valuable to students.

Overall, students in this study were pleased with their learning experiences using E!. However, student perspectives gained from our findings indicate three clear problems in the studied online platform, which can inform further development of online learning. One was the confusion that resulted from too many simultaneous interactions, such as audio, typed chat, and whiteboard/PowerPoint or group questions that could be answered using emoticons, Yes/No, or multiple choice responses. This problem can be managed by the instructor. In E!, it is possible to determine the number of communication devices that can be used at any time. For instance, the 
typed chat feature can be turned off. It may be in large classes in particular that allowing only one type of communication at a time, or at least limiting the uses, could increase students' ability to attend.

Second, some students found that the lack of non-verbal communication reduced their educational experience. Given the increasing affordability of webcams, this issue might be resolved if the instructor and students installed webcams and used them during their online classes. E! now includes functionality for webcams. Finally, technology issues, from broken links to faulty headphones, continue to plague synchronous online classes. Institutions of higher learning that are implementing cost-reduction measures must not cut resources for web technicians or for professors who aim to develop high-quality web-based courses if they want to increase their distance learning offerings. In light of the rapid growth of online technologies, professors and students will always be in need of instruction to best utilize these ever-changing platforms.

There is an increasing impetus to create distance learning courses both at the university and secondary school levels, and it is critical for teachers to evaluate the ways in which they deliver online classes, so they can insure that quality does not suffer because of an over-emphasis on convenience. The current study, while not generalizable, suggests that most of our students had a positive online experience using synchronous learning technology. However, their concerns about too much stimuli, their desire for non-verbal communication, and their technological problems must be considered and overcome in order to create a positive learning experience for all students. 


\section{References}

Battin-Little, B., Passmore, D., \& Schullo, S. (2006, November/December). Using synchronous software in Web-based nursing courses. CIN: Computers, Informatics, Nursing. 24(6), 317-325.

Belz, J. A., \& Müller-Hartmann, A. (2003). Teachers as intercultural learners: Negotiating German-American telecollaboration along the institutional fault line. Modern Language Journal, 87, 71-89.

Butner, B.K., Smith, A. B., \& Murray, J. (1999). Distance technology: A national study of graduate higher education programs. Online Journal of Distance Learning Administration, 2(3). Retrieved May 2, 2007, from http://www.westga.edu/ distance/ojdla/fall23/butner23.html

Chen, Y., and Willits, F. K. (1999). Dimensions of educational transactions in a videoconferencing learning environment. American Journal of Distance Education, 13, 45-59.

Cohen, L., Manion, L., \& Morrison, K. (2001). Research methods in education. London: Routledge Falmer.

Gorsky, P., \& Caspi, A. (2005). A critical analysis of transactional distance theory. The Quarterly Review of Distance Education, 6(1), 1-11.

Huberman, A. M., \& Miles, M. B. (1994). Data management and analysis methods in education. London: Sage Publications.

Jones, P., West, E., \& Stevens, D. (2006) "I realized I knew nothing, that I had an awful lot to learn, and that I would have to help others see teachers in a different light": An international perspective on effective moments of teacher learning. British Journal of Special Education, 33(2), 82-90.

Jung, I. (2001). Building a theoretical framework of Web-based instruction in the context of distance education. British Journal of Educational Technology, 32, 525-34.

Moore, M. G. (1993). Theory of transactional distance. In D. Keegan (Ed.), Theoretical principles of distance education. New York: Routledge.

Moore, M. G., \& Kearsley, G. (1996). Distance education: a systems view. Belmont: Wadsworth.

Ng, K. C. (2007). Replacing face-to-face tutorials by synchronous online 
technologies: Challenges and pedagogical implications. International Review of Research in Open and Distance Learning. Retrieved July 2, 2008, from http://eric.ed.gov/ERICDocs/data/ericdocs2sql/content_storage 01/0000019b/80/28/08/7 $\underline{0 . p d f}$

Silverman, D. (2000) Doing qualitative research. London: Sage.

Smeaton, A.F., \& Keogh, G. (1999). An analysis of the use of virtual delivery of undergraduate lectures. Computers \& Education, 32, 83-94.

West, E., \& Jones, P., (2007). A framework for planning technology used in teacher education programs that serve rural communities. Rural Special Education Quarterly, 26(4), 3-15.

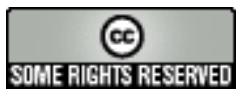


June - 2009

\title{
Video-Driven Multimedia, Web-Based Training in the Corporate Sector: Pedagogical Equivalence and Component Effectiveness
}

\author{
Katherine Pang \\ University of Texas at Tyler, USA
}

\begin{abstract}
The purpose of this study was to assess the pedagogical equivalence, as determined by knowledge gains, and the pedagogical effectiveness of certain components in a video-driven multimedia, web-based professional development training program as compared to a traditional, face-to-face program under real-world constraints of time and limited economic resources. The study focused on the use of video-driven multimedia, web-based instruction in the corporate environment to determine if the quality of the learning experience and the knowledge gained from the instruction were the same as with traditional methods. This experimental study assigned business professionals quasi-randomly to either a control group or an experimental group, where they attended either a live-instructed professional development program or a video-driven multimedia, web-based professional development program. Overall, results indicated that the video-driven multimedia, web-based instruction was not only pedagogically equivalent in terms of knowledge gains to the live instruction but that the knowledge gains were slightly higher among the webbased participants. Further, certain components in the web-based environment contributed more than components in the live environment to pedagogical effectiveness.
\end{abstract}

Keywords: Web-based training; video-driven multimedia; pedagogical equivalence; pedagogical effectiveness; corporate training; professional development; e-learning; instructional design

\section{Introduction}

The primary purpose of the current study was to assess the pedagogical equivalence, as determined by knowledge gains, of video-driven multimedia, web-based instruction and traditional live instruction. A secondary purpose was to determine the pedagogical effectiveness of certain components in both the web-based and the live instruction. The study focused on the use of video-driven multimedia, web-based training in the corporate environment to determine not only if the quality of the learning experience was the same as with traditional, face-to-face instruction but also whether the knowledge gains were equivalent to establish pedagogical equivalency. The study was conducted using working professionals under real-world constraints 
of time and location and was conducted in the same manner as regularly conducted corporate training or professional development programs. The instructional design of the web-based, videodriven multimedia program was based on a modified version of Taylor's (1994) NOVEX (novice-to-expert) analysis approach. The modified instructional design condensed his nine-step approach to six steps, emphasizing scaffolding and the use of expert declarative knowledge to develop a range of learning activities that measured pedagogical equivalence, such as knowledge gains and content mastery.

\section{Instructional Design}

Since educational technology is in itself not transformative, it must use meaningful instructional design methodologies. It is important that technology as a delivery medium effectively highlight the content so it can be applied by the learner and aligned with learning goals. The web-based instructional program used in this study was designed according to the work of Taylor (1994) in his extension of Tennyson's (1992) cognitive and constructivist learning theory known as the NOVEX (novice-to-expert) analysis approach to instructional design. The theory is based on the analysis of the cognitive structures of both novices and experts (NOVEX Analysis) and is derived from a constructivist heuristic. The fundamental structure of the NOVEX analysis approach to instructional design is to start with an identified domain-specific cognitive skill and then analyze the knowledge base of the expert in terms of the structure of the domain-specific objective knowledge. The expert's framework is then used to measure the knowledge base of the targeted learner, who is the novice. The advanced organizer allows the instructional designer to develop learning strategies within the context of the expert knowledge base and to provide "explicit ideational scaffolding for the generation of the expert knowledge base which is the terminal objective of the instruction" (Taylor, p.8). An advanced organizer is material that is presented prior to learning, which is used by the learner to organize and interpret new, incoming information (Mayer, 2003).

The importance of the constructivist approach is well-accepted and as Huitt (2003) notes, the emphasis is that "an individual learner must actively build knowledge and skills (e.g., Bruner, 1990) and that information exists within these built constructs rather than in the external environment" (p. 386). For example, the proliferation of Moodle, an open-source learning management system (LMS) that is built on a foundation of constructivist pedagogy, is evidence of the use of constructivist principles in instructional design (Bellefeuille, Martin, \& Buck, 2005). The NOVEX approach to instructional design integrated the constructivists' approach, which mandates that instructors and educators design instruction based on existing learner knowledge and the experiences that learners bring to the learning environment. According to Taylor (1994) the NOVEX analysis approach to instructional design required a team approach of not only the instructional designer and content expert but also the novice, who can test the effectiveness of the knowledge transfer from the content expert. As a result, the instructional design for the content in this study was based on the analysis of the cognitive structures of both novices and experts. It emphasized relational and strategic information processing, and it was built in accord with constructivist precepts. 


\section{The Use of Technology}

The use of technology in competency-based professional development and corporate training is well established. According to Blocker (2005), web-based or e-learning provides an opportunity to address many known business issues, such as cost reduction, access to information, learning accountability, and increased employee competence. The organizations dedicating the greatest level of resources to training recognize that learning can be a significant contributor to revenue. Rapid advances in Internet-based technologies and the use of the web as an educational resource have driven many organizations to deploy web-based professional development programs. In addition, instructional design theory that correlates to expected learner realities and organizational level e-learning solidifies objectives and outcomes. However, many educators and trainers in the corporate environment have been frustrated by their organization's "effort to simply get something up and running" (Dick, 1996), rather than the organization focusing on how to best use cognitive and constructivist instructional design models to produce measurable outcomes. For many, frustration levels have centered on the question of the equivalence and effectiveness of learning and the application of skills within the realities of the organizational environment.

The use of technology is no longer a major issue in professional development and corporate training (Ertmer, 1999). Now, the major issues are how to design effective web-based instruction, whether there is a pedagogical difference between live and web-based training, and whether certain components of web-based training are integral to effective instructional design. The literature suggests (Reeves, 2002; Slotte \& Herbert, 2006) that there are still doubts about the benefits of e-learning, so it is important to assess pedagogical equivalence and component effectiveness. If there is no trade-off in the pedagogical equivalence as determined by knowledge gains and if certain components of web-based instruction are identified as effective then the cost benefit of employing video-driven multimedia, web-based training may be used to create new opportunities for competency-based learning and to promote worker success and achievement. The current study is important in the field of cognition and instruction because most research has not emphasized professional development and competency-based learning that is designed in accord with cognitive based instructional design strategies in a video-driven multimedia, webbased learning context. Therefore, this study has both theoretical and practical significance in advancing video-driven multimedia, web-based training for professional development in the corporate environment. As most research has focused on web-based learning in college coursework, there is an emergent need to consider this issue within the real-world organizational context where training is juxtaposed with the cost-benefit of the training pedagogy.

Since the importance of professional development is vital to the maintenance and effectiveness of today's workforce, organizations recognize that there is a need to frequently examine the pedagogy, instructional strategies, and delivery mediums of workplace training. According to Staron, Jasinski, and Weatherley (2006), we are now in the "knowledge era," which is defined by its complexity, multiple priorities, high levels of energy, and opportunities. "It is an "intangible era' where the growing economic commodity is knowledge . . . It is not just about accessing information but about how we learn to continually select, borrow, interpret, share, contextualize, generate, and apply knowledge to our work" (p. 3). Goodyear and Ellis (2008) posit that "our 
methods of analysis - and design - have to become more organic or ecological" (p. 148), and according to Fok and Ip (2006), there remain issues as to whether there is a tangible and real commitment, given time and money constraints, to examine learning benefits. It would therefore appear that although vendors, instructional designers, and subject matter experts unanimously emphasize the importance of training and instruction that allows for job-specific evaluation, there is a lack of sound research material in the area of pedagogical equivalency and effectiveness. This is particularly true in web-based learning and training that is based on a modified NOVEX approach to instructional design, which integrates video-driven multimedia components.

\section{The Study}

The current study examined the effects of a video-driven multimedia, web-based, competencybased professional development program in contrast to a live, instructor-led program, using the same instructional content on organizational leadership. Specifically, the following hypothesis was tested: A video-driven multimedia, web-based professional development program is pedagogically equivalent to a live, instructor-led program in delivering competency-based professional development training, as measured by knowledge gains. Further, certain components in the web-based environment are more effective for learning. To simplify the process while maintaining the integrity of the NOVEX analysis approach, this study used a modified version of the NOVEX analysis as a methodology for the instructional design of the web-based instructional content with an emphasis on relational and strategic information processing. The instructional content was delivered through a video-driven multimedia, web-based learning environment.

For purposes of this study pedagogical equivalence was operationalized by the participants' knowledge gains and mastery of the instructional content. The effectiveness of the instructional design was operationalized in terms of certain components in the learning environment (i.e., videos, whiteboard, PowerPoint). A multiple choice post-test measured the equivalence of the instruction modalities, and a self-reported post-test measured the participants' responses to the effectiveness of the components. Effectiveness was operationalized as its enhancement of learning in the learning environment.

\section{Method}

This study included 38 participants. The ages of the participants ranged from 21 to over 51 years; the majority of participants were 31 years of age and older. Additionally, the participants have worked from one to 21 years. Educational backgrounds of the participants varied from a high school diploma to a doctoral degree. Participants held a variety of positions within organizations. Many of the participants were business owners; other participants included members of sales teams, managers, or administrators (see Table 1). 
Table 1

Participant Demographics

\begin{tabular}{lll}
\hline Age & Web participants & Live participants \\
\hline Under 21 & 0 & 0 \\
$21-30$ & 3 & 0 \\
$31-40$ & 1 & 6 \\
$41-50$ & 8 & 8 \\
Over 51 & 7 & 5 \\
\hline
\end{tabular}

Years working

\begin{tabular}{lll}
\hline $1-3$ & 2 & 0 \\
$4-7$ & 2 & 6 \\
$8-12$ & 1 & 2 \\
$13-20$ & 6 & 5 \\
Over 21 & 8 & 12 \\
\hline
\end{tabular}

Educational background

$\begin{array}{lll}\text { High School Graduate } & 1 & 0 \\ \text { Junior College } & 5 & 7 \\ \text { 4-Year Degree } & 8 & 10 \\ \text { Masters Degree } & 1 & 2 \\ \text { Doctoral Degree } & 1 & 0 \\ \text { Professional Certification } & 1 & 0\end{array}$

Position in organization

\begin{tabular}{lll}
\hline Owner & 8 & 3 \\
Executive & 2 & 1 \\
Director & 0 & 1 \\
Manager & 1 & 4 \\
Sales Team & 4 & 2 \\
Customer Service & 2 & 1 \\
Administrative & 2 & 4 \\
Other & 0 & 3 \\
\hline
\end{tabular}




\section{Materials}

Two self-reporting instruments were used to measure the dependent variables: (1) the pedagogical equivalence between the video-driven multimedia, web-based instruction and the live instruction, and (2) the effectiveness of certain components. A computer and Internet experience questionnaire determined if there were differences in homogeneity between the two groups. This survey had four questions on a 5-point Likert scale, ranging from 1 (lowest) to 5 (highest). The other questionnaire, which measured exposure to and experience with professional development programs, consisted of ten questions on a 5-point Likert scale, ranging from 1 (lowest) to 5 (highest). This self-reporting post-test measured the participants' attitudinal responses to the components of the medium for instruction. Content characteristics were measured via a multiple choice post-test on the instructional content. The instructional design method was operationalized by certain components of the learning environment (i.e., videos, whiteboard, PowerPoint). A volunteer participant consent form and demographic survey were also administered.

\section{Research Design and Instruments: Post-Tests}

The research design was formulated based on a classical experimental design. Through selfselection and selection by a supervisor, participants were assigned quasi-randomly to an experimental group $(N=19)$, the web-instructed program, and to a control group $(N=19)$, the live-instructed program, to create equivalence between the groups. The primary dependent variable in this study was pedagogical equivalence between the video-driven multimedia, webbased instruction and the live instruction of a competency-based professional development program. A secondary dependent variable was the effectiveness of certain components in both the live and web-based training. Two self-reporting instruments measured these dependent variables. A self-report post-test measured the participants' attitudinal responses to the components of the medium of instruction. A multiple choice post-test on the content of the instruction measured pedagogical equivalence as determined by knowledge gains.

The first post-test measured pedagogical effectiveness in the form of participants' attitudes to the components of instruction. The first post-test was prepared by the experimenter and reviewed by the subject matter expert (SME) instructor. There were two matched versions of this post-test, including one for the live-instructed participants and one for the web-instructed participants. The questions were designed to mirror one another. Minor changes were made to adjust for the tools used as part of the instruction. For example, in the web-based post-test, the word e-learning was used; for the live post-test, the word live was substituted for e-learning in the same question. To maintain the integrity of equivalence and balance, only two other changes were made to the wording of the questions. These alterations were made to capture the appropriate component for the learning environment. Question 5 was worded differently for the e-learning post-test (i.e., "The videos in the e-learning instruction enhance my knowledge of the instructional content") in comparison to the live post-test (i.e., "The White Board used in the live program facilitates my learning"). In question 9, a variety of instructional modalities were used in the live post-test. 
The second post-test measured pedagogical equivalence, specifically knowledge gains represented by responses on an objective multiple choice post-test for the content of the instruction. The multiple-choice post-test was highly analogous, in form and content, to the type used in any college classroom. This second post-test was developed by the instructor of the live program; the instructor was a SME with a master's degree in human resources and substantial experience developing and delivering live, competency-based training. The post-test consisted of 15 multiple choice questions that were derived directly from the instructional content. This test was identical for both the web-instructed and live-instructed participants. A percentage score was attributed to each participant. To eliminate bias on the part of the scorer a set of correct answers was provided and used to score the post-test. For the experimental group, the study used the modified NOVEX approach to instructional design. The instructional content was delivered through a video-driven multimedia, web-based environment accessible by any web browser. The web-based learning management system included multimedia instructional content composed of video, text, hyperlinks, and self-assessment quizzes. For the control group, the study used a traditional live conference room with an instructor, PowerPoint presentation, and a whiteboard. A different instructor was used for the video content and the live instruction. Both instructors were proficient in instruction of the content. The control group and experimental group were exposed to the same instructional content for the same length of time. It is important to note that the delivery mediums (i.e., web-based multimedia versus live instruction) are akin to comparing "apples to oranges." In many organizations live instruction is the preferred training method. This is due to a perception of pedagogical superiority. As a result, the comparison in this study was necessary to assess the pedagogical equivalence and, perhaps, to change the training culture in many organizations.

The learning tasks for the experiment were designed to be suitable for working professionals attending a professional development program. In addition, the length of the tasks was standardized so that the "length of task" would not be a contaminating artifact in the determination of complexity. To improve the instruments' and post-tests' content validity, two business professionals were invited to review the questions, to provide assessments, and to evaluate the inclusion of the questions in the instruments. The business professionals delivered their assessments informally by providing feedback to the instructor and experimenter, and they were involved in the development process.

Controls for validity threats were implemented to ensure that internal threats, such as inadequate procedures, problems in applying treatments (i.e., discussions between participants), or participants' characteristics, were minimized. This was accomplished by stating in the instructions that participants should not discuss their participation in this research with other business associates or colleagues and by drawing from a diverse pool of participants who would not have access to the course materials. In addition, possible external threats, such as generalization and inferential conclusions, were avoided by using volunteer participants from a random sample. In addition, due to the small sample size, a power analysis was performed to determine the ability to detect accurate and reliable effects and results. An a priori power analysis was conducted during the design of the study to determine what sample size would be necessary 
for $80 \%$ power based on the $t$-tests with two independent groups based on an $\alpha=.05$ as illustrated in Table 2.

Table 2

Approximate Sample Size Needed for 80\% Power $(\alpha=.05)$

\begin{tabular}{llll}
\hline \multicolumn{3}{c}{ Effect Size } & \\
\cline { 1 - 3 } $\begin{array}{l}\text { Small } \\
(d=.20)\end{array}$ & $\begin{array}{l}\text { Medium } \\
(d=.50)\end{array} \quad$ Large \\
\hline 7 & 18 & 36 \\
\hline
\end{tabular}

Note. Results were calculated using software by Lenth (2006).

\section{Results and Discussion}

Descriptive statistics were assembled for the questionnaire data, the assessment, and post-tests. No statistical difference existed between the two groups in computer and Internet experience (see Table 2). On a scale of 1 to 5, the participants' familiarity with computers for the web-based participants $(M=3.79)$ was equivalent to the live-instructed participants $(M=4.1)$. The use of Windows as an operating platform was similar for both the web-based participants $(M=3.9)$ and the live-instructed participants $(M=4.2)$. Additionally, the use of Internet Explorer to access the Internet was equivalent for the web-participants $(M=4.1)$ and the live-instructed participants $(M$ $=4.3$ ). Familiarity with using Flash or QuickTime to watch web-based video and animation on the Internet was closely related for both the web-based participants $(M=3.3)$ and the liveinstructed participants $(M=3.1)$.

An $F$-test and $t$-test were used to analyze the data for the assessment and the two post-tests. The assessment listed 10 traits or practices that are characteristic of leadership or management; statistical analysis revealed significant results, $p<.001$ (see Table 3). The results revealed a difference between the web-instructed participants $(M=.831, S D=.088)$ and the live-instructed participants $(M=.610, S D=.253)$. 
Table 3

Professional Development Programs

\begin{tabular}{|c|c|c|c|c|}
\hline Questions & WM & LM & WSD & LSD \\
\hline 1. Exposure to live programs* & 3.52 & 3.47 & 1.17 & .90 \\
\hline 2. Exposure to web-based programs & 2.94 & 2.78 & 1.18 & 1.03 \\
\hline 3. Experience instructing live programs* & 3.05 & 2.10 & 1.58 & 1.15 \\
\hline 4. Experience instructing web-based programs & 2.15 & 1.73 & 1.12 & 1.05 \\
\hline 5. Exposure to competency-based live programs & 2.84 & 2.31 & 1.34 & 1.16 \\
\hline 6. Exposure to competency-based web-based programs & 1.94 & 2.15 & .91 & 1.07 \\
\hline 7. Exposure to live programs on leadership & 3.05 & 2.63 & 1.03 & 1.16 \\
\hline 8. Exposure to web-based programs on leadership & 2.05 & 2.15 & .97 & 1.01 \\
\hline 9. Experience as a leader in your organization* & 4.05 & 3.26 & 1.18 & 1.48 \\
\hline 10. Experience as a manager in your organization & 3.82 & 3.26 & 1.30 & 1.48 \\
\hline
\end{tabular}

Note. Descriptive statistics of Exposure to and Experience with Professional Development Programs, from 1 ("no exposure or experience") to 5 ("highly exposed or experienced"); $\mathrm{WM}=$ the mean for web-based participants; LM = the mean for live-instructed participants; WSD = standard deviation for web-based participants; and LSD = the standard deviation for live-instructed participants. An asterisk denotes significance at $p<.05$ based on $t$-tests.

Based on $t$-tests, differences existed between the web-instructed and live-instructed participants on the questionnaire to determine exposure to and experience with professional development programs. Significant effects resided in questions 1, 3, and 9: question 1, exposure to live programs, $p=.04$; question 3, experience instructing live programs, $p=.02$; and question 9 , as a leader within an organization, $p=.04$. The results revealed that some participants had more experience in and exposure to attending or instructing live professional development programs. However, results did not indicate more experience in the content domain of this study. In addition, the differences pertained to attending and instructing live programs and not web-based programs; therefore, a bias in favor of web-based instruction cannot be inferred from the data. The differences in self-assessed leadership did not relate to learning environment, its components, or instructional content; instead, the differences related to a position within an organization. Results indicated that web-based participants were better able to ascribe certain traits and characteristics to a leadership or management function than the participants in the live session. 
The results showed non-equivalence in the groups only on this particular assessment. The assessment was broad-based in nature and not derived from the instructional content. Thus, it should not affect the validity and reliability of the post-test on the instructional method and the effectiveness of its components. Also, it should not impact the measure of the content characteristics as the questions were not derived from the specific content of the instruction. In addition, there were no significant results in the subject matter post-test. As a result, it did not appear that the lack of equivalence on the assessment impacted the dependent variables of pedagogical equivalence (knowledge gains) and effectiveness (i.e., measured by components and content).

The $t$-test results for the e-learning and live program post-test showed that of the 10 items, four were significant: The first significant result was question 5, "The videos in the e-learning instruction enhance my knowledge of the instructional content," $p<.001$; the second was question 7, "The Handout provided in the e-learning program enhances my understanding of the instructional content," $p<.001$; the third was question 8 , "The interactivity in the e-learning instruction enhances my understanding of the instructional content," $p=.03$; and the last was question 9 , "The multimedia environment in the e-learning program facilitates my learning," $p=$ .03 .

The second post-test consisted of 15 multiple choice questions that were derived directly from the instructional content. The questions were scored and a percentage assigned to each participant, with $100 \%$ representing 15 out of 15 . The web-instructed participants scored slightly higher $(M=$ $.766, S D=0.142)$ than the live-instructed participants $(M=.760, S D=.0 .140), p=.38)$, establishing an equivalency in knowledge gains (see Table 4).

Table 4

E-Learning and Live Program Post-Test Questions

No. Question

M SD

1 The e-learning program is effective in developing my work-based competencies

$4.158 \quad 0.958$

The live program is effective in developing my work-based competencies

2 The e-learning program improves my thinking skills $\quad 3.947 \quad 1.025$

$\begin{array}{lll}\text { The live program improves my thinking skills } & 4.105 & 0.186\end{array}$

3 The e-learning program enhances my problem-solving skills $\quad 3.474 \quad 1.020$

$\begin{array}{lll}\text { The live program enhances my problem-solving skills } & 3.984 & 0.848\end{array}$

$4 \quad$ The PowerPoint used in the e-learning program facilitates my learning $\quad 4.316 \quad 1.108$ 
5 The videos in the e-learning instruction enhance my knowledge of the $\begin{array}{lll}\text { instructional content } & 4.316 & 1.00\end{array}$

The White Board used in the live program facilitates my learning $\quad 2.684 \quad 2.00$

6 The instructor in the e-learning program facilitates my acquisition of the $\begin{array}{lll}\text { instructional content } & 3.947 & 1.026\end{array}$

The instructor in the live instruction facilitates my acquisition of the $\begin{array}{lll}\text { instructional content } & 4.158 & 0.765\end{array}$

7. The Handout provided in the e-learning program enhances my understanding $\begin{array}{lrr}\text { of the instructional content } & 4.368 & 0.684\end{array}$

The Handout provided in the live instruction enhances my understanding

$\begin{array}{lrl}\text { of the instructional content } & 2.895 & 1.792\end{array}$

8. The interactivity in the e-learning instruction enhances my understanding of the $\begin{array}{lrr}\text { instructional content } & 4.526 & 0.964\end{array}$ The interactivity in the live instruction enhances my understanding of the $\begin{array}{lrl}\text { instructional content } & 3.474 & 1.219\end{array}$

9. The multimedia environment in the e-learning program facilitates my learning $4.474 \quad 0.612$

The variety of instructional modalities (i.e., PPT, Handout, Whiteboard) $\begin{array}{lll}\text { in the live program facilitates my learning } & 3.895 & 1.145\end{array}$

10. The e-learning program is an effective instructional tool $\quad 4.631 \quad 0.597$ $\begin{array}{lll}\text { The live program is an effective instructional tool } & 4.316 & 0.749\end{array}$

Note. $M=$ Mean and $S D=$ Standard deviation, from 1 ("strongly disagree") to 5 ("strongly agree"). E-Learning questions are on the first line and the live questions are on the second line.

As the results indicated, the hypothesis was supported by the findings and highlighted the foundational point of this study, that a video-driven multimedia, interactive learning environment is pedagogically equivalent, as measured by knowledge gains, to traditional, live training in the delivery of a competency-based program. This was supported by 4 out of 10 questions in the first post-test. The significant results are as follows:

1. "The videos in the e-learning instruction enhance my knowledge of the instructional content," as compared to "the White Board used in the live program facilitates my learning." 
2. "The Handout provided in the e-learning program enhances my understanding of the instructional content," as compared to "the Handout provided in the live instruction enhances my understanding of the instructional content."

3. "The interactivity in the e-learning instruction enhances my understanding of the instructional content," as compared to "the interactivity in the live instruction enhances my understanding of the instructional content."

4. "The multimedia environment in the e-learning program facilitates my learning," as compared to "the live program is an effective instructional tool."

These results demonstrated that participants attributed a higher score to the functions that comprised video-driven multimedia, web-based learning. Additionally, the results indicated that those in a web-based program may use a handout more frequently if they can download it. These significant functions illustrated that the video-driven multimedia, web-based environment was not pedagogically inferior to traditional, live learning. In fact, knowledge gains in the web-based learning environment were a little higher suggesting not only pedagogical equivalence but also that the web-based environment may be a better alternative because of its cost-effectiveness.

\section{Conclusion}

This study provides a foundation for future experimental research in understanding other aspects of pedagogical equivalence and the effectiveness of components in video-driven multimedia, web-based professional development training as contrasted with face-to-face training. The current research indicated that video, a multimedia environment, and interactivity are important functions to deliver effective web-based professional development programs. Therefore, instructional designers, corporate trainers, and organizations can use these indicators to develop instructional strategies for designing and delivering more effective training programs. They can also use this study to diminish the perception that traditional, live training is pedagogically superior or more effective than web-based training in that the results from this study establish that knowledge gains were not only evident in both groups but slightly higher among the web-based learners. Many individuals in human resources, professional training societies (e.g., ASTD), e-learning communities (e.g., the E-Learning Guild), and elsewhere will benefit from the expansion of these results. Publications (e.g., Journal of Workplace Learning, Human Resource Development, and Studies in Continuing Education) can use this study to generate additional interest in research of this area. Although the sample size was small, there was ample power to validate the findings, and although a majority of the participants was drawn from those with business ownership or management experience, additional research can prove valuable for generalizing the results to other populations. In addition, using participants from a variety of organizational settings where professional development training is an important part of increasing an organization's profitability would prove interesting. The significant findings of this study can be used in further research on different types of professional development training. The results have wide implications for corporate training, where on-demand learning, cost, and loss of revenue from travel and instruction often determine the mode and method for training. Thus implications exist for a variety of organizations that are tasked with training workers and delivering cost-effective professional development programs. 


\section{References}

Bellefeuille, G., Martin, R. R., \& Buck, M. P. (2005). From pedagogy to technology in social work education: A constructivist approach to instructional design in an online, competency-based child welfare course. Child \& Youth Care Forum, 34, 371-389.

Blanchette, J., \& Kanuka, H. (1999). Applying constructivist learning principles in the virtual classroom. Proceedings of Ed-Media/Ed-Telecom 99 World Conference. Retrieved April 10, 2008, from http://proxy.tamucommerce.edu:8436/ehost/pdf?vid=17\&hid=19\&sid=9e630777-2219-4b27-80517cee8e49b925\%40sessionmgr9

Blocker, M. J. (2005). E-learning: An organizational necessity (White Paper). Retrieved April 6, 2008, from http:// www.rxfrohumanperformance.com

Bruner, J. (1990). Acts of meaning. Cambridge, MA: Harvard University Press.

Bryans, P., Gormley, N., Stalker, B., \& Williamson, B. (1998). From collusion to dialogue: Universities and continuing professional development. Continuing Professional Development, 1, 136-44.

Dick, W. (1996). The Dick and Carey model: Will it survive the decade? Educational Technology Research and Development, 44(3), 55-63.

Ertmer, P. (1999). Addressing first- and second-order barriers to change: Strategies for technology integration. Educational Technology Research and Development, 47, 47- 61.

Fok, A. W. P., \& Ip, H. H. S. (2006). An Agent-based framework for personalized learning in continuing professional development. International Journal of Distance Education Technologies, 4(3), 48-61.

Goodyear, P., \& Ellis, R. A. (2008). University students' approaches to learning: Rethinking the place of technology. Distance Education, 29(2), 141-152.

Gunawardena, C. N., Lowe, C. A., \& Anderson, T. (1997). Analysis of a global online debate and the development of an interaction analysis model for examining social construction of knowledge in computer conferencing. Journal of Educational Computing Research, 17, $397-431$.

Huitt, W. (2003). Constructivism. Educational Psychology Interactive. Retrieved July 16, 2008, from http://chiron.valdosta.edu/whuitt/col/cogsys/construct.html

Johnson, S. D., \& Aragon, S. R. (2002). Emerging roles and competencies for training in elearning environments. Advances in Developing Human Resources, 4(4), 424-439. 
Kauffman, D. (2004). Self-regulated learning in Web-based environments: Instructional tools designed to facilitate cognitive strategy use, metacognitive processing, and motivational beliefs. Journal of Educational Computing Research, 301, 139-161.

Lenth, R. V. (2006). Java Applets for Power and Sample Size [Computer software]. Retrieved December 1, 2008, from http://www.stat.uiowa.edu/ rlenth/Power.

Martinez, M., \& Bunderson, V. (2000). Building interactive World Wide Web (Web) learning environments to match and support individual learning differences. Journal of Interactive Learning Research, 11, 163-195.

Mayer, R. (2003). Learning and instruction. New Jersey: Pearson Education.

Reeves, T. C. (2002). Keys to successful e-learning: Outcomes, assessment and evaluation. Educational Technology, 42, 23-9.

Slotte, V., \& Herbert, A. (2006). Putting professional development online: Integrating learning as productive activity. Journal of Workplace Learning, 18, 235-247.

Staron, M., Jasinski, M., \& Weatherley, R (2006). TAFE NSW ICVET 2006, Capability development for the knowledge era: Reculturing and life based learning. Paper presented at AVETRA Conference 2006, 'Global VET: Challenges at Global, National and Local Levels.' Retrieved December 1, 2008, from http://www.icvet.tafensw.edu.au/ezine/year_2006/may_jun/research_capability_develop ment.htm

Taylor, J. C. (1994). NOVEX analysis: A cognitive science approach to instructional design. Educational Technology, 34, 5-13.

Tennyson, R. (1992). An educational learning theory for instructional design. Educational Technology, 32, 36-41.

Von Glasersfeld, E. (1995). A constructivist approach to teaching. In L. Steffe \& J. Gale (Eds.), Constructivism in education (pp. 3-16). Hillsdale, NJ: Lawrence Erlbaum Associates. 
June - 2009

\title{
Sage without a Stage: Expanding the Object of Teaching in a Web-Based, High-School Classroom
}

\author{
Elizabeth Murphy and Maria A. Rodriguez-Manzanares \\ Memorial University of Newfoundland
}

\begin{abstract}
This paper reports on a study that uses cultural historical activity theory (CHAT) to make sense of e-teachers' activity in a context of high-school distance education. Data collection involved semistructured interviews with 13 e-teachers as well as seven management and support personnel in an organization responsible for the design and delivery of high-school distance education in the province of Newfoundland and Labrador, Canada. As well, the authors conducted a second round of interviews with 12 of the 13 teachers. Findings revealed that the traditional metaphor of teacher as 'sage on the stage' ceased to have a reference point in the distributed online classroom. The e-teachers were widening the object of their activity to include less teacher-centered forms of learning that involved more student independence.
\end{abstract}

Keywords: Online learning; e-teaching; high school; cultural historical activity theory; expansive learning.

\section{Introduction}

In reviews of research conducted in the 1980s and 1990s, Cradler and Bridgforth (1996) described technology as a "catalyst for education reform" (Preliminary Research Findings section, II 1). Technology has also been referred to as an agent of change (e.g., Furneaux, 2004; Girod \& Cavanaugh, 2001; Kiesler \& Sproull, 1987; McClintock, 1992). Guile (1998) argued that this change comes about because technology is not suited to practices where teachers operate as managers and didactic teachers. A similar argument was made earlier by Pea (1985) who explained that computers tend to be thought of as amplifying or extending our capabilities, but they can also play a role in changing what we do and how we do it by reorganizing our mental functioning. Besides being a catalyst for reform or a change agent, technology has been referred to as a Trojan horse. Salmon (1992) argued that computers fuel pedagogical change when they afford activities that require changes in the learning environment.

What these three metaphors have in common is their view of technology as an element that disrupts current practices. Christensen (see Bower \& Christensen, 1995; Christensen, 1997) first 
applied the term disruptive technology or disruptive innovation to the area of economics. In that context, disruptive technologies are described as "simple, convenient-to-use innovations that initially are used only by unsophisticated customers at the low end of markets" (Christensen \& Armstrong, 1998, p. 69). They constitute an alternative to established products or technologies dominating a field. They are perceived as being more responsive, agile, user-empowering, and potentially transformative.

Engeström's (2001) perspective on cultural historical activity theory (CHAT) and its principle of expansive learning provides a systematic and comprehensive tool to understand the transformative potential of disruptive technologies. Engeström argues that standard theories of learning "have little to offer" (p. 138) to our understanding of the processes involved in organizations where people "are all the time learning something that is not stable, not even defined or understood ahead of time" (p. 137). Engeström's argument focuses specifically on contexts where change is taking place or during "important transformations." At those times, as he notes, "we must learn new forms of activity which are not yet there. They are literally learned as they are being created. There is no competent teacher" (p. 138).

In this paper, we apply a lens of CHAT and its principle of expansive learning to make sense of a context where teachers are learning new forms of activity "which are not yet there." CHAT considers the cultural and historical dimensions of activity. With respect to the study of learning activity in particular, CHAT has been described as "one of many social approaches to learning" (Russell \& Yañez, 2003, p. 335). CHAT draws on Vygotsky's (1978) construct of cultural mediation of activity. Vygotsky represented cultural mediation as the mediation of a tool (artefact) between subject and object. CHAT broadened Vygotsky's triad of subject, object, and mediating artefact to include rules, community, division of labour, and outcome (see Engeström, 1987) in order to represent the activity system, which is defined as "object-oriented, collective, and culturally mediated human activity" (Engeström, 1999, p. 9). The object of activity is reinterpreted and "reconstructed in a wider perspective" (Virkkunen \& Kuutti, 2000, p. 303) when components of the activity system change substantially.

The e-teachers participating in our study were subjects in an activity system that had undergone considerable change. They had a history of practice of more than a decade in brick and mortar schools where physical co-presence formed the basis for interaction and communication. At the time of the study, they had all been working fewer than five years in an online, decentralized classroom where communication and interaction were mediated almost entirely by text and voice.

In this paper, we portray their new activity system and the contradictions that arise and lead to a change in the object of their activity of teaching. We begin with an overview of CHAT and its principle of expansive learning. We follow with a synthesis of studies that have used CHAT and its principle of expansive learning. Our findings are presented in relation to the elements of activity system and discussed using CHAT with a specific focus on expansive learning. 


\section{Cultural Historical Activity Theory and Expansive Learning}

The subject of an activity system is the individual or group whose viewpoint is adopted. Object "refers to the 'raw material' or 'problem space' at which the activity is directed and which is moulded or transformed into outcomes with the help of physical and symbolic, external and internal tools" (Engeström, 1993, p. 67). Tools (artefacts or instruments) mediate the object of activity. They can be external, material tools (e.g., a textbook, a computer) or internal, symbolic tools (e.g., language). Community refers to the participants of an activity system, who share the same object (Engeström, 1993). The division of labour involves the division of tasks and roles among members of the community and the divisions of power and status (Kuutti, 1996). Rules refer to explicit or implicit norms. Activity systems are typically represented as a triangle as follows:

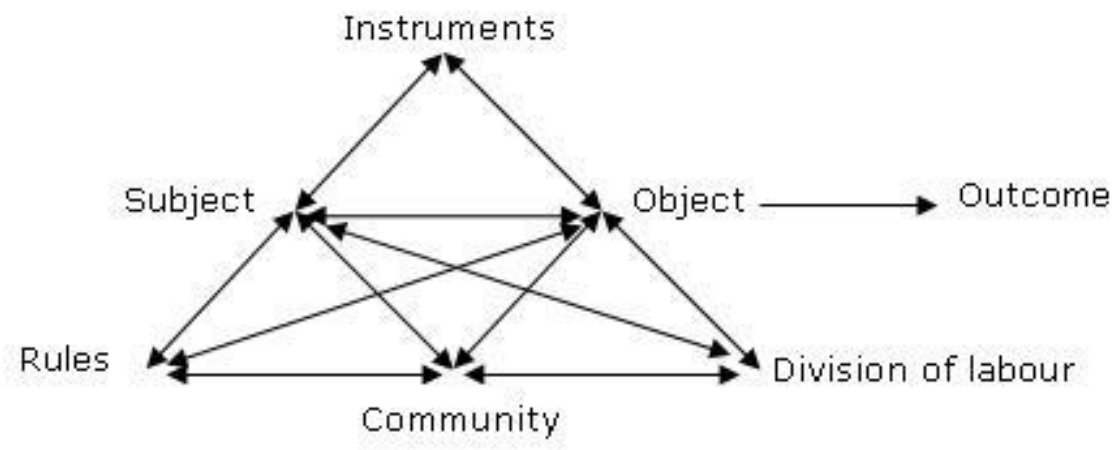

Figure 1. Activity theory diagram (Engeström, 1987).

According to the first of the five principles of CHAT as formulated by Engeström (2001), the main unit of analysis in CHAT is the activity system. An activity system is more robust than any of its individual members, as Engeström explains: "Goal-directed individual and group actions, as well as automatic operations, are relatively independent but subordinate units of analysis, eventually understandable only when interpreted against the background of entire activity systems" (p. 136). The second principle is the multivoicedness of activity systems, which can be both a source of trouble and of innovation. Multivoicedness refers to multiple perspectives, traditions, and interests.

As Engeström (2001) explains, "the division of labor in an activity creates different positions for the participants, the participants carry their own diverse histories, and the activity system itself carries multiple layers and strands of history engraved in its artifacts, rules and conventions" ( $p$. 136). The third principle is that of historicity. Engeström considers the history of activity systems as an essential step to understand their problems and potentials: "History itself needs to be studied as local history of the activity and its objects and as history of the theoretical ideas and tools that have shaped the activity" (pp. 136-137). Historical analysis is needed to understand an activity system in its present form because "parts of older phases of activities stay often embedded in them as they develop" (Kuutti, 1996, p. 26). 
The fourth principle highlights the central role of contradictions as sources of change and development. Contradictions are "historically accumulating structural tensions within and between activity systems" (Engeström, 2001, p. 137). They can create conflicts and disturbances but also attempts to transform the activity. A contradiction might occur, for example, when a new technology is adopted and then clashes with an old element such as the rules or division of labour.

The fifth principle refers to the possibility of expansive transformations in activity systems. An expansive transformation involves a reconceptualisation of the object and the motive of activity whereby "the practitioners ask what they are doing, and why, not just how they are doing it" (Engeström, 1991, p. 269). As Engeström (2001) notes, in a context of learning, such as learning within an organisation, the object of expansive learning activity is the entire activity system in which the learners are engaged, and expansive learning activity produces "new patterns of activity" (p. 139).

Virkkunen and Kuutti (2000) characterize expansive learning as a transformation in the object of activity. They draw on Engeström (1987) to argue that expansive learning occurs "when the object of the activity is reinterpreted, and the actors' interaction with the object is remediated to the effect that the object of the activity expands...." (p. 302). In activity systems, the object of activity is a key element, "the societal motive" (p. 301). The object "defines the activity and separates activities from each other" (p. 301). It is "a horizon of possibilities and possible objectives for the actors, something that unfolds in the process of the activity" (p. 301). Activity systems are multivoiced with "many competing and partly conflicting views" because, as Virkkunen and Kuutti note, "each individual taking part in a common activity has a slightly different view and interpretation of the object and purpose of the activity depending on the individual's position in the division of labor, his or her history in the activity, training and experience etc.” (p. 301).

The object of activity is reinterpreted and "reconstructed in a wider perspective" (Virkkunen \& Kuutti, 2000, p. 303) when components of the activity system change substantially and misalign, resulting in contradictions or double binds, which the individuals in the system overcome. Virkkunen and Kuutti provide this illustration:

For instance, new technology that has been adopted causes many disturbances and problems, but, it is impossible to return to the old technology.... Adopting new tools and practices creates contradictions between the old practices and the new ones. These contradictions are manifested in new kinds of problems, ruptures and disturbances in the activity. (p. 303)

It is in the resolution of the contradiction and a widened or expanded range of possibilities that learning and transformation occur in the form of a new object: "There is a constant tension between the expansive, future oriented solutions and the regressive ones that would mean return to the old practices. The solutions to the problems gradually give form to a new practice...." (Virkkunen \& Kuutti, 2000, p. 303). 


\section{Literature Review}

Kärkkäinen (1999) conducted a longitudinal study of teacher team planning and curriculum implementation in an elementary school setting in Finland. He identified disturbance clusters, together with questioning and interaction of different voices, as indicators of turning points. Disturbance clusters are clusters of dilemmas, disturbances, and innovation attempts of team discourse (Engeström, 1991). Kärkkäinen identified different types of turning points in object formation: widening the object in terms of spatiality, temporality and depth, narrowing the object, switching the object, and disintegration of the object.

The widening of the object in terms of depth took place when "the team elaborated on and created the concept of theme-working and also evaluated and reelaborated on the concept so that the ideological dimension of the object became deeper" (Kärkkäinen, 1999, p. 191). The author also argued that the tension between controlling students' choices and offering choice resulted in the team's elaboration of a new pedagogy emphasizing the facilitation of students' learning. Spatial widening involved the teachers' attempts to expand teacher collaboration.

Engeström, Engeström, and Suntio (2002a, 2202b) investigated middle school teachers' integration of technology in a Finnish school and the teachers' ways of constructing or defining their students. Analysis of data revealed a contradiction related to "teachers' repeated talk about students as apathetic," which contrasted with "occasional utterances where they would contradict their very assessment" (Engeström et al., 2002a, p. 215). Teachers changed this conceptualization of students as "apathetic" moving to one of students as "capable." The authors identified expansive actions on the part of teachers related to this redefinition of students. An instance in which teachers sought input from students before a unit was implemented was interpreted as an illustration of expansive action which was "atypical to the everyday instructional practice in the school” (Engeström et al., 2002b, p. 323).

Carr, Morrison, Cox, and Deacon (2007) investigated wikis as mediating artefacts in a final-year undergraduate political science course which was taught face-to-face. The study revealed that the collective process of creating and using wikis challenged well-established teacher-centered instruction and resulted in "uncertainties and anxieties for both educators and students" (p. 271). The authors highlighted the "multiple mediations" characteristic of wikis, whereby "web pages can... not only be read but also be easily edited and extended by multiple participants through a browser" (p. 268). Students' use of wikis involved a shift from "just-in-time individual projects" (p. 278) to collaborative writing. For the tutors and lecturer in the study, this shift meant developing practices to help students with collaborative writing in wikis.

In a context of teacher education at the University of Hong Kong involving partnering of university tutors, mentor teachers, and student teachers, Tsui and Law (2007) identified a shift in the conceptualization of teacher learning. One contradiction between the subjects and the division of labour stemmed from the fact that "while lessons are collectively prepared, they are individually enacted by teachers in the classroom" (p. 1298). 
The experienced university tutors and mentor teachers brought their multiple perspectives to the collective lesson planning in which they considered student teachers "partners;" however, student teachers "were completely overwhelmed by the input... [and] did not have enough time and space to make sense of the input and to gain ownership of the ideas" (Tsui \& Law, 2007, p. 1298). Subsequently, participants agreed to change lesson planning so that student teachers could prepare on their own, with university tutors and mentor teachers adopting a consultative role. Tsui and Law interpreted this shift as expansive learning where the new concept of lesson planning constituted a "new mediating tool for learning... [which] led to a transformation of the activity system from the 'supervision' of novices to the professional development of both novices and experts” (p. 1300).

In Australia, Fåhræus (2004) collected data from 40 distance education students, most of whom were at the secondary level, as well as teachers and others who were part of the students' learning activity. The main contradiction in the study related to a tradition of individual learning in distance education where students do not interact with each other. This lack of interaction clashed with the affordances of the new tools that enabled collaboration in the online leaning environment. It clashed as well with learners' preference for collaborating during online classes. Fåhræus suggested that potential activities to resolve that contradiction might involve a redefinition of roles and rules as well as changes in pedagogy to adapt to collaborative views of learning.

Russell and Schneiderheinze (Russell, 2004; Russell \& Schneiderheinze, 2005) reported on a study of four teachers designing a problem-based unit delivered using technology in fourth- and fifth- grade classrooms in four different schools in Missouri. Each teacher's work activity was analysed using the elements of the activity system. Analysis focused on indications of object transformation or "ways in which the teacher delineated the object in a new way" (Russell \& Schneiderheinze, 2005, p. 40). Contradictions could be resolved when "the teacher was able to maintain or expand her object by working out the tensions in the system" (Russell, 2004, Method section, ๆ 7). They could be unresolved when "the teacher did not work out the tensions and the object was narrowed" (Method section, ๆ 7).

\section{Methods}

\section{The Context}

The context for our study was distance education at the high-school level in the province of Newfoundland and Labrador, Canada, where approximately 65 percent, or 184 out of a total of 285 schools, are classified as rural. The Centre for Distance Learning and Innovation (CDLI) was created in the year 2000 to provide web-based high-school education to these populations. At the time of our study, 30 courses were offered to high-school students in approximately 100 schools, with 1,500 enrolments and 27.5 e-teachers (see Government of Newfoundland and Labrador, 2006, 2007). Students attend physical schools and supplement their course offerings with distance courses delivered by CDLI. 
E-teachers teach courses from multiple locations across the province, such as offices within schools, within the university, or within other centers, through both synchronous and asynchronous classes (CDLI, 2007). Some of the e-teachers are also involved in course development (Barbour, 2007). Asynchronous instruction was supported by the learning management system WebCT ${ }^{\mathrm{TM}}$. Synchronous classes relied on Elluminate Live ${ }^{\mathrm{TM}}$ (E-Live), which includes features such as voice-based communication, direct messaging, a whiteboard, polling, breakout rooms, application sharing, and a graphing calculator. E-Live supported twoway audio when the study was conducted. Videoconferencing was not used extensively at that time due to bandwidth requirements.

\section{Participants and Data Collection}

Volunteer participants were recruited among teachers and other management and support staff working for the organisation. Recruitment involved obtaining permission from the organisation to contact potential participants, who received information about the study in writing as well as a consent form. All participants who returned signed consent forms were included in the study.

The first phase of data collection took the form of 90-120 minute semi-structured interviews (Patton, 1990). Interviews were primarily conducted using E-Live, the voice-based collaborative tool that CDLI e-teachers use for synchronous classes. The first set of interviews was conducted with 13 e-teachers representing a range of subject areas. In order to gain additional insights into the organization, we also interviewed seven individuals such as managers and support personnel who were part of the teachers' activity system. Questions were grouped into categories and related to teachers' personal histories, teaching approaches, tools, challenges, and constraints.

In the second phase of data collection, 12 of the 13 e-teachers interviewed in the first phase were interviewed once again. This second set of interviews focused more specifically on e-teaching. Participating e-teachers were encouraged to use E-Live to display e-teaching resources. Questions

for this second set of interviews were designed to consider how teachers make use of the tools to engage and interact with students.

\section{Data Analysis}

Interviews were recorded and archived in E-Live and subsequently transcribed. The transcriptions from both sets of interviews were gathered into one file. Instead of using the sentence or paragraph as a reference point for analysis, we broke the interview transcripts into statements "which convey one identifiable idea" (Aviv, 2001, p. 59). Statements were then associated with elements of the activity system. For example, all statements pertaining to the e-teacher, him or herself, were grouped under 'subject'. Statements pertaining to norms or established ways of proceeding were grouped under 'rules.' Likewise statements were grouped under headings of 'community,' 'division of labour,' 'tools,' and 'object.' Like statements were synthesized. Findings are reported under these headings and use, as much as possible, the actual words of the e-teachers. 


\section{Findings}

\section{Subjects}

All e-teachers in the study had a minimum of 11 years of experience teaching in the face-to-face (F2F) classroom before coming to teach in an online classroom. They had not received formal education or training related to teaching online beyond in-service activities offered within CDLI, learning on the job, and sharing between e-teachers.

Recruitment policies of CDLI require that those hired be innovative, experienced, established, risk-taking, inquisitive, open to dialogue, self-aware, aware of others as well as willing to experiment, to collaborate, and to reach out to colleagues. It is expected that they show "due diligence" and "attention to detail and individual needs." In addition, hiring practices favour those who have a cooperative spirit, who put students first, who are "givers and not takers" and who "have succeeded well in the $[\mathrm{F} 2 \mathrm{~F}]$ classroom."

\section{Object}

All e-teachers had attended F2F schools as learners themselves and had participated in teachereducation programs in F2F learning environments where, as one individual noted, you learned that "you were the source" and "students are there to be taught." One e-teacher noted that if he went back to the classroom his F2F teaching would be enhanced by what he learned online in terms of "the techniques of engaging students." One e-teacher described how her teaching had evolved:

I've become more a facilitator. I don't teach [students] anymore... They take control of what they do... I provide the tools... In the first year or two that I taught, I taught like I would in a face-to-face classroom, a lecture, [but] I've adapted my role as a teacher... When I moved to teaching online, I still retained a percentage of the old 'sage on the stage' model of teaching. That is changing.

In terms of the future vision and potential for the activity of the e-teacher in the organisation, one manager referred to his desire for use of the Internet to create "multiple pathways" to knowledge and establish a democratic power structure where "power shifts from the organization, the institution, to the learner." The organisation was moving towards an "activity-centered" approach to online teaching. One individual commented regarding online teaching as follows:

We have got a vision of what good teaching looks like. I think there is more consistency in that image than there is inconsistency.... We are all there trying to work towards what we think good learning is at this point in time. We are going to change like we've always changed. 
Moving to the new online environment meant that "no one had a road map to follow, nobody had firmly established their routine" because "people were in such a new area." The newness created an opportunity to establish new forms of practice, as illustrated by the comment from one manager: "I usually create this expectation, this sense of tension, well in advance; we are on the road towards moving to a more student-centered approach to education.... Here's the roadmap and we expect [e-teachers] to get on it." The lack of spontaneity afforded by the technologicallymediated classroom meant that e-teachers had to become more intentional, deliberate, more organised, better listeners, and more aware of gauging student understanding.

\section{Community}

When e-teachers taught in F2F contexts, they could get to know students personally and outside of the classroom through, for example, participating in extra-curricular activities, such as coaching sports' teams. In most cases, they lived and worked in the same community as their students. This meant that they were also able to have easy contact with them outside of school. Students already knew who their teachers were, where they came from, what kind of person they were to work with on a day-to-day basis, and what they were involved in around the school.

As e-teachers, they were teaching students from a variety of communities within the province. Contact had to be deliberate and planned. The limitations of bandwidth meant that videoconferencing was not always a preferred option for communicating. Given that students might be dispersed across two provinces, two time zones, and up to 100 communities, F2F visits were an exception. Creating community online "requires a conscious effort," unlike in the F2F context, where it can occur naturally because of physical co-presence. Additionally, online students can be "distributed,... one in every community," which means that they come with different learning styles or academic levels, as in F2F classrooms, but also with different school cultures and community differences regarding the value attached to education.

\section{Rules}

Teaching in the F2F environment could be informal, spontaneous, and "on the fly." As one person noted, "in a face-to-face classroom, in the two minutes it takes for kids to find their seats I can assess the homework." Teachers could also make up the time next day if they hadn't covered all the content in one class. They could easily just physically move students to one part of the room for small group discussion.

In the online environment, scheduling difficulties and glitches were common because not all schools had adapted their schedules to those of the online courses. In some cases, e-teachers were required to juggle class schedules that overlap in Newfoundland versus Labrador's time zone. Teachers might sometimes "revert back to... a lecture-type based hour" in order to cover curriculum in the six out of 10 periods of synchronous classes.

In the F2F classroom, instruction was confined to a typical 9:00 to 3:00 day when teachers and students were physically co-present. In the online classroom, access to online communication 
tools meant that interaction with students was no longer confined to the school day but could be potentially "24/7." Teaching was no longer defined by co-presence because students were expected to work independently for approximately $40 \%$ of the time. Monitoring students in the four out of 10 periods of asynchronous classes might be difficult, especially if students did not have the skills to work independently.

\section{Tools}

In the F2F classroom, students could get to know teachers visually when they walked into the classroom because of the information conveyed by physical presence. It was possible to monitor students' work and discern whether students were understanding or paying attention simply by walking down the aisles, by "the look on their faces" or by "that glazed-over look." As one individual noted, in the F2F classroom, "you can pretty easily read the body language of a student who is unfocused and quickly get them back on track." Communication was made easier by reliance on "visual cues in posture and facial expression." In the online classroom, the lack of physical co-presence as a mediating tool made it more difficult to spontaneously interact with students because, as one individual commented, “you don't get to see the reactions, you don't get to see the frowns or smiles, you don't get to take visual cues from your environment... you are not getting the body language."

E-Live can be used for a "lecture-mode" style of teaching to the point that one e-teacher described having to "monitor" himself when using it. According to one manager, E-Live "does not really celebrate that democratic function [of] the internet..., the luxury of exploration." Although connectivity had improved, there were still technological difficulties related to bandwidth limitations. In addition, it might be difficult to "draw students out" during synchronous lessons because they preferred text-based messaging as opposed to voice communication, or they might be shy, "hibernate," or "want to be invisible."

E-teachers could overcome the disadvantages in the technology and counter its limitations, as one individual highlighted: "The tools are what they are. I don't see them as being constraining. I think we just have to make best use of them." Some e-teachers referred to taking advantage of the private communication feature of instant messaging for one-on-one support outside of class or for feedback in synchronous classes, as one individual explained:

We're not getting feedback, the facial expressions; you're not reading the signals from the students that indicate lack of comprehension or boredom. But at the same time we can get instant feedback, so you have to use the technology to counter that limitation.

Some voices in the system argued that effective use of the tools could allow e-teachers to know students better online than in the F2F classroom: "I can't recall having some of the contact with students in the regular classroom that I have now that I'm online." 


\section{Division of Labour}

Historically, teachers could often perceive students' problems by talking to them in the corridors during "off-chance" casual conversations or by going down the hall and meeting with the principal. They could know from the principal about an issue with a student and the principal would address the issue with the teachers. Because all CDLI students are enrolled in physical schools, their e-teachers must deal with different schools for administration and invigilation of examinations, technical support, and reporting periods. Students might be absent from class yet the e-teacher might not know in advance whether the reason is sickness, a school event, holiday, or a closure due to weather. E-teachers might "find out after that fact that... a student has gone through a difficult time."

The "immediacy" of communication and "reduction of bureaucracy" in the organization were "unlike the face-to-face world of school districts." As one e-teacher explained, he "felt much more isolation" when he taught F2F. Unlike in the F2F classroom, online "there are no walls or doors, and... as a result, sharing is something that happens naturally." One individual described the organization as "very supportive environment and very helpful." Specific examples of support include attention to ergonomic needs, additional preparation time beyond what would be provided to other teachers within the province in F2F classrooms, mentoring, and professional development. The system's division of labour also creates opportunities for e-teachers' input to be considered, as one manager described:

It's easier with a small group of people ... [whereas] in a regular face-to-face environment, to actually be able to do that, you would have to go to the school and the school board and so on and so forth... It's easier for an e-teacher... to effect change with us.

In Figure 2 below, we provide a graphic summary of the elements of the activity system of the eteachers in our study. 


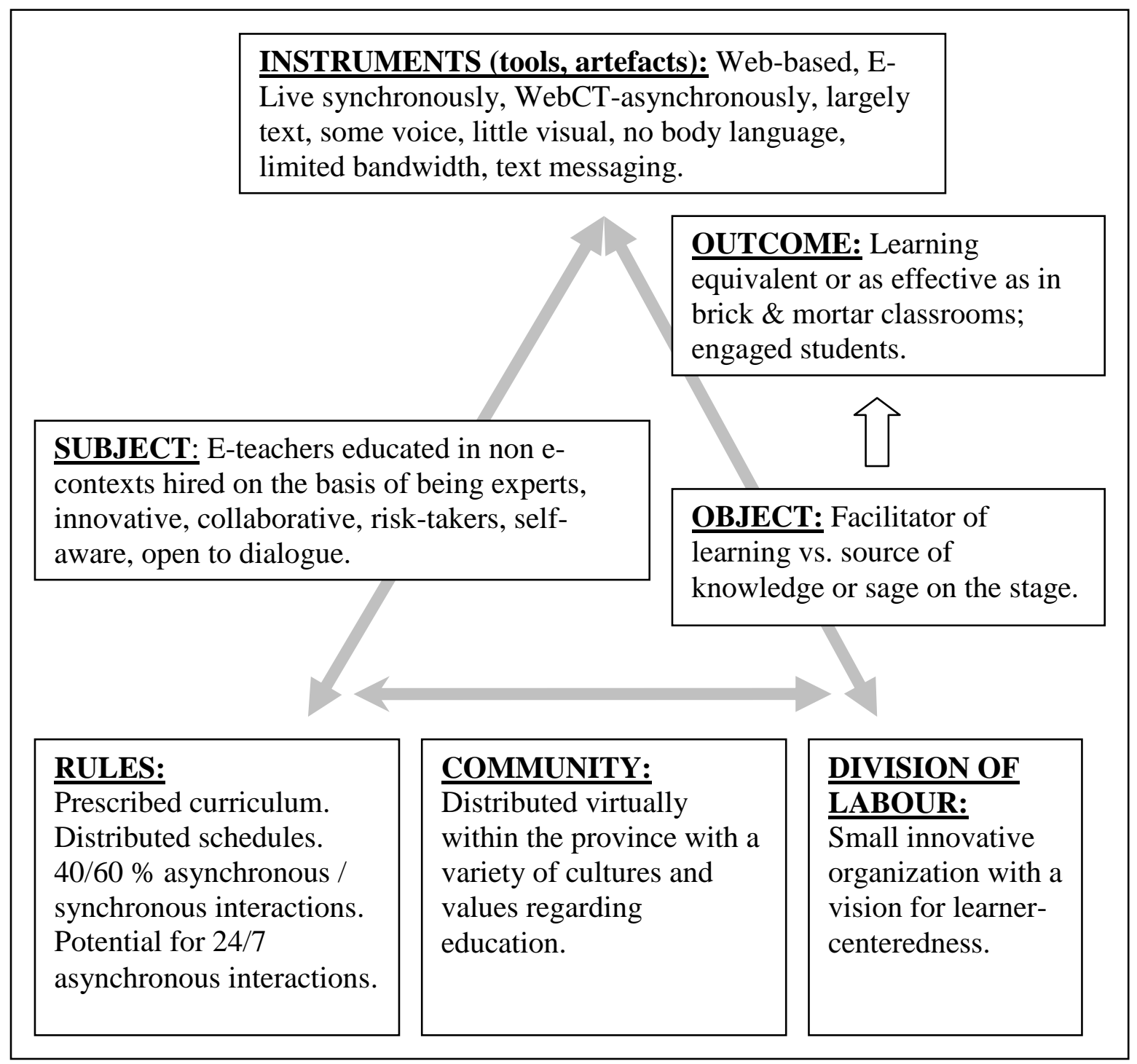

Figure 2. Activity system of e-teachers in study.

\section{Discussion}

The e-teachers were practicing in the online classroom but their reference points for teaching were, for the most part, based on brick and mortar F2F classrooms. Their history of teaching, their own experiences as learners, as well as their pre-service education program have not prepared them for the changes brought about by web-based learning. They are in a position where they must, as Engeström (2001) explains, "learn new forms of activity which are not yet there" (p. 138).

As Virkkunen and Kuutti (2000) explain, the object of activity is reinterpreted and "reconstructed in a wider perspective" (p. 303) when components of the activity system change substantially. Many aspects of the activity system of the e-teachers in our study had undergone substantial change. The community was distributed rather than centralized. In terms of rules, teaching and 
learning had become almost as much an asynchronous as a synchronous activity. In relation to the division of labour, the teacher was part of not a school but an innovative organization dedicated to online learning. The symbolic tools of body language were replaced in this system by text and some voice interactions.

Community as place, familiar faces, spontaneous interactions, and automatic social presence was not what the online classroom offered. Community in the online classroom was something in the process of being defined and that was slowly emerging as a new form of activity. Rules dictating that a student be in class with a teacher during the school day were replaced with periods of independent work. Working in a technologically mediated environment called for new norms, new strategies, and new ways of behaving. All interactions from checking homework to communicating required more deliberate, intentional, and planned approaches.

In terms of the division of labour, there was a lack of spontaneity in the online classroom, which meant that e-teachers could not interact informally with students nor could they walk down the hall to make enquiries at the principal's office about a particular student. Identifying problems in students was a part of the teacher's practice but online it could not be done in the same way as the teachers had done it historically.

It was the change in tools that caused the most disruption in the e-teacher's activity system. The behaviours and repertoire of strategies teachers might have relied on as practitioners in F2F contexts did not always make sense when interaction and communication were mediated by a different set of tools. The traditional reliance on symbolic mediating tools of body language and visual cues was no longer possible in their online classrooms.

The contradictions between, on one hand, how teachers had historically learned to practice and, on the other, the fact that the online classroom didn't support those ways of practicing required the e-teachers to adopt new approaches, new beliefs, and new ways of thinking about teaching. Some voices were nostalgic about the loss of the F2F classroom while others were focused on adapting to the new classroom and on seeing its possibilities. Some voices had resolved the contradictions between how they had traditionally conceptualized and practiced teaching and how it needed to be practiced and conceptualized for the online classroom. Moving towards more independent, facilitative, and engaged forms of learning represented a means of resolving many of the contradictions faced in the activity system.

Engeström (2001) refers to an expansive learning trigger as "conflictual questioning of the existing standard practice" (p. 151). The existing standard practice in the case of the e-teachers would be the teacher-centred classroom, characterized by what one e-teacher described as the "sage on the stage" model of teaching, with teacher as "source." The metaphors of sage on the stage and source ceased to have a reference point because in the distributed online classroom there was no longer a stage or a single, central source. The object of the activity of the e-teachers had become widened to involve more independent and engaged forms of learning. 


\section{Conclusions, Implications, and Limitations}

The metaphors of technology as a catalyst, an agent of change, or a Trojan horse focus attention on the fact that technology brings about changes in teaching and learning. In our study, the use of CHAT provides a comprehensive and complex illustration of how teachers were required to learn new forms of activity in order to effectively teach in an online classroom. The new forms of activity required that the e-teachers question many of the behaviours practiced historically and that they adopt more learner-centered forms of practice.

As our literature review illustrated, others have used a CHAT framework to understand expansive learning. Unlike those studies, in our context the introduction of web-based learning necessitated substantial changes in all aspects of the activity system. The changes of the object described in the studies reported on in our review focused typically on one aspect of teaching and learning, for example on teacher team work (Kärkkäinen, 1999), conceptualization of students (Engeström et al., 2002a, 2202b), developing practices to help students with collaborative writing (Carr et al., 2007), professional development of both novices and experts (Tsui \& Law, 2007), and collaborative forms of learning (Fåhræus, 2004).

Our study was also different from other studies of K-12 distance learning (e.g., Rice, Dawley, Gasell, \& Florez, 2008) in that adopting a CHAT perspective allowed us to move beyond identifying needs or difficulties in order to focus on changes in teachers' practices. The context of our study was an ideal vantage point for understanding how teachers might change their practice to move towards more learner-centred, facilitative forms of teaching. These forms are clearly identified in the literature, for example in learner-centeredness frameworks (e.g., APA Work Group of the Board of Educational Affairs, 1997) and the educational literature on constructivism (e.g., Duffy \& Cunningham, 1996; Savery \& Duffy, 1996, Wells \& Chang-Wells, 1992), as being ideals to which teachers and schools should aim.

In terms of implications, the e-teachers in our study may need more opportunities to reconcile the past and present forms of their practice. This reconciliation might be accomplished through professional development experiences that focus reflection on the differences between what is possible or not possible in an online versus a F2F classroom. They may also need opportunities to envisage and realise the potential of the tools to help them meet their goals and to support learnercentered approaches. Ongoing dialogue and open and frequent communication within the organisation may help communicate the road map more explicitly. In general, the findings suggest that the pre-service education programs from which the e-teachers graduated may not be preparing them for online teaching.

Our study was limited to only one context of high-school distance education, in one province of Canada, with one group of e-teachers. Future studies of distance education contexts might take the perspective of students or parents. We did not use data sources besides interviews, such as observations or document analysis. It is possible that use of other sources may have provided different insights from those reported on in this paper. 


\section{Acknowledgements}

This study was made possible by a grant from the Social Sciences and Humanities Research Council of Canada (SSHRC) and by in-kind support from the Centre for Distance Learning and Innovation, Government of Newfoundland and Labrador, Canada. Thank you to research assistants Bruce Nolan and Janine Murphy and to the two blind reviewers of an earlier version of this paper who added invaluable insights and modifications. 


\section{References}

APA Work Group of the Board of Educational Affairs (1997). Learner-centered psychological principles: A framework for school reform and redesign. Washington, DC: American Psychological Association. Retrieved February 4, 2009, from http://www.apa.org/ed/cpse/LCPP.pdf

Aviv, R. (2001). Educational performance of ALN via content analysis. Journal of Asynchronous Learning Networks, 4(2), 53-72. Retrieved August 13, 2008, from http://www.aln.org/publications/jaln/v4n2/pdf/v4n2_aviv.pdf

Barbour, M. K. (2007). Principles of effective web-based content for secondary school students: Teacher and developer perceptions. The Journal of Distance Education, 21(3), 93-114.

Bower, J. L., \& Christensen, C. M. (1995). Disruptive technologies: Catching the wave. Harvard Business Review, 73(1), 43-53.

Carr, T., Morrison, A., Cox, G., \& Deacon, A. (2007). Weathering wikis: Net-based learning meets political science in a South African university. Computers and Composition, 24(3), 266-284.

Centre for Distance Learning and Innovation (CDLI) (2007). CDLI, The Centre for Distance Learning and Innovation. Retrieved September 21, 2007, from http://www.cdli.ca/index.php

Christensen, C. M. (1997). The innovator's dilemma. Cambridge, MA: Harvard Business School Press.

Christensen, C. M., \& Armstrong, E. G. (1998). Disruptive technologies: A credible threat to leading programs in continuing medical education? Journal of Continuing Education in the Health Professions, 18(2), 69-80.

Cradler, J., \& Bridgforth, E. (1996). Technology as a catalyst for education reform. San Francisco, CA: Far West Laboratory for the California Department of Education. Retrieved September 25, 2007, from http://www.wested.org/techpolicy/techreform.html/

Duffy, T., \& Cunningham, D. (1996). Constructivism: Implications for the design and delivery of instruction. In D. H. Jonassen, (Ed.), Handbook of research for educational communications and technology (pp. 170-198). New York: Simon and Schuster.

Engeström, Y. (1987). Learning by expanding: An activity-theoretical approach to developmental research. Helsinki: Orienta-Konsultit. Retrieved July 19, 2007, from http://communication.ucsd.edu/MCA/Paper/Engestrom/expanding/toc.htm 
Engeström, Y. (1991). Developmental work research: Reconstructing expertise through expansive learning. In M. I. Nurminen \& G. R. S. Weir (Eds.), Human jobs and computer interfaces (p. 265-290). Amsterdam: Elsevier Science Publishers.

Engeström, Y. (1993). Developmental studies of work as a testbench of activity theory: The case of primary care medical practice. In S. Chaiklin \& J. Lave (Eds.), Understanding practice: Perspectives on activity and context (pp. 64-103).New York, NY: Cambridge University Press.

Engeström, Y. (1999). Activity theory and individual and social transformation. In Y. Engeström, R. Miettinen, \& R. Punamaki (Eds.), Perspectives on activity theory (pp. 19-38). New York: Cambridge University Press.

Engeström, Y. (2001). Expansive learning at work: Toward an activity theoretical reconceptualization. Journal of Education and Work, 14(1), 133-156.

Engeström, Y., Engeström, R., \& Suntio, A. (2002a). Can a school community learn to master its own future? An activity theoretical study of expansive learning among middle school teachers. In G. Wells \& G. Claxton (Eds.), Learning for life in the 21st century: Sociocultural perspectives on the future of education (pp. 211-224). Cambridge, MA: Blackwell.

Engeström, Y., Engeström, R., \& Suntio, A. (2002b). From paralyzing myths to expansive action: Building computer-supported knowledge into the curriculum from below. In G. Stahl (Ed.), Computer support for collaborative learning: Foundations for a CSCL community (pp. 318-324). Hillsdale, NJ: Lawrence Erlbaum.

Fåhræus, E. R. (2004). Distance education students moving towards collaborative learning: A field study of Australian distance education students and systems. Educational Technology \& Society, 7(2), 129-140.

Furneaux, C. (2004, May). How does information technology impact the methods, potential and purpose of education? Paper presented at the Effective Teaching and Learning Conference, Griffith University, Brisbane. Retrieved July 20, 2008, from http://eprints.qut.edu.au/archive/00000794/01/Craig_Furneaux_-

_Information_Technology.pdf

Guile, D. (1998). Information and communication technology and education. London: Institute of Education, University of London.

Government of Newfoundland and Labrador (2006). Education statistics: Elementarysecondary, 2005-2006. Retrieved November 22, 2006, from http://www.ed.gov.nl.ca/edu/pub/stats05 06/stats05 06.htm 
Government of Newfoundland and Labrador (2007). Department of Education annual report 2005-2006. Retrieved May 22, 2007, from http://www.ed.gov.nl.ca/edu/pub/ann_rep/doe_ar05-06.pdf

Kärkkäinen, M. (1999). Teams as breakers of traditional work practices: A longitudinal study of planning and implementing curriculum units in elementary school teacher teams. Doctoral dissertation, University of Helsinki, Finland. Retrieved January 11, 2007, from http://ethesis.helsinki.fi/julkaisut/kas/kasva/vk/karkkainen/teamsasb.pdf

Kiesler, S., \& Sproull, L. (1987). Computing and change on campus. New York: Cambridge University Press.

Kuutti, K. (1996). Activity theory as a potential framework for human-computer interaction research. In B. A. Nardi (Ed.), Context and consciousness: Activity theory and humancomputer interaction (pp. 17-44). Cambridge, MA: MIT Press.

McClintock, R. (1992). Power and pedagogy: Transforming education through information $\begin{array}{lllll}\text { technology. } & \text { Retrieved } & \text { February } & \text { 2009, from }\end{array}$ http://www.ilt.columbia.edu/publications/mcclintock.html

Patton, M. (1990). Qualitative evaluation and research methods (2nd ed.). Thousand Oaks, CA: Sage.

Pea, R. D. (1985). Beyond amplification: Using the computer to reorganize mental functioning. Educational Psychologist, 20(4), 167-182.

Rice, K., Dawley, L., Gasell, C., \& Florez, C. (2008). Going virtual! Identifying the unique needs and challenges of K-12 online teachers. Washington, D.C.: North American Council for Online Learning. Retrieved February 20, 2009, from http://edtech.boisestate.edu/goingvirtual/goingvirtual2.pdf

Russell, D. (2004). Paradigm shift: A case study of innovation in an educational setting. International Journal of Instructional Technology and Distance Learning, 1(12). Retrieved January 29, 2009, from http://www.itdl.org/Journal/Dec_04/article03.htm

Russell, D. L., \& Schneiderheinze, A. (2005). Understanding innovation in education using activity theory. Educational Technology \& Society, 8(1), 38-53.

Russell, D. L., \& Yañez, A. (2003). 'Big picture people rarely become historians': Genre systems and the contradictions of general education. In C. Bazerman \& D. R. Russell (Eds.), Writing selves/writing society: Research from activity perspectives (pp. 331-362). Fort Collins, CO: WAC Clearinghouse. Retrieved January 30, 2009, from http://wac.colostate.edu/books/selves societies/selves societies.pdf 
Salmon, G. (1992). Effects with and of computers and the study of computer-based learning environments. In E. De Corte, M. Linn, H. Mandl, \& L. Verschaffel (Eds.), Computerbased learning environments and problem-solving (pp. 247-262). Berlin: SpringerVerlag.

Savery, J., \& Duffy, T. (1996). Problem based learning: An instructional model and its constructivist framework. In B. Wilson (Ed.), Constructivist learning environments: Case studies in instructional design (pp. 135-148). Englewood Cliffs, NJ: Educational Technology Publications.

Tsui, A. B. M., \& Law, D.Y. K. (2007). Learning as boundary-crossing in school university partnership. Teaching and Teacher Education, 23(8), 1289-1301.

Virkkunen, J., \& Kuutti, K. (2000). Understanding organizational learning by focusing on "activity systems." Accounting, Management and Information Technologies, 10, 291319.

Wells, G., \& Chang-Wells, G. L. (1992). Constructing knowledge together: Classrooms as centers of inquiry and literacy. Portsmouth, $\mathrm{NH}$ : Heinemann.

Vygotsky, L. (1978). Mind in society: The development of higher psychological processes. Cambridge, MA: Harvard University Press.

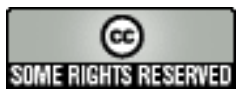


June - 2009

\title{
Transparency in Cooperative Online Education
}

\author{
Christian Dalsgaard \\ Aarhus University, Denmark \\ Morten Flate Paulsen \\ The Norwegian School of Information Technology, Norway
}

\begin{abstract}
The purpose of this article is to discuss the following question: What is the potential of social networking within cooperative online education? Social networking does not necessarily involve communication, dialogue, or collaboration. Instead, the authors argue that transparency is a unique feature of social networking services. Transparency gives students insight into each other's actions. Cooperative learning seeks to develop virtual learning environments that allow students to have optimal individual freedom within online learning communities. This article demonstrates how cooperative learning can be supported by transparency. To illustrate this with current examples, the article presents NKI Distance Education's surveys and experiences with cooperative learning. The article discusses by which means social networking and transparency may be utilized within cooperative online education. In conclusion, the article argues that the pedagogical potential of social networking lies within transparency and the ability to create awareness among students.
\end{abstract}

Keywords: Online education; social networking; transparency; e-learning; cooperative learning; learning community

\section{Introduction}

The purpose of this article is to discuss the following question: What is the pedagogical potential of social networking to support cooperative online learning? Often, the potential of social software and Web 2.0 is related to collaborative activities and user-generated content, not least in the context of online education. In other words, "social" is often described as communication, construction, and collaboration. This article will focus on other qualities of social software and Web 2.0 that are characteristic of social networking and are found in services such as weblogs, social networking sites, micro-blogging, and social presence tools. The article will argue that a central characteristic of social networking is the potential to facilitate transparency between students. The basic assumption is that transparency is important to cooperative online education. 
People can cooperate only if they know about each other and have access to some common information and services.

We understand transparency as students' and teachers' insight into each other's activities and resources. Transparency means that you and your doings are visible to fellow students and teachers within a learning environment. For instance, transparency could mean that students and teachers are made aware of and have access to each other's interests, thoughts, concerns, ideas, writings, references, and assignments. The purpose of transparency is to enable students and teachers to see and follow the work of fellow students and teachers within a learning environment and in that sense to make participants available to each other as resources for their learning activities.

Transparency is not a given, especially within online education. Students might work at a distance and individually, and, thus, they are not necessarily aware of the activities of other students. In their individual work, however, students write notes, search for literature, find relevant websites, write assignments, etc. This information and these products are relevant to other students. A central aspect of cooperative learning is to enable students to make use of each other while at the same time maintaining individual freedom. This article illustrates the theory of cooperative freedom with current examples from NKI Distance Education in Norway. With an enrollment of about 14,000 students, the institution is one of the European megaproviders of online education (Paulsen, 2007) and is Scandinavia's largest provider of distance education. About 75 percent of the students are enrolled in NKI's more than 450 online courses, and to accommodate this volume NKI operates a self-developed learning management system (LMS) called SESAM. The system was developed to support NKI's model for large-scale distance education, which features individual student progress as it is described in the articles NKI Fjernundervisning: Two Decades of Online Sustainability (Paulsen \& Rekkedal, as cited in Paulsen, 2003) and Cooperative Online Education (Paulsen, 2008). The authors of the current article refer to three internal evaluation reports regarding individual progress planning, follow-up, and cooperation. The first survey (Paulsen, 2005) was answered by 364 students, the second (Paulsen, 2006) by 542 students, and the third (Paulsen, 2008) by 763 students.

\section{Social Networking and Cooperative Learning}

Social networking technologies have actualized the question concerning which social infrastructures support learning. There is an ongoing debate about the potential of different forms of social interaction, i.e., groups, communities, collectives, connections, and networks (Dron \& Anderson, 2007; Downes, 2007; Wenger et al., 2005; Anderson, 2008; Ryberg \& Larsen, 2008; Jones, 2004; Jones et al., 2006; Siemens, 2005). The debate has its origin in the concept of network, which challenges a number of other forms of social relations. As Dron and Anderson (2007) state, research and practice in the area of e-learning has focused primarily on groups. They describe groups as "individuals who see themselves as part of that group." A group, such as a study group, is a defined collection of individuals who in some way are engaged in joint work. 
Further, Jones et al. (2006) criticize Wenger's concept of communities of practice and the tradition of computer supported collaborative learning (CSCL). Jones et al. argue that the two traditions are not able to describe the kinds of relations that exist within learning environments. The traditions of communities of practice and CSCL have focused on participation, collaboration, and negotiation of meaning (Wenger 1998), or, in other words, on tight-knit structures. The use of technology in support of groups and communities of practice has often focused on collaboration, especially within the field of CSCL (Jones et al., 2006). This highlights the emphasis within elearning and also more broadly within technology-supported learning on supporting or developing tight-knit social structures.

The concept of network has challenged the concept of a tight-knit social construct. Networks are loosely organized structures (Dron \& Anderson 2007) in which people do not necessarily collaborate or communicate directly. However, the question is what role networks play in relation to learning. A conclusion of this debate is that there exists a form of social interaction - social networking - that learning theories have difficulty explaining. More questions arise: What kind of relations support learning, and, specifically, how do networks support learning?

Jones (2004) uses the concept of networked learning and draws a direct line between networking and learning. He stresses the importance of facilitating "connections between learners, learners and tutors, and between learners and the resources they make use of in their learning" (Jones et al. 2006, p. 90). Jones (2004) writes, "Networked learning doesn't privilege any particular types of relationships between people or between people and resources." The problem with this definition is that it does not establish which kinds of relations should be supported. Studies within networked learning have, according to Jones (2004), focused primarily on strong links, and he prefers to draw attention to the so-called weak ties. This is an interesting focus because it is the support of weak ties that makes social networking unique. Thus, we will focus on what could be termed weak ties. However, as Ryberg and Larsen (2008) argue, it is important to clarify what defines weak ties and how they differ from strong ties.

Social networking relates to concepts within social capital theory. Central to social capital theory is the point that human relations are an important and valuable resource (Field, 2003). Social capital theory describes characteristics of different types of social structures and relations, which makes it a relevant theory in an elaborated discussion of social networking and transparency (Coleman, 1990). However, our argument for the potential of transparency within social networks is based on learning theory, i.e., the theory of cooperative freedom and socio-cultural theory. Although relevant, we believe a coupling of these different theoretical approaches is outside the scope of this article. For our purpose, it is necessary to clarify how different kinds of social relations support learning. Thus, it is necessary to make a connection between learning and types of social relations.

The theory of cooperative freedom can offer such a connection. The first version of the theory was published in the monograph From Bulletin Boards to Electronic Universities (Paulsen, 1992). It was updated in the book Online Education and Learning Management Systems (Paulsen, 2003), and further versions with more examples are available in English (Paulsen, 2006 and 
2008), Portuguese (2007), and Norwegian (Paulsen, 2007). The theory is based on three theoretical perspectives on distance education, described by Keegan (1996, p. 56). The three perspectives are autonomy and independence (e.g., Moore, 1988), industrialization (e.g., Peters, 1988), and interaction and communication (e.g., Holmberg, 1988).

Learning theories can be individual, collaborative, or cooperative, and online education technology can support the theories. In a white paper from Epic Group p.l.c. on personalization and e-learning (Clark, 2004, p. 26), the author concludes that technology may support both individual learning and access to social networks. In the article Collaborative versus Cooperative Learning, Panitz (2003) points out that there is a certain amount of overlap or inter-concept usage between cooperative and collaborative learning and that it is an elusive goal to find a distinction between their definitions. There is considerable ambiguity about the meaning of collaborative learning. The two terms (cooperative learning and collaborative learning) are, therefore, typically used as interchangeable and synonymous (Johnson et al., 2004, p. 788). Our distinction between the two concepts is in line with the use of the terms within the fields of computer supported collaborative learning (CSCL) and computer supported cooperative work (CSCW) (Roschelle \& Teasley, 1995; Dillenbourg et al., 1996). Roschelle and Teasley (1995) offer the following insight:

We make a distinction between 'collaborative' versus 'cooperative' problem solving. Cooperative work is accomplished by the division of labour among participants, as an activity where each person is responsible for a portion of the problem solving. We focus on collaboration as the mutual engagement of participants in a coordinated effort to solve the problem together. (Roschelle \& Teasley, 1995, p. 70)

In the theory of cooperative freedom, the three terms are clearly distinguished and related to the distinction above. They are described as follows:

Individual learning provides superior individual flexibility but very limited affinity to a learning community. It has a strong position in online education delivered by institutions with a tradition in distance education. Individual learning environments can be more or less rigid or flexible, for example, with regard to time, place, and pace.

Collaborative learning requires participation in a learning community but limits individual flexibility. One may say that collaborative learning requires that students sink or swim together. Collaborative learning is common in online education offered by traditional face-to-face institutions.

Cooperative learning focuses on opportunities to encourage both individual flexibility and affinity to a learning community. Cooperative learning seeks to foster some benefits from individual freedom and other benefits from cooperation 
in online learning communities. It thrives in virtual learning environments that emphasize individual freedom within online learning communities.

Another way to distinguish between the three terms is to claim that individual learning is conducted alone, collaborative learning depends on groups, and cooperative learning takes place in networks. One may also add that the ties between people are much tighter in groups than in networks. The differences between the three learning theories are illustrated in Figure 1.

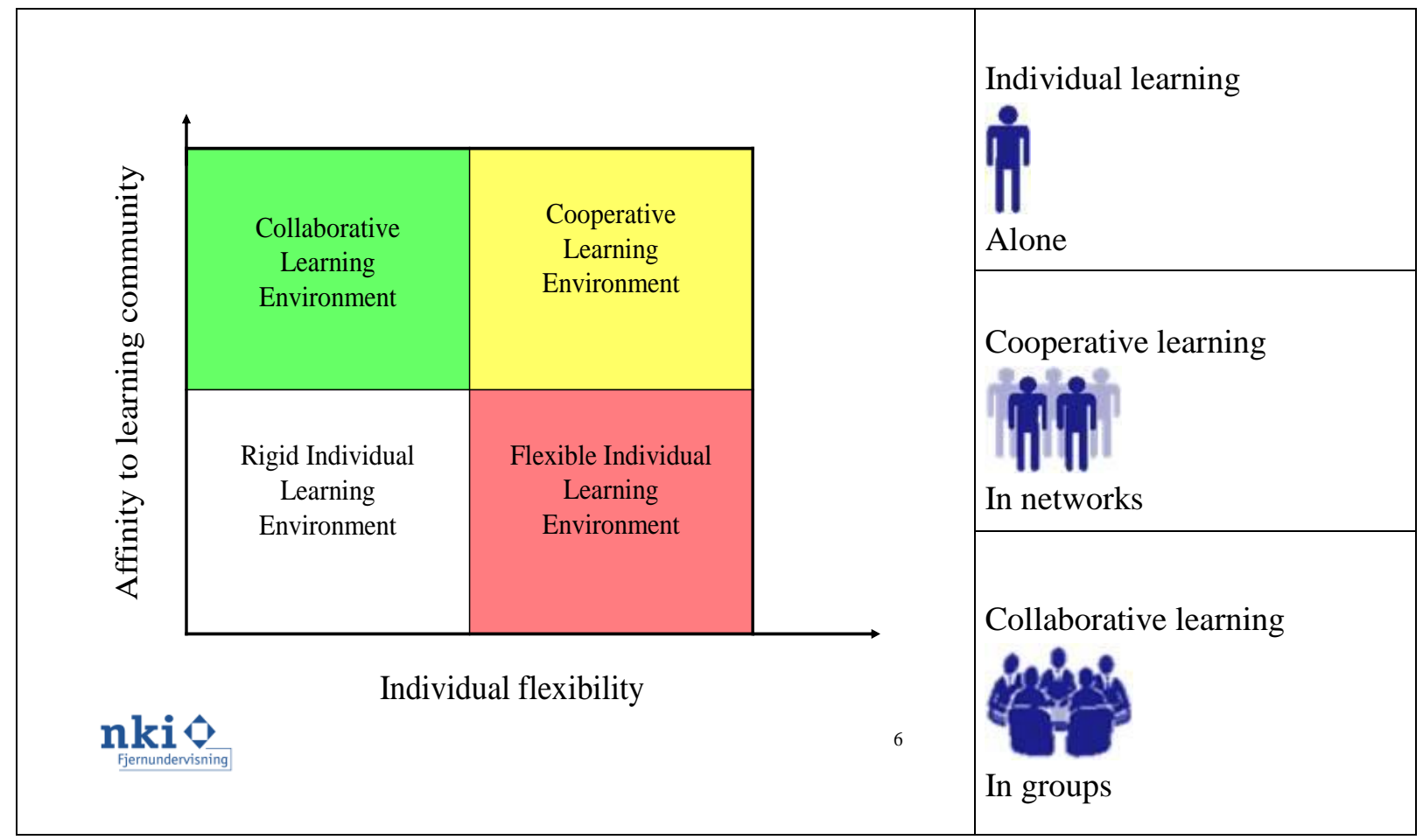

Figure 1. Individual, cooperative, and collaborative learning environments.

Well-designed virtual cooperative learning environments build on a number of means that support individual flexibility and other means that facilitate affinity to a learning community. The theory of cooperative freedom is based on the following three pillars:

1. voluntary but attractive participation,

2. means promoting individual flexibility, and

3. means promoting affinity to learning community.

The theory of cooperative freedom is supported by a socio-cultural perspective, which emphasizes problem-oriented and self-governed learning activities (Dalsgaard, 2006). Learning is first of all considered an active process. Learning takes place through problem-oriented activities, in which students are directed at solving a problem or achieving a goal. In this respect, the sociocultural approach emphasizes the importance of the activities of the individual. However, the approach also stresses that individual activities are always situated in a collective practice 
(Vygotsky, 1978; Brown, Collins, \& Duguid, 1989; Bang \& Dalsgaard, 2006; Leont'ev, 1978; Engeström, 1987).

Consequently, social relations are central to learning in a socio-cultural approach. However, collective activity does not take place only within collaborative and tight-knit groups or communities. Relations between activities may not promote awareness of the activities of other people. Thus, an important objective within a learning environment is to support consciousness and awareness of the activities of others. This is a main objective of cooperative learning.

From the perspective of the theory of cooperative freedom and the socio-cultural approach, an individual's awareness of the activities of other individuals becomes a focal point of attention within learning. The objective is not community-building or collaboration but increased awareness. Supporting awareness within a cooperative learning environment will be the focus of the discussion of the pedagogical potential of social networks.

\section{Transparency and Cooperative Learning}

\section{Transparency as a Special Kind of Communication}

As stated above, social networking does not necessarily involve dialogue or collaboration. Instead, we will argue that transparency is a dominant feature of social networking. An interesting aspect of social networking is that the starting point is the individual or personal. This is in opposition to discussion forums in which communication always takes place in a shared forum. In a social networking site each individual has a personal page and profile, which the individual develops and modifies. Other people can view these pages and follow activities of their "friends." In other words, actions within a social networking site are transparent. This creates a kind of indirect or passive form of communication and sharing. In opposition to discussion forums, people do not necessarily send messages or documents in order to communicate or share. Instead, they update their profile, add pictures or texts, etc. to their own page. The starting point for this kind of communication is students' own work and their personal pages. The personal page is then shared in a social network. The personal page provides opportunities for personalization; the individual can choose the look and content of the page. An important function of the personal page is that it serves as the individual's personal representation on the web. This makes social networking sites radically different from discussion groups and other community-based tools. In a discussion forum you are represented by your posts only, whereas you are always "present" in a social network through your personal page.

The personal page also provides a basis for social networking. In discussion forums, on the other hand, the shared forum itself is the starting point. The social space for interaction is developed beforehand, whereas the social network for interaction develops on the basis of the personal page. Socialization begins when a personal page is connected to other personal pages of other individuals. Each individual builds a network of personal relations. In that respect networks are also personal. A unique form of communication in social networks takes place through subscriptions and notifications. This kind of communication means that people within a network subscribe to personal pages (such as weblogs) and are notified whenever a page is modified or 
whenever a person performs any kind of action within the network. Consequently, a form of indirect communication emerges, indirect in the sense that it is not intentional.

Based on this we argue that communication within social networks, to a large extent, is a matter of awareness and transparency. Our objective is not to reject relations that exist within groups or communities. Instead, we wish to highlight the pedagogical potential of social networking in relation to transparency. Transparency is particularly relevant within cooperative learning, where students are working on related projects or assignments but are not collaborating. Within cooperative online learning a central challenge is to enable students to follow the work of their colleagues. If students are unaware of the activities of fellow students, they might not make use of each other. This problem is reinforced within online education, where students do not meet faceto-face (Paulsen, 2008).

\section{Cooperative Learning Requires Transparency}

Cooperative learning and a socio-cultural approach provide a strong motive for support of transparency between students. A cornerstone in cooperative online education is that cooperation should be voluntary, but attractive and appealing. It should be offered as an appealing opportunity to those who seek cooperation. The challenge is therefore primarily to help those who are interested in cooperation to engage in a network of suitable learning partners. In addition it is necessary to stimulate the rest of the students to contribute to the learning community. This means that students should not be encouraged or tempted to withdraw from the learning community. Total seclusion is undesirable. Students should be stimulated to be visible as potential partners and resources for others. Transparent information could be a huge cooperative resource. The dilemma is that students who do not contribute to the community cannot be perceived as learning resources for others. The potential of the learning community will then be diluted. So one may argue that a successful cooperative learning community may depend on a mutual understanding that the members have a commitment to serve as a resource for the learning community.

NKI Distance Education has developed the following philosophy on cooperative online learning: NKI Distance Education facilitates individual freedom within a learning community in which online students serve as mutual resources without being dependent on each other.

Version 6 of SESAM, NKI's learning management system, was developed in 2007 when there was considerable focus on Web 2.0 services. Therefore, it was based on a systems development philosophy stating that the services should be personal, interactive, dynamic, and transparent. Further, the services should stimulate students and teachers to produce, share, and refine content they will all benefit from.

Transparency is important for cooperative online education. People can only cooperate if they know about each other and have access to some common information and services. Cooperation will benefit when general and personal information related to the learning and the learners is available directly or indirectly to the learning community. This transparent information may 
include personal information about the users and statistics related to the users' deployment of the online tools. It may further include work students and teachers provide in online notebooks, blogs, and discussion forums as well as results from quizzes, surveys, and assignments.

Transparency implies that users to a certain extent can see and be seen, but it is important to find a suitable transparency level. Transparency is also an important driver for improved quality. It has the following three positive effects on quality:

\section{Preventive quality improvement}

We are prone to provide better quality when we know that others have access to the information and contributions we provide.

\section{Constructive quality improvement}

We may learn from others when we have access to their data and contributions.

\section{Reactive quality improvement}

We may receive feedback from others when they have access to our data and contributions.

Transparency may reduce the number of low quality contributions and may make high quality work more accessible as paragons for others. In transparent online learning environments, poor contributions from teachers and course designers cannot be hidden easily behind closed doors. It is important to realize that transparency must be handled carefully with regard to privacy issues. The users must be confident that their privacy is assured. They should be able to choose their preferred privacy level and understand how this choice controls how much of their personal data and contributions will be available to others. The challenge of finding the correct transparency level is illustrated in Figure 2.

\section{Transparency barometer}

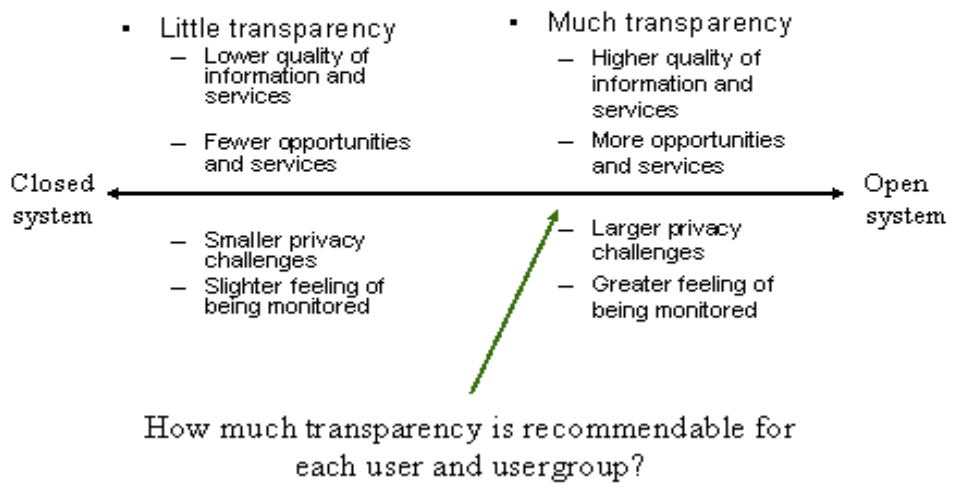

Figure 2. Transparency and privacy. 
A few examples of information that may be more or less transparent in virtual learning environments are presented in Table 1. It is an interesting exercise to discuss the consequences of making each of the items in the matrix transparent to various user groups.

Table 1

Transparency Matrix for Discussion of Transparency Levels in Virtual Learning Environments

$\begin{array}{lllll}\text { Some information that may be transparent } & \text { Self? } & \text { Teachers? } & \begin{array}{l}\text { Students } \\ \text { in class? }\end{array} & \begin{array}{l}\text { Students } \\ \text { in other classes? }\end{array} \\ \text { The teachers average response times } & \text { Yes } & \text { Yes } & \text { No } & \text { No } \\ \text { Information about students' progress plans } & \text { Yes } & \text { Yes } & \text { Yes } & \text { No } \\ \text { The last time teacher logged on } & \text { Yes } & \text { Yes } & \text { Yes } & \text { No } \\ \text { Students grades } & \text { Yes } & \text { No } & \text { No } & \text { No } \\ \text { Student assessment of teacher performance } & \text { Yes } & \text { No } & \text { No } & \text { No } \\ \text { Teachers' feedback on student assignments } & \text { Yes } & \text { Yes } & \text { No } & \text { No } \\ \text { Teachers' contributions in their online forums } & \text { Yes } & \text { Yes } & \text { Yes } & \text { No } \\ \text { Teachers' personal presentations } & \text { Yes } & \text { Yes } & \text { Yes } & \text { Yes } \\ \text { The courses each teacher teaches } & \text { Yes } & \text { Yes } & \text { Yes } & \text { Yes } \\ \text { How many students each teacher serves } & \text { Yes } & \text { Yes } & \text { Yes } & \text { Yes }\end{array}$

Note: The matrix is filled in for an imaginary learning environment.

Information that is too personal to be transparent could still be very useful if it is presented as statistics or averages. Individual grades are usually only presented to the student and to the teacher. However, it might be useful to make average course grades transparent to everyone.

\section{Transparency and Social Presence Tools}

The Internet trends that are most interesting for online education today are related to social software and Web 2.0. Some well-known examples of social software that are relevant for online education are blogs, wikis, social networking sites, RSS, and social bookmarking. The most interesting characteristic of Web 2.0 is the development of social networks that are hugely successful since the users produce, share, and refine information of mutual interest and benefit for all community members. Social networking sites (such as MySpace, Facebook, Bebo, and Ning) are websites used to build online networks. However, the principles of social networking are not confined to social networking sites. For example, media sharing sites such as flickr and Youtube also contain elements of social networking. The difference is that media sharing sites revolve around media materials, whereas the starting point for social networking sites is socializing. Further, social networking can be accomplished by relations between blogs or by the use of social awareness services such as Twitter or Friendfeed. In relation to the distinction between different social networks, Engeström (2005) has initiated a discussion of what makes social networks successful. He argues that "The social networking services that really work are the ones that are built around objects." This is a relevant point to bear in mind in relation to transparency. 
Developing what Engeström calls "objects of sociality" supports transparency because objectcentered social networks are based on the availability and visibility of objects.

\section{Transparency as a Means to Promote Affinity to Learning Communities}

There are a number of means that could be used to strengthen affinity to virtual learning communities. Transparency and social presence services are central to these means. It is paramount that the participants are visible and accessible. In addition, the community members must be urged and stimulated to contribute to the community and to benefit from it. In the following sections, some of these means are discussed.

\section{Cooperative student catalogues.}

Student catalogues are important tools for showing students that they have access to a learning community. A comprehensive catalogue that provides relevant information about students is crucial to students acquiring an overview of the learning community. Student catalogues usually provide information about all students enrolled in a course; however, if students can access information about the students enrolled in other courses offered by the institution, they may benefit from taking part in a larger learning community. Moreover, a catalog that includes alumni could be of interest to students who seek advice on courses they are considering or on future employment.

To facilitate cooperation, a student catalogue should include information that makes it easy to initiate and maintain communication, such as e-mail addresses, telephone numbers, chatting identities, etc. It may also include information on geographical location (e.g., zip codes) to facilitate identification of potential partners for occasional face-to-face meetings. Similarly, it may include progress plan information so that students can identify peers who are working with the same study unit. Finally, one may argue that student catalogues should include CV-type information to make it possible to search for peers who have special competencies.

Student catalogues must address privacy issues appropriately. Some information in student catalogues may be regarded as sensitive and may require student consent. Some students may also be opposed to inclusion in a student catalogue. The challenge is to find the balance between

providing as much relevant information as possible to stimulate cooperation without trespassing students' privacy thresholds. A viable solution is to ask students for permission to make the information available to the staff, to the students enrolled in the actual course, or to all students in all courses.

\section{Cooperative learner profiles.}

The acronym CLIP, which refers to the phrase cooperative learner information profile, has evolved as a result of one of the author's deliberations (Paulsen, 2006) on effective cooperative student catalogues. Using CLIPs, LMSs may help students find motivated and suitable learning partners (study buddies). CLIPs could herald a new and innovative pedagogy for cooperative 
learning. They could provide efficient tools for establishing smaller and larger networks with the right mix of students, and they could facilitate contact between junior students and experienced students who are willing to function as personal mentors. Further, they could facilitate small colloquial networks of students who live in the same geographic area or who have similar progress plans. These networks may result in reduced dropout rates and better learning.

Based on CLIPs and algorithms for teaming students, the system should suggest partners that make cooperation interesting. Elements from NKI's implementation of CLIPs are illustrated in Figure 3 and Figure 4. The students should be provided with enough information to establish contact and with appropriate tools to maintain cooperation. However, developing suitable algorithms is not a trivial task.

\section{I would like to have a learning partner}

I accept that my data is available to my learning partners

\section{G Global Everyone on the Internet may see my presentation \\ C Open All NKI students may see my presentation \\ Limited The students in my course may see my presentation \\ Closed Only my teachers and the NKI staff may see my presentation}

Figure 3. Choose learning partner preference and visibility level: An element from the students' user interface.

By the end of January 2009, NKI's 9,628 users had indicated their visibility and learning partner preferences, as shown in Table 2.

Table 2

Distribution of Visibility and Learning Partner Preferences

\begin{tabular}{|l|l|l|l|l|}
\hline & $\begin{array}{l}\text { Want learning } \\
\text { partners }\end{array}$ & $\begin{array}{l}\text { Don't want } \\
\text { learning partners }\end{array}$ & Sum & Percent \\
\hline Closed & 137 & 875 & 1012 & $10.51 \%$ \\
\hline Limited & 2260 & 2980 & 5240 & $54.42 \%$ \\
\hline Open & 763 & 1709 & 2472 & $25.68 \%$ \\
\hline Global & 537 & 367 & 904 & $9.39 \%$ \\
\hline Sum & 3697 & 5931 & 9628 & $100.00 \%$ \\
\hline Percent & $38.40 \%$ & $61.60 \%$ & $100.00 \%$ & \\
\hline
\end{tabular}




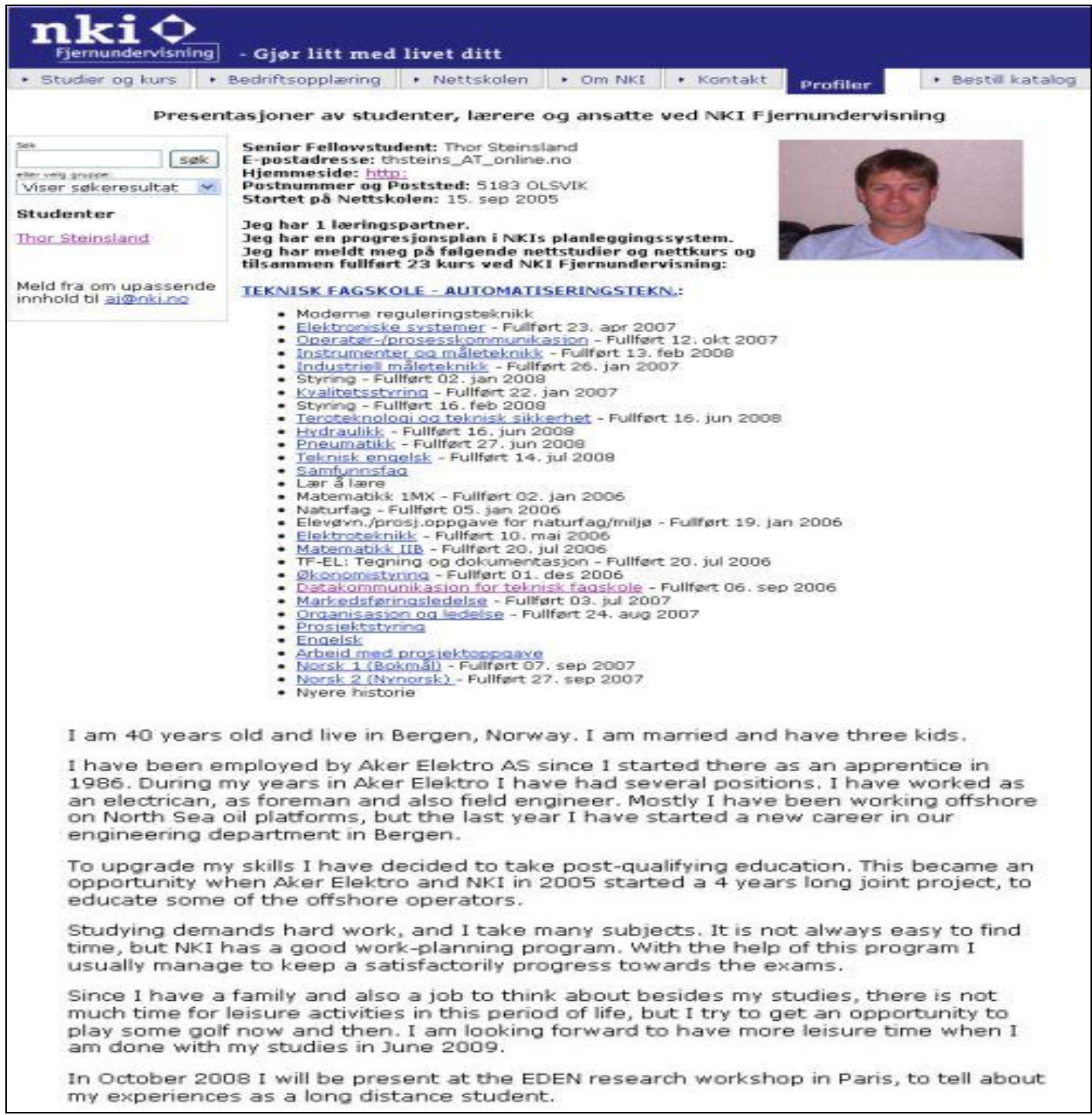

Figure 4. A personal presentation of an NKI student. Included with permission from Thor Steinsland.

CLIPs may build on theories, ideas, and features discussed in social capital and social software literature. Resnick (2002, p. 1) argues that socio technical capital is a new construct that provides a framework for generating and evaluating technology-mediated social relations. In online education one may think of this as learning capital. In a blog entry, Butterfield (2003) characterizes social software as tools that people use to interact with other people, employing information about identity, presence, relationships, conversations, and groups.

Although Facebook, one of the most successful social software services, was developed as a network service for students, social software applied for organized educational purposes is scarce. In Norway, the university of Troms $\varnothing$ has introduced a social software service (www.hvaskjer.no) to enroll more students from secondary schools. The Norwegian School of Management has introduced an online alumni service, and in its alumni magazine, the school (2005, p. 92) states 
that 9,000 alumni have made use of it. All alumni have online contact cards that they may update and supplement with information about their work and professional interests, and alumni may search the complete database of information in order to find useful resources and contacts.

An online survey (Paulsen, 2005) completed by 154 NKI students showed that the majority wanted closer cooperation with one or more students. As many as 64 percent stated that they probably or definitely wanted closer cooperation. Only 16 percent responded that they probably or definitely did not want closer cooperation. The verbal comments also showed that many respondents wanted cooperation. Many stated that they needed, wanted, or missed cooperation and study buddies. Some pointed out that it was difficult to contact other students; others wanted better tools to find partners. However, there were some respondents who stated that they didn't need cooperation. Further, they thought cooperation should be voluntary and they stated that they preferred to study without being dependant on others. The survey also showed that 71 percent of the respondents were positive or very positive to see each other's progress plans. Similarly, 76 percent were positive or very positive about obtaining access to each other's zip codes.

In a large institution, teachers could also benefit from finding partners for cooperation. Therefore, NKI provides teachers with a discussion forum and dynamic contact information for all 150 online teachers and the online courses they teach.

\section{Learning partners.}

Based on the learning profile concept and the student survey referred to in this article (Paulsen 2005), in March 2006, NKI introduced a service to help students find learning partners (Slåtto \& Paulsen, 2006). The students who seek learning partners are asked to do the following:

1. Register their personal presentations.

2. Decide who may access their presentations.

3. Search for potential learning partners.

4. Invite somebody to become their learning partner.

By November 2006, 3,100 students had registered a personal presentation (an increasing number of the presentations include a personal picture). At the same time, 2,500 had indicated their privacy level and preference regarding having learning partners. About 450 of the students had found one or more learning partners.

As of December 2007, 3,900 students had registered a personal presentation. At the same time, 3,700 had indicated their privacy level and preference regarding having learning partners, as indicated in Table 3. About 750 of the students had found one or more learning partners. 
Table 3

Student Preferences regarding Learning Partners and Privacy

\begin{tabular}{|l|l|l|l|l|}
\hline & $\begin{array}{l}\text { Want learning } \\
\text { partners }\end{array}$ & $\begin{array}{l}\text { Do not want } \\
\text { learning } \\
\text { partners }\end{array}$ & Sum & Percent \\
\hline Closed & 79 & 657 & 736 & $20.0 \%$ \\
\hline Limited & 1192 & 706 & 1898 & $51.5 \%$ \\
\hline Open & 752 & 303 & 1055 & $28.6 \%$ \\
\hline Sum & 2023 & 1666 & 3689 & \\
\hline Percent & $54.8 \%$ & $45.2 \%$ & & \\
\hline
\end{tabular}

The first major survey (Paulsen, 2008), including a question about the learning partner services, had responses from 763 NKI students. The results showed that $54 \%$ of the respondents were very satisfied or satisfied, and $2 \%$ were dissatisfied or very dissatisfied. The remaining respondents were either neutral or expressed no opinion. The report concludes that the service has the potential to be developed further and that the students need more time to become familiar with the services.

\section{Cooperative assignments.}

Assignments are a crucial way to support learning theories. An assignment should consist of a task and a direction. An assignment focusing on one task can easily support individual, cooperative, or collaborative learning by varying the assignment directions. This is illustrated in the following example:

Assignment task

Explain the differences between individual learning, cooperative learning, and collaborative learning.

Alternative assignment directions

\section{Individual learning direction}

Send your submission as an e-mail to your teacher.

\section{Cooperative learning direction}

Discuss the assignment with a colleague or a peer student in your network. Write a short summary of the discussion and send it as an e-mail to your teacher.

\section{Collaborative learning direction}

Write a paper in a group with one or two other students and submit the paper as an e-mail to your teacher. 


\section{Cooperative assessment.}

Online assessment may be grouped in four categories (Paulsen, 2003, page 68): self-assessment, computer assessment, tutor assessment, and peer assessment. All categories could have a cooperative flavor if they are designed with transparency and cooperation in mind:

1. Computer-based assessment could be cooperative if students exchange or have access to statistics, results, or information derived from all or some other students taking the tests.

2. Self-assessment could be cooperative if students are encouraged to exchange selfassessments or if students may access some statistics or information from other students who have completed self-assessments.

3. Peer assessment could be cooperative if students are encouraged to assess each other's work voluntarily.

4. Teacher assessment could be cooperative if the students have access to some of the information the tutor provides or derives from assessing other students.

Portfolio assessment can support cooperative learning if the system allows students to access and comment on each other's portfolios.

\section{Cooperative gating (COG).}

Wells (1992) described gating as a pacing technique that denies students access to information before they have completed all prerequisite assignments. The acronym COG, which refers to cooperative gating, has evolved as an NKI term. It signals that students must complete a task to get access to a cooperative resource. This could for example be used as a stimulus for motivating students to answer in-text questions. They are allowed to see what others have answered only if they provide an answer others may read.

\section{Cooperative evaluation and quality barometers.}

Evaluation and quality control are crucial but challenging in large-scale online education that is based on individual progress plans. Some of the challenges are related to the following questions:

- When should it be done: once a year, near the end of the course, or continuously?

- What should be evaluated if the aim is to improve quality?

- How should the results be presented, and how transparent should they be to have the best impact?

- How could evaluation be automated and managed as part of a reasonable workload?

In cooperative learning environments, the findings and results should be reasonably transparent, and relevant information should be available to the appropriate user groups so that they can learn from the results and understand that they are members of a larger learning community. 
NKI developed an evaluation tool which was used for the first time in 2003. The system allows NKI to develop common forms of questionnaires and evaluation forms. Each form can be assigned to one or more user categories, e.g., teachers, students in one course, or all students. A user may respond only once and all replies are anonymous. When a user responds, the evaluation database is updated and the user is granted access to a personal evaluation report. The transparent reports that are generated from the database vary according to the user category:

- Students may see a report showing qualitative statistics of interest to students in their course.

- Teachers may see the same report as the students with additional teacher information. The teacher information could come from certain parts of the questionnaire or from data related to other courses (for the purpose of comparison).

- Administrative staff may see comparative reports showing responses from all user groups and questionnaires. This means, for example, that one can compare responses in all courses in the LMS system. This could be used to identify teachers who receive excellent evaluations or courses that receive worrying evaluations.

One weakness is that the system is not meant for continuous evaluation. Therefore, NKI is integrating a new feature, termed quality barometer, which continuously records evaluation data and presents dynamic reports on important indicators of quality.

The evaluation tool was used in a survey among all NKI online students at the end of 2007. There were 763 students who answered the questionnaire, which included nine quantitative and 10 qualitative questions. Students who were enrolled in more than one course could respond one time per course. There were close to 900 responses. The results are available in an internal NKI report (Paulsen, 2008), and the main conclusion states that NKI can be very satisfied with the results. The responses provide substantial information about how the students perceive the tools NKI has developed to support cooperative learning. An overview of the responses to the nine quantitative questions is provided in Table 4. 
Table 4

Summary of the Responses to the Nine Quantitative Questions in the 2007 Survey

\begin{tabular}{|c|c|c|c|c|c|c|c|}
\hline \multirow[b]{2}{*}{$\begin{array}{l}\text { How satisfied are you with the } \\
\text { following: }\end{array}$} & \multicolumn{6}{|c|}{ Percentages } & \multirow{2}{*}{ 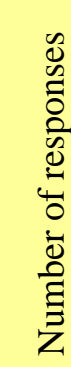 } \\
\hline & 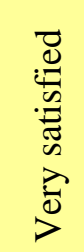 & 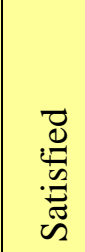 & 蔦 & 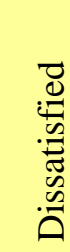 & 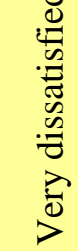 & 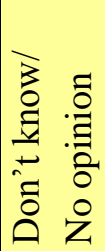 & \\
\hline NKI's submission system? & 55.7 & 34.1 & 6.2 & 0.8 & 0.2 & 2.9 & 885 \\
\hline NKI's planning system? & 47.7 & 38.7 & 10.1 & 2.3 & 0.2 & 1.0 & 894 \\
\hline Being an online NKI student? & 37.2 & 49.4 & 8.2 & 3.5 & 0.8 & 0.9 & 898 \\
\hline This course? & 30.2 & 54.1 & 10.8 & 2.7 & 0.6 & 1.7 & 892 \\
\hline The teacher's work? & 36.4 & 36.7 & 12.8 & 4.7 & 1.2 & 8.2 & 891 \\
\hline NKI's follow-up system? & 26.0 & 44.9 & 19.0 & 2.7 & 0.8 & 6.6 & 890 \\
\hline The course material? & 23.0 & 59.0 & 11.0 & 4.9 & 1.5 & 0.6 & 896 \\
\hline The contact with NKI? & 22.9 & 45.5 & 21.5 & 5.3 & 1.0 & 3.8 & 892 \\
\hline The learning partner system? & 16.6 & 36.5 & 30.4 & 1.1 & 0.8 & 14.6 & 892 \\
\hline
\end{tabular}

\section{Personal tools.}

Personal tools are tools that first and foremost support the activities of the individual. This means that personal tools are used by the individual for individual purposes. In that sense, they are related to a personal profile or web page within a social network, which is developed and used by the individual. For example, personal tools could support activities such as finding literature, writing texts, taking notes, keeping track of links, solving assignments, etc.

Personal tools support transparency when they are made available to others. The personal tools become social. It is possible to use the personal tools as the starting point for social networks. Students can connect to and subscribe to the personal tools of other students. The web service del.icio.us is a good example of a personal tool that can be used socially. Del.icio.us is a social bookmarking service, which enables people to collect their bookmarks on a web page. Initially the service supports individual organization and use of bookmarks. However, the bookmarks are made available for everyone on the web, which means that they are shared. Students can use similar personal tools to organize their work, collect literature, write notes, brainstorm, develop thoughts and ideas, write assignments, etc. Sharing these tools with other students through networking supports transparency and consequently awareness among students. 


\section{Transparency: Potential for Online Education}

What is the pedagogical potential of social networking? We have discussed the pedagogical potential of social networking for cooperative learning. We have argued that transparency is important to online education. In relation to cooperative learning with continuous enrollment and examinations, a challenge is to motivate students to engage in joint work. We have argued that transparency is a prerequisite for distance students to work cooperatively. Transparency enables students to be visible to each other as potential partners and resources.

Following the outlined theory of cooperative freedom and the socio-cultural approach, an important objective is to support an individual's consciousness and awareness of the activities of others. This can be achieved by making a variety of information transparent, for instance by developing student catalogues and learner profiles, by encouraging learners to become partners, and by sharing personal learning tools.

The result is a different kind of transparency than is found in, for instance, discussion forums. Whereas discussion forums and other tools for direct communication and collaboration focus on direct sharing, social networking can support students' indirect sharing of resources, thoughts, ideas, productions, writings, notes, etc. This kind of sharing can provide students with insights into the workings of other students, and, thus, give them an increased consciousness and awareness of the activities of other students.

The pedagogical potential lies within developing social networks in which students' activities are visible to other students. The potential is to support transparency through a combination of personalization and socialization and through sharing personal information and tools within social networks (Dalsgaard 2006).

\section{Conclusion}

Social networking sites are not the new learning management systems. From the perspective of the theory of cooperative freedom, however, the special kind of communication and interaction afforded by social networking sites is interesting and has pedagogical potential. From this point of view, social networking should be considered as a supplement to other tools. The potential of social networking lies within transparency and the ability to create awareness among students. 


\section{References}

Anderson, T. (2008) Networks vs. groups in higher education. Message posted to http://terrya.edublogs.org/2008/03/17/networks-versus-groups-in-highereducation/\#more-90

Bang, J., \& Dalsgaard, C. (2006). Rethinking e-learning: Shifting the focus to learning activities. In E. K. Sorensen \& D. Murchú (Eds.), Enhancing learning through technology. Information Science Publishing.

BI, (2005). BI Alumni - din arena for nettverksbygging. In BI Magasinet, June 2005.

Brown, J. S., Collins, A., \& Duguid, P. (1989). Situated cognition and the culture of learning. Educational Researcher, 18(1), 32-42.

Butterfield, S. (2003). Blog entry retrieved July 14, 2005, from www.sylloge.com/personal/2003_03_01_s.html\#91273866

Clark, D. (2004). Personalisation and e-learning. Brighton, UK: Epic Group p.l.c.

Coleman, J. S. (1990). Foundations of social theory. Cambridge, Massachusetts and London: The Belknap Press of Harvard University Press.

Collis, B., \& Moonen, J. (2001). Flexible learning in a digital world. London: Kogan Page.

Dalsgaard, C. (2006). Social software: E-learning beyond learning management systems. European Journal of Open, Distance and E-Learning, 2006/II. http://www.eurodl.org/materials/contrib/2006/Christian_Dalsgaard.htm

Dillenbourg, P., Baker, M., Blaye, A., \& O’Malley, C. (1996). The evolution of research on collaborative learning. In E. Spada \& P. Reiman, (Eds.), Learning in Humans and Machine: Towards an interdisciplinary learning science ( pp. 189-211). Oxford: Elsevier. Retrieved March 18, 2009, from http://tecfa.unige.ch/tecfa/publicat/dil-papers2/Dil.7.1.10.pdf

Downes, S. (2007). Learning networks in practice. Emerging Technologies for Learning, 2, 19-

27. British Educational Communications and Technology Agency. http://ijklo.org/Volume3/IJKLOv3p029-044Downes.pdf

Dron, J., \& Anderson, T. (2007). Collectives, networks and groups in social software for elearning. Proceedings of World Conference on E-Learning in Corporate, Government, Healthcare, Higher Education, Quebec. www.editlib.org/index.cfm/files/paper 26726.pdf.

Engeström, J. (2005). Why some social network services work and others don't - Or: the case 
for object-centered sociality. Message posted to http://www.zengestrom.com/blog/2005/04/why some social.html

Fagerberg, T. (2005). Fjernstudenters vurdering av nettbaserte pedagogiske tjenester. Unpublished master's thesis. København: Danmarks Pædagogiske Universitet.

Field, J. (2003). Social capital: Key ideas. Routledge: New York.

Holmberg, B. (1988). Guided didactic conversation in distance education. In D. Sewart, D.

Keegan, and B. Holmberg (Eds.), Distance education: International perspectives (pp. 114-22). London/New York: Croom Helm/St. Martins Press.

Johnson, D. W., \& Johnson, R. T. (2004). Cooperation and the use of technology. In D. Jonassen (Ed.), AECT handbook. Retrieved July 15, 2008, from http://lrnlab.edfac.usyd.edu.au/CoursesPG/Resources/AECT/chp30.pdf

Jones, C., Ferreday, D., \& Hodgson, V. (2006). Networked learning a relational approach - weak and strong ties. Proceedings of the Networked Learning Conference 2006.

Jones, C. (2004). The conditions of learning in networks. Kaleidoscope CSCL SIG. Lausanne.

Keegan, D. (1996). Foundations of distance education (3rd ed.). London: Routledge.

Leont'ev, A. N. (1978). Activity, consciousness, and personality. http://www.marxists.org/archive/leontev/works/1978/index.htm.

Moore, M. G. (1983). On a theory of independent study. In D. Sewart, D. Keegan, and B.

Holmberg (Eds.), Distance education: International perspectives (pp. 68-94). London/New York: Croom Helm/St. Martin's Press.

Panitz, T. (2003): Collaborative versus cooperative learning - a comparison of the two concepts which will help us understand the underlying nature of the interactive learning. Retrieved July 15, 2005, from http://home.capecod.net/ tpanitz/tedsarticles/coopdefinition.htm

Paulsen, M. F et al. (2008). Resultater fra spфrreunders $\phi$ kelsen blant nettstudentene ved NKI Fjernundervisning høsten 2007. Internal report. Oslo: NKI.

Paulsen, M. F. (2008). Cooperative online education. Seminar.net 4(2). Retrieved November 18, 2008, from www.seminar.net/current-issue/cooperative-online-education

Paulsen, M. F. (2007). Cogs, clips e outros instrumentos de apoio à aprendizagem cooperativa 
realizada em ambientes virtuais. In B. Almeida et al. (Eds), Livro de actas encontro de educacao em fisca do ensino basico ao supirior no sec, XXI.

Paulsen, M. F. (2007). Kooperativ frihet som ledestjerne i nettbasert utdanning. Bekkestua: NKI Forlaget.

Paulsen, M. F. (Ed) (2007). Megaproviders of e-learning in Europe. Bekkestua: NKI Forlaget.

Paulsen, M. F. (2006). Cogs, clips and other instruments to support cooperative learning in virtual learning environments. In U. Bernath \& A. Sangrà (Eds.), Research on competence development in online distance education and e-learning - Selected papers from the 4th EDEN research workshop, Castelldefels/Spain.

Paulsen, M. F. (2006). Resultater fra spфrreunders $\phi$ kelsen blant nettstudentene ved NKI Fjernundervisning høsten 2005. Internal report. Oslo: NKI.

Paulsen, M. F. (2005). Resultater fra spфrreunders $\phi$ kelsen om NKI Fjernundervisnings planleggings- og oppfølgingssystem. Internal report. Oslo: NKI.

Paulsen, M. F. (2003). Online education and learning management systems: Global e-learning in a Scandinavian perspective. Oslo: NKI Forlaget. Retrieved July 18, 2005, from www.studymentor.com/

Paulsen, M. F., \& T. Rekkedal, (2003). NKI Fjernundervisning: Two decades of online sustainability. In M. F. Paulsen, Online education and learning management systems: Global e-learning in a Scandinavian perspective. Oslo: NKI Forlaget. Retrieved July 18, 2005, from www.studymentor.com/studymentor/NKI.pdf

Paulsen, M. F. (1992). From bulletin boards to electronic universities: Distance education, computer-mediated communication, and online education. University Park, Pennsylvania: The American Center for the Study of Distance Education.

Peters, O. (1988). Distance teaching and industrial production: A comparative interpretation in outline. In D. Sewart, D. Keegan, \& B. Holmberg (Eds). Distance education: International perspectives (pp. 95-111). London/New York: Croom Helm/St. Martin's Press.

Resnick, P. (2002). Beyond bowling together: Socio technical capital. In J. Carroll (Ed.), Human computer interaction in the new millennium. (pp. 247-272). Addison-Wesley. Retrieved July 18, 2005, from www.si.umich.edu/\%7Epresnick/papers/stk/ResnickSTK.pdf.

Roschelle, J., \& Teasley, S. D. (1995). The construction of shared knowledge in collaborative problem solving. In C. O’Malley (Ed.), Computer supported collaborative learning (pp. 69-97). Springer-Verlag. 
Ryberg, T., \& Larsen, M. C. (2008). Networked identities: Understanding relationships between strong and weak ties in networked environments. Journal of Computer Assisted Learning, 24, 103-115.

Siemens, G. (2005). Connectivism: A learning theory for the digital age. http://www.elearnspace.org/Articles/connectivism.htm.

Slåtto, T., and M. F. Paulsen, (2006). Learning partner - opportunities for cooperation in distance learning. Retrieved November 14, 2006, from www.elearningeuropa.info/index.php?page $=$ doc\&doc $\_i d=8294 \&$ doclng $=6 \&$ menuzone $=2$

Vygotsky, L. S. (1978). Mind in society. Harvard University Press.

Wells, R. (1992). Computer-mediated communication for distance education: An international review of design, teaching, and institutional issues. University Park, Pennsylvania: The American Center for the Study of Distance Education.

Wenger, E. (1998). Communities of practice. Cambridge University Press.

Wenger, E., White, N., Smith, J. D., \& Rowe, K.(2005). Technology for communities. http://www.ewenger.com/pub/index.htm.

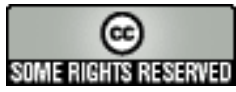


June - 2009

\title{
Preferences of Residents in Four Northern Alberta Communities Regarding Local Post-Secondary Programming
}

\author{
Patrick J. Fahy and Nancy Steel \\ Athabasca University, Canada \\ Patricia Martin \\ Banshee Consulting, Canada
}

\begin{abstract}
The western Canadian province of Alberta has used some of the proceeds from exploitation of its extraordinary natural resources to make available a range of post-secondary training and education opportunities to residents. While these provisions appear comprehensive, this study examined how well they actually suit the express needs of the residents of remote, Northern areas of the province, many of them Aboriginal.
\end{abstract}

The literature shows that while Aboriginal people are underrepresented in Canada in university enrollments, they are no longer underrepresented in college or other institutions, suggesting that gains have been made for some residents of rural and remote parts of Canada. Further, when Northern residents (especially Aboriginal males) complete advanced training, Statistics Canada reports they are highly successful in employment and income. Access is the pivotal issue, however: leaving the local community to attend training programs elsewhere is often disruptive and unsuccessful. As will be seen, the issue of access arose in this study's findings with direct implications for distance delivery and support.

This study was conducted as part of Athabasca University's Learning Communities Project (LCP), which sought information about the views and experiences of a broad range of northern Alberta residents concerning their present post-secondary training and education opportunities. The study addresses an acknowledged gap in such information in relation to Canada in comparison with other OECD countries.

Results are based on input from 165 individuals, obtained through written surveys (some completed by the researchers in face-to-face exchanges with the respondents), interviews, discussions, and observations, conducted with full-time or part-time residents of the study communities during 2007 and 2008. The four northern Alberta communities studied were 
Wabasca, Fox Lake, Ft. McKay (sometimes MacKay), and Ft. Chipewyan, totaling just over 6,000 residents.

While respondents had varied backgrounds in relation to training and education, consensus emerged on several points: training in the studied communities must be flexible to be realistic; the negative emotional and economic impacts on families and individuals when they are forced to leave the local community to take training can be enormous; alternatives such as distance education may now be acceptable to and technologically feasible for many; and certain subjects (especially business-related courses, pre-employment preparation, such as safety and computer skills, trades training, and basic skills upgrading programs in essential skills such as math, English, writing, and life skills) were of broad interest to these residents.

The LCP was cautioned that future programming inspired by this research should avoid mistakes made by others in relation to northern learners and their local realities: not considering students' preferences for programming, employing inappropriate technologies, failing to provide adequate orientation and support to the learning system, and failure to use existing, proven delivery models.

\section{Introduction}

The province of Alberta has benefitted greatly from the resources booms of the last thirty years (Alberta Finance and Enterprise, 2008a). Based on revenues primarily from energy (in conventional oil and oil sands), Alberta has generated the highest provincial growth rate in Canada, the lowest unemployment rate, and an accumulated surplus (as of 2008) of approximately \$16 billion (Alberta Finance and Enterprise, 2007d, 2007e, 2008b, 2008c, 2008d, 2008e).

Alberta is also socially distinct in Canada with educational and social implications in its uniqueness. The province has the lowest average age of any province (the median in 2006 was 36.0 years; for Canada, it was 39.5 years); its senior population (65 years and over) is the lowest in Canada at 10.6\% (Canada, 13.7\%); the average age of Alberta's Aboriginal population was 25 in 2006, whereas for non-Aboriginals it was 36 (Alberta Finance and Enterprise, 2007a, 2007b, 2007c, 2007f); the Aboriginal population (defined as "people [who] reported Aboriginal identity (First Nation, Métis or Inuit)" grew 45\% from 1996 to 2006, as compared to a non-Aboriginal population growth rate of $8 \%$ (Canada's Aboriginal population, 2008).

In response to these challenging realities, Alberta provides a range of training and education opportunities for its residents. The province has 20 public post-secondary institutions, comprising 14 public colleges, four universities, and two technical institutes. Distance education is supported in several ways: the intent and policy of Campus Alberta (Alberta Advanced Education and Technology, 2002), and the Roles and Mandates Policy Framework (Alberta Advanced Education and Technology, 2007) assure that any course available in any Alberta institution will be open to enrollment by all Albertans; SuperNet, the broadband network, brings high-speed Internet access to large areas of the province; eCampusAlberta specifically promotes the distance learning 
offerings of Alberta post-secondary institutions; and Athabasca University specializes in distance delivery of university-level undergraduate and graduate training throughout the province and across Canada.

This study was conducted under the aegis of Athabasca University's Learning Communities Project (LCP), which commenced in 2006 as the Rural and Remote Learner Project. The project was designed to determine how educational programs and services might be improved and extended in rural and remote communities and oil sands work camps in northern Alberta. LCP was funded initially by a donation from a senior official of a major oil sands developer. As it proceeded with managing the project, Athabasca University contributed development and research expertise and services; in early 2009, the project became known simply as Learning Communities with a focus extending beyond oil sands and northern communities to all remote areas of the province.

This report concerns findings in Alberta's north in relation to the initial focus of the LCP. It addresses the following question: In an era of increasing availability of online learning, what are the preferences of Alberta's northern residents for education and training offerings, including delivery models? The study was intended to address this question by examining the views and experiences of residents of four northern communities: Fort Chipewyan, Fort McKay, Fox Lake, and Wabasca. Data were drawn from federal and provincial statistical sources and from interviews conducted by staff of LCP with, and written responses from, citizens of the selected communities.

\section{Background}

As will be discussed below, Canada has historically experimented with innovative approaches to education and training for distributed (often isolated from educational opportunity) populations; the fact that "Canada's Open University," Athabasca University, is located in Alberta is evidence of this province's commitment to non-traditional educational delivery.

Occasionally, however, mixed signals have been sent in Canada about the importance of these efforts. In 2002, the Association of Canadian Community Colleges (ACCC, 2002) in response to a federal government call for more innovation from education providers responded that colleges were already "widely accessible and well placed to support community, economic, social, and cultural development" (ACCC, 2002, slide 2). Perhaps proving the government's point, the Association made only one mention of possible need for access from remote areas to postsecondary opportunities: "[the system might improve access] by expanding capacity and access to distance learning with the goal of eliminating the gap between the have and have nots, especially those individuals living in remote or isolated communities" (ACCC, 2002, slide 4).

This study was piqued in part by the growing concern in Canada about the lack of relevant information on access nationally to education and training. In the Organization for Economic Cooperation and Development's (OECD) fall 2007 annual Education at a Glance report, Canada failed to provide information on 57 of 96 indicators (almost 60\%), the worst performance of any 
member country. As a result, in early 2008, the Director General of the Council of Ministers of Education Canada began consultations with Statistics Canada to develop a strategy for better collection and reporting of data for all education sectors. Universities, for their part, began work on a common set of data and reporting criteria, measuring such basics as student enrollment, faculty numbers, class sizes, and graduation rates (Charbonneau, 2008).

The OECD disappointment followed other embarrassments that profiled the lack of basic data about educational access in Canada. In 2003, Canada's premiers created a Council of the Federation (2006), in part to address several problems the country recognized in relation to its trading partners. These problems included the comparatively low levels of post-secondary training (especially at the graduate level), the lack of employer involvement in worker training, and the need for investment in research. Results were not immediately apparent, however: in 2007, Canada was called a "land of mediocrity" in a report that recounted the country's low level of worker literacy, failure to take advantage of the potentials of proven training technologies, and falling levels of professional creativity (Scoffield, 2007).

However, a lack of awareness of the needs for educational innovation to benefit more remote residents is not unique to Canada. In a 2001 paper discussing the evolution of adult education in Australia, Tennant and Morris (2001) did not mention the term "distance" or "distance education" at all, though the paper includes discussion of demographic and workplace changes, the role of the state in the provision of adult education, the emerging global knowledge economy, and vocational and non-vocational issues in adult and community education, including the issue of access (p. 2). On the other hand, Tapsall (2001), also writing from Australia, vividly describes the global "bandwagon" for "cyberspace solutions," which he concludes too often "marginalise[s] the traditional emphasis within distance education on ... the provision of opportunities for the socially disadvantaged" (p. 35).

In 2003, a Scottish report by Osborne shed some light on the problem of access from an operational perspective. He identified a range of initiatives colleges could use to increase access and encourage enrollments, including prior learning assessment and recognition (PLAR), open and distance learning policies, and use of information and communications technologies (p. 43). In his paper, Osborne acknowledged Canada's leadership in two areas related to enhanced flexibility: PLAR and transfer credit arrangements.

Some of the literature on flexible access cites specifically the needs of Aboriginal residents of remote communities (although the needs of any specific ethnic group were not a focus of this study, Aboriginals constitute a high proportion of residents of Canada's northern communities, including the communities studied here) (Association of Canadian Community Colleges, 2005; Census of Canada, 2008). McMullen and Rohrback (2003) reported being disappointed that while distance education has the capability to provide educational opportunities for Aboriginal students, "To date, distance education has failed to meet this ability" (p. 6). They cited various program failures, including ignoring the needs of the student, the salient characteristics of the environment, and predictable barriers; not considering students' learning styles and expectations; failing to recognize local political expectations; and reliance on unreliable delivery and 
communications technologies (pp. 6-7). Overall, the writers charge, few Canadian educational institutions or directors of education know about, or emulate, the successful programs and models, domestic and foreign, that might result in more successes with presently marginalized populations (p. 9).

Despite the above criticisms, some potentially useful Canadian models for serving isolated people have emerged from previous studies. From 1987 to 1989, the Keewatin Region, which was then part of the Northwest Territories (NWT), offered upgrading, General Educational Development (GED) preparation, life skills, and pre-employment training via PLATO computer-assisted learning in seven adult learning centres throughout the region (Fahy, 1989). While the project reported successes in skills acquisition, participation was limited in this pre-Internet era by the requirement for students to attend on-site at computer-equipped community learning centres.

Nevertheless, the project demonstrated technology-based delivery could be effective in the North. Another successful project in northern Canada, described by Gruber and Coldevin (1994), was intended to provide accelerated management training to local people training as administrators, prior to the creation of the northern territory of Nunavut in 1999. The project reiterated the point made by McMullen and Rohrbach concerning the relatively low impact of distance education to date: "[D]istance education has made relatively few inroads into Inuit settlements across the Canadian North" (Background and project rationale, 93 ). In this project, a total of 76 participants completed business and management training using satellite video transmissions, telephone/fax interaction, community learning groups, local facilitators, and specifically designed study materials in workshops delivered to six communities in three Arctic regions (Workshop design, If 1). Positive and encouraging results included "as much or more" learning than was expected (Overall impact, II 2), employer perceptions of greater self-confidence among trainees (II 3), and agreement by $90 \%$ of participants that the program should be offered again (II 4).

In another study, Knight and Tobin (2002) describe a successful project intended to enhance literacy and numeracy of Northwestern Ontario residents. The participants (primarily native females under forty years of age, described as "severely [economically] limited" by their need for upgrading) had a "positive experience" in the six to eight week program. According to the report, the delivery medium, audiographic teleconferencing (audio plus video), provided the immediacy of visual contact and created "increased rapport" between participants and instructors (p. 1). While complex and costly, experiences such as the above show that projects emphasizing technology to address accessibility can reduce barriers and can prove attractive to residents of remote communities.

In 2001, the Conference Board of Canada conducted case studies of the use of digital learning technologies in ten Northern communities across Canada (Greenall \& Loizides, 2001). The case studies identified some barriers to the use of learning technologies, including problems with highspeed Internet access, lack of local computer and Internet expertise, inexperienced instructors, and unreliable infrastructure elements. Nevertheless, the report concluded optimistically that technology provided residents with “... opportunities to enhance their skills and improve employment prospects" (p. ii), and that residents were “... embracing the potential of technologies 
for learning so members can both develop and be in a position to take advantage of economic opportunities." The report continued, "Aboriginal educators and economic development practitioners are developing and implementing creative and innovative initiatives to promote the achievement of Aboriginal 'digital opportunities"' (p. i).

These efforts at making learning opportunities more available can be highly economically successful, especially for Native people. Walters, White, and Maxim (2004) report that both male and female Aboriginals earn significantly more than other minorities when they possess postsecondary credentials; that male Aboriginals are at the top of the earnings hierarchy, compared with all post-secondary graduates; and that Aboriginals, both males and females, have better employment prospects if they have graduated from a trades or college program than from a university program if they do not return to reserves where there are (usually) fewer employment opportunities (p. 296). Aboriginal people are evidently beginning to recognize these facts: Statistics Canada (2008) reports that while the participation rate of Aboriginals in university-level programs was significantly lower than for non-Aboriginals, “... differences between the Aboriginal and non-Aboriginal population participation rates were not significant for college and for other types of institution" (Table 3, ๆ 1). As noted by others (Malatest and Associates, 2004), "Aboriginal student [post-secondary] enrollment rates are growing substantially faster than those of other demographic groups, albeit from a very low base" (p. 5).

Finally, the need for innovative delivery of post-secondary education and training in Northern Alberta is indicated by past enrollment trends. According to government data, total public postsecondary enrollments rose $10.6 \%$ in Alberta, from 124,432 to 137,676 FLEs (full-load equivalents), during the period 2001-2002 to 2006-2007 (Figure 1). However, over that period, there were other trends:

- Enrollments at the colleges that serve Alberta's northern regions fell an average of over $11 \%$ (in one northern institution, the decline was almost 27\%);

- Enrollments at public colleges elsewhere in the province remained almost constant (they increased $0.6 \%$ );

- University enrollments increased by $13.9 \%$ province-wide;

- The two institutes of technology increased enrollments by $15.7 \%$;

- Athabasca University increased its enrollment by $38.7 \%$, all at a distance. (During the six years previous to the study, Athabasca's rate of growth was from 2.6 to 57 times greater than that of Alberta's other three conventional universities.) 


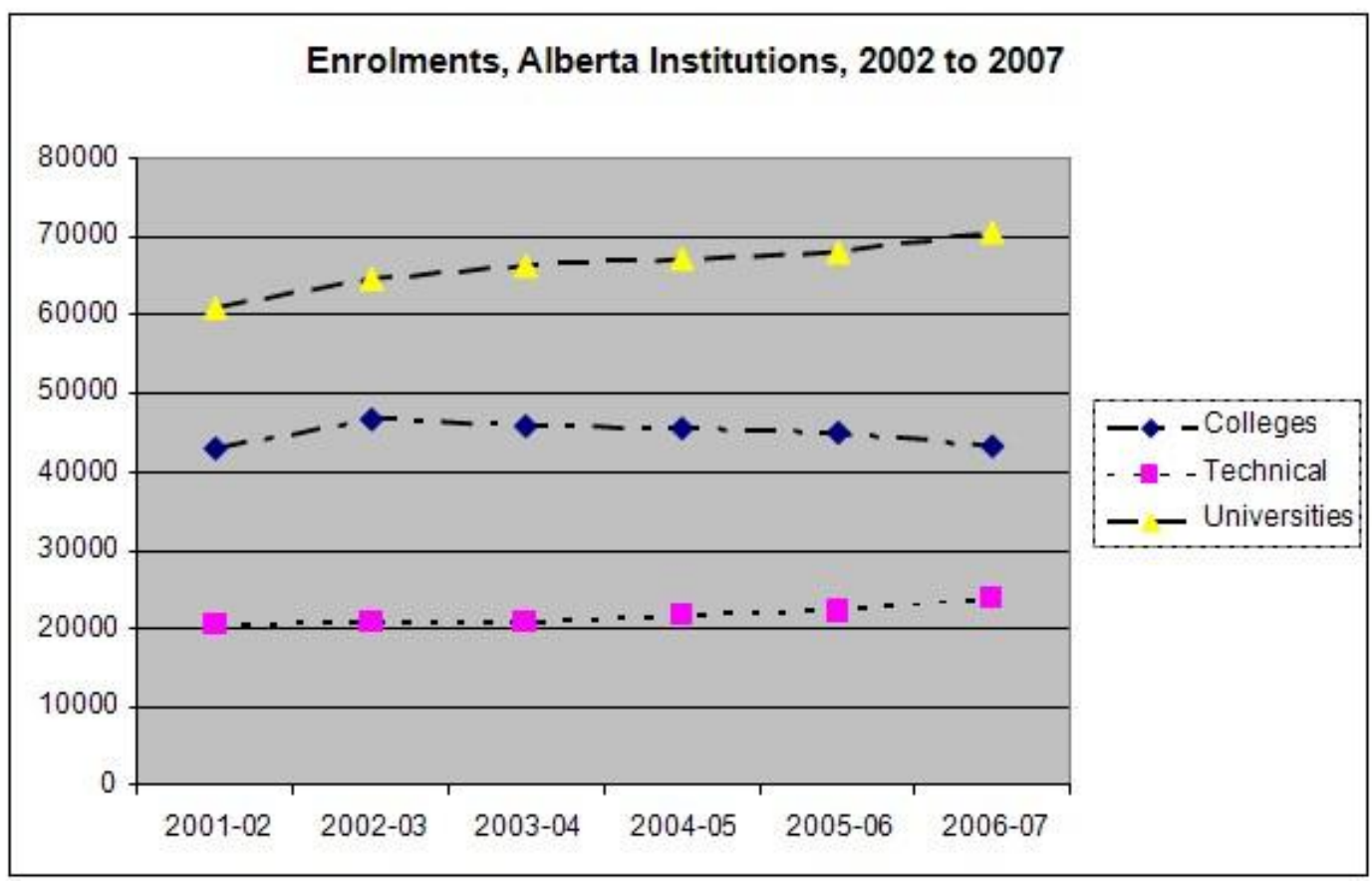

Figure 1: Fulltime-equivalent enrolments (FLEs), all Alberta post-secondary institutions, $2002-2007$.

In summary, post-secondary education appears to be a promising route for remote residents, especially those who wish to continue to reside in their communities for as long as possible during training. While some successful models of community-based training and education exist, there have also been problems with unsuccessful strategies, lack of support, poor technology selections, and a general lack of consultation with those expected to participate.

This study, focusing on the degree to which present online offerings and supports are meeting the stated preferences of residents of Alberta's remote communities, appears likely to add importantly to the picture formed by previous reports and to update and confirm the literature on the educational and training preferences and learning experiences of remote residents in an era of the emergence - even ascendance - of technology-based learning.

\section{The Study}

\section{Purpose}

The study addressed the following question: With the increasing availability of online learning, what are the preferences of Alberta's Northern residents for education and training offerings, including delivery models? The study addressed this question by examining the views of residents of four northern communities: Fort Chipewyan, Fort McKay, Fox Lake, and Wabasca (Figure 2). Data were drawn from federal and provincial statistical sources and from interviews with and written responses from residents of the selected communities. 


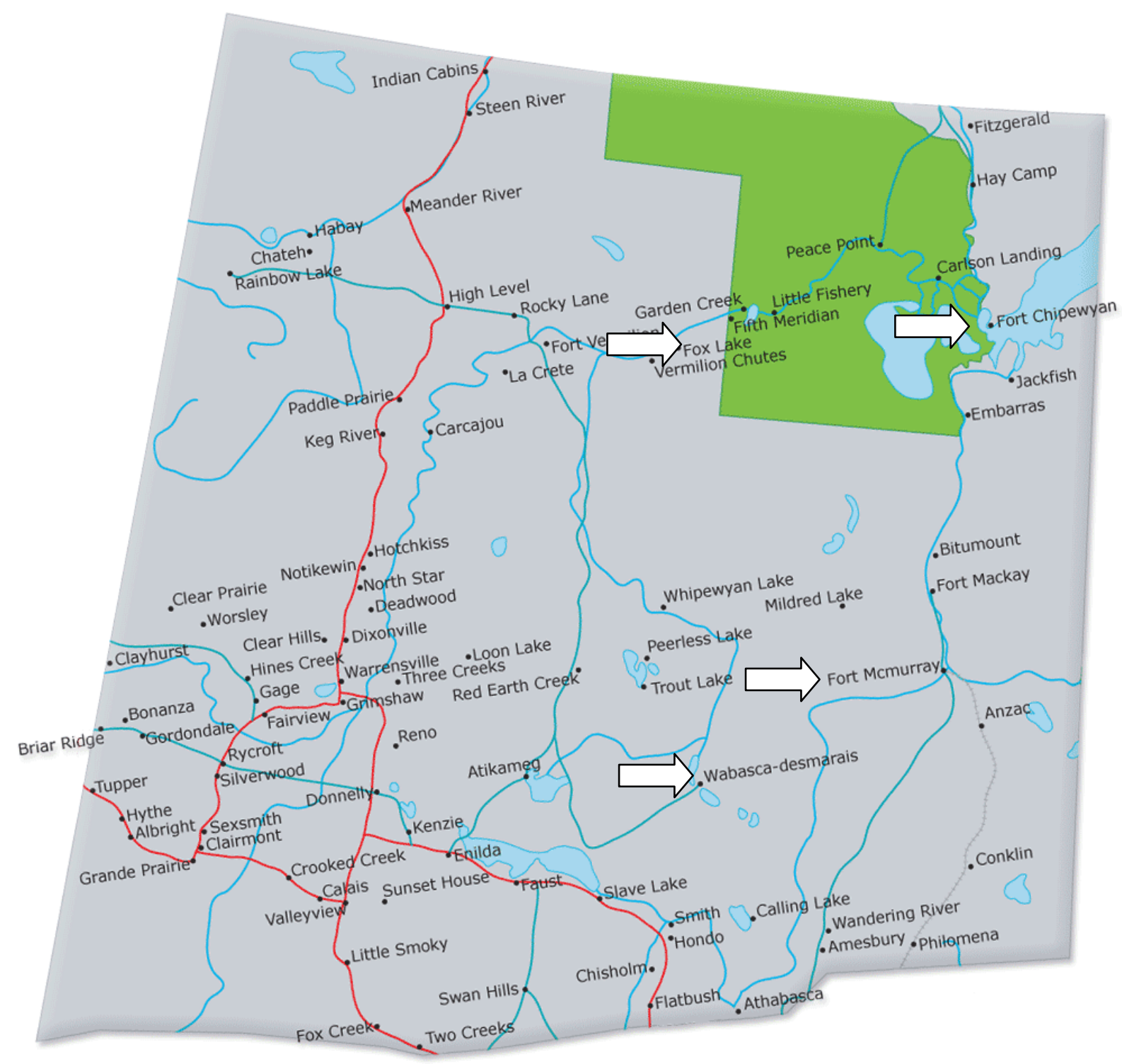

Figure 2: Location of study communities, Alberta, Canada.

\section{Some Demographic, Educational, and Economic Facts about the Study}

\section{Communities}

The four study communities are compared in the following table based on some basic educational and economic descriptors. 
Table 1

Demographic, Educational, and Economic Descriptors of the Target Communities

\begin{tabular}{|c|c|c|c|c|c|}
\hline Descriptors & $\begin{array}{l}\text { Fox } \\
\text { Lake }\end{array}$ & $\begin{array}{l}\text { Ft. } \\
\text { Chip* }\end{array}$ & $\begin{array}{ll}\text { Ft. } & \text { McKay } \\
(2006) & \end{array}$ & Wabasca & Alberta \\
\hline Population (2006) & 1,753 & 915 & 521 & 2,847 & $3,290,350$ \\
\hline $\begin{array}{l}\# / \% \text { of participants in the } \\
\text { study }\end{array}$ & $47 / 28 \%$ & $49 / 30 \%$ & $17 / 10 \%$ & $52 / 32 \%$ & \\
\hline \multicolumn{6}{|l|}{$\begin{array}{l}\text { Education }(15+\text { years of } \\
\text { age })\end{array}$} \\
\hline - No certificate or diploma & $89 \%$ & & $66.3 \%$ & $63.0 \%$ & $23 \%$ \\
\hline - Apprenticeship or trade & $1 \%$ & & $6.3 \%$ & $7.4 \%$ & $11 \%$ \\
\hline - High school diploma & $6 \%$ & & $17.5 \%$ & $14.9 \%$ & $26 \%$ \\
\hline - Unemployment rate & $19.7 \%$ & & $18.0 \%$ & 15.1 & $4.3 \%$ \\
\hline - Participation rate & $34.7 \%$ & & $61.7 \%$ & 61.3 & $74.0 \%$ \\
\hline \multicolumn{6}{|l|}{ Income $(2005)$} \\
\hline - Median, census families & $\$ 22,592$ & & $\$ 52,736$ & $\$ 42,926$ & $\$ 73,823$ \\
\hline $\begin{array}{l}\text { - Median, fulltime } \\
\text { employed }\end{array}$ & $\$ 23,584$ & & $\$ 44,384$ & $\$ 36,093$ & $\$ 43,964$ \\
\hline - Median, married couples & $\$ 41,600$ & & $\$ 72,192$ & $\$ 55,917$ & $\$ 83,046$ \\
\hline - Median, common law & $\$ 19,520$ & & $\$ 64,000$ & $\$ 45,748$ & $\$ 67,184$ \\
\hline - Median, lone parent & $\$ 11,744$ & & $\$ 35,968$ & $\$ 25,785$ & $\$ 40,397$ \\
\hline
\end{tabular}

Source: http://www12.statcan.ca/english/census06/data/profiles/community/Index.cfm?Lang=E

*Information for Fort Chipewyan was not separate from the general census data for the Wood Buffalo region, including Fort McMurray, an area of over 51,000 people.

Table 1 illustrates the fact that these four communities were not homogeneous: education and training levels were lower in the target communities, but, outside of Fox Lake, residents held more apprenticeship and trades credentials; the overall unemployment rate was higher in these Northern communities taken together, but the labour-market participation rate was considerably higher in Ft. McKay and Wabasca than in Fox Lake. Further, Ft. McKay residents had notably better incomes than the other communities - higher in the case of the median incomes for the fulltime employed than the average for all Albertans. As well, the median income of married couples in Ft. McKay was nearly equal to the median family income for the province. (Ft. McKay has economic advantages due to the services it provides to nearby oil sands companies.)

\section{Rationale}

To address how well Alberta's current educational offerings meet the preferences of the communities' residents, the study employed written surveys (some completed by respondents independently online, others completed by researchers during face-to-face contacts in the study communities). Interviews were conducted with full- and part-time residents during visits to the communities in 2007 and 2008. 
While every community member's input was invited and welcomed (announcements of the researchers' presence and purposes were circulated prior to their arrival, and methods to forward comments after the researchers' departure were provided), some individuals in each community were sought out, based on their positions in the community or on the recommendations of others. These methods resulted in input from a total of 165 residents of the four communities (see Table 1 for distribution of responses).

The study focused on the current patterns of enrollment in the selected communities and on the participants' self-reported learning experiences and preferences, including views of residents about both present program content and available delivery formats. Data from Alberta Advanced Education and Technology (2008) from the COGNOS database and information from colleges actively programming in the region provided present and historical enrollment patterns.

\section{Focus, Purpose, and Processes}

In the four Northern communities studied, technologies such as SuperNet and administrative and policy initiatives such as Campus Alberta and eCampusAlberta were expected to provide local alternatives to traditional campus-based education and training. These communities represent a range of typical northern Canadian settlements in mixed culture and demographics, economic and social structures, and relative geographic isolation (Table 1).

To determine the degree to which the provisions for post-secondary education and training in these communities meet the stated expectations and interests of the residents, the researchers reviewed available data on post-secondary registration rates, interviewed students and potential students, and consulted face-to-face with community members (including employers and representatives of various government and social services). Two researchers visited each community together, allowing them to compare their observations and interpretations. The study attempted to be blind in relation to participants' ethnic or racial backgrounds, except in providing multiple avenues for participation. The study used a combination of methods (written and oral), face-to-face contact with respondents in the communities, and ongoing contact and interaction with the respondents and the communities over time (including seeking out individuals recommended by others to invite their participation) to assure the results were rooted in the current views of a range of actual or potential students and to provide access for anyone wishing to participate.

Interviews were conducted while researchers were present in the communities; as well, the researchers left copies of the survey form for anyone who might wish to complete and return it later. In some cases, the researchers completed the surveys for residents while speaking with them (with their awareness and permission). The purpose was to determine the experiences of respondents with formal institutional learning, including both content and delivery models. The question was whether present offerings might use technology to more satisfactorily enhance accessibility and choice for Northern residents. 


\section{Ethics}

The proposal for this research was reviewed by the Athabasca University Research Ethics Board (REB) in late 2008 and approved in December 2008. It was emphasized in the ethics proposal that this research was designed to gain information, not to provide advice, and that the primary stance of the researchers throughout the process was to listen and record, obtaining the broadest possible input from the target communities.

\section{Findings}

The face-to-face surveys, including interviews, resulted in articulation of the following common themes and concerns:

1. Northern residents preferred to remain in their home communities for post-secondary training. McMullen (2004) previously reported that this preference along with the lack of financial support of a nearby delivery institution and the lack of role models were the greatest barriers to post-secondary participation of northerners. Repetition of this finding, in light of technological advances that make it more realistic in relation to learning, confirms both its enduring importance to residents and its feasibility.

2. Supportive of the above, a great majority of respondents reported access to a computer and felt they possessed sufficient computer skills to learn online. Whether those without broadband experienced this as a barrier to access was not addressed.

3. Supportive of community-based learning, over forty percent of respondents said their preferred mode of learning was "computer, Internet."

4. Not surprisingly, jobs, inconvenient timing and location of courses, and family responsibilities were the primary barriers to enrolling in or, in the past, completing programs.

5. Many respondents were concerned about financing their learning while working. (Delivery models were expected to assure that learning and work could coexist.)

6. More literacy programming is needed, particularly English conversation for speakers of native languages. Lack of conversational skills in English mainly affected older, native residents, but there were also increasing numbers of non-native immigrant speakers of English in these communities who required enhanced language and literacy skills.

7. Local colleges were generally well respected; along with the community library and the Internet, local college staff members were seen as good sources of information on educational programming, careers, and training.

8. About half of the residents who participated in the survey had engaged in training of some kind, and a majority reported the experience had been useful. (This suggests the respondents represented those already familiar with and committed to formal institutional learning.)

9. University and college courses, work-related training, parenting, and safety were primary areas of interest; business management, life skills, basic math and English, music, languages, advanced software, and Bachelor of Commerce were others. 
10. PLAR was thought to be relevant by about three-quarters of the respondents. (Taylor, Friedel, and Edge [2009] reported that lack of PLAR recognition was a common experience of youth in the North, especially Aboriginals.)

\section{Details on Educational Skills and Experiences}

The following table shows information about educational experiences and resources, as reported on the surveys.

Table 2

Combined Results, Educational Experiences, Interests, Skills (Ranked)

\begin{tabular}{|l|l|l|l|l|l|}
\hline Survey question & $\begin{array}{l}\text { Fox } \\
\text { Lake } \\
(\mathbf{n = 4 7 )}\end{array}$ & $\begin{array}{l}\text { Fort } \\
\text { Chip } \\
(\mathbf{n = 4 9})\end{array}$ & $\begin{array}{l}\text { Fort } \\
\text { McKay } \\
(\mathbf{n = 1 7}\end{array}$ & $\begin{array}{l}\text { Wabasca } \\
(\mathbf{n = 5 2})\end{array}$ & $\begin{array}{l}\text { Total } \\
(\mathbf{n = 1 6 5})\end{array}$ \\
\hline Can you use a computer? & $85 \%^{*}$ & $96 \%$ & $94 \%$ & $94 \%$ & $\mathbf{9 2 \%}$ \\
\hline Do you have access to a computer? & 83 & 88 & 88 & 92 & $\mathbf{8 8 \%}$ \\
\hline Do you have a computer in your home? & 81 & 84 & 88 & 90 & $\mathbf{8 6 \%}$ \\
\hline Is computer access convenient? & 81 & 73 & 88 & 85 & $\mathbf{8 2 \%}$ \\
\hline $\begin{array}{l}\text { Would you like more information about } \\
\text { PLAR? }\end{array}$ & 66 & 76 & 65 & 58 & $\mathbf{6 6 \%}$ \\
\hline Have you taken a college course? & 57 & 61 & 71 & 64 & $\mathbf{4 9 \%}$ \\
\hline $\begin{array}{l}\text { Is prior learning assessment and } \\
\text { recognition of interest? }\end{array}$ & 68 & 63 & 0 & 62 & $\mathbf{5 8 \%}$ \\
\hline $\begin{array}{l}\text { Have you ever taken a course on a } \\
\text { computer? }\end{array}$ & 30 & 49 & 18 & 79 & $\mathbf{4 4 \%}$ \\
\hline
\end{tabular}

*Proportion of "yes" replies to these questions.

From the above came the following indications of the learning experiences and readiness of the respondents:

1. Very high numbers of residents reported they could use a computer, had a computer in their home, or had convenient access to one.

2. Almost half had taken a course of some kind on a computer.

3. About half had previously taken a college course.

4. Two-thirds were interested in more information about prior learning assessment and recognition (PLAR).

5. The following table combines the data from the four communities regarding previous education and training patterns. 
Table 3

Combined Results, Previous Education, Present Training Interests

\begin{tabular}{|c|c|c|c|c|c|}
\hline Education element & $\begin{array}{l}\text { Fox } \\
\text { Lake } \\
(n=47)\end{array}$ & $\begin{array}{l}\text { Fort } \\
\text { Chip } \\
(n=49)\end{array}$ & $\begin{array}{l}\text { Fort } \\
\text { McKay } \\
(n=17)\end{array}$ & $\begin{array}{l}\text { Wabasca } \\
(n=52)\end{array}$ & $\begin{array}{l}\text { Total } \\
(n=165) \\
\%\end{array}$ \\
\hline \multicolumn{6}{|l|}{ Courses, programs most wanted } \\
\hline Accounting & & 1 & 2 & 2 & $3 \%$ \\
\hline Business management, admin. & 14 & 14 & 3 & 19 & 30 \\
\hline Computer skills, computer training & 1 & 4 & 1 & 4 & 6 \\
\hline Crafts, culture & 2 & 1 & 1 & 2 & 4 \\
\hline Environment & & 1 & & & 1 \\
\hline Health, nursing-related & 2 & 1 & & 1 & 2 \\
\hline Life skills & 1 & 6 & 5 & 3 & 9 \\
\hline Parenting & 1 & 4 & 2 & 4 & 6 \\
\hline Safety, First aid, H2S, CPR, WHMIS & 4 & 6 & 5 & 10 & 15 \\
\hline Sports & & & & 1 & 1 \\
\hline Technical, work-related & & 10 & 1 & & 6 \\
\hline Trades & & & & 4 & 2 \\
\hline Transportation, machine operation & & 1 & & & 1 \\
\hline Upgrading, GED & 13 & 16 & 5 & 30 & 39 \\
\hline College-, university-level courses & 3 & 2 & & 1 & 4 \\
\hline \multicolumn{6}{|l|}{$\begin{array}{l}\text { Delivery model of training previously } \\
\text { taken }\end{array}$} \\
\hline Teacher-conducted & 30 & 30 & 11 & 38 & $66 \%$ \\
\hline Computer-based & 14 & 24 & 8 & 23 & 42 \\
\hline \multicolumn{6}{|l|}{ Student-perceived barriers to learning } \\
\hline Job & 25 & 31 & 7 & 35 & $59 \%$ \\
\hline Family & 14 & 20 & 6 & 20 & 36 \\
\hline Timing & 24 & 24 & 8 & 24 & 48 \\
\hline $\begin{array}{l}\text { Location (student's own, or training } \\
\text { site) }\end{array}$ & 9 & 12 & 8 & 15 & 27 \\
\hline \multicolumn{6}{|l|}{$\begin{array}{l}\text { Reasons for not taking or not } \\
\text { completing previous training }\end{array}$} \\
\hline & 6 & 12 & 5 & 20 & $26 \%$ \\
\hline
\end{tabular}




\begin{tabular}{|l|l|l|l|l|l|}
\hline Not offered at a convenient time, place & & & & & \\
\hline Desired course not offered & 4 & 14 & 5 & 10 & $\mathbf{2 0}$ \\
\hline Cost (computer, & 1 & 3 & 0 & 4 & $\mathbf{4}$ \\
\hline $\begin{array}{l}\text { Needed } \\
\text { broadband) not available }\end{array}$ & & & & & $\mathbf{5}$ \\
\hline & & & & & \\
\hline Preferred method of learning & 21 & 35 & 15 & 26 & $\mathbf{5 9 \%}$ \\
\hline Teacher, in a classroom & 16 & 23 & 13 & 17 & $\mathbf{4 2}$ \\
\hline Computer, Internet & 6 & 12 & 5 & 10 & $\mathbf{2 0}$ \\
\hline Video & 4 & 10 & 0 & 5 & $\mathbf{1 2}$ \\
\hline TV & & & & 7 \\
\hline
\end{tabular}

From the above the following conclusions were drawn:

1. Three-quarters of the respondents reported positive previous learning experiences. (This was seen as an indication that the respondents were already learning-oriented; they were not necessarily highly schooled, however, as shown by the next two points.)

2. Upgrading (including GED and specific subjects such as math and English) were of greatest interest; next were business management and administration, followed by safetyrelated subjects.

3. Trades and technologies training were mentioned in every community by both employers and others (often in the context of "work-related" training).

4. While most respondents preferred a teacher-led learning experience, almost half (42\%) were open to computer-based learning.

5. In the interviews, job was the most often mentioned barrier to further training, followed by the timing and location of training opportunities, and family issues.

6. Training not offered at a convenient time was the most often discussed reason for nonparticipation. Lack of availability of desired courses was the next most often mentioned barrier.

\section{Discussion and Conclusions}

This study used enrollment patterns and trends and non-random sampling techniques (Simon \& Burstein, 1985, pp. 121-122) to determine, in a time of increasing availability of online learning, the preferences of Alberta's northern residents for education and training offerings, including delivery models. The findings suggest that if a range of upgrading, business- and employmentrelated programming (including trades) were offered locally, with both face-to-face and computer-based options that could accommodate work and family responsibilities, most of the expressed preferences of the study's respondents would be met. Most importantly, if the offerings were by distance methods only, over $40 \%$ of the respondents reported they would be open to enrolling.

Presently, while the institutions offering programs locally are respected, consulted, and attended, records show that northern residents have increasingly chosen employment over training, as 
shown by recent enrollment declines. They reported in interviews that they were less willing to interrupt their careers or seriously inconvenience themselves and their families to access formal institutional training programs. The study thus confirmed the potential viability of distance learning as an alternative for some residents, supported by the fact that respondents in all the study communities reported access to, and confidence in the use of, distance technologies located either in their homes or conveniently nearby and a willingness to learn to use technology.

In combination, some of the study's findings are suggestive of actions institutions might take and decisions policy makers might adopt to enhance their appeal to Northern Albertans and, to the degree these individuals are representative, to Northern Canadians. While a majority of the respondents indicated they had access to, and were comfortable with, computer technologies, had access to computers in their homes, or had convenient access somewhere to a computer, a minority (42\%) had actually used computers in learning. Combined with the residents' express desire to stay in their home communities for training, the flexibility and accessibility of online and distance learning might be attractive if residents knew more about this option and its workings. This interpretation is bolstered by the finding that the reason most often given by respondents for failing to enroll in or complete a program was the usual inconvenience associated with program access. A delivery methodology that reduces inconvenience, or that positively facilitates access to learning, might address a fundamental problem related to enrollment presently experienced by northerners: clashes with job, personal, and family priorities.

The task of making distance delivery a viable option in the North is complex; learners have to be shown how to be successful with online learning and distance methods of delivery. Peters (2004) has warned that "situational factors" such as employment, lack of employer support, and past (negative) experiences with formal education, can be significant in the decision by adults to engage in or avoid formal learning projects. The study demonstrates that institutions offering technology-based programs in the North need to provide relevant information on the differences between traditional and online learning; give information to employers, the community, and families about the requirements to be successful in online learning; and provide training in how to be a successful online learner.

The findings relate to historical patterns by suggesting that some new possibilities may now exist for learners in remote areas. Historically, studies have established that personal and situational factors vary in individuals and are significant for learning success (Cross, 1981); that adults have various and diverging reasons for learning (Houle, 1961; Boshier, 1971; Hough, 1984; Furst, 1986); that cognitive factors are but one of the influences on learning, others being attitudes and emotions (affect) and the quality of instruction (including delivery methods) (Bloom, 1976); and that previous preparation is likely to profoundly impact the success of subsequent learning efforts (Carroll, 1963; Bonds of Time, 2009). While the representatives of the Northern communities we studied differed on some questions, they agreed with the view that training and education must become more flexible to be compatible with adult situational factors; that personal purposes and preferences (including a people's educational history) are significant to present attitudes; that quality of content and support is expected in online programs; and that the earlier experiences of potential individual Northern learners cannot be ignored, especially as related to failures or 
disappointments (Taylor et al., 2009). Local differences aside, the consensus was that a delivery model is needed for the study communities that respects learners' needs and preferences, rather than requiring them to make most of the adjustments; that recognizes prior learning (formal and non-formal); and that is consistent and compatible with residents' personal, family, and workrelated realities.

It must be noted that the researchers were "outsiders" to the communities studied and that the research did not arise from internal priorities of the residents or of the communities themselves. While both researchers had considerable experience residing and working in the North, neither was a resident of one of the four communities. The researchers nevertheless felt that the views expressed to them, and the findings they reported, reflected the candid and honest responses of the participants, but the possible impact of their non-resident status and the possible perceptions of some residents regarding the pertinence of the research itself cannot be assessed.

Finally, and positively, it should be encouraging to present institutional education providers that the study found large majorities of the respondents had found community educational programming useful (89\%) and that they desired more of it (100\%). At $42 \%$, the minority seeking distance access is a substantial one. Serving them will increase awareness of delivery options by those not enrolled and should help inform those in face-to-face courses about possible alternatives to that form of delivery. Expanding distance offerings would help address the need confirmed by this study for "greater control over program content and delivery" in the North (Taylor et al., 2009). 


\section{References}

Alberta Advanced Education and Technology (2002). Campus Alberta - a policy framework. Retrieved October 9, 2008, from http://www.advancededucation.gov.ab.ca/pubstats/CampusPolicy/default.asp?Chapter=V ision

Alberta Advanced Education and Technology (2007). Roles and mandates: Policy framework for Alberta's publicly funded advanced education system. Available from http://www.advancededucation.gov.ab.ca/reading/policy/roleframework/Roles $\% 20$ and $\% 2$ 0Mandates\%20Policy\%20Framework\%20FINAL.pdf

Alberta Advanced Education and Technology (2008). Adult learning: COGNOS reporting. [Online (extranet) database.] Available from https://phoenix.edc.gov.ab.ca/login/default.asp

Alberta Finance and Enterprise (2007a). 2006 census highlights: Population and dwelling counts. Available from http://www.finance.gov.ab.ca/aboutalberta/census/index.html

Alberta Finance and Enterprise (2007b). 2006 census highlights: Age and sex. Available from http://www.finance.gov.ab.ca/aboutalberta/census/2007_0717_2006_age_sex.pdf

Alberta Finance and Enterprise (2007c). 2006 census highlights: Aboriginal peoples. Available from http://www.finance.gov.ab.ca/aboutalberta/census/2008_0118_Aboriginal_release.pdf

Alberta Finance and Enterprise (2007d). Alberta Heritage Savings Trust Fund 2008-09 second quarter update. Available from http://www.finance.gov.ab.ca/business/ahstf/index.html

Alberta Finance and Enterprise (2007e, November 20). Heritage Fund to receive injection from surplus. Available from http://www.finance.gov.ab.ca/business/ahstf/index.html

Alberta Finance and Enterprise (2007f). Information from the 2006 census of Canada: Age and sex. Available from http://www.finance.gov.ab.ca/aboutalberta/census/2007 $0717 \quad 2006$ age sex.pdf

Alberta Finance and Enterprise (2008a.) Highlights of the Alberta economy. Available from http://www.albertacanada.com/documents/SP-EH_highlightsABEconomyPres.pdf

Alberta Finance and Enterprise (2008b, June 24). Alberta Heritage Savings Trust Fund 2007-08 annual report (news release). Available from http://alberta.ca/ACN/200806/23865BB504BD6-ABFC-B59F0AD211025CB9B96C.html 
Alberta Finance and Enterprise (2008c). Current economic indicators by province (for the week $\begin{array}{llll}\text { ending } & 25 & \text { July } & \text { Available }\end{array}$ http://www.finance.gov.ab.ca/aboutalberta/economic_bulletins/current_economic_indicat ors.pdf

Alberta Finance and Enterprise. (2008d). Labour force developments: September 2008.

Available from http://www.finance.alberta.ca/aboutalberta/labour_force/2008/2008_09_developments.pd $\underline{\mathrm{f}}$

Alberta Finance and Enterprise (2008e). Budget 2008. Available from http://www.finance.alberta.ca/publications/budget/budget2008/fiscal.pdf

Association of Canadian Community Colleges. (2002). Colleges and institutes and Canada's innovation strategy. Retrieved October 9, 2008, from www.accc.ca/ftp/zGovRelations/2002Innovation.pdf

Association of Canadian Community Colleges (2005). Meeting the needs of Aboriginal learners: An overview of current programs and services, challenges, opportunities and lessons learned. Retrieved December, 17, 2008 from http://www.accc.ca/ftp/pubs/200507_Aboriginal.pdf

Bloom, B. S. (1976). Human characteristics and school learning. Toronto: McGraw-Hill Book Co.

Bonds of time. (2009, January 10). The Economist, 390(8613), 66.

Boshier, R. (1971). Motivational orientations of adult education participants: A factor analytic exploration of Houle's typology. Adult Education Quarterly, 21(2), 3-26.

Canada's Aboriginal population has broken the one-million mark. (2008). Alberta Sweetgrass. Retrieved November 12, 2008, from http://findarticles.com/p/articles/mi 6964/is 2 15/ai_n28489110

Carroll, J. B. (1963). A model of school learning. Teachers College Record, 64, 723-733.

Census of Canada. (2008). Aboriginal release. Available from http://www.finance.gov.ab.ca/aboutalberta/census/2008_0118_Aboriginal_release.pdf

Charbonneau, L. (2008, March.) Two new projects aim to fill gap in PSE [post-secondary education] data. University Affairs, 31-32.

Council of the Federation. (2006). Competing for tomorrow: A strategy for postsecondary 
education and skills training in Canada. Retrieved July 12, 2007, from http://www.councilofthefederation.ca/pdfs/PSE\%20Strategy-July-ENG.pdf

Cross, P. (1981). Adults as learners. San Francisco: Jossey-Bass.

Fahy, P. J. (1989). External evaluation of PLATO cluster installations in seven Arctic Communities, July, 1987, to June, 1989 (Unpublished report). Keewatin Region Education Authority, Arctic College.

Furst, E. J. (1986). An interpretation of the Boshier-Collins cluster analysis testing Houle's typology. Adult Education Quarterly, 36(4), Summer.

Greenall, D., \& Loizides, S. (2001). Addressing Aboriginal learning needs through the use of learning technologies. Conference Board of Canada. Available from http://www.hrsdc.gc.ca/en/hip/lld/olt/Skills_Development/OLTResearch/aborig_e.pdf

Gruber, S. \& Coldevin, G. (1994). Management training at a distance for Inuit administrators: The ATII pilot project. The Journal of Distance Education, 9(2), 21-34.

Houle, C. O. (1961). The inquiring mind. Madison: University of Wisconsin Press.

Hough, M. (1984). Motivation of adults: Implications of adult learning theories for distance education. Distance Education, 5(1), 7-23.

Knight, D., \& Tobin, L. (2002). Building basic skills for adults in small rural communities. Final report to the Office of Learning Technologies, project \#99561. Thunder Bay, Ontario: Contact North.

Malatest \& Associates. (2004). Aboriginal peoples and post-secondary education: What educators have learned. Available from http://www.millenniumscholarships.ca/images/Publications/Aboriginal_en.pdf

McMullen, K. (2004). Distance as a post-secondary access issue. Available from http://www.statcan.gc.ca/pub/81-004-x/200404/6854-eng.htm.)

McMullen, B., \& Rohrbach, A. (2003). Distance education in remote Aboriginal communities: Barriers, learning styles and best practices. Prince George BC: College of New Caledonia press. Available from http://www.cnc.bc.ca/mackenzie

Osborne, M. (2003). Policy and practice in widening participation: A six country comparative study of access as flexibility. International Journal of Lifelong Education, 22(1), 43-58. DOI: $10.1080 / 02601370304826$

Peters, V. (2004). Working and training: First results of the 2003 Adult education and training 
survey (81-595-MIE2004015). Ottawa, ON: Statistics Canada. Retrieved July 30, 2007, from http://www.statcan.ca/english/freepub/81-004-XIE/200412/aets.htm

Scoffield, H. (2007, June 13). Canada: Land of mediocrity. Globe \& Mail (globe\&mail.com). Retrieved June 14, 2007, from http://license.icopyright.net/user/viewFreeUse.act?fuid=Mzc0ODUz).

Simon, J., \& Burstein, P. (1985). Basic research methods in social science (3rd ed.). Toronto: McGraw-Hill, Inc.

Statistics Canada. (2008, November 17). Participation, graduation and dropout rates. Available from http://www.statcan.gc.ca/pub/81-595-m/2008070/6000003-eng.htm

Tapsall, S. (2001). All aboard the borderless education bandwagon. Open Learning, 16(1), 3546.

Taylor, A., Friedel, T. L., \& Edge, L. (2009). Pathways for First Nation and Metis youth in the oil sands. Canadian Policy Research Networks Research Report, April 2009. Available from http://www.cprn.org/documents/51241_EN.pdf

Tennant, M., \& Morris, R. (2001). Adult education in Australia: Shifting identities 1980 2000. International Journal of Lifelong Education, 20(1), 44-54.

Walters, D., White, J., \& Maxim, P. (2004). Does post-secondary education benefit Aboriginal Canadians? An examination of earnings and employment outcomes for recent Aboriginal graduates. Available from http://economics.ca/cgi/jab?journal=cpp\&view=v30n3/CPPv30n3p283.pdf 
June - 2009

\title{
Online Teaching Effectiveness: A Tale of Two Instructors
}

\author{
Paul Gorsky and Ina Blau \\ Open University of Israel
}

\begin{abstract}
Upon completion of a graduate level course at the Open University of Israel, one instructor received very high student ratings while the other received very low ratings. We utilized this exceptional situation to perform ad hoc analyses of their course forums. The objective of this study was to map the dialogic behavior that occurred and to create suggestions for best practice and for worst practice in terms of active and passive participation, instructor response time, and the extent of teaching presence, social presence, and cognitive presence.
\end{abstract}

Keywords: Effective online teaching; role of online instructor; community of inquiry model; virtual learning community; dialogic behavior; best practice

\section{Introduction}

Teaching effectiveness may be defined as how an instructor can best direct, facilitate, and support students toward certain academic ends, such as achievement and satisfaction. Teaching effectiveness has been investigated extensively in traditional classrooms for more than seven decades (for a meta-analysis of empirical studies from 1995-2004, see Seidel \& Shavelson, 2007). Over the past five years, research has become directed toward teaching effectiveness in online or virtual classes. As a preface to our study, we discuss findings and conclusions concerning teaching effectiveness in traditional classrooms. We do so for two reasons: practically, since all findings are relevant to online teaching, and theoretically, since current research has shown the theoretical equivalency of all kinds of instructional systems within the framework of a unified theory of instructional design (Gorsky \& Caspi, 2005; Gorsky, Caspi, \& Chajut, 2007).

One of the most widely cited sources for teacher effectiveness in traditional classrooms is Chickering and Gamson (1987), who suggested seven principles for good practice in undergraduate education. Given their simplicity and eloquence, no further commentary is added. A good teacher does the following:

1. encourages student-faculty contact, 
2. encourages cooperation among students,

3. encourages active learning,

4. gives prompt feedback,

5. emphasizes time on task,

6. communicates high expectations,

7. respects diverse talents and ways of learning.

The authors added this statement:

These principles are intended as guidelines for faculty members, students, and administrators... to improve teaching and learning. They rest on 50 years of research on the way teachers teach and students learn, how students work ... with one another, and how students and faculty talk to each other. (Chickering \& Gamson, 1987, p.3)

Given their importance for guiding teaching in traditional classrooms, these principles have since been adapted to web-based and virtual classrooms that rely on diverse instructional technologies. A decade after the principles were published, Chickering and Ehrmann (1996) wrote the following:

Since the seven principles of good practice were created in 1987, new communication and information technologies have become major resources for teaching and learning in higher education. If the power of the new technologies is to be fully realized, they should be employed in ways consistent with the seven principles. (Chickering \& Ehrmann, 1996, p.2)

These seven principles are defined formally. How can we define these principles operationally so as to be appropriate for research in online classrooms? We propose, as have others (i.e., Shea, Pickett, \& Pelz, 2003), that the community of inquiry model (Garrison, Anderson, \& Archer, 2000) reflects the principles of good practice in undergraduate education and can accurately quantify them. Relying on a quantitative content analysis technique, the model affords a detailed set of categories and indicators through which to examine issues of pedagogy, dialogue, and interaction. We now present an overview of the model along with representative research.

\section{The Community of Inquiry Model}

Garrison, Anderson, and Archer (2000) developed the community of inquiry model as an online learning research tool. The framework consists of three elements - cognitive presence, teaching presence, and social presence - as well as categories and indicators to define each of the presences and to guide the coding of transcripts. Cognitive presence is defined by Garrison, Anderson, and Archer (2001) as the extent to which participants are able to construct meaning through sustained communication. Teaching presence includes subject matter expertise, the design and management of learning, and the facilitation of active learning (Anderson, Rourke, Garrison, \& Archer, 2001). Social presence is the perceived presence of others in mediated 
communication (Rourke, Garrison, \& Archer, 1999), which Garrison et al. (2000) contend supports both cognitive and teaching presence through its ability to instigate, to sustain, and to support interaction. It had its genesis in the work of John Dewey and is consistent with all theoretical approaches to learning in higher education. This framework has provided significant insights and methodological solutions for studying online learning (Garrison \& Archer, 2003; Garrison, Cleveland-Innes, Koole, \& Kappelman, 2006). The structure of the community of inquiry model has been confirmed through factor analysis (Arbaugh \& Hwang, 2006; Garrison, Cleveland-Innes, \& Fung, 2004; Shea \& Bidjerano, 2009).

Social presence is described as the ability to project one's self and to establish personal and purposeful relationships (Rourke et al., 1999). The three main categories of social presence are affective communication, open communication, and group cohesion. Richardson and Swan (2003) explored perceptions of social presence in online courses and found that students' perceptions of social presence were highly correlated with perceived learning and satisfaction with their instructors (see also Steinweg, Trujillo, Jeffs, \& Hopfengardner-Warren, 2006). Picciano (2002) found relationships between student perceptions of social presence, learning, and interactions in the course discussions. The positive correlation between perceived social presence, seen according to the community of inquiry model as self projection, and most aspects of perceived learning may lead to the conclusion that social presence affords learning by setting a convenient climate (Caspi \& Blau, 2008). However, actual interaction in the course discussions in Picciano's (2002) study was not correlated with actual performance (their scores on a multiple choice exam and on a written assignment). Whether and how actual social interaction might or might not affect actual learning online remains unclear and constitutes an important area for future research (Caspi \& Blau, 2008; Swan \& Shea, 2005). Swan (2002) studied the apparent shift of social presence over time in online course discussions. She reported that open communication indicators ("affective" and "interactive") of social presence increased over time, while cohesive indicators decreased. One possible explanation is that the use of such references became less necessary as a galvanized classroom community was formed. Another possible explanation addressed the fact that discussion was more exploratory than collaborative. Contrary to the nature of the shift in social presence reported by Swan (2002), Vaughan (2004) and Vaughan and Garrison (2006) found that the frequency of affective and open communication comments decreased, while group cohesion comments increased. It is important to note that the context of Vaughan's study (2004) was a blended professional development community. The interpretation was that affective and open communication was necessary to establish a sense of community. It was only after the social relationships were established and the group became more focused on purposeful activities that cohesive comments began to take precedence. Social presence online becomes somewhat transparent as the focus shifts to academic purposes and activities.

Cognitive presence is defined as the exploration, construction, resolution, and confirmation of understanding through collaboration and reflection in a community of inquiry (Garrison et al., 2001). Cognitive presence is grounded in the work of Dewey (1933) on reflective thinking. Four phases are defined: Triggering event, exploration, integration, and resolution. Garrison et al. (2001) argue that the third phase, integration, is the most difficult to detect from a teaching or research perspective. This phase requires active teaching presence to diagnose misconceptions, to 
provide probing questions, comments, and additional information in an effort to ensure continuing cognitive development, and to model the critical thinking process. Often students will be more comfortable remaining in a continuous exploration mode; therefore, teaching presence is essential in moving the process to more advanced stages of critical thinking and cognitive development.

Teaching presence is defined as "the design, facilitation and direction of cognitive and social processes for the purpose of realizing [students'] personally meaningful and educationally worthwhile outcomes" (Anderson et al., 2001, p.5). Vygotsky's (1978) scaffolding analogies illustrate an assistive role for teachers in providing instructional support to students from their position of greater content knowledge. Although many authors recommend a "guide on the side" approach to moderating student discussions, a key feature of this social cognition model is the adult, the expert, or the more skilled peer who scaffolds a novice's learning (Anderson et al., 2001). The community of inquiry model defines three categories of teaching presence: design and organization, facilitating discourse, and direct instruction. The categories of teacher presence have been tested by Anderson et al. (2001) in an analysis of the complete transcripts of two online courses and have proved reasonably reliable and useful in identifying differences in both the quantity and quality of the teaching presence projected by different online instructors. How these differences might relate to community has not yet been hypothesized, but the community of inquiry model might provide a starting point for such investigations (Swan \& Shea, 2005).

The body of evidence attesting to the importance of teaching presence for successful online learning is growing rapidly (Garrison \& Cleveland-Innes, 2005; Meyer, 2003; Murphy, 2004; Pawan, Paulus, Yalcin, \& Chang, 2003; Shea, Pickett, \& Pelz , 2004; Swan, 2002; Swan \& Shih, 2005; Varnhagen, Wilson, Krupa, Kasprzak, \& Hunting, 2005; Vaughan, 2004; Wu \& Hiltz, 2004). The consensus is that teaching presence is a significant determinate of perceived learning, student satisfaction, and sense of community. Perceived teaching had a strong direct effect on self-reported learning outcomes (LaPointe \& Gunawardena, 2004). Each category of a tutor's presence is vital to learning and to the establishment of the learning community; tutors' behavior must be such that they are seen to be "posting regularly, responding in a timely manner and modeling good online communication and interaction" (Palloff \& Pratt, 2003, p.118). Without an instructor's explicit guidance and "teaching presence," students were found to engage primarily in "serial monologues" (Pawan et al., 2003). Baker (2004) discovered that "instructor immediacy, i.e., teaching presence (Rourke et al., 1999), was a more reliable predictor of effective cognitive learning than whether students felt close to each other. Studies have demonstrated that instructor participation in threaded discussion is critical to the development of social presence (Shea, Li, Swan, \& Pickett, 2005; Swan \& Shih, 2005) and sometimes not fully appreciated by online faculty (Liu, Bonk, Magjuka, Lee, \& Su, 2005). Shea, Li, and Pickett (2006) proposed that teaching presence - viewed as the core role of the online instructor - is a promising mechanism for developing learning community in online environments. The majority of students and instructors in Vesely, Bloom, and Sherlock's (2007) study identified the same elements for building online community, but students ranked instructor modeling as the most important element in building online community, while instructors ranked it fourth. 
To conclude, we note a recent study that questioned whether there are three categories of teaching presence. Shea (2006), who completed an extensive study of teaching presence and online learning, concluded that two categories ("design" and "directed facilitation") sufficed to define the construct. In this study, we opt for the three categories of teaching presence as defined originally by Garrison et al. (2000).

Extensive research into effective online teaching has been carried out without using the community of inquiry model. We now present representative findings concerning the impact of interaction and feedback on students' perceptions of, and satisfaction with, online learning. Both constructs are closely interrelated with instructor response time, the rate at which instructors respond to students' posts.

\section{Effective Online Teaching: Research Findings}

Regarding interaction, Ridings and Gefen (2004) found that across all types of communities, information exchange was the most commonly cited reason for participation while social support was the second most popular reason for members in communities devoted to professional topics. Communities are used not only for informational purposes but also as an opportunity for social interaction (Kaye, 2005). Kalman, Ravid, Raban, and Rafaeli (2006) argued that interactivity is an essential characteristic of effective online communication and plays an important role in keeping message threads and their authors together. Interactive communication (online as well as in traditional settings) is engaging, and loss of interactivity results in a breakdown of the communicative process.

Research indicates the existence of a relationship between learners' perceptions of social presence and their motivation for participation in online discussions (Weaver \& Albion, 2005). The importance of social interaction to individuals who participate in online communities explains why sociability may be a key element in determining the success or failure of an online community. It has been found that learner satisfaction depends on student-instructor interactions and that students' perceptions of 'good' interactions have a positive impact on their enthusiasm and learning (Swan, 2001; Tricker et al., 2001; Ussher, 2004).

Qualitative data from Weaver and Albion's (2005) study showed that students placed a high priority on the role of the course instructor as initiator and maintainer of momentum in discussions. This was most evident in the comments of students who experienced infrequent participation by the course instructor. Northrup (2002) found that online learners felt it was important for instructors to promote collaboration and conversation. When interactive activities are carefully planned, they lead not only to greater learning but also to enhanced motivation (Berge 1999; Northrup, 2002).

Interaction in a forum is closely related to the rate at which new messages are posted. Increased frequency of posting in asynchronous communications can lead to more favorable impressions of communication partners (Liu, Ginther, \& Zellhart, 2001; Walther \& Bunz, 2005). Researchers have suggested that timing of messages can serve as a proxy for a sense of social presence 
(Blanchard, 2004), as an indication of attentiveness (Walther \& Bunz, 2005) or respect (Bargh \& McKenna, 2004), and as a clue to the sociability of a community (Maloney-Krichmar \& Preece, 2005). As such, the frequency of messages may serve as a signal for how engaged participants are with the community.

Regarding feedback, a survey conducted by McCollum, Calder, Ashby, and Morgan (1995) showed that students ranked feedback as the highest factor in determining course quality. Similar findings were reported by Tricker et al. (2001), Spangle, Hodne, and Schierling (2002) and Young (2006). At the same time, faculty members found interacting with and providing feedback to students in online classes to be more time consuming than in face-to-face classes (Chabon, Cain, \& Lee-Wilkerson, 2001; Jennings \& McCuller, 2004; Herrmann \& Popyack, 2003; Smith, Ferguson, \& Caris, 2002).

Kearsley (2000) and Simonson, Smaldino, Albright, and Zvacek (2000) found that instructors can either enhance or decrease course interaction depending on how consistently, quickly, and helpfully they respond. The most successful online courses are those in which instructor-tostudent interaction is both frequent and productive (Northrup, 2002; Swan, 2001). Thus, evidence of high instructor engagement ranged from low to high in the quality, speed, and usefulness of feedback to students. Jiang and Ting (2000) further reported that both perceived learning and perceived interaction with instructors were linked to the actual average numbers of responses per student that instructors made. Swan, Shea, Fredericksen, Pickett, Pelz, and Maher (2000) also found a correlation between students' perceived interaction with their instructors and the actual frequency of instructor participation in online course discussions, and Picciano (1998) reported that instructors' activity was related to students' perceived learning from them in an online graduate level course. The number and type of facilitator postings also increased the level of interaction between students (Gilbert \& Dabbagh, 2005).

On the other hand, Eom (2006) found that instructor facilitation and feedback did not affect the perceived satisfaction of students who take web-based courses. Eom found that the most significant factors for increasing student satisfaction with online classes are paying attention to students and responding to their concerns.

\section{The Current Study: Rationale and Research Questions}

At the end of an ordinary graduate level course at the Open University of Israel, one instructor received very high student ratings while the other received very low ratings, relative to university standards. Given this exceptional situation, we used the quantitative content analysis technique (Garrison et al., 2000) and data logs to perform post-hoc analyses of their forums. The quantitative content analysis technique, based on the community of inquiry model, has been widely used to analyze forums (Garrison, 2007). Given the reliability and validity of this procedure and that all other relevant variables in the learning environment (course policy, content and difficulty, equivalent numbers of instructor assignments, group size, semi-random assignment to groups) were controlled, we expected to identify the impact of the instructors' actions on the dialogic behavior in the two forums. 
We defined two objectives for this study. The first was to test the hypotheses, theory-based and empirically supported, that in a forum led by a very highly rated instructor, as opposed to a forum led by an instructor held in very low esteem, the following would occur:

1. Active and passive participation would be significantly higher,

2. Levels of social presence, teaching presence, and cognitive presence would be significantly higher, and

3. Instructor response time would be significantly shorter.

The second was to create initial suggestions for comparing one asynchronous, virtual learning community with another. Specifically, we hoped to establish tentative boundary conditions for best practice and for worst practice in terms of active and passive participation in the forum, instructor response time, the extent of social presence, teaching presence, and cognitive presence, and the ratios of each.

\section{Methodology}

\section{Background}

The Open University of Israel is a distance education university that offers undergraduate and graduate studies to students throughout Israel. The learning environment is blended: The University offers a home study system based on textbooks, face-to-face tutorials, and a webbased instructional environment wherein each course has its own website. Course sites simplify organizational procedures and enrich students' learning opportunities and experiences. Website use is optional or non-mandatory so that equality among students is preserved. It does not replace textbooks or face-to-face tutorials, which are the pedagogical foundations of the Open University. The website provides forums for asynchronous instructor-student and student-student interactions. Each course has a coordinator who is responsible for all administrative and academic activities and instructors who lead tutorials. Instructors and coordinators are available for telephone consultations at specified days and times. Course coordinators define the number of forums made available and their purpose.

In this particular course, three forums were defined: a central forum, led by the course coordinator and available to all students, which dealt with administrative and organizational issues and two smaller forums, led by each of the instructors, which dealt with subject-matter issues. Prior to the start of the course, the coordinator met with both instructors and defined for them the goal of their forums: to provide a haven wherein subject-matter issues could be criticized, reflected upon, discussed, and debated within the context of the course, beyond the context of the course (students' personal experience), and in any other way deemed appropriate. Both instructors were expressly told to encourage and to facilitate such activities. It appeared that both accepted the task readily and eagerly. In addition, at the start of the course, the course coordinator communicated to all the students (via the general course forum) the purpose of the instructor-led forums. As well, each instructor clearly communicated to her group of students the 
goals and expectations she held vis-à-vis the forum. This was done by posting messages in the forum and at the face-to-face tutorial sessions.

\section{Participants}

Participants were two female instructors and 42 graduate students enrolled in the course. Of the 42 students, thirty $(71 \%)$ were female. Students were divided equally into two forums led by each of the two instructors. One possibly significant difference between the two instructors was their prior experience in tutoring Open University courses: one instructor, subsequently held in low esteem, had 4 years experience, while the second instructor, subsequently held in high esteem, was new to the task. She was, however, experienced in the ways of distance education. It is especially noteworthy that previous evaluations of the instructor subsequently held in low esteem were generally average, not below average or low.

\section{Instruments and Procedure}

Three instruments were employed for obtaining data: (1) survey data, elicited near the course's end, rated students' assessments of the instructors and perceived course difficulty; (2) the course log site recorded the amount of active participation, the amount of passive participation (lurking), the number of threads, and instructor response time; and (3) the quantitative content analysis technique, based on the community of inquiry model (Garrison et al., 2000), was used to code and analyze transcriptions from the two forums. This technique has been widely used; it is reliable and valid (Garrison, 2007). Its implementation, however, requires that several methodological issues be resolved.

One issue is the level of coding (e.g., indicator vs. category). Content analysis, as described by Rourke and Anderson (2004), is time consuming, and coding at the indicator level is difficult, often yielding poor reliability (Murphy \& Ciszewska-Carr, 2005). In this study, we coded at the category level (Garrison et al., 2006).

Another issue is the unit of analysis. Rourke et al. (1999) identified five units of analysis used in computer conferencing research: proposition units, sentence units, paragraph units, thematic units, and message units. While there has been some discussion around this issue (Garrison et al., 2006; Fahy, 2001; Rourke, Anderson, Garrison, \& Archer, 2001), it remains a challenging decision influenced by research question and context. In the present study, we used the message unit, in accord with Anderson et al.'s (2001) study of teaching presence, Garrison et al.'s (2001) study of cognitive presence, and Rourke et al.’s (1999) study of social presence.

Other issues are objectivity, reliability, and replicability (Rourke et al., 2001). No established standards exist for inter-rater reliability (De Wever, Schellens, Valcke, \& Van Keer, 2006). There is no consensus for the percent agreement statistic. Often a cut-off figure of $0.75-0.80$ is used to determine reliability; others use 0.70 (Neuendorf, 2002; Rourke et al., 2001). To increase reliability and to control errors brought on by inexperience or misinterpretation, Garrison et al. (2006) suggest a negotiated coding approach: researchers code the transcripts and then actively 
discuss their respective codes with their fellow judges in order to achieve consensus or near consensus. Gros and Silva (2006) propose the use of a research methodology based on the intervention of the participants, especial course instructors, for analyzing computer supported communication. In this study we used the traditional coding approach (without negotiation or participant intervention): $25 \%$ of postings were randomly chosen and re-estimated by a second rater; 92\% agreement was achieved (Cohen's $k=0.93$ ).

\section{Findings}

The Open University of Israel routinely offers students the opportunity to rate each course they participate in along several dimensions. Questionnaires are posted in the course forum close to the semester's end, prior to the final examination. Anonymity is assured. For the course involved, 23 of the 43 students $(53.5 \%)$ returned questionnaires.

One dimension, instructor satisfaction, includes a cluster of 12 questions; each is rated on a scale of 0-5, with five indicating high satisfaction. Overall, the highly esteemed instructor received an average rating of 4.3 ( $S D: 0.26)$ while the instructor held in low esteem received a rating of 2.3 $(S D: 0.42$ ). Figure 1 shows ratings achieved by the two instructors for each of the 12 questions. The relatively small numbers of students involved precluded the use of $t$ test or Mann Whitney statistics. However, differences between students' satisfaction vis-à-vis the two instructors for all parameters were apparent.

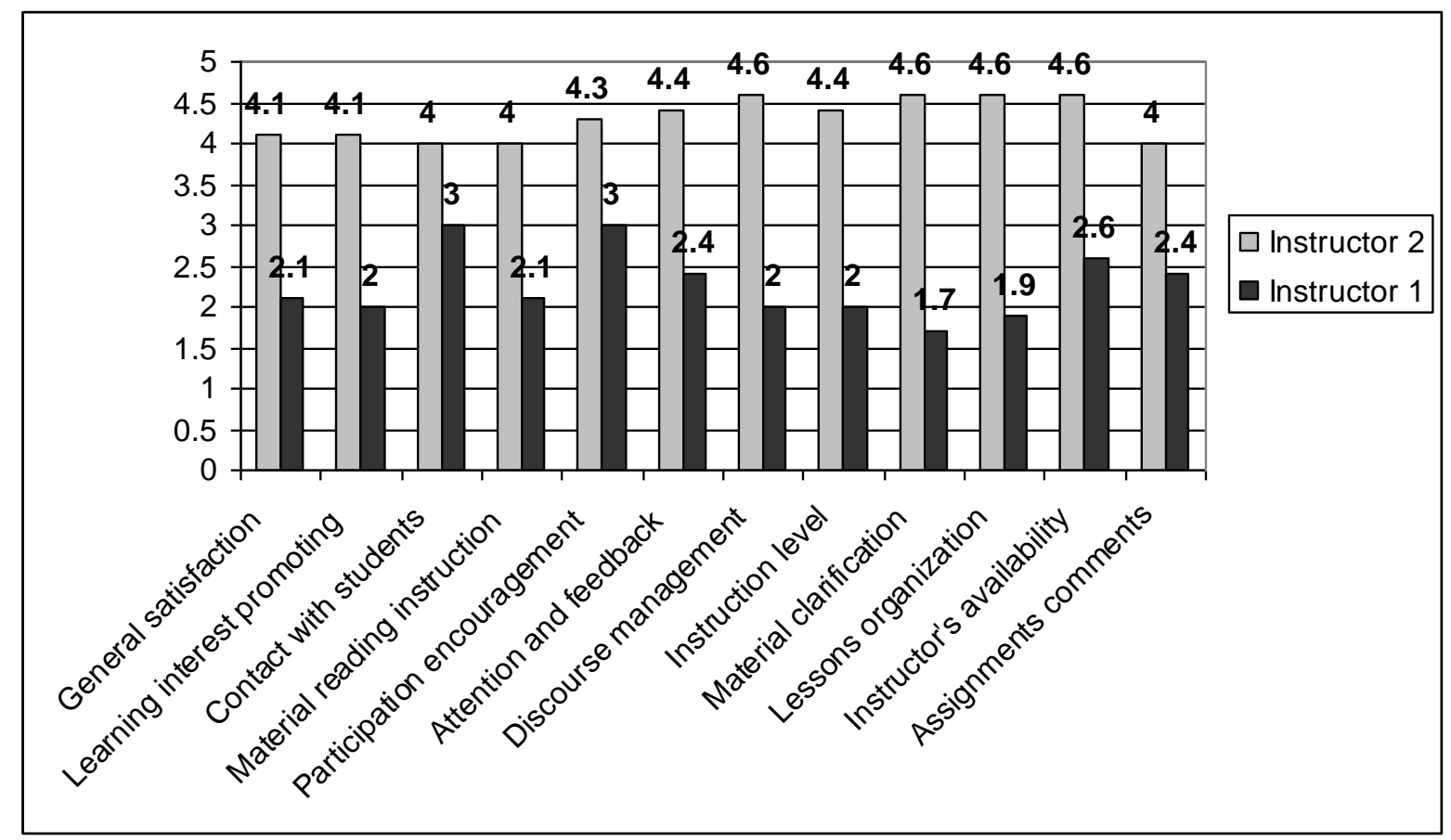

Figure 1. Students' evaluations of instructors.

We note that no specific question or questions address how instructors managed their asynchronous course forums. For the purpose of this research, we assumed that student 
satisfaction vis-à-vis this parameter would be similar to all the other parameters. Indeed, the findings described below support this assumption.

Data obtained from the course log site enabled measurement of active and passive participation for each forum. Passive participation, lurking, occurs when a student logs onto the forum but does not post a message. Highly significant differences were found between the two forums for active and passive participation by both instructors and students. Forum 1, led by the instructor held in low esteem, included a total of 55 postings; forum 2, led by the highly esteemed instructor, included a total of 125 postings $\left(\chi^{2}=27.22, p<0.001\right)$. Table 1 summarizes these findings for the duration of the semester.

Table 1

Active and Passive Participation (Lurking) During the Semester

\begin{tabular}{|c|c|c|c|c|}
\hline Participation & Months & $\begin{array}{l}\text { Forum1 } \\
\text { (low esteem) }\end{array}$ & $\begin{array}{l}\text { Forum2 } \\
\text { (high esteem) }\end{array}$ & $\chi^{2}$ \\
\hline \multirow{5}{*}{$\begin{array}{l}\text { Instructor } \\
\text { postings }\end{array}$} & $1^{\text {st }}$ & 4 & 6 & n.s. \\
\hline & $2^{\text {nd }}$ & 11 & 7 & n.s. \\
\hline & $3^{\text {rd }}$ & 4 & 29 & $18.94 * * *$ \\
\hline & $4^{\text {th }}$ & 1 & 11 & $8.33^{* *}$ \\
\hline & Totals & 20 & 53 & $14.92 * * *$ \\
\hline \multirow{5}{*}{$\begin{array}{l}\text { Student } \\
\text { postings }\end{array}$} & $1^{\mathrm{st}}$ & 12 & 12 & n.s. \\
\hline & $2^{\text {nd }}$ & 14 & 8 & n.s. \\
\hline & $3^{\text {rd }}$ & 8 & 40 & $21.33 * * *$ \\
\hline & $4^{\text {th }}$ & 1 & 12 & $9.31 * *$ \\
\hline & Totals & 35 & 72 & $12.79 * * *$ \\
\hline \multirow{5}{*}{ Threads } & $1^{\mathrm{st}}$ & 5 & 7 & n.s. \\
\hline & $2^{\text {nd }}$ & 7 & 6 & n.s. \\
\hline & $3^{\text {rd }}$ & 5 & 18 & $7.35^{* *}$ \\
\hline & $4^{\text {th }}$ & 1 & 7 & $4.5^{*}$ \\
\hline & Totals & 18 & 38 & $7.14 * *$ \\
\hline \multirow{5}{*}{ Lurking } & $1^{\text {st }}$ & 181 & 207 & n.s. \\
\hline & $2^{\text {nd }}$ & 276 & 260 & n.s. \\
\hline & $3^{\text {rd }}$ & 187 & 487 & $133.53 * * *$ \\
\hline & $4^{\text {th }}$ & 131 & 435 & $163.28 * * *$ \\
\hline & Totals & 775 & 1389 & $174.21 * * *$ \\
\hline
\end{tabular}

Regarding active participation, data showed that while the instructor and students in forum 2 posted until the end of semester, the instructor and students in forum 1 stopped posting approximately a month earlier. This may indicate a total loss of interest in the forum as a learning resource. Indeed, threads, which are essentially dialogues, came to a near halt after the third 
month in the forum led by the instructor held in low esteem. Regarding passive participation, data indicated that students in forum 2 entered in high rates; students in forum 1, despite the lack of activity, continued to enter the forum until the semester's end, possibly in the hope that something of consequence had happened.

Next, the quantitative content analysis technique was applied in order to determine the extent of teaching, social, and cognitive presence for each forum. The first analytic procedure viewed both forums in their entirety; that is, all instructor and student postings were evaluated. Table 2 presents these data.

Table 2

Teaching, Social, and Cognitive Presence

\begin{tabular}{|l|l|l|l|l|}
\hline \multirow{2}{*}{ Presence } & \multicolumn{2}{|l|}{$\begin{array}{l}\text { Forum1 } \\
\text { (low esteem) }\end{array}$} & \multicolumn{2}{l|}{$\begin{array}{l}\text { Forum2 } \\
\text { (high esteem) }\end{array}$} \\
\cline { 2 - 5 } & instances & $\%$ & instances & $\%$ \\
\hline Teaching & 43 & 24.4 & 73 & 19.9 \\
\hline Social & 78 & 44.3 & 236 & 64.3 \\
\hline Cognitive & 55 & 31.3 & 58 & 15.8 \\
\hline Totals & 176 & $100 \%$ & 367 & $100 \%$ \\
\hline
\end{tabular}

First, highly significant differences were found between the two forums for instances of teaching presence $\left(\chi^{2}=7.77, p<.01\right)$ and for social presence $\left(\chi^{2}=79.50, p<.001\right)$; no significant difference was found for cognitive presence $\left(\chi^{2}=0.04\right.$, n.s.). Second, a highly significant difference was found between the two forum's internal distribution of the presences expressed as percentages $\left(\chi^{2}(2)=23.05, p<.001\right)$.

In order to gain deeper insights into these findings, we next investigated the teaching, social, and cognitive presence actively engaged in by each of the instructors. Significant differences were found between the two instructors for all three presences: teaching presence $\left(\chi^{2}=17.75, p<\right.$ $.001)$, social presence $\left(\chi^{2}=64.10, p<.001\right)$ and cognitive presence $\left(\chi^{2}=4.26, p<.05\right)$. Tables 3,4 , and 5 summarize occurrences of each type of presence along with the related categories. 
Table 3

Teaching Presence: Instructors' Postings Only

\begin{tabular}{|c|c|c|c|c|}
\hline Categories & Months & $\begin{array}{l}\text { Forum1 } \\
\text { (low esteem) }\end{array}$ & $\begin{array}{l}\text { Forum2 } \\
\text { (high esteem) }\end{array}$ & $\chi^{2}$ \\
\hline \multirow{5}{*}{ Design } & $1^{\text {st }}$ & 1 & 3 & n.s. \\
\hline & $2^{\text {nd }}$ & 4 & 0 & n.s. \\
\hline & $3^{\text {rd }}$ & 0 & 3 & n.s. \\
\hline & $4^{\text {th }}$ & 0 & 0 & n.s. \\
\hline & Totals & 5 & 6 & n.s. \\
\hline \multirow{5}{*}{ Discourse } & $1^{\mathrm{st}}$ & 2 & 3 & n.s. \\
\hline & $2^{\text {nd }}$ & 3 & 0 & n.s. \\
\hline & $3^{\text {rd }}$ & 0 & 13 & $13.00 * * *$ \\
\hline & $4^{\text {th }}$ & 0 & 3 & n.s. \\
\hline & Totals & 5 & 19 & $8.17 * *$ \\
\hline \multirow{5}{*}{ Instruction } & $1^{\text {st }}$ & 3 & 2 & n.s. \\
\hline & $2^{\text {nd }}$ & 4 & 5 & n.s. \\
\hline & $3^{\text {rd }}$ & 0 & 13 & $13.00 * * *$ \\
\hline & $4^{\text {th }}$ & 0 & 7 & $7.00^{* *}$ \\
\hline & Totals & 7 & 27 & 11.77 *** \\
\hline
\end{tabular}

Table 4

Social Presence: Instructors' Postings Only

\begin{tabular}{|c|c|c|c|c|}
\hline Categories & Months & $\begin{array}{l}\text { Forum1 } \\
\text { (low esteem) }\end{array}$ & $\begin{array}{l}\text { Forum2 } \\
\text { (high esteem) }\end{array}$ & $\chi^{2}$ \\
\hline \multirow{5}{*}{ Affective } & $1^{\text {st }}$ & 0 & 4 & n.s. \\
\hline & $2^{\text {nd }}$ & 3 & 3 & n.s. \\
\hline & $3^{\text {rd }}$ & 0 & 19 & $19.00 * * *$ \\
\hline & $4^{\text {th }}$ & 0 & 1 & n.s. \\
\hline & Totals & 3 & 27 & $19.2 * * *$ \\
\hline \multirow{5}{*}{$\begin{array}{l}\text { Open } \\
\text { communication }\end{array}$} & $1^{\text {st }}$ & 4 & 4 & n.s. \\
\hline & $2^{\text {nd }}$ & 11 & 7 & n.s. \\
\hline & $3^{\text {rd }}$ & 3 & 29 & $21.13^{* * *}$ \\
\hline & $4^{\text {th }}$ & 0 & 11 & $11.00 * * *$ \\
\hline & Totals & 18 & 51 & $15.78 * * *$ \\
\hline \multirow{4}{*}{ Cohesion } & $1^{\text {st }}$ & 3 & 6 & n.s. \\
\hline & $2^{\text {nd }}$ & 4 & 6 & n.s. \\
\hline & $3^{\text {rd }}$ & 0 & 27 & $27.00 * * *$ \\
\hline & $4^{\text {th }}$ & 0 & 11 & $11.00 * * *$ \\
\hline
\end{tabular}




\begin{tabular}{|l|l|l|l|l|}
\hline & Totals & 7 & 50 & $32.44 * * *$ \\
\hline$* * p<.01, * * * p<.001$
\end{tabular}

Table 5

Cognitive Presence: Instructors' Postings Only

\begin{tabular}{|c|c|c|c|c|}
\hline Indicators & Months & $\begin{array}{l}\text { Forum1 } \\
\text { (low esteem) }\end{array}$ & $\begin{array}{l}\text { Forum2 } \\
\text { (high esteem) }\end{array}$ & $\chi^{2}$ \\
\hline \multirow{5}{*}{ Trigger } & $1^{\text {st }}$ & 3 & 3 & n.s. \\
\hline & $2^{\text {nd }}$ & 5 & 0 & $5.00 *$ \\
\hline & $3^{\mathrm{rd}}$ & 0 & 0 & n.s. \\
\hline & $4^{\text {th }}$ & 0 & 0 & n.s. \\
\hline & Totals & 8 & 3 & n.s. \\
\hline \multirow{5}{*}{ Exploration } & $1^{\mathrm{st}}$ & 1 & 2 & n.s. \\
\hline & $2^{\text {nd }}$ & 3 & 2 & n.s. \\
\hline & $3^{\text {rd }}$ & 0 & 3 & n.s. \\
\hline & $4^{\text {th }}$ & 0 & 1 & n.s. \\
\hline & Totals & 4 & 8 & n.s. \\
\hline \multirow{5}{*}{ Integration } & $1^{\mathrm{st}}$ & 0 & 2 & n.s. \\
\hline & $2^{\text {nd }}$ & 2 & 1 & n.s. \\
\hline & $3^{\text {rd }}$ & 0 & 7 & $7.00 * *$ \\
\hline & $4^{\text {th }}$ & 0 & 0 & n.s. \\
\hline & Totals & 2 & 10 & $5.33 *$ \\
\hline \multirow{5}{*}{ Resolution } & $1^{\text {st }}$ & 0 & 1 & n.s. \\
\hline & $2^{\text {nd }}$ & 2 & 1 & n.s. \\
\hline & $3^{\text {rd }}$ & 0 & 6 & $6.00 *$ \\
\hline & $4^{\text {th }}$ & 0 & 1 & n.s. \\
\hline & Totals & 2 & 9 & $4.46^{*}$ \\
\hline
\end{tabular}

No significant differences between the two forums for levels of all three types of presence during the first month of the semester were found. During the second month, for nine of the ten categories, no significant differences were found; interestingly, for one category of cognitive presence (triggering event), the forum led by the instructor held in low esteem was significantly more active. One last item is tabulated (Table 6), the ratio of triggering events with all instances of cognitive presence. 
Table 6

The Ratio of Instructors' Triggering Events with Cognitive Presence

\begin{tabular}{|l|l|l|}
\hline & $\begin{array}{l}\text { Forum1 } \\
\text { (low esteem) }\end{array}$ & $\begin{array}{l}\text { Forum2 } \\
\text { (high esteem) }\end{array}$ \\
\hline Triggering events & 8 & 3 \\
\hline Total cognitive presence & 16 & 30 \\
\hline Ratio & $1: 2$ & $1: 10$ \\
\hline
\end{tabular}

The overall picture that emerges from these data is that during the second half of the semester (months 3 and 4), the instructor held in low esteem became nearly dysfunctional in her forum. Over this interval, she posted three times only (3 instances of social presence/open communication). This finding may indeed be the primary causal factor that led to the near cessation of active participation. The highly esteemed instructor was especially active from semester midpoint to semester end; she more than doubled her active participation in both teaching presence (especially discourse and instruction) and social presence (all three categories).

In order to further explore active participation in the forums, we next investigated the teaching, social, and cognitive presence engaged in by students. No significant differences were found between forums for students' teaching presence and cognitive presence. A highly significant difference was found $\left(\chi^{2}=21.29, p<.001\right)$ for students' social presence: It was higher in the forum led by the highly esteemed instructor. Table 7 presents these data.

Table 7

Social Presence: Students' Postings Only

\begin{tabular}{|l|l|l|l|l|}
\hline Categories & Months & $\begin{array}{l}\text { Forum1 } \\
\text { (low esteem) }\end{array}$ & $\begin{array}{l}\text { Forum2 } \\
\text { (high esteem) }\end{array}$ & $\chi^{2}$ \\
\hline \multirow{4}{*}{ Affective } & $1^{\text {st }}$ & 3 & 1 & n.s. \\
\cline { 2 - 5 } & $2^{\text {nd }}$ & 7 & 0 & $7.00^{* *}$ \\
\cline { 2 - 5 } & $3^{\text {rd }}$ & 2 & 11 & $6.23^{*}$ \\
\cline { 2 - 5 } & $4^{\text {th }}$ & 0 & 3 & n.s. \\
\cline { 2 - 5 } & Totals & 12 & 15 & n.s. \\
\hline \multirow{4}{*}{$\begin{array}{c}\text { Open } \\
\text { communication }\end{array}$} & $1^{\text {st }}$ & 5 & 7 & n.s. \\
\cline { 2 - 5 } & $2^{\text {nd }}$ & 8 & 5 & n.s. \\
\cline { 2 - 5 } & $3^{\text {rd }}$ & 2 & 18 & $12.80^{* * *}$ \\
\cline { 2 - 5 } & $4^{\text {th }}$ & 0 & 8 & $8.00^{* *}$ \\
\cline { 2 - 5 } & Totals & 15 & 38 & $9.98^{* *}$ \\
\hline \multirow{4}{*}{ Cohesion } & $1^{\text {st }}$ & 9 & 31 & n.s. \\
\cline { 2 - 5 } & $2^{\text {nd }}$ & 11 & 5.12 & $29.12^{* * *}$ \\
\cline { 2 - 5 } & $3^{\text {rd }}$ & 2 & 31 & \\
\hline
\end{tabular}




\begin{tabular}{|l|l|l|l|l|}
\hline & $4^{\text {th }}$ & 1 & 10 & $7.36^{* *}$ \\
\cline { 2 - 5 } & Totals & 23 & 55 & $13.13^{* * *}$ \\
\hline
\end{tabular}

The final parameter investigated was instructor response rates. These were determined from the course log. Response rates measure the time interval between students' postings and instructors' responses. The median response time for the highly esteemed instructor was 3.25 hours $(N=53)$ while the median response time for the instructor held in low esteem was 26.30 hours $(N=20)$. The difference in response time is profound. Furthermore, to the detriment of the lowly esteemed instructor, an additional six students' postings (23\% of the total messages posted) remained unanswered; these were not included in the median statistic. Unanswered postings began to occur in the third month. One student, who posted an unanswered query, wrote: "Why isn't anyone answering? Is anyone here? Should I turn the lights off?" Figure 2 shows the scatter plot for each instructor's response time.

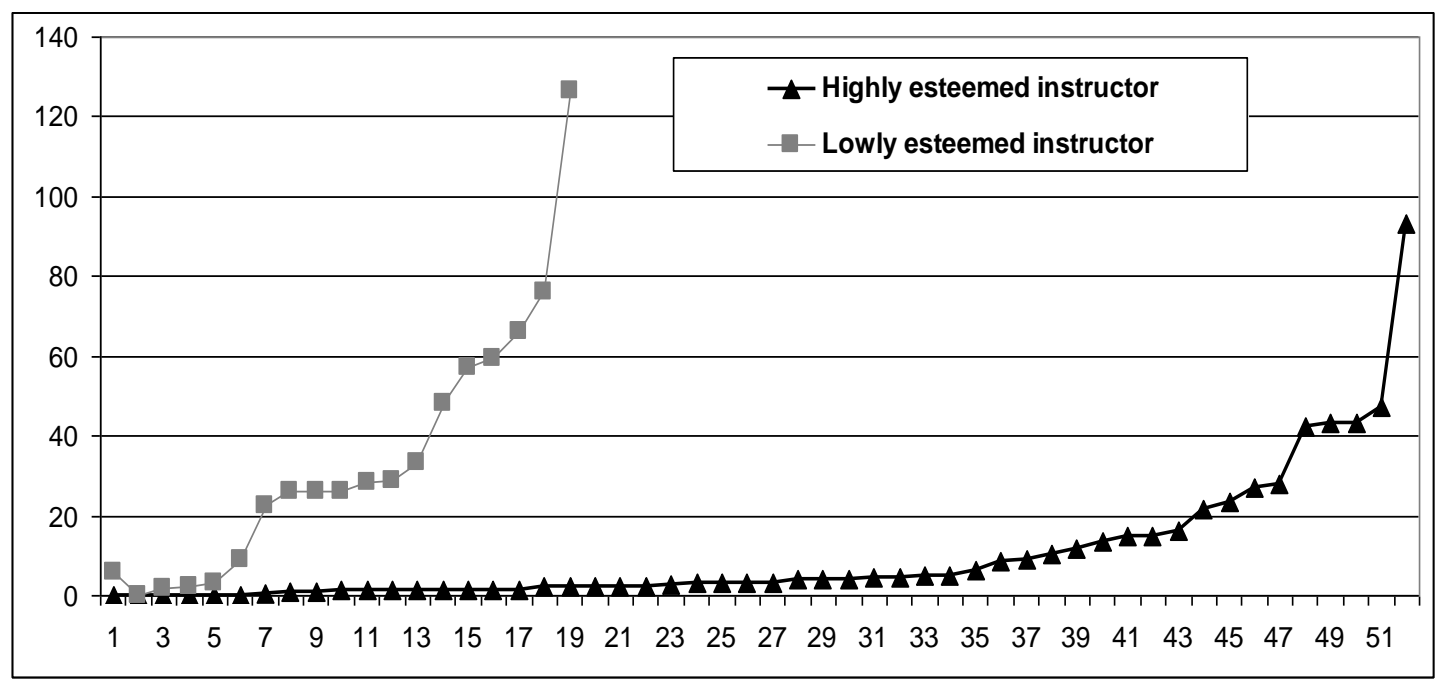

Figure 2. Instructors' response times (in hours).

\section{Discussion}

This ad hoc analysis, very carefully controlled in retrospect, identified the roles played by two online instructors (one held in high esteem and the other held in low esteem) and described their impact on two graduate level course forums wherein participation was voluntary. Based on theory and empirical findings, it was hypothesized that in a forum led by a highly rated instructor, as opposed to a forum led by an instructor held in low esteem, the following would occur:

1. Active and passive participation would be significantly higher.

2. Social presence would be significantly higher.

3. Teaching presence would be significantly higher.

4. Cognitive presence would be significantly higher.

5. Instructor response time would be significantly shorter. 
All hypotheses, except for hypothesis 4, were supported clearly and unequivocally. In order to understand the implications of these findings, we next analyze active participation in the forum as a function of hypotheses 2-5. We begin by attempting to explain the unsupported hypothesis, namely that cognitive presence will be significantly higher in the forum led by the highly esteemed instructor. We asked ourselves why this did not happen and proceeded in two directions: (1) the need for defining specific goals or tasks for sustaining student engagement, and (2) perceived course difficulty.

\section{The Equivalent Sparsity of Cognitive Presence in Both Forums}

The emergence of cognitive presence in an online learning environment depends on many factors. One factor deemed significant by Garrison and Arbaugh (2007) is what they call the "progressive development of inquiry" (p.162). They found that cognitive presence may be defined in terms of a "cyclical process of practical inquiry, where participants move deliberately from understanding the problem or issue through to exploration, integration and application" (p.162). Research has shown that this is oftentimes difficult to achieve (e.g., Luebeck \& Bice, 2005; Vaughan \& Garrison, 2005).

In our study, specific tasks, tailored especially to the needs of the course forum, were not preprepared. The forum was more open-ended regarding the ways by which subject-matter oriented topics were discussed. This, however, does not preclude the progressive development of cognitive presence spontaneously, as a function of the instructor's teaching presence, especially "facilitating discourse." We now analyze the extent of cognitive presence in both forums.

On the one hand, during the first two months of the semester, the instructor held in low esteem initiated eight triggering events. This would indicate that she was indeed motivated to provide her students with learning opportunities. These initiatives, however, met with lukewarm response and petered out rapidly. The ratio of triggering events and total instances of cognitive presence was a mere $1: 2$ (Table 6). The number of threads for her forum (a measure of more extensive dialogue) was a mere 18 (Table 1). For this instructor, the lack of specific, progressively structured inquiry tasks and/or the lack of facilitation skills (teaching presence/facilitating discourse) may have contributed to the relatively limited occurrences of cognitive presence.

On the other hand, for the instructor held in high esteem, the ratio of triggering events and total instances of cognitive presence was $1: 10$ (Table 6). The number of threads in her forum was 38 (Table 1). This would indicate that for the highly esteemed instructor, the lack of specific preplanned inquiry tasks did not apparently restrict achieving high levels of integration and resolution by way of teaching presence/facilitating discourse. In other words, we wish to reaffirm what we cited above: teaching presence, especially the category "facilitating discourse," seems to play a highly significant role in achieving and sustaining cognitive presence (i.e., learning).

The Open University questionnaire also elicits from students their evaluation of "course difficulty." This course was rated as "average" (3 on a scale of 1-5). This non-difficulty may, in 
part, also account for the general lack of cognitive presence found in both forums, despite the fact that the explicit goal of both forums was to provide a place to learn. Research has shown that students turned to interpersonal dialogue primarily when they couldn't cope with conceptual difficulties or with difficult tutor assignments (Gorsky, Caspi, \& Tuvi-Arad, 2004; Gorsky, Caspi, \& Trumper, 2004, 2006; Gorsky, Caspi, \& Smidt, 2007). Given the absence of such difficulties and that participation in the forum was non-mandatory, students seemed to have studied on their own.

In other words, there are reasonable, theory-based explanations for the relative lack of cognitive presence found in both forums. This implies that something else accounted for the extreme satisfaction and dissatisfaction experienced by students in the two forums. The something else may be the two exceptional events that occurred during the third month: The instructor held in low esteem became nearly dysfunctional, while the highly esteemed instructor exhibited very high teacher presence and social presence (see Table 3 and 4).

\section{The Impact of Teaching Presence, Social Presence, and Instructor Response Time}

We found highly significant relationships between levels of social presence and teaching presence, on the one hand, and students' active and passive participation in the forum and their satisfaction with it, on the other hand. These findings clearly support previous ones for both social presence (Richardson \& Swan, 2002; Steinweg et al., 2006; Weaver \& Albion, 2005) and for teaching presence (Garrison \& Cleveland-Innes, 2005; Meyer, 2003; Murphy, 2004; Pawan et al., 2003; Shea et al., 2004; Swan, 2002; Swan \& Shih, 2005; Varnhagen et al., 2005; Vaughan, 2004; Wu \& Hiltz, 2004). In addition, findings concerning instructor response time (frequent instructor responses correlate with students' active and passive participation in the forum) are in accord with previous research (Kearsley, 2000; Northrup, 2002; Simonson et al., 2000; Swan, 2001). In other words, these findings corroborate previous research.

Moving beyond these studies, we wish to suggest a tentative two-tier model of causality, based on recently reported research findings. The model appears in Figure 3. 


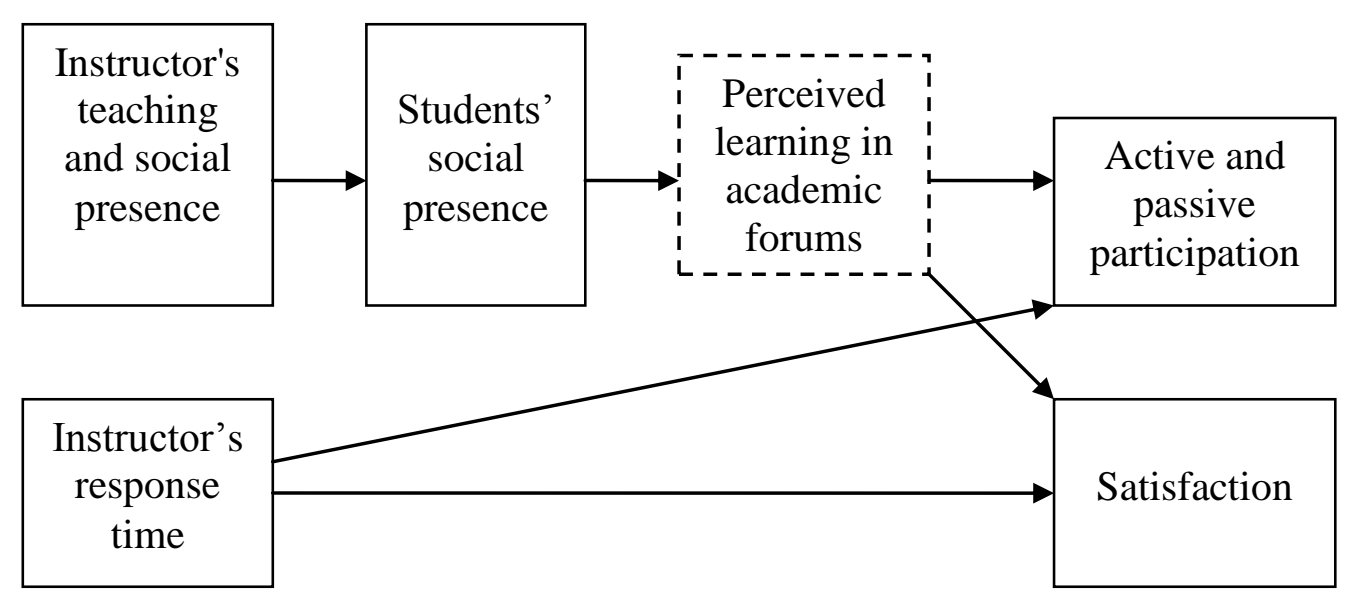

Figure 3. Factors affecting participation and satisfaction in academic forums.

The first tier is based on the well-documented relationship between instructor response time, on the one hand, and student participation and satisfaction, on the other hand. The second tier of the model includes the mediating variable "students' perceived learning." Caspi and Blau (2008) and Swan and Richardson (2003) found that students' perceived social presence in academic forums correlates with their perceived learning. This correlation points to the tentative conclusion that social presence affords learning by setting a convenient climate. In a similar vein, Shea, Pickett, and Pelt (2003) found that students' perceived teacher presence also correlates with perceived learning as well as with students' satisfaction with the forum. This correlation points to the tentative conclusion that teaching presence affords learning by setting a convenient climate. In our study, we found that very high versus very low instructor teaching presence and social presence during the third month affected students' social presence, which, in turn, affected their active and passive participation as well as their sense of satisfaction. Based on these findings and on the three previous ones cited (Caspi \& Blau, 2008; Shea et al., 2003; Swan \& Richardson, 2003), we suggest that students' perceived learning in course forums has a significant impact on their participation (both active and passive) and satisfaction. In other words, "students' perceived learning" may be a mediating variable as illustrated in Figure 3. This hypothesis, based on a combination of findings from different studies is, at best, speculative. Further research is needed to explore this explanation.

\section{Suggestions for Effective Online Teaching}

We suggest that teaching presence, social presence, and instructor response time appear to be important factors in the ratings attained by instructors under the very specific conditions described in this study. Table 8 compares findings for these factors along two dimensions: between-forum ratios and within-forum distributions expressed as percentages. These quantities may aid in evaluating the quality of academic forums that are similar to the ones described in this study. 
Table 8

Suggestions for Best and Worst Practice

\begin{tabular}{|c|c|c|c|c|c|}
\hline \multirow[t]{2}{*}{ Criteria } & \multicolumn{2}{|c|}{ Best practice } & \multicolumn{2}{|c|}{ Worst practice } & \multirow{2}{*}{$\begin{array}{l}\text { Ratio* } \\
\text { instances } \\
: \\
\text { instances }\end{array}$} \\
\hline & instances & $\%$ of total & instances & $\%$ of total & \\
\hline Instructor postings & 53 & $42.4 \%$ & 20 & $36.4 \%$ & $2.5: 1$ \\
\hline Student postings & 72 & $57.6 \%$ & 35 & $63.6 \%$ & $2: 1$ \\
\hline Totals & 125 & $100 \%$ & 55 & $100 \%$ & $2.5: 1$ \\
\hline Teaching presence (totals) & 73 & $19.9 \%$ & 43 & $24.4 \%$ & $2: 1$ \\
\hline Social presence (totals) & 236 & $64.3 \%$ & 78 & $44.3 \%$ & $3: 1$ \\
\hline Cognitive presence (totals) & 58 & $15.8 \%$ & 55 & $31.3 \%$ & $1: 1$ \\
\hline Totals & 367 & $100 \%$ & 176 & $100 \%$ & $2: 1$ \\
\hline Teaching presence (instructor) & 52 & $24.8 \%$ & 17 & $22.7 \%$ & $3: 1$ \\
\hline Social presence (instructor) & 128 & $60.9 \%$ & 28 & $37.3 \%$ & $5.5: 1$ \\
\hline Cognitive presence (instructor) & 30 & $14.3 \%$ & 30 & $40.0 \%$ & $1: 1$ \\
\hline Totals & 210 & $100 \%$ & 75 & $100 \%$ & $3: 1$ \\
\hline Teaching presence (students) & 26 & $15.0 \%$ & 21 & $20.4 \%$ & $1: 1$ \\
\hline Social presence (students) & 108 & $62.4 \%$ & 53 & $51.4 \%$ & $2: 1$ \\
\hline Cognitive presence (students) & 39 & $22.6 \%$ & 29 & $28.2 \%$ & $1: 1$ \\
\hline Totals & 173 & $100 \%$ & 103 & $100 \%$ & $2: 1$ \\
\hline Threads & 38 & & 18 & & $2: 1$ \\
\hline Instructor response time (median) & 3.25 hrs. & & $26.50 \mathrm{hrs}$. & & $1: 8$ \\
\hline
\end{tabular}

$*$ rounded to nearest half integer

These tentative reference points for best and worst practice are for illustrative purposes only. A great deal of additional research is required in order to define the attributes of these forums in terms of academic discipline, learning environment (blended), perceived course difficulty, communication type (asynchronous), duration, participation (non-mandatory), group size, etc. Such a classification is necessary in order to achieve a standard basis for comparison and reasonable confidence levels. However, the table is suggestive of the eventual possibility of having an "objective" tool for evaluating the quality of a given forum. 


\section{References}

Anderson, T., Rourke, L., Garrison, D. R., \& Archer, W. (2001). Assessing teaching presence in a computer conferencing context. Journal of Asynchronous Learning Networks, 5(2). Retrieved April 2, 2009, from http://sloanc.org/publications/jaln/v5n2/pdf/v5n2_anderson.pdf

Arbaugh, J. B., \& Hwang, A. (2006). Does "teaching presence" exist in online MBA courses? The Internet and Higher Education, 9(1), 9-21.

Baker, J. D. (2004). An investigation of relationships among instructor immediacy and affective and cognitive learning in the online classroom. The Internet and Higher Education, 7(1), $1-13$.

Bargh, J. A., \& McKenna, K.Y.A. (2004). The Internet and social life. Annual Review of Psychology, 55, 573-590.

Berge, Z.L. (1999). Interaction in post-secondary Web-based learning. Educational Technology, 39(1), 5-11.

Caspi, A., \& Blau, I. (2008). Online discussion groups: The relationship between social presence and perceived learning. Social Psychology of Education, 11, 323-346.

Chickering, A. W., \& Gamson, Z. F. (1987). Seven Principles of good practice in undergraduate education. AAHE Bulletin, 39(7), 3-7.

Chickering, A., \& Ehrmann, S. (1996). Implementing the seven principles: Technology as lever. AAHE Bulletin, 49(2), 3-6.

Chabon, S., Cain, R., \& Lee-Wilkerson, D. (2001). Facilitating those dreaded discussions on diversity, through threaded discussions: An inter-institutional, internet-based model. Distance Education, 22(1), 137-143.

De Wever, B., Schellens, T., Valcke, M., \& Van Keer, H. (2006). Content analysis schemes to analyze transcripts of online asynchronous discussion groups: A review. Computers \& Education, 46, 6-28.

Dewey, J. (1933). How we think (Rev. ed.). Boston: D.C. Heath.

Eom, S. (2006). The role of the instructors as a determinant of students' satisfaction in university online education. Proceedings of the Sixth IEEE international Conference on Advanced Learning Technologies- ICALT, Washington, DC: IEEE Computer Society, 985-988.

Fahy, P. J. (2001). Addressing some common problems in transcript analysis. International 
Review of Research in Open and Distance Learning, 1(2). Retrieved April 2, 2009, from http://www.irrodl.org/index.php/irrodl/article/view/321/530

Garrison, D. R. (2007). Online community of inquiry review: Social, cognitive, and teaching presence issues. Journal of Asynchronous Learning Networks, 11(1), 61-72. Available at http://www.ucalgary.ca/ nvaughan/coiissues.pdf

Garrison, D. R., Anderson, T., \& Archer, W. (2000). Critical inquiry in a text-based environment: Computer conferencing in higher education. The Internet and Higher Education, 2(2-3), 87-105.

Garrison, D. R., Anderson, T., \& Archer, W. (2001). Critical thinking and computer conferencing: A model and tool to assess cognitive presence. American Journal of Distance Education, 15(1), 7-23. Available at http://communityofinquiry.com/files/CogPres_Final.pdf

Garrison, D. R., \& Arbaugh, J. B. (2007). Researching the community of inquiry framework: Review, issues, and future directions. The Internet and Higher Education, 10(3), 157172.

Garrison, D. R., \& Archer, W. (2003). A community of inquiry framework for online learning. In M. Moore (Ed.), Handbook of distance education. New York: Erlbaum.

Garrison, D. R., \& Cleveland-Innes, M. (2005). Facilitating cognitive presence in online learning: Interaction is not enough. American Journal of Distance Education, 19(3), 133148.

Garrison, D. R., Cleveland-Innes, M., \& Fung, T. (2004). Student role adjustment in online communities of inquiry: Model and instrument validation. Journal of Asynchronous Learning Networks, 8(2), 61-74. Available at http://www.sloanc.org/publications/jaln/v8n2/pdf/v8n2 garrison.pdf

Garrison, D. R., Cleveland-Innes, M., Koole, M., \& Kappelman, J. (2006). Revisiting methodological issues in the analysis of transcripts: Negotiated coding and reliability. The Internet and Higher Education, 9(1), 1-8.

Gilbert, P. K., \& Dabbagh, N. (2005). How to structure online discussions for meaningful discourse: A case study. British Journal of Educational Technology, 36(1), 5-18.

Gorsky, P., \& Caspi, A. (2005). Dialogue: A theoretical framework for distance education instructional systems. British Journal of Educational Technology, 36(2), 137-144.

Gorsky, P., Caspi, A., \& Chajut, E. (2007). The theory of instructional dialogue: Toward a unified 
theory of instructional design. In R. Zheng \& S. Pixy-Ferris (Eds.), Understanding online instructional modeling: Theories and practices (pp. 47-68). Hershey, PA: Idea Group, Inc. Available at http://books.google.com/books?id=WF4Y03EYj08C

Gorsky, P., Caspi, A., \& Trumper, R. (2004). University students' use of dialogue in a distance education physics course. Open Learning, 19(3), 265-277.

Gorsky, P., Caspi, A., \& Trumper, R. (2006). Campus-based university students' use of dialogue. Studies in Higher Education, 31(1), 71-87.

Gorsky, P., Caspi, A., \& Smidt, S. (2007). Use of instructional dialogue by university students in a difficult distance education physics course. Journal of Distance Education, 22(1), 1-12.

Gorsky, P., Blau, I., Caspi, A., \& Antonovsky, A. (in progress). The impact of academic discipline on the dialogic behavior in academic course forums.

Gros, B., \& Silva, J. (2006). El problema del análisis de las discusiones asincrónicas en el aprendizaje colaborativo mediado. Revista de Educación a Distancia- RED, 16. Retrieved April 2, 2009, from http://www.um.es/ead/red/16/gros.pdf

Herrmann, N., \& Popyack, J. L. (2003). Electronic grading: When the tablet is mightier than the pen. Syllabus: Technology for Higher Education, 16, 1-16.

Jennings , S. E., \& McCuller, M. Z. (2004). Meeting the challenges of grading online business communication assignments. Proceedings of the 69th Annual Convention, Association for Business Communication (pp. 9-14). Cambridge, Massachusetts.

Jiang, M., \& Ting, E. (2000). A study of factors influencing students' perceived learning in a web-based course environment. International Journal of Educational Telecommunications, 6(4), 317-338.

Kalman, Y. M., Ravid, G., Raban, D. R., \& Rafaeli, S. (2006). Pauses and response latencies: A chronemic analysis of asynchronous CMC. Journal of Computer-Mediated Communication, 12(1). Retrieved April 2, 2009, from http://jcmc.indiana.edu/vol12/issue1/kalman.html

Kaye, B. K. (2005, August). Web side story: An exploratory study of why weblog users say they use weblogs. Paper presented at the AEJMC Annual Conference, San Antonio, TX. Retrieved April 2, 2009, from http://www.journalism.wisc.edu/blog-club/Site/Kaye2.pdf

Kearsley, G. (2000). Learning and teaching in cyberspace. Toronto, Ontario: Wadsworth, Thompson Learning.

LaPointe, D. K., \& Gunawardena, C. N. (2004). Developing, testing and refining of a model to 
understand the relationship between peer interaction and learning outcomes in computermediated conferencing. Distance Education, 25(1), 83-106.

Liu, X., Bonk, C. J., Magjuka, R. C., Lee, S., \& Su, B. (2005). Exploring four dimensions of online instructor roles: A program level case study. Journal of Asynchronous Learning Networks, 9(4), 29-48.

Liu, Y., Ginther, D., \& Zelhart, P. (2001). How do frequency and duration of messaging affect impression in computer-mediated communication? Journal of Universal Computing, 7(10), 893-913. Available at http://www.jukm.org/jucs_7_10/how_do_frequency_and/Liu_Y.pdf

Luebeck, J. L., \& Bice, L. R. (2005). Online discussion as a mechanism of conceptual change among mathematics and science teachers. Journal of Distance Education, 20(2), 21-39.

Maloney-Krichmar, D., \& Preece, J. (2005). A multilevel analysis of sociability, usability, and community dynamics in an online health community. ACM Transactions on ComputerHuman Interaction, 12(2), 201-232.

McCollum, A., Calder, J., Ashby, A., Thorpe, M., \& Morgan, A. (1995, June). Quality and effectiveness in vocational education. Paper presented at the One World Many Voices, the 17th World Conference for Distance Education, Birmingham, UK.

Meyer, K. A. (2003). Face-to-face versus threaded discussions: The role of time and higher-order thinking. Journal of Asynchronous Learning Networks, 7(3), 55-65.

Murphy, E. (2004). Recognizing and promoting collaboration in an online asynchronous discussion. British Journal of Educational Technology, 35(4), 421-431.

Murphy, E., \& Ciszewska-Carr, J. (2005). Sources of difference in reliability: Identifying sources of difference in reliability in content analysis of online asynchronous discussions. International Review of Research in Open and Distance Learning, 6(2). Retrieved April 2, 2009, from http://www.irrodl.org/index.php/irrodl/article/view/233/855

Neuendorf, K. A. (2002). The content analysis guidebook. Thousand Oaks, CA: Sage Publications.

Northrup, P. (2002). Online learner's preferences for interaction. Quarterly Review of Distance Education, 3(2), 219-229.

Palloff, R., \& Pratt, K. (2003). The virtual student: A profile and guide to working with online learners. San Francisco, CA: Jossey-Bass Inc.

Pawan, F. T., Paulus, M., Yalcin, S., \& Chang, C. (2003). Online learning: Patterns of 
engagement and interaction among in-service teachers. Language Learning \& Technology, 7(3), 119-140.

Picciano, A. G. (1998). Developing an asynchronous course model at a large, urban university. Journal of Asynchronous Learning Networks, 2(1), 1-14.

Picciano, A.G. (2002). Beyond student perceptions: Issues of interaction, presence, and performance in an online course. Journal of Asynchronous Learning Networks, 6(1). $\begin{array}{llll}\text { Retrieved April 2009, from } & \text { 2, }\end{array}$ http://www.aln.org/publications/jaln/v6n1/pdf/v6n1_picciano.pdf

Richardson, J.C., \& Swan, K. (2003). Examining social presence in online courses in relation to students' perceived learning and satisfaction. Journal of Asynchronous Learning $\begin{array}{lllll}\text { Networks, } & 7(1) . & \text { Retrieved } & \text { April 2009, } & \text { from }\end{array}$ http://www.aln.org/publications/jaln/v7n1/pdf/v7n1_richardson.pdf

Ridings, C. M., \& Gefen, D. (2004). Virtual community attraction: Why people hang out online. Journal of Computer-Mediated Communication, 10(1). Retrieved April 2, 2009, from http://jcmc.indiana.edu/vol10/issue1/ridings_gefen.html

Rourke, L., \& Anderson, T. (2004). Validity issues in quantitative computer conference transcript analysis. Educational Technology Research and Development, 52(1) 5-18.

Rourke, L., Anderson, T., Garrison, D. R., \& Archer, W. (1999). Assessing social presence in asynchronous test-based computer conferencing. Journal of Distance Education, 14(2), 50-71. Available at http://www.jofde.ca/index.php/jde/article/viewArticle/153/341

Rourke, L., Anderson, T., Garrison, D. R., \& Archer, W. (2001). Methodological issues in the content analysis of computer conference transcripts. International Journal of Artificial Intelligence in Education 12(1), 8-22.

Seidel, T., \& Shavelson, R. (2007). Teaching effectiveness research in the past decade: The role of theory and research design in disentangling meta-analysis Results. Journal of Applied Behavioral Science, 43(1), 89-107.

Shea, P. (2006). A study of students' sense of learning community in online environments.

Journal of Asynchronous Learning Networks, 10(10). Retrieved April 2, 2009, from http://www.sloan-c.org/publications/jaln/v10n1/v10n1_4shea_member.asp

Shea, P., \& Bidjerano, T. (2009). Community of inquiry as a theoretical framework to foster "epistemic engagement" and "cognitive presence" in online education. Computers and Education, 52(3), 543-553.

Shea, P., Li, C. S., \& Pickett, A. M. (2006). A study of teaching presence and student sense of 
learning community in fully online and web-enhanced college courses. The Internet and Higher Education, 9(3), 175-190.

Shea, P., Li, C. S., Swan, K., \& Pickett, A. M. (2005). Developing learning community in online asynchronous college courses: the role of teaching presence. Journal of Asynchronous Learning Networks, 9(4). Retrieved April 2, 2009, from http://www.sloanorg/publications/jaln/v9n4/pdf/v9n4_shea.pdf

Shea, P., Pickett, A. M., \& Pelt, W. E (2003). A follow-up investigation of teaching presence in the SUNY Learning Network. Journal of the Asynchronous Learning Network, 7(2). Retrieved April 2, 2009, from http://www.sloanc.org/publications/jaln/v7n2/pdf/v7n2 shea.pdf

Shea, P. J., Pickett, A. M, \& Pelz, W. E. (2004). Enhancing student satisfaction through faculty development: The importance of teaching presence. In J. Bourne \& J. C. Moore (Eds.), Elements of quality online education: Into the mainstream, Volume 5 (pp.39-59). Needham, MA: Sloan-C.

Simonson, M., Smaldino, S. Albright, M., \& Zvacek, S. (2000). Teaching and learning at a distance: Foundations of distance education. Upper Saddle River, NJ: Merrill, Prentice Hall.

Smith, G., Ferguson, D.,\& Caris, M. (2002). Teaching over the web versus in the classroom: Differences in the instructor experience. International Journal of Instructional Media, 29(1), 61-67.

Spangle, M., Hodne, G., \& Schierling, D. (2002, November). Approaching value-centered education through the eyes of an electronic generation: Strategies for distance learning. Paper presented at the Annual Meeting of the National Communication Association. New Orleans, LA.

Steinweg, S. B., Trujillo, L., Jeffs, T., \& Hopfengardner-Warren, S. (2006). Maintaining the personal touch in a growing program: Strategies for establishing social presence in online classes. Journal of the Research Center for Educational Technology, 2(2). Retrieved April 2, 2009, from http://www.rcetj.org/?type=art\&id=79598\&

Swan, K. (2001). Virtual interaction: Design factors affecting student satisfaction and perceived learning in asynchronous online courses. Distance Education, 22, 306-331.

Swan, K. (2002). Building communities in online courses: The importance of interaction.

Education, Communication and Information, 2(1), 23-49. Available at http://www.kent.edu/rcet/Publications/upload/SocPres\%20ECI.pdf

Swan, K., Shea, P., Fredericksen, E., Pickett, A., Pelz, W., \& Maher, G. (2000). Building 
knowledge building communities: Consistency, contact and communication in the virtual classroom. Journal of Educational Computing Research, 23(4), 389-413.

Swan, K., \& Shea, P. (2005). The development of virtual learning communities. In S.R. Hiltz \& R. Goldman, Asynchronous learning networks: The research frontier (pp. 239-260). New York: Hampton Press.

Swan, K, \& Shih, L. F. (2005). On the nature and development of social presence in online course discussions. Journal of Asynchronous Learning Networks, 9(3). Retrieved April 2, 2009, from http://www.sloan-c.org/publications/JALN/v9n3/v9n3 swan.asp

Tricker, M., Rangecroft, M., \& Long, P. (2001). Evaluating distance education courses: the student perception. Assessment and Evaluation in Higher Education, 26(2), 165-177.

Ussher, B. (2004, July). Interactions, student enthusiasm and perceived learning in an online teacher education degree. Paper presented at the Third Pan-Commonwealth Forum PCF Conference. Hamilton, New Zealand. Retrieved April 2, 2009, from http://www.col.org/pcf3/Papers/PDFs/Ussher_Bill.pdf

Varnhagen, S., Wilson, D., Krupa, E., Kasprzak, S., \& Hunting, V. (2005). Comparison of student experiences with different online graduate courses in health promotion. Canadian Journal of Learning and Technology, 31(1), 99-117.

Vaughan, N. (2004). Investigating how a blended learning approach can support an inquiry process within a faculty learning community. Doctoral dissertation, University of $\begin{array}{lllll}\text { Calgary. } & \text { Retrieved } & \text { April } & 2009, & \text { from }\end{array}$ http://www.ucalgary.ca/ nvaughan/norm/nvaughandissertation.pdf

Vaughan, N., \& Garrison, D. R. (2005). Creating cognitive presence in a blended faculty development community. Internet and Higher Education, 8, 1-12.

Vaughan, N., \& Garrison, D. R. (2006). How blended learning can support a faculty development community of inquiry. Journal of Asynchronous Learning Networks, 10(4). Retrieved April 2, 2009, from http://www.sloanc.org/publications/JALN/v10n4/v10n4_vaughan.asp

Vesely, P., Bloom, L., \& Sherlock, J. (2007). Key elements of building online community: Comparing faculty and student perceptions. MERLOT Journal of Online Learning and Teaching, 3(3). Retrieved April 2, 2009, from http://jolt.merlot.org/vol3no3/vesely.pdf

Vygotsky, L. (1978). Mind in Society: The development of higher psychological processes. Cambridge MA: Harvard University Press.

Walther, J. B., \& Bunz, U. (2005). The rules of virtual groups: Trust, liking, and performance in 
computer-mediated communication. Journal of Communication, 55(4), 828-846. Available at http://bunz.comm.fsu.edu/JoC2005 55 4 virtual.pdf

Weaver, C. M., \& Albion, P. R. (2005). Momentum in online discussions: The effect of social presence on motivation for participation. Proceedings of Australasian Society for Computers in Learning in Tertiary Education Conference (ASCILITE 2005), Balance, Fidelity, Mobility: Maintaining the momentum? (pp. 703-706). Sydney, Australia. Available http://www.ascilite.org.au/conferences/brisbane05/blogs/proceedings/81_Weaver.pdf

Wu, D., \& Hiltz, S. R. (2004). Predicting learning from asynchronous online discussions. Journal of Asynchronous Learning Networks, 8(2), 139-152. Available at http://www.aln.org/publications/jaln/v8n2/pdf/v8n2_wu.pdf

Young, S. (2006). Student views of effective online teaching in higher education American. Journal of Distance Education, 20(2), 65-77. 
June - 2009

\title{
Creating Effective Collaborative Learning Groups in an Online Environment
}

\author{
Jane E. Brindley and Christine Walti \\ University of Oldenburg, Germany \\ Lisa M. Blaschke \\ University of Maryland University College, USA
}

\begin{abstract}
Collaborative learning in an online classroom can take the form of discussion among the whole class or within smaller groups. This paper addresses the latter, examining first whether assessment makes a difference to the level of learner participation and then considering other factors involved in creating effective collaborative learning groups. Data collected over a three year period (15 cohorts) from the Foundations course in the Master of Distance Education (MDE) program offered jointly by University of Maryland University College (UMUC) and the University of Oldenburg does not support the authors' original hypothesis that assessment makes a significant difference to learner participation levels in small group learning projects and leads them to question how much emphasis should be placed on grading work completed in study groups to the exclusion of other strategies. Drawing on observations of two MDE courses, including the Foundations course, their extensive online teaching experience, and a review of the literature, the authors identify factors other than grading that contribute positively to the effectiveness of small collaborative learning groups in the online environment. In particular, the paper focuses on specific instructional strategies that facilitate learner participation in small group projects, which result in an enhanced sense of community, increased skill acquisition, and better learning outcomes.
\end{abstract}

Keywords: Distance education; open learning; online learning; e-learning; collaborative learning; pedagogy; instructional design; learner motivation

\section{Introduction: The Challenge of Creating Effective Study Groups}

Online courses offer the opportunity to create a highly social learning environment, characterized by participation and interactivity for both students and instructors. According to Kearsley (2000), online learning is as much a social activity as an individual one. However, the quality and quantity of interactivity can vary dramatically from course to course. Swan (2001), citing a 
number of authors, identifies course design as a critical factor in determining the quantity, quality, and type of interactivity (learner interaction with content, instructors, or peers) in a course. Kearsley (nd) points to the importance of instructor skill in creating and managing interaction in online courses, particularly when collaborative learning is required. However, he also points out that most people have little formal training in how to successfully interact or work with others and that the social milieu of online activities is quite different from in-person interactions, thus requiring new skills and behaviors.

Engagement, defined as "student-faculty interaction, peer-to-peer collaboration and active learning..." (Chen, Gonyea, \& Kuh, 2008, para. 2), has been positively related to the quality of the learning experience. Social learning or learning as part of a group is an important way to help students gain experience in collaboration and develop important skills in critical thinking, selfreflection, and co-construction of knowledge. Online learners should not be impoverished in terms of social learning because they cannot or choose not to come to a campus. Access to education should not mean merely access to content (which is readily available without formal enrollment with an educational provider); rather, it should mean access to a rich learning environment that provides opportunity for interaction and connectedness. Quality learning environments include opportunities for students to engage in interactive and collaborative activities with their peers; such environments have been shown to contribute to better learning outcomes, including development of higher order thinking skills. Specific pedagogical benefits of collaborative learning include the following:

- Development of critical thinking skills,

- Co-creation of knowledge and meaning,

- Reflection,

- Transformative learning. (Palloff \& Pratt, 2005)

Different learning styles and cultures can be accommodated more easily because effective collaborative learning values diversity (Palloff \& Pratt, 2005). Further, skills gained from the experience of collaborative learning are highly transferable to team-based work environments (Shaw, 2006). Chapman, Ramondt, and Smiley (2005) also establish a strong link between building effective online communities and deeper learning and confirm that "... the world of work requires that learners can apply, analyse, synthesise and evaluate information...” (p. 220). Despite these documented benefits and the intense popularity of informal social networking using Web 2.0 tools and mobile devices, collaborative learning in the form of small groups (four to six peers), which is not of their own choosing, is often dreaded and avoided by online learners.

Online learners who seek flexibility in their study situations can view participation in group learning as an impediment to their progress and often balk at or at best tolerate collaborative learning situations imposed by course design. Students may have reservations about their ability to work as part of a group (Harasim, Hiltz, Teles, \& Turoff, 1998), or they may have become reluctant to participate based on negative past experiences of working with an unproductive or very difficult peer, having had to carry more than their fair share of the workload, or having received a grade that they felt did not reflect their level of contribution to a group project. 
One proposed method of ensuring learner participation in online collaboration is to demonstrate the value of group learning by assessing (defined here as assignment of a grade) both the product and process of group work (Swan, Shen, \& Hiltz, 2006). Swan et al. (2006) propose that "Assessment can be seen as the engine that drives student course activity, online or off. It is particularly important in encouraging and shaping collaborative activity online" (p. 45). This paper proposes an alternate perspective. The authors present data gathered over a three year period from a class in an international master of distance education (MDE) program that indicates that the introduction of grading has made no discernible difference to participation in study groups based on a straightforward comparison of participation rates between the graded and nongraded sections. Based on experience from this course and a model from another course in the same program where group work has never been graded, the authors propose alternative methods to encourage learners to experience the value of collaborative learning by creating study group experiences that are motivating and rewarding.

\section{Collaborative Learning and Connectivism}

Siemens (2005) proposes a contemporary theory of learning called connectivism that recognizes the impact of technology on society and ways of knowing. Although some writers have challenged both the need for a new learning theory and whether connectivism meets the parameters of theory (Kop \& Hill, 2008), Siemens provides a premise and a framework that are very useful for understanding collaborative learning in an online environment. From his viewpoint, learning in the digital age is no longer dependent on individual knowledge acquisition, storage, and retrieval; rather, it relies on the connected learning that occurs through interaction with various sources of knowledge (including the Internet and learning management systems) and participation in communities of common interest, social networks, and group tasks.

From this perspective, learning consists of retrieving information from self, others, and machines, collaborating to create knowledge, and applying information to current contexts. Hence, Siemens' (2005) learning theory is about individuals connecting with each other and with technology. Effective learners are those who can cope with complexity, contradictions, and large quantities of information, who seek out various sources of knowledge, and who can create and sustain learning communities and networks. According to Siemens (2005), learning ecologies (communities and networks) facilitate important information sharing and co-construction of knowledge while encouraging life-long learning in the individual as well as the group.

In a collaborative learning environment, knowledge is shared or transmitted among learners as they work towards common learning goals, for example, a shared understanding of the subject at hand or a solution to a problem. Learners are not passive receptacles but are active in their process of knowledge acquisition as they participate in discussions, search for information, and exchange opinions with their peers. Knowledge is co-created and shared among peers, not owned by one particular learner after obtaining it from the course materials or instructor. The learning process creates a bond between and among learners as their knowledge construction depends on each other's contribution to the discussion. Hence, collaborative learning processes assist students to develop higher order thinking skills and achieve richer knowledge generation through shared 
goals, shared exploration, and a shared process of meaning making (Brookfield, 1995; Christiensen \& Dirkinick-Holmfeld, 1996; Jonassen, Davidson, Collins, Campbell, \& Haag, 1995; Palloff \& Pratt, 2005).

Connectivism (Siemens, 2005) recognizes that in the online learning environment, seeking and constructing knowledge is most often accomplished through interaction and dialogue. The authors of this paper agree with Siemens and like most online educators acknowledge the importance of creating learning environments that promote group connectivity and collaboration experiences that help students to acquire the skills necessary to create and effectively participate in learning communities and social networks. The question that arises for online teachers is how to incorporate small group learning experiences into courses that are inviting and provide productive, engaging, and skill building spaces for learners, which encourage them to repeat the collaborative learning experience independently.

Siemens (2002) notes that learner-learner interactions in an e-learning course can be viewed as a four stage continuum:

\section{Communication}

People 'talking,' discussing

\section{Collaboration}

People sharing ideas and working together (occasionally sharing resources) in a loose environment

3. Cooperation

People doing things together, but each with his or her own purpose

4. Community

People striving for a common purpose

This continuum of involvement provides a useful framework for thinking about scaffolding with learners through progressively more complex interaction skills leading to the creation of an effective working group. Siemens (2002) proposes that in an online course, interaction will probably not go beyond communication/collaboration most of the time. He notes that while it is not realistic to expect community in many online courses, it should be possible in graduate level programs with high learner-learner contact. In the MDE program that provides the context for this paper, acquisition of skills associated with collaborative learning is an explicit goal. Courses have little static content, other than a comprehensive syllabus and course outline, and are heavily driven by interaction among learners and between instructor and learners. Small group projects are a common learning method, and discussion has intensified about the merits of grading students' collaborative group work as a means of motivating student participation. The study described in this paper is a form of reflective practice in that it considers the literature and data from the program for the purpose of informing these discussions. 


\section{Objectives and Research Hypothesis}

The initial objective of the study was to determine whether grading collaborative projects is positively related to higher student participation levels in small group work. The hypothesis leading to the research was that student participation levels would be higher in small group work where group projects were graded as compared to those where they were not graded. The results from the investigation of this main hypothesis led to a post-hoc research question about factors other than grading that might positively influence participation in collaborative learning in small groups. These factors are discussed in the latter half of the paper.

\section{Context and Methodology}

In January 2000, the University of Maryland University College (UMUC), USA, and Oldenburg University, Germany, began offering a joint online master's program, the Management of Distance Education (MDE). Courses within the program are provided online and delivered using UMUC's proprietary course software, WebTycho. WebTycho supports asynchronous dialogue using main conference threads as well as collaboration for smaller groups within a study group area using synchronous online chat and collaborative documents (See Figure 1).

Students in the MDE program are adults who have attained at least a baccalaureate degree and are generally between the ages of 30 and 50 (67\%); they are mainly from the United States, with a minority from other countries. Approximately $70 \%$ are female and $30 \%$ are male. Most are working full- or part-time (90\%). The classes from which the data was collected for the purpose of this study fit this profile (Porto, Bernath, \& Walti, 2006).

The Foundations of Distance Education (MDE 601) course is intended to provide graduate students with a foundation of the knowledge, skills, and attitudes required for them to become competent practitioners of distance education. This initial, introductory course to the MDE program has been offered continuously since 2000 during each university semester - spring, summer, and fall; at times, more than one section has been offered per semester. The course is structured into four modules with a main conference posting area for each module. Smaller study group areas with three to six students can be found in the study group conferences, which are only accessible by the instructor and the student members of the respective study group. 


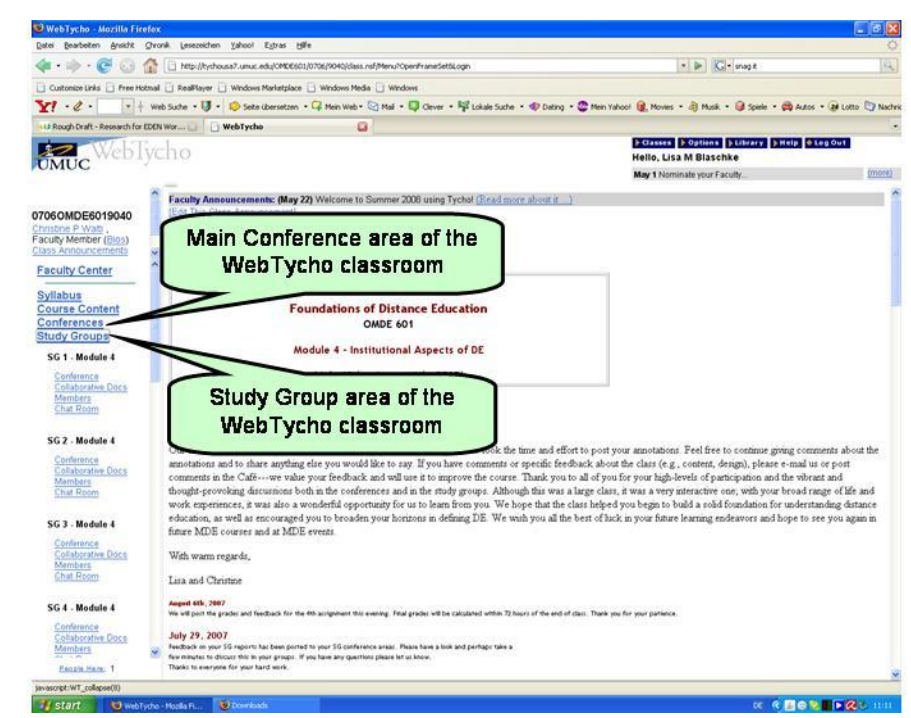

Figure 1: WebTycho conferences and study group areas.

The MDE 601 course includes two study group projects:

1. In the first module, students collaborate within their individual study groups to articulate and present a group definition of distance education.

2. In the fourth module, students select and/or define a typology of distance education institutions (e.g., dual-mode and single-mode institutions) and then conduct research on institutions that meet the schematic defined for the typology. They then present the results of their collaborative efforts in a group paper.

Data was gathered from fifteen sections of MDE 601, from 2005 to 2008. The collaborative work in module1 has never been graded and the collaborative work in module 4 of the first 13 sections of the course offered during the period covered by this study (spring 2005 to summer 2007) was not graded. However, during this time detailed instructor feedback for group projects was provided. In the sections of fall 2007 and spring 2008, faculty began to assign a formal grade after repeated requests by students to have this second group project graded. The group projects were then assigned a cumulative grade based on the following: 1) the collaborative group process, 2) the final product (group paper), and 3) peer-to-peer evaluation of the collaborative work.

During the period for which data was collected, the number of students within a course section ranged from 13 to 35, with an average of 20 students per section, and the study groups comprised on average four to five students each. The content and instructions for the collaborative group project assignments in modules 1 and 4 were consistent over this period.

For the purposes of the study, the following data was collected for each of the 15 course sections:

1. number of students,

2. number of posts in each study group area during each of module 1 and module 4 . 
Calculations were made for each course section as follows:

1. total number of posts in both study group areas (module 1 and module 4),

2. percentage of posts in module 1 compared to total posts for both study group areas,

3. percentage of posts in module 4 compared to total posts for both study group areas,

4. average number of posts per student during each of module 1 and module 4 ,

5. comparison (by multiple) of number of posts in module 4 compared to module 1 .

All of these figures are presented in Table 1.

\section{Findings}

When comparing study group behaviour between module 1 and module 4 within each course section, it was found that participation levels during the second study group project were on average 2.05 times the participation levels for the first study group project when neither module was graded (see Table 1). This finding for sections where neither group project was graded (spring 2005 to summer 2007) was expected because the study group project in module 4 is significantly more complex and work-intensive than the project in module 1 , requiring more interaction among group members. It was expected that there would be noticeably more study group activity (> 2.05 times that in module 1) during the second study group project once instructors initiated grading for that project. However, this was not the case. When the second group project was graded (fall 2007 and spring 2008), participation levels during the second study group project were on average 1.93 times the participation levels during the first study group project.

To further control for the varying levels of participation (activity as measured by \# of postings) that naturally occur between course sections, participation levels between graded and non-graded sections of the course were compared by considering the level of activity within module 4 in the context of total activity in both modules within each section of the course. The initial findings in fall 2007 did not support the original hypothesis that participation levels would increase when the module 4 project was graded; these findings were further reinforced in spring 2008. In both of these sections, which had a grade assigned to the second study group project, student participation levels remained consistent with those in previous sections where there had been no grading. In other words, in a straightforward comparison of participation levels as measured by percentage of postings in module 4 (\# of postings in module 4 study group area/total \# of postings in both study group areas), there was no discernible increase or decrease in participation levels when a grade was assigned in comparison to student participation levels in the thirteen previous offerings of the course when a grade was not assigned to the group project (see Table 1 and Figure 2). These preliminary findings do not show an immediate benefit in assigning grades to the collaborative study group project, but this is based on only two sections of the course that have had graded projects. A greater number of cohorts and a more extensive statistical analysis are required before any firm conclusions can be reached. 
Table 1: MDE 601 Research Data - Participation Levels [15 Cohorts (2005-2008)]

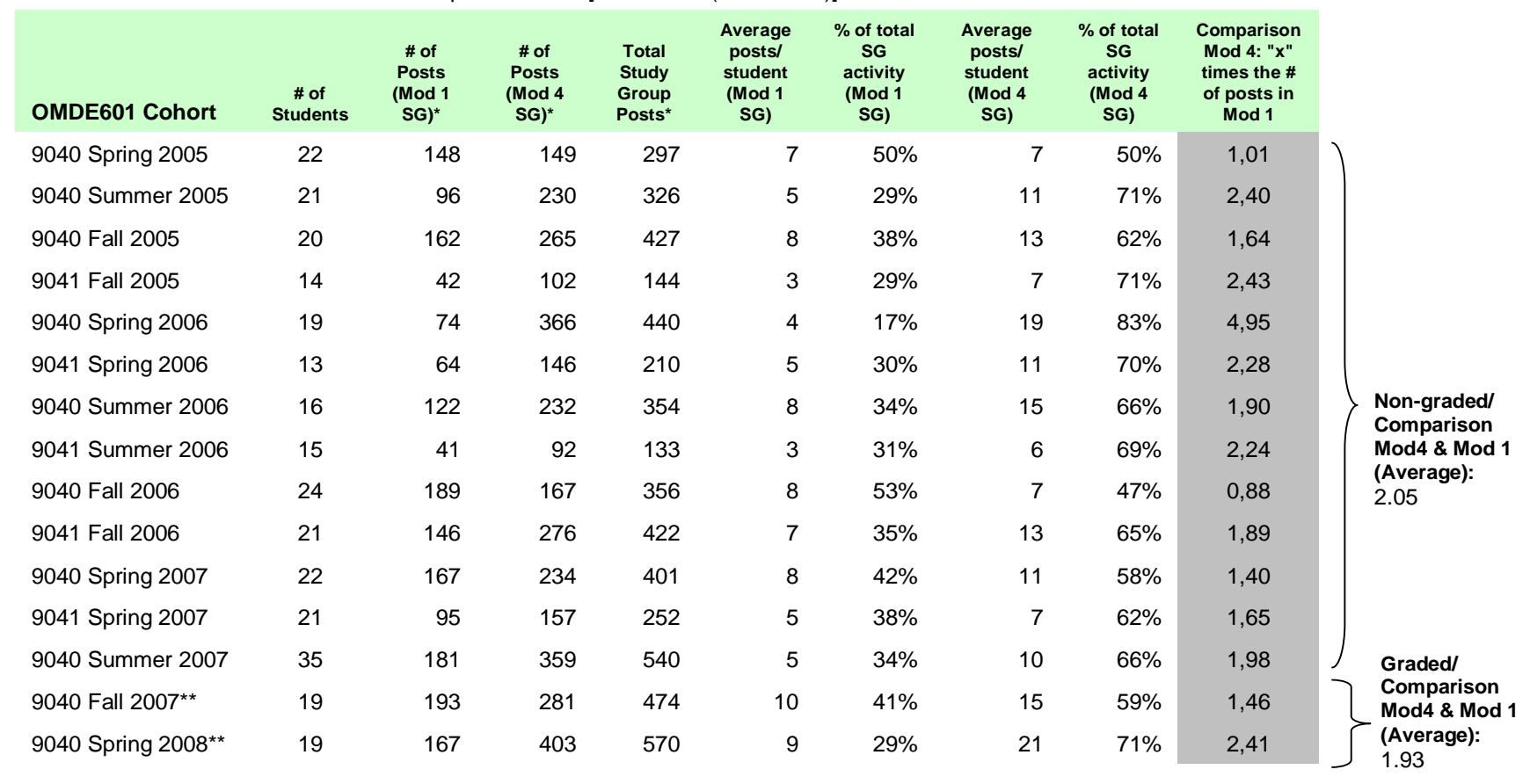

* Numbers do not include instructor postings or collaborative documents

${ }^{\star *}$ Courses where Module 4 study group project was graded

Figure 2: MDE 601 - Module 4 as a percentage of total group activity.

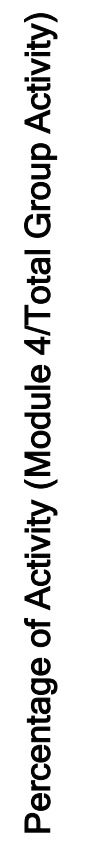

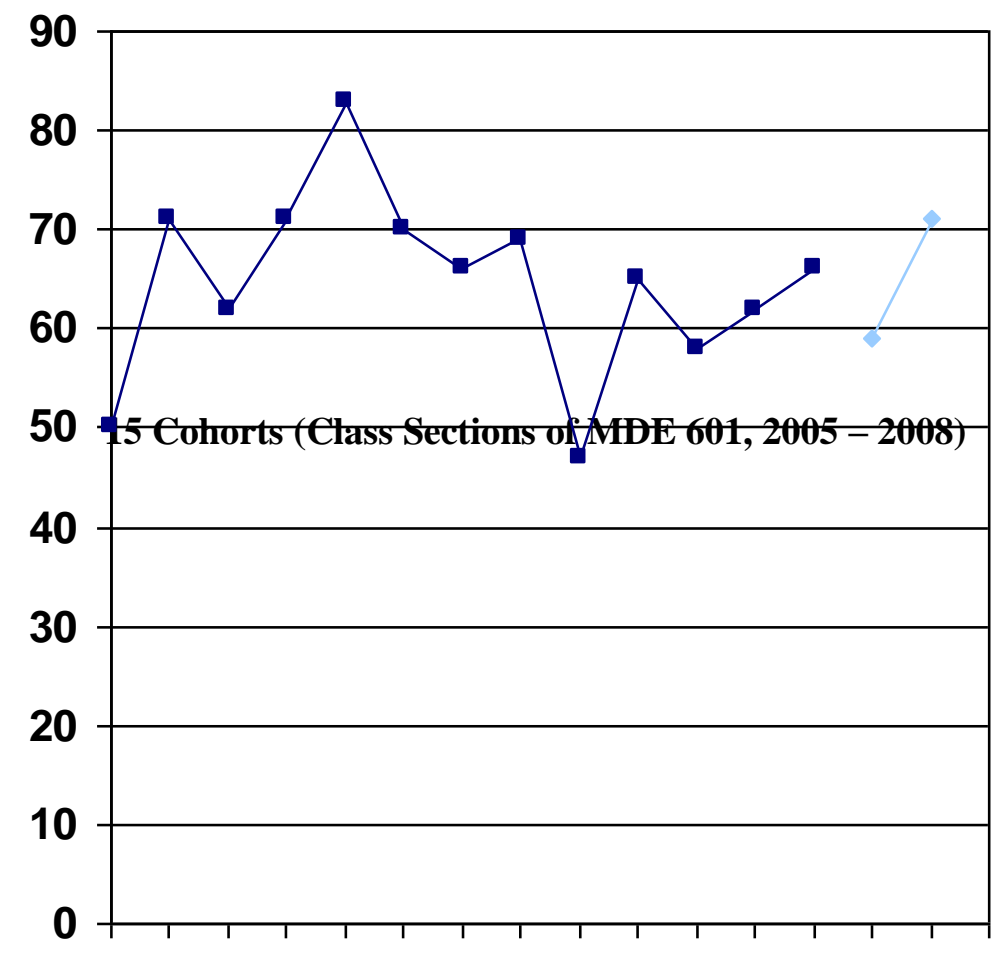


In addition to the main findings, it was revealed that in general students participated more in study groups than in the larger main conferences. So-called "witness learners" (Beaudoin, 2003), those who never appear in module conference discussions, almost always actively participate in study group activities even when the group work is not graded. It could thus be concluded that some students prefer small group interaction to interaction within larger class conferences; however, additional research would be necessary to further support this claim. Based on the preliminary data, it was also hypothesized that although students may have the will to participate in collaborative projects, the skills to effectively engage in online collaboration are often lacking. In the case of MDE 601, this could well be the case because this course is often the first online study experience the students have undertaken within the MDE program, and they have not yet developed the necessary skills to collaborate effectively online.

As a result of the preliminary findings, a post-hoc question of what other factors in addition to grading might contribute to encouraging participation in small group study projects was posed. The authors decided to consider MDE 608, a required course in the MDE program where group work has never been graded (at the request of students) but where participation levels in the study group project are consistently high. The authors do not offer it as a direct comparison with MDE 601 (comparable data is not available) but rather as a case study of a course where strategies identified in the literature as encouraging participation in small groups have been explicitly employed with success. In fact, a number of the strategies used in MDE 608 are also used in MDE 601, and this may, in part, account for the lack of increase in participation rates in MDE 601 study groups when grading was added as additional inducement. It should be noted that high participation levels in MDE 608 study groups (which can be verified by data) may be due, at least in part, to students having more study group experience by the time they reach this advanced course.

\section{An Alternative Model for Effective Collaborative Learning - MDE 608}

The Learner Support in Distance Education and Training course (MDE 608) is a required course in the MDE program but can be taken at any time prior to graduation. Most students who take the course have completed at least MDE 601. Hence, the students who take MDE 608, relative to those in MDE 601, generally have more experience as online learners. The overall objective of MDE 608 is to help students develop the knowledge and skills to be able to assess learner needs and contextual demands in order to plan and implement appropriate learner support for a particular situation. The course is designed so that students acquire basic knowledge of the field of learner support and, at the same time, are given assignments that help them to build increasingly complex skills (e.g., critically analyzing literature, articulating a position and supporting it with references to the literature, working in a small group to do an environmental scan and needs assessment in a particular education or training context, applying their knowledge in designing a learner support system for a particular context).

As with other MDE courses, study groups (small groups that work collaboratively on a project) are an integral part of the instructional design. Although a small portion (10\%) of the overall grade in MDE 608 is awarded for overall participation in the course, the projects completed by 
the study groups are not graded. The course has been offered for 7 years and during that time the study groups have enjoyed full participation with rare exceptions, usually due to unusual circumstances, supporting the findings from MDE 601, which revealed no significant relationship between grading and participation. MDE 608 has used other means of valuing and encouraging participation in the study groups that are built into the design of the course. A thoughtful examination of this course in the context of the research questions posed by this paper suggest that these strategies contribute significantly to the effectiveness of the study groups both in participation levels and the quality of work produced by the study groups, which tends to be quite high.

The strategies employed in the course to both communicate the value of collaborative learning and to increase motivation to participate in the study groups in MDE 608 were identified as follows:

\section{Transparency of expectations}

Details of the requirements to participate in a study group are posted in the course syllabus. The purpose (learning objectives) of collaboration and expectations of the learners are made very clear in the main conference. If students communicate reluctance about study group participation, instructors encourage participation and are open about discussing the purpose and process.

\section{Clear instructions}

The group task, timelines, and usability of the desired product are described in detail, giving students the best opportunity to focus on collaborating to share ideas and the workload rather than leaving them to spend a great deal of time trying to clarify the task and develop a common understanding of it.

3. Appropriateness of task for group work

Each study group works as a team of consultants to carry out an environmental scan and needs analysis of a particular educational or training provider (develop a case study) in preparation for a second task (done individually). This type of task is easier and a much more rich experience when performed by a group as opposed to an individual.

\section{Meaning-making/relevance}

The group assignment is an opportunity to apply principles and knowledge gained in the course to the analysis of a real life situation, often from a student's work context. Further, in the last week of the course, the group projects are exchanged and peer reviewed (by the groups), making full use of the learning potential of the project.

\section{Motivation for participation embedded in course design}

Individual success is dependent upon group success. The group product (comprehensive case study) is needed by individual learners in order to complete their final assignment, that is, to design a learner support system for their group's case study. 


\section{Readiness of learners for group work}

The group project takes place during the final third of the course after students demonstrate that they have sufficient mastery of the subject matter to reflect on how to apply their knowledge in particular contexts, including their own work settings (as demonstrated in the conference discussions), and they have had the opportunity to develop a sense of community and hone their collaborative learning skills.

\section{Timing of group formation}

Although the group project is not undertaken until the third section of the course, the study groups are formed during the second unit. This allows time for a sense of collaboration and interdependence to develop among the members before the task is assigned. During the period before the task, group members discuss their shared interests and possible scenarios for the case study.

\section{Respect for the autonomy of learners}

Study group participation is mandatory but learners have the freedom to form their own groups based on shared interests. Instructors provide guidelines for group formation and open a space in the virtual classroom for this purpose. The choice of educational or training context for the case study is the decision of each group, and groups often have lively discussions and do significant research before consensus is reached, resulting in high ownership of the project.

\section{Monitoring and feedback}

The study group conferences and chats are monitored closely by instructors who provide respectful and timely feedback on process and direction when necessary to prevent groups from getting stalled or going off course. Instructors also provide feedback on draft versions of the case studies and provide time for revisions before presentation of the final project.

\section{Sufficient time for the task}

Most of the third and last unit of the course (approximately four weeks) is devoted to the study group project to provide sufficient time for the process and to accommodate varying work schedules and time zone differences of these adult learners.

Course evaluations from MDE 608 consistently reveal learner satisfaction with the course and with the study group experience. Occasionally, one member of a study group does not pull his or her weight but this is the exception rather than the rule, and in most cases the groups organize themselves relatively quickly and all learners contribute fairly equally to the task. Grading the study group project would not only undermine the values and motivational aspects of the course design but based on the data gathered in MDE 601 would not have a positive impact in terms of participation by learners or the quality of the work presented by the groups. Further, most students have a very positive reaction to not having their group work graded. From the experience in this course, it appears that instructional strategies can be an effective motivational tool to encourage participation and to enhance collaborative learning in small groups and a positive 
alternative to using grading as an incentive. As well, instructional strategies such as the ones described herein provide students with a positive experience of group work and contribute to learner autonomy and self-direction.

\section{Implications for Practice}

Based on these findings from MDE 601 and MDE 608, the authors propose that rather than focus on the grading of collaborative group projects, instructors should incorporate a variety of instructional strategies to improve the quality of group collaboration and to increase the likelihood of student participation. These strategies are outlined below:

\section{Facilitate learner readiness for group work and provide scaffolding to build skills} Scaffolding is important in preparing learners for small group projects. This can be accomplished through instructional design (sequencing activities within the course that build on previously learned skills) and positioning small group activity later in the course when students have acquired the confidence and skills to be successful. Students need to be taught the necessary skills for effective online collaboration, particularly those skills that will help them succeed in a group environment, such as planning and negotiation skills (Curtis \& Lawson, 2001). Chapman, Ramondt, and Smiley (2005) recommend using ice breakers, seeding, and statements about expectations regarding participation, etiquette, and guidelines for behaviour, and Smith (2003) discusses uses of interaction standards, tools, and techniques. Learners often need help with acquiring information literacy skills (how to retrieve, evaluate, apply, and source information effectively) and with using the technology effectively.

\section{Establish a healthy balance between structure (clarity of task) and learner autonomy} (flexibility of task)

The instructor should provide guidelines for team member performance in conducting the group project (Palloff \& Pratt, 1999) and ensure that the task is achievable, sustainable, and properly timed within the course (Bouchat, 2007). Juwah (2006) has found that allowing learners to form their own groups and select their own topics facilitates socializing within groups and positive group dynamics. Effective course design will make the purpose and parameters of group tasks and the learning goals clear and explicit while still allowing students flexibility, such as choice of group membership, member roles, and specifics of the topic. When students have personal control over the task (content, process, intentions, goal setting, consequences, outcomes, group partners), their engagement, responsibility, and sense of the relevance of the task are heightened.

\section{Nurture the establishment of learner relationships and sense of community}

In order for true collaboration to occur, a sense of community needs to be established within groups (Palloff \& Pratt, 2005; Chapman, Ramondt, \& Smiley, 2005). Important elements for establishing successful learning communities are informality, familiarity, honesty, openness, heart, passion, dialogue, rapport, empathy, trust, authenticity, disclosure, humour, and diverse opinions (Chapman, Ramondt, \& Smiley, 2005). 
Instructors can model, discuss, and reinforce these elements in the main conference, helping students to prepare for smaller, more intense group learning experiences. If students develop relationships with their peers early, they can build on these relationships in group work.

\section{Monitor group activities actively and closely}

During the collaborative process, the instructor needs to be available for feedback, general information, and private counsel. In addition, the instructor needs to intervene as required to keep discussions on track, support and animate dynamic conversation, help students stay focused on the task, assist with relationship building, and provide reassurance. Although this paper does not advocate formal assessment, continuous feedback is a type of formative evaluation that helps students develop specific skills and deepens the learning process.

\section{Make the group task relevant for the learner}

Research by Curtis \& Lawson (2001) has found that the more interested a student is in a group topic, the more motivated the student is in participating in the collaborative effort. Allowing learners to pursue topics according to mutual interest sets groups up to share and co-create knowledge. Authentic, real-world environments and relevant content provide motivation for collaborative learning. Enabling students to control and direct their learning to the greatest extent possible helps them to achieve a purpose that is specific to their needs and challenges their zone of proximal development (Vygotsky, as cited in Lin, 2008).

6. Choose tasks that are best performed by a group

Individual learners make compromises regarding flexibility of study in order to participate in a collaborative exercise. Engaging in tasks that benefit from teamwork will increase their sense of purposefulness and motivation to participate.

\section{Provide sufficient time}

Course design should allow sufficient time for collaborative learning activities, including time for scheduling, planning, and organizing. Most importantly, time is required for the discussion and exchange of ideas that are crucial to deeper learning.

\section{Some Further Thoughts on the Realities of Online Teaching and Learning}

Occasionally, despite best efforts in course design and instruction, a group will have low participation by some group members and/or low quality outcomes in terms of the interchange/discussion and the final product. It is important to recognize that there are a number of circumstances and factors that can contribute to a lack of participation and/or dysfunction within the virtual classroom and particularly within small groups. These can sometimes be mitigated by the instructor but their presence is often beyond his/her control. Learners who choose online study most often do so because of the flexibility and convenience of choosing their 
own study hours, usually because they have very busy lives. Particularly in the case of adult learners, other roles may be primary to that of student. Academic work is important but must fit around demands of career, home, and community. Group projects require that learners be present on a particular schedule, reducing the flexibility and convenience factor in online study and may cause anxiety and/or resentment, particularly if the purpose of the group work is not clear and the group experience is not positive.

Although most adult learners manage their multiple roles fairly effectively, unexpected events such as illness, a death in the family, or other changes in their personal circumstances can tip the balance and prevent them from being online over extended periods of time. A singular event such as a statutory holiday, a world cup soccer game, or a natural disaster may adversely affect short and longer duration discussions (Bouchat, 2007). Obviously, absences from small groups have a more profound impact than absences from the general conferences.

Students who are assigned a group project without an adequate level of readiness and/or guidance may be set up for failure. An interesting factor discussed by Sanders (2008) is that students are often ill-equipped through their previous educational experiences to collaborate (in general) or peer-review and often see colleagues as rivals. In such cases, peer reviewing (a common task for small group collaboration) is often superficial, unhelpful, and/or judgmental. It takes time to establish community, and 12 weeks (the common length of a semester in a paced program) is sometimes insufficient for those new to online learning to develop both the requisite skills and confidence to fully participate in collaborative learning.

The accessibility of technology to individual members of a group and each learner's skill level in using the medium can support or hinder a positive collaborative dynamic in that the technology can be the source of either frustration or motivation. There are also indications that the asynchronous format hinders the negotiation of difficult issues and conversations that require quick, direct turn-around. Confusion and breaks in communication can result from the delays between initial postings and responses that characterize asynchronous communication. Tools more suitable to collaborative learning (wikis, social bookmarking, RSS, and Skype) are readily available on the Internet but are not necessarily introduced to learners or incorporated into virtual classrooms in a systematic way.

The most effective learning is transformative but the required adjustment may temporarily disrupt a learner's ability to effectively collaborate with his/her peers. Lin (2008) posits that “... adult learning is not always joyful or motivated by heart-felt needs..." (p. 4) and notes that adult learners commonly experience anxiety over the gap between old thinking and new knowledge or capability as well as a sense of disconnectedness at various stages of the learning process.

Groups are comprised of individuals with unique personalities and learning styles and differing levels of skill. Personalities can clash, group leadership may be lacking or dominant, or there can be dysfunction and/or conflict within the group. For example, there are sometimes students who have a low commitment to the class for personal reasons. At the same time, they may not be ready to drop the course, and no amount of effort by instructors may increase their participation 
or commitment. Alternatively, there are occasionally students with difficult interpersonal styles, who can have a negative impact within their team. In these cases, it is sometimes best to encourage the group members to carry on without being overtly critical of the non-functioning member. Students pick up on the instructor's sensitivity to the situation and will usually respond by doing what they can to complete their group project. Handled in a constructive and positive way, this can present a good learning experience for all of the students including the ones who are low performers.

Finally, the dissatisfaction and reluctance that students express over mandatory participation in group projects often result from a sense of not having full control over the quality of the project and the subsequent grade assigned, particularly when someone in the group has less than satisfactory performance. This may be a good reason for not placing emphasis on grading as much as helping students to learn the skills of collaboration, including how to deal effectively with group members who are unable or unwilling to participate fully in the group process. If the right environment is created, both high performing and low performing students are able to reflect on and articulate their opinions about their experience and the outcomes of their learning. That being said, it is important to acknowledge the extra time and special skills required of instructors to ensure the effectiveness of small group learning experiences. Research appears to confirm that small group collaboration online needs careful management by the instructor (cf. Swan, Shen, \& Hiltz, 2006, p. 51).

\section{Limitations of the Study}

The sample for the main research question consisted of all students in the MDE 601 classes (the mandatory Foundations course of the MDE program) offered between 2005 and 2008, and for the post hoc question all students in the MDE 608 classes between 2000 and 2008, and as such is representative of the larger population of MDE students in the UMUC/Oldenburg online program. The MDE program population is similar to that of a number of other North American online university programs catering to working adults (i.e., in terms of characteristics such as age, gender, employment status, cultural diversity). That being said, this investigation of the effect of grading on participation in small study groups was only preliminary. Cross program and cross institutional studies with larger sample sizes are required in order to perform formal statistical analyses to confirm whether grading makes a significant difference to participation levels in online study groups. Evaluative research is also needed to test the efficacy of the suggested instructional strategies to increase participation in and satisfaction with small group learning, and further investigation is required to better understand and test the interactional effects among variables.

\section{Summary}

There appears to be a strong argument for including small group collaborative learning experiences in online courses. The literature reveals a significant relationship between participation in these experiences and deeper learning as well as the development of learning and teamwork skills. Further, collaborative learning appears to increase a sense of community, which 
has been shown to be closely linked to learner satisfaction and retention. However, the preliminary data collected in MDE 601 does not support a strong reliance solely on assessment (assignment of a grade) of group work to encourage participation in study groups. Although assessment may enhance participation for some students, observations of the methods used in MDE 608 and 601 and the authors' combined experiences of guiding students' collaborative efforts in the online classroom suggest that other factors, in particular instructional strategies, accomplish the same goal, perhaps more effectively and with added benefits for the learner.

This paper reinforces the importance of reflective practice for instructors. Assumptions about what impact specific strategies have on learner behaviour need to be tested constantly. In this case, it appears that instructional strategies may be equally or more effective than assessment in encouraging participation in small group activities in the online classroom. Further, well planned instructional strategies that are intended to improve the group learning experience appear to have a number of added benefits, such as helping students to achieve deeper learning and to build their confidence and skills. Further data collection and analysis are required to provide more conclusive evidence of the impact of grading on participation behaviour in online groups, but this preliminary investigation points to the need to continue to study this relationship. Future studies are also recommended to examine the impact of instructional strategies and assessment on the quality of group projects and the effectiveness of using journaling and e-portfolios in evaluating the impact of group work on learning outcomes. 


\section{References}

Beaudoin, M. (2003). Learning or lurking? Tracking the 'invisible' online student. In U. Bernath \& E. Rubin (Eds.), Reflections on teaching and learning in an online master program (pp. 121-130). Oldenburg: Bibliotheks- und Informationssystem der Universität Oldenburg.

Bouchat, C. (2007, December 17). Threaded discussion tips for designers. Learning Solutions eMagazine. Retrieved January 31, 2008 through personal subscription to The eLearning Guild.

Brookfield, S. D. (1995). Becoming a critically reflective teacher. San Francisco: Jossey-Bass.

Chapman, C., Ramondt, L., \& Smiley, G. (2005). Strong community, deep learning: Exploring the link. Innovations in Education and Teaching International, 47(3), 217-230.

Chen, P., Gonyea, R., \& Kuh, G. (2008). Learning at a distance: Engaged or not? Innovate, 4(3). Retrieved February 26, 2008, from http://www.innovateonline.info/index.php?view=article \&id=438\&action=article

Christiensen, E., \& Dirkinick-Holmfeld, L. (1995). Making distance learning cooperative. Retrieved May 19, 2008, from http://vbn.aau.dk/research/making_distance_learning_collaborative(125626)/

Curtis, D. D., \& Lawson, M. J. (2001). Exploring collaborative online learning. Journal of Asynchronous Learning Networks, 5(1), 21-34.

Harasim, L., Hiltz, S. R., Teles, L., \& Turoff, M. (1998). Learning networks: A field guide to teaching and learning online. Cambridge, MA/London, England: The MIT Press.

Jonassen, D., Davidson, M., Collins, M., Campbell, J., \& Haag, B. (1995). Constructivism and computer mediated communication in distance education. American Journal of Distance Education, 9(2), 7-25.

Juwah, C. (2006). Interactions in online peer learning. In R.C. Sharma \& C. Juwah (Eds.) Interactions in online education. Implications for theory and practice (pp. 171-190). New York: Lawrence Erlbaum.

Kearsley, G. (2000). Online education: Learning and teaching in cyberspace. Belmont, CA: Wadsworth.

Kearsley, G. (nd). Tips for training online instructors. Retrieved May 26, 2008, from http://home.sprynet.com/ gkearsley/OItips.htm 
Kop, R., \& Hill, A. (2008). Connectivism: Learning theory of the future or vestige of the past? International Review of Research in Open and Distance Learning, 9(3). Retrieved January 20, 2009, from http://www.irrodl.org/index.php/irrodl

Lin, L. (2008). An online learning model to facilitate learners' rights to education. Journal for Asynchronous Learning Networks, 12(1). Retrieved May 17, 2008, from http://www.distanceandaccesstoeducation.org/Results.aspx? searchMode=3\&criteria=en

Palloff, R. M., \& Pratt, K. (1999). Building learning communities in cyberspace: Effective strategies for the online classroom. San Francisco, CA: Jossey-Bass.

Palloff, R. M., \& Pratt, K. (2005). Collaborating online: Learning together in community. San Francisco, CA: Jossey-Bass.

Porto, S., Bernath, U., \& Walti, C. (2006). MDE program self-assessment report for the EFMD CEL accreditation. Oldenburg, Germany. http://www.c31.unioldenburg.de/literat/EFMDfinalrevised.pdf

Sanders, M. (2008, Feb. 18). A failure to collaborate. The Chronicle of Higher Education. First Person. Retrieved February 18, 2008, through personal account.

Siemens, G. (2005). Connectivism: Learning theory for the digital age. International Journal of Instructional Technology and Distance Learning, 2(1), January 2005. Retrieved May 25, 2008, from http://www.itdl.org/Journal/Jan_05/index.htm

Siemens, G. (2002). Interaction. E-Learning Course. October 8, 2002. Retrieved May 19, 2008, from http://www.elearnspace.org/Articles/Interaction.htm

Shaw, S. (2006). New reality: Workplace collaboration is crucial. Eedo Knowledgeware Whitepaper. Retrieved through personal subscription.

Smith, L. (2003). Assessing student needs in an online graduate program. In U. Bernath \& E. Rubin (Eds.), Reflections on teaching and learning in an online master program - A case study (pp. 255- 265). Oldenburg: Bibliotheks- und Informationssystem der Universität Oldenburg.

Swan, K. (2001). Virtual interaction: Design factors affecting students' satisfaction and perceived learning in asynchronous online courses. Distance Education, 22(2), 306-331.

Swan, K., Shen, J., \& Hiltz, S.R. (2006). Assessment and collaboration in online learning. Journal of Asynchronous Learning Networks, 10(1), 45-62. 
June - 2009

\title{
Teachers' and Students' Experiences of Simultaneous Teaching in an International Distance and On-Campus Master's Programme in Engineering
}

\author{
Oleg Popov \\ Umeå University, Sweden
}

\begin{abstract}
Swedish universities frequently offer campus-based education as well as online courses, a system commonly referred to as dual mode. This paper analyses some challenging pedagogical aspects of a master's programme in engineering developed and delivered simultaneously online and on campus. Course evaluations, questionnaires, and interviews with the programme teachers were the main instruments used in this study. Activity theory was used as a theoretical framework for data collection and analysis. The study evidences the nature of problems experienced by oncampus and distance students as well as conflicts of interest and expectations existing between these two student groups. Teaching simultaneously in two modes demands extra effort from the course teachers, who are aware of the problems related to pedagogical communication needed by both groups. Though teaching in the dual mode offers economic benefits for the department, the simultaneous mode of teaching is experienced as problematical by both groups of students, with distance students appearing to be more disadvantaged in the programme.
\end{abstract}

Keywords: Activity theory, distance education; higher education pedagogy, qualitative research

\section{Introduction}

There is a strong international trend in higher education to develop distance education using information and communication technology (ICT) in order to provide high-quality education at the least possible cost (Casey, 2008; Högskoleverket, 2008). Science and engineering faculties around the world are also active in the process of introducing online learning, and they seek alternative ways of providing practical, laboratory, and project components of academic studies (Bhattacharya, 2008). Support for ICT-enhanced education is also part of the current political agenda in Europe. The European Commission (2008) emphasizes the importance of supporting educational institutions that promote creativity and innovation through developing specific teaching and learning methods (including the use of new ICT tools). In general, the spread of 
electronically customized education around the world seems to be an irreversible process as more courses and programs are delivered online. London and Draper (2008) call this phenomenon "the silent revolution in higher education."

A strong utilitarian argument for online education is that it provides the opportunity to reach new groups of students in new places around the world. For Swedish science and engineering programmes struggling with small enrollments for face-to-face courses, the opportunity to widen the range of potential students through online learning is crucial. In Sweden, the same universities that organise campus-based education also offer e-learning courses and programmes. This system is commonly called dual mode (Högskoleverket, 2008). The policy states that the same fundamental quality requirements should apply to e-learning as to campus-based higher education. However, there is also consensus that there are significant differences between elearning and campus-based education (Högskoleverket, 2008). Switching from the regular oncampus style to a remote one is not an easy process. Researchers express concern (Kuleshov, 2008) that if an aspiration to this web-enhanced online teaching is not supported by adequately prepared faculties, technical support staff, and students, it will lead to the degradation of the teaching process rather than to its improvement.

Exploration of the effectiveness of online education and the quality of educational processes relying on Internet and computerised technology usage has thus been an important part of educational research for many years (for literature review on this topic, see Conole \& Oliver, 2007). Currently, new discussions are appearing on the possibilities of mutual enrichment of pedagogies of distance and on-campus teaching when teachers move between face-to-face and online classrooms, transferring ideas, strategies, and practices from one to the other (Lowes, 2008). Researchers are also working actively on analysing the particularities of e-learning in international communities (Hudson, Hudson, \& Steel, 2006).

This paper aims to describe and analyse some challenging pedagogical aspects of an international master's programme in engineering developed and delivered in dual mode at a Swedish university. The programme introduced a pedagogical approach of mixing distance and on-campus engineering students on the same course. Though the economic advantages of such an arrangement are obvious as many more students are enrolled on the courses with a marginal increase in the course delivery costs, the design of the pedagogical delivery of the programme is complex and needs deeper analysis, including a focus on the processes involved in simultaneous teaching. With this purpose in mind, the following research questions were formulated:

- What is the student's experience of simultaneous distance and on-campus teaching in the programme?

- How do the teachers experience teaching distance and on-campus students on the same courses simultaneously?

The issue of quality in teaching has not been specifically dealt with in this paper and student performance indicators were used only for illustrative purposes. 


\section{Brief Programme Presentation}

The distance master's programme in engineering (DME) $)^{\mathrm{i}}$ analysed in this paper aims to provide state-of-the-art engineering education to places where such education would not be possible otherwise. It has been running for four years and is currently two years in duration (120 ECTS). The first three semesters consist of coursework and the last semester involves a thesis based on research project work. The main part of the course involves lectures, self-studies, and evaluation exercises. Lectures are given in the technically enhanced rooms for on-campus students in the Swedish university but are also aimed at distance students. These lectures can be followed by the distance students synchronously and/or asynchronously via Internet. An important aspect of the programme is that most distance students come from cultures that differ from the national Swedish culture.

The syllabus of the DME programme is identical to the on-campus master's programme in engineering. The courses are provided with the same educational requirements for the distance as for the on-campus students. Examinations are taken by DME students at their place of residence following the procedures and requirements that exist at the Swedish university. Student responses to examination questions are sent to Sweden by express mail for grading by course teachers. The students submit projects and assignments using an interactive web platform. Thus, both groups of students go through all the stages of the programme simultaneously. Student intake to the distance and on-campus sections of the programme are shown in the diagram below.

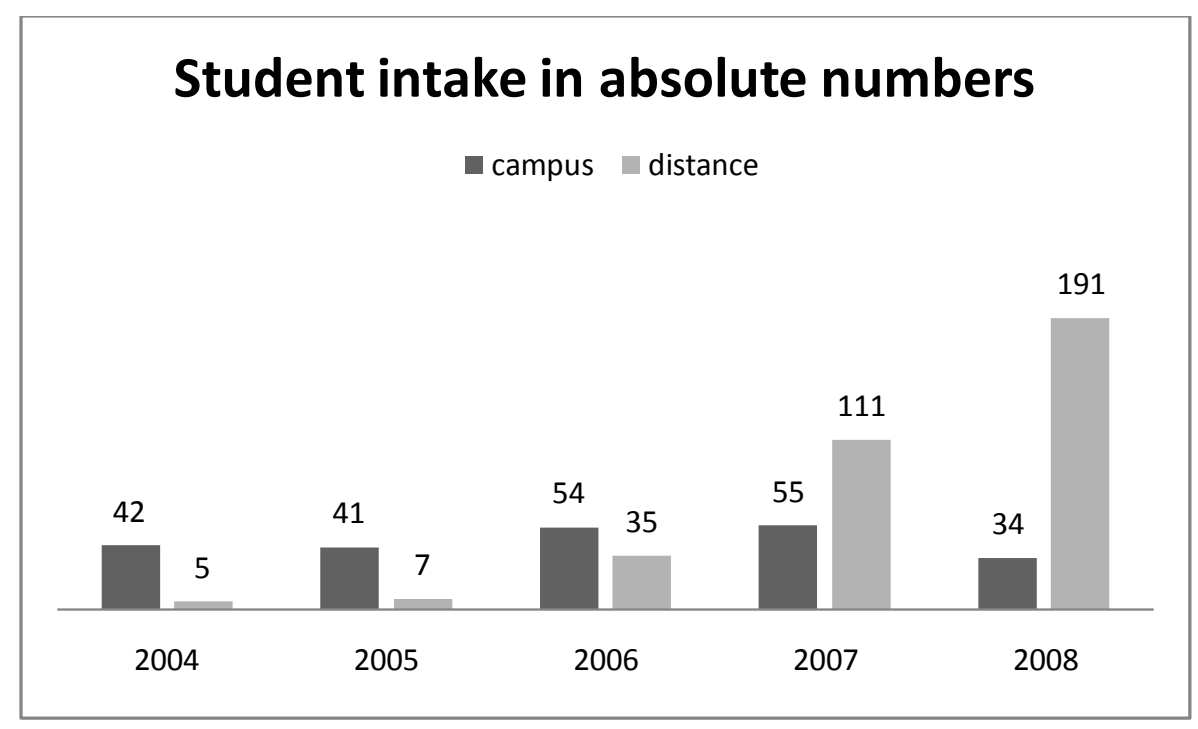

Figure 1. Student intake to the programme.

As shown in the diagram (Figure 1), it is obvious that the distance section of the programme (DME) is gaining in importance in terms of the number of students registered in successive years. Initially, the distance programme was open for applicants from any country in the world. However, two years ago (2007) a decision was taken to restrict the scope of the DME to nine 
countries (in Africa and Asia) with the aim of making the students' management process easier to control and compliant with Swedish university rules and regulations (e.g., exam organisation).

The programme completion rate is poor for distance students. For the intakes of 2004 and 2005 only $40 \%$ of the students (5 of 12) graduated. Nobody from the intake of 2006 was able to finish the programme on time. Differences in achievement are visible already in the first courses. For example, a short introductory course (on energy technology) in 2007 was passed by $95 \%$ of oncampus students (63 of 66; there were also 11 free-movers on the course) but by only $75 \%$ of distance programme students (83 of 111). Most of the distance students are chronically delayed in their studies. The average course completion rate for DME students is under 50\%. This situation awakened the author's interest to look deeper into pedagogical aspects of the programme and, in particular, into the process of simultaneous dual mode teaching.

\section{Theoretical Framework}

Activity theory is used as a theoretical framework for data collection and analysis. Particularly, the socio-cultural part of the theory was found to be useful for the study. This theory is broadly applied by researchers as an approach to the investigation of information technologies in the context of human practice and as a methodological framework for the design and analysis of computer-supported collaborative learning activities (Kaptelinin \& Nardi, 2006; Collis \& Margaryan, 2004). The main ideas and theoretical constructs of activity theory that helped to frame the research and analysis of the findings are presented below.

\section{Socio-Cultural Context}

The importance of the context as an active component of the learning process that interplays with learners' and teachers' activities is suggested by Vygotsky (1978). The conditions of the physical and socio-cultural environment, the resources available to the students, the students' learning traditions, and skills developed in their previous studies (or absence of such) all constitute important contextual factors that should be considered in the educational process.

\section{Practical Collaborative Activity}

According to Leont'ev (1981), the first and most fundamental form of human activity is external, practical collaborative activity that is idealised later on human thought. The value of practical activities cannot be underestimated in developing the professional knowledge and skills of future engineers.

\section{Mediation}

The fundamental claim of activity theory is that human activity (on both the interpsychological and intrapsychological planes) can be understood only if we take into consideration the technical and psychological tools that mediate this activity. The programme analysed relies highly on the 
functionality of ICT tools. The effectiveness of technological and pedagogical mediation is decisive for the success of distance education.

\section{Object of Activity}

The content of human activity is determined first of all by its object, and activity is oriented towards it (Leont'ev, 1981). The object of the programme analysed (and of the students' activities in the programme) is the engineering knowledge and skills used for the transformation of natural or human made objects, with their properties reflected in scientific and technological principles, laws, and theories. In other words, the object of learning activity is that which the programme aims to prepare the students for. The teachers' and students' perceptions of the object of activity influence the teachers' activities and the students' learning motives, actions, and strategies. The process of mediation in DME learning activities can be illustrated by the following diagram (Figure 2).

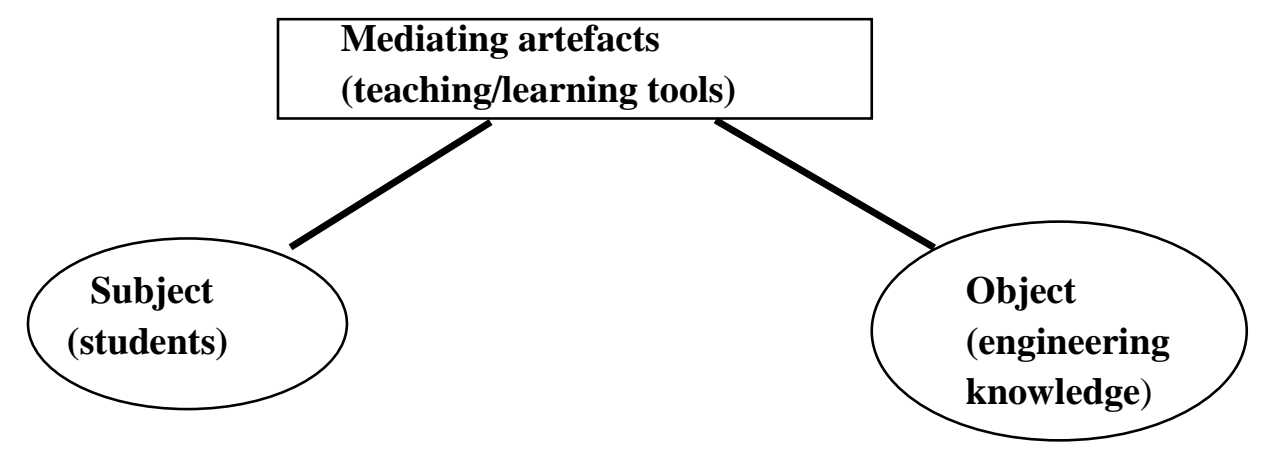

Figure 2. Mediation of learning activity.

The acquisition of new engineering competencies can be considered as an expected outcome of the activity.

\section{Motives}

According to activity theory, goals and motives are considered the basic (key) components of learning activities. Leont'ev (1981) emphasises that motives determine the sense of the activity. The motivation for learning can be more idealistic (such as personal and professional growth) or pragmatic (such as the acquisition of scholarships and diplomas). Activity theory also requires that human interactions with reality be analysed in the context of development. The theoretical constructs presented above were helpful in defining the study.

\section{Research Methods}

The main research instruments used in this study were the students' course evaluations, questionnaires, interviews with programme teachers, and analysis of DME programme documentation. Seven course evaluations from years 2007-2008 were analysed. The choice of 
courses was incidental as the program administrator sent arbitrarily selected evaluations of different courses to the author. In total, 347 students filled in the web-based course evaluation forms. These forms consisted of Likert-scale questions and a space for free comments. The evaluation forms did not contain a variable concerned with the study form (distance or oncampus) and the questions did not explicitly address the issues related to dual-mode teaching. This information was extracted from the students' free comments. The relevant comments and ideas about the teaching/learning process in the courses were put together through an iterative reading process and summarised in categories that were used for further qualitative analysis (Ritchie, Spencer, \& O’Connor, 2008).

Eleven lecturers answered a questionnaire (with 17 open questions) and nine of these teachers attended a three-hour group interview session. Thus, group interviews and additional telephone interviews (with two people) involved most of the staff working in the programme. The interviews took place in the conference room of the department responsible for the DME programme. The questionnaires and interviews with teachers provided some insights into the students' progress in the programme. The anonymity of informants was incorporated into the process of data collection and presentation of results. Documents available on the DME programme website provided background information and gave an overview of the programme structure and design.

\section{Presentation and Analysis of the Results}

Using the course evaluations and information provided by the teachers, different problematical aspects of simultaneous dual-mode teaching were identified through an iterative data analysis process. Looking at these problems through the lens of activity theory, various categories could be generated corresponding to the students' and teachers' perceptions of the mediating tools and their reflections about the object and context of the learning activity. They are presented under a number of headings in the text below and illustrated by the informants' quotations. Various tensions and contradictions became visible in the different actors' interpretations of the pedagogical activities of the programme.

\section{Level of Interaction}

Many on-campus students commented in the course evaluations on the level of interaction with the lecturers during the classes. They experienced that the lecturers were focusing more on the needs of the distance students thus causing face-to-face teaching to suffer: "no dialog and peer cooperation during the lectures that are otherwise common in on-campus teaching." Distance students often expressed disappointment that they did not have the possibility of interacting with the teachers while they were lecturing and also immediately after a lecture. They also complained about the low teacher response to their emails. This problem caused extensive discussions among the teachers and programme managers. With constantly increasing numbers of distance students, maintaining individual communication became problematical and it was decided to use an Internet-platform as the only form of communication. The students now had to post individual 
questions to a common collaborative space to which either the teacher and/or other classmates could respond. However, not all distance students felt that it was easy to post questions to the common e-space instead of addressing them directly to the teacher.

The teachers acknowledged delays in communication as being the main problem in working with distance students and that this factor put them at a disadvantage in comparison with campus students. A teacher explained the reasons for this:

We teachers receive the tasks (assignments, project, exams) normally much later from distance group. This of course means that we focus our priority on the first tasks that come (tasks that came on time from the campus students) and leave the rest for correction later. Sometimes the delay is months and thus we are already engaged in other activities.

Delay with the teacher's feedback on the assignments was experienced by many students as a very discouraging factor for their studies.

\section{Technical and Pedagogical Mediation}

The distance and on-campus students had different needs and requests when working with the course content. Engineering education includes a variety of calculations and problem solving exercises. When hints for calculations were given, on-campus students needed less-detailed guidance than distance students as they had easier access to the teachers, peer students, and reference literature. Some of the on-campus students saw detailed step-by-step recommendations and explanations as rather unnecessary. In the same way, on-campus students experienced lectures based on PowerPoint slides as adjustments to the needs of the distance students and were unhappy about the lecturers' "slide-reading method of teaching." This was particularly the case when slides (PowerPoint presentations) were overloaded with information and were not easy to grasp.

There were many complaints in the course evaluations about the quick pace of the lectures, speed of speech, rate of changing slides, etc. These complaints usually came from the students who attended presentations in the lecture theatre. They expected to be able to follow lecturers' reasoning without the need to go to the material on the Internet and recapitulate the lecture once more at home. On the other hand, distance students studied recorded lectures, so they could pause a presentation whenever they wanted to. They requested that teachers not use the whiteboard (as it is not video-recorded) and when the teachers showed objects in the class or had questions from the audience in the lecture-halls to make sure that this information would also be available to the distance students.

Some campus students considered the use of technical devices, e.g., e-pens for writing on the computer screens, as excessive "when a whiteboard can be used and video filmed." Teachers also felt that the technology might cause some problems for lecture delivery. Commenting on the use of the Internet-based study platform, a teacher wrote, "it is very easy to make a mistake as there 
are so many 'buttons to push' to make it work. This sometimes delays the start of lectures, which is also a problem for the campus students." Thus, technical mediation appeared to cause some problems for all actors involved.

\section{Examination and Assessment Practices}

Examination traditions and practices form an important part of the socio-cultural context of the DME and these might vary significantly between countries. The DME programme follows Swedish rules of examination, which are stipulated in the curriculum. Some Swedish traditions and rules can be unusual for people coming from other academic cultures. For example, distance students commented in their course evaluation on the extensiveness of examination tasks. Five hour exams (and longer) were seen as too long. After three hours students became too tired and were not able to concentrate. The level of stress was high during the exam and it was difficult to tolerate such stress for as long a period of time as 5-6 hours. According to the students' comments, those who had a good memory could pass, but they asserted that engineering reasoning skills were not tested adequately in the written exams. The use of an Internet-platform to post assignments was very discouraging for the students as there was a low tolerance for errors. Even the correct procedure could give a wrong answer. Assignments could be sent and rejected by the system several times without explanation. The system did not look at the way exercises were solved (method) but only at the results. This approach seemed unfair to many students.

Both teachers and students agreed that the use of regular assignments and quizzes appears to be an important mechanism in course delivery. The distance students coped better when they were required to study the material presented systematically and when they were tested regularly on the content of that material. However, the teachers reported that many distance students lacked a culture of keeping deadlines. A teacher gave an example:

In my course last year assignments were due in September/October (2007). Few distance students submitted them on time due to problems with accounts, etc. I gave them the chance to submit the task in December and got little response. Then I gave them another chance in March 2008 with not much response...So this created a lot of logistical problems for the teacher responsible for the course and other teachers/assistants involved.

There were comments from teachers and learners that master's students in the on-campus mode of the programme were required to make systematic presentations of their studies for their colleagues. Thus, they were training not only to collect and analyse data but also to present and defend their results publicly, which was a part of the course evaluation. This component was seen as important for students to gain confidence in communicating and evaluating engineering projects, something that the distance students missed. 


\section{Practical Activities}

The DME programme appeared to provide good general theoretical preparation for the students but provided limited practical engineering skills. Even on-campus students stated in course evaluations that the programme "lacked identity." It struggled between establishing a practical engineering profile and communicating generic knowledge: "We are engineers. We want to understand the nitty-gritty of things." The students pleaded for practical exposure to real situations during the courses.

The situation with practical work was particularly difficult for distance students. The programme attempted to provide alternative solutions for practical activities. One teacher explained it this way:

What we have tried to do in the courses that I am involved in is to carry out virtual lab exercises on the web, including short videos of the equipment used etc. This should be (almost) as good as attending the lab onsite.

Study visits to industrial sites in Sweden had also been video-recorded and were available on the Internet-based study platform. Teachers also told of attempts to use remotely controlled labs, which required large investments in hardware and labour. They were not aware of research on the effectiveness of such remote labs in comparison with recorded lab sessions and pre-measured data provided for the students to carry out the necessary engineering calculations. Remote controlled labs also demand high-speed Internet connections that not all the distance students have. Only a few DME students came from industry, so most of them could not develop practical skills by being associated with an industry. In general, the practical component of the programme remains a problematical issue.

\section{Study and Self-Monitoring Skills}

To be successful in online courses, students need good self-organization and independent learning skills. Their participation in and completion of online courses is entirely up to them. The data collected indicated that many students lacked the study and communication skills that were expected of them. Traditions and methods of learning gained in their previous studies were different and not very helpful in distance and computer-based education. However, the DME curriculum did not include an introductory course aimed to improve students' distance study and communication skills.

The structure of the programme was quite complex. The DME started with five courses in parallel (at the same time) and this put a lot of pressure on the students. The courses were composed of several modules with their own quizzes and assignments (given and corrected by different instructors at different times, which had a certain weight in the final grade) and the exam. Thus, even after passing the exam the students would not have completed the entire course if they had failed some assignments. 
Monitoring student progress in the programme was left mainly to the students themselves. Many distance students felt unaware of the progress of their studies, even though data was available on the Internet. The lecturers' feedback on assignments was often delayed and it could take a long time for the students to finally understand if they had passed the course. The teachers recognised the problem, as indicated by this statement:

It has been very difficult in general to follow the DME students' progress. They are taking parallel courses, many teachers are involved in correcting assignments, and sometimes it takes a long time for the assignments to arrive and to be corrected. There have also been problems with keeping track of who is who as the students do not have the personal ID numbers we use, and their names are long and sometimes used/written in different ways. All this makes it difficult to keep track of their progress and thereby to keep track of who needs help.

In general, the students felt unaware of their progress and had poor distance study and selfmonitoring skills.

\section{Content and Context}

For the DME teachers it was challenging to adapt the content and methods of teaching to the distance students' different socio-cultural contexts. The study identified two main obstacles. First, when teaching was conducted simultaneously for on-campus and distance students, teachers tended to meet the interests and needs of the students who sat in front of them. Second, teachers had little personal experience and knowledge of the distance students' contexts and did not know much about their needs and conditions.

In the course evaluations, the students commented, for example, on missing content on the use of renewable technology in a non-Western context; solar energy was covered briefly but heating was tackled extensively. The DME programme did not target non-European students in particular or the needs of their local industries. These needs vary greatly between countries and even places within a particular country.

During the interview with the lecturers, the point was made that it would probably be better to have two sets of teaching material, one for on-campus students and one targeted specifically at distance students. However, the lecturers admitted that this would require extra work and time that they did not have. 


\section{Fairness and Equality}

The study conditions for distance and campus students were quite different, particularly for the students in economically disadvantaged parts of the world, even though all of them faced the same curriculum requirements. The course teachers were aware of some unfairness in the situation but experienced unease in dealing with it. A DME teacher commented about approaching the problem of disadvantages faced by distance students in the following words:

They get a positively higher level of study support compared to campus students in terms of preparation for exams, alternative exercises replacing labs that are impossible to perform over the internet, etc. This is often not justifiable as all students should get the same level of support.

Another course teacher gave an alternative view: "We do not make any distinctions between these students and other students, no. But their study situation is probably different from European students and from the situation for on-campus students."

An experienced course leader offered his perspective:

Generally, I set the tolerance level lower with respect to submitting course deliverables (e.g. assessments) on time due to unreliable internet connections. This is however a major problem as our distance education largely uses the internet as the main tool assuming good performance. If a student contacts me to say that he or she did not have internet access during the last 2-3 weeks I have no reason not to believe him/her as I do not have a reference. Still, it is in my interest to get all students out of the other end of the pipeline. Therefore it is necessary to evaluate such situations individually (= time and energy consuming).

Thus, there were different approaches used on different courses of the programme with regard to what was considered as fair and equal treatment of the students.

\section{Course Material}

The analysis of the curriculum indicated that the amount of reference e-material in the program courses was huge. The absence of books and hard copies of lectures (as books were not available in many developing countries and printing costs were very high) compelled the distance student to read material from the computer screen. This was a very tiring exercise when the students needed to study dozens of documents/files presented in different media formats in order to prepare for assignments. The teachers did not see this as a problem. A lecturer stated: "Whether the students have the literature etc. as hardcopies or in digital form should not make a difference." Other teachers agreed: "There are high quality lecture series available in the study platform for my subject. It is screen reading but it is still the right stuff." 
The Internet platform used in the DME programme did not allow easy editing of lectures. If a recorded lecture had sound or image problems (which often happened) or if the lecturer made a mistake writing with an e-pen (which was not noticed directly) it was practically impossible to edit the material later. So all of the students needed to live with this. They did not have access to lectures from previous years. All electronic information and course material was made available on the Internet simultaneously for all students. However, on-campus students had access to additional sources of information that distance students did not. The course teachers admitted that the on-campus group had much broader opportunities and a variety of ways to access the necessary information through personal contacts with the teachers, course administrators, and peers.

\section{Discussion}

The development of distance education through information and communication technology is an important part of the work at modern universities. This paper analyses a specific model of engineering education where courses are delivered simultaneously to distance and on-campus students following the same curriculum. The general conclusion emerging from the study is that adding a distance component to an on-campus programme and merging them into one is experienced as pedagogically problematical by both students and teachers. Looking at the teaching/learning situation from different perspectives (teachers, distance, and on-campus students) and using conceptual constructs of activity theory, the following reflections can be made.

Concerning the object of the learning activity, from the data collected in this study it becomes clear that the content of the DME programme is not particularly adapted to a non-European context. In course evaluations, the students made comments about the lack of examples using solar and other renewable technologies in hot-climate contexts in low-tech societies; at the same time, they experienced an extensive focus on heating systems and the needs of high-tech societies. Local context knowledge and experience seemed not to be valued in the DME programme.

Concerning the use of mediating tools in teaching, some on-campus students commented in the course evaluations about the need for appropriate graduate level teaching methodology and level of content. They experienced the current teaching of some courses as spoon-feeding and related this to the teachers' adjustments to the necessities of the distance students.

The automatic correction of quizzes and assignments used in the programme is reminiscent of traditions of "programmed education." Through this teaching method a massive outcome can be achieved by providing learning tasks using technological tools and also correcting the students' results using the technology. In this respect, even on-campus students missed the "human dimension in training modern engineers who can think creatively and not just get mechanical right or wrong marks from a machine on pure recall-type assignments." Here, an argument can be put forward for ongoing peer and formative assessment through the programme design and the notion of assessment for learning in contrast to assessment of learning (Hudson, Hudson, \& Steel, 2006). 
According to the lecturers, some of the above-mentioned pedagogical problems could be related to the large size of classes rather than to the distance form of education. They also experienced that some distance students show low study motivation and engagement in the programme activities. However, many of these problems can also be attributed to poor pedagogical, administrative, and technical mediation of the students' studies in the programme.

In fact, the mediation of learning activities for on-campus students seems to be more efficient than for distance. The elements of the mediation process can be the same for both groups, but their organisation and the students' access to them can be different. Here it is possible to adopt the physics analogy suggested by Kuleshov (2008) and liken mediation in learning activities to the phenomenon of conductivity in an electric circuit with parallel and serial connections of elements. For on-campus students mediation is possible in parallel form where several alternative ways of gaining information, acquiring knowledge, and solving problems are available (different course instructors, laboratory technicians, peer students, administrators, library and technical support staff, study advisors, and director of studies, etc., some of which are not available to distance students). When elements of a circuit are connected in parallel the total conductivity is greater than conductivity of any particular branch of the circuit. The alternative situation of serial connection of elements leads to the total resistance being greater than resistance of any particular element. So, the conductivity falls to zero if at least one component of the chain has a conductivity of zero value (i.e., does not work). The distance students seem to experience more mediation of the latter (serial) type when a step-by-step process of solving pedagogical and administrative issues, transfer of information, submitting assignments, reporting the results, etc. becomes very resistant. Therefore, most of them seldom finish the program on time. The learning outcomes of the programme are much better for on-campus students.

The findings confirm what Bates and Poole (2003) have pointed out: The workload associated with teaching with technology is the most pressing issue from an instructor's perspective. Teaching simultaneously in two modes, both e-learning and face-to-face, demanded extra effort from the course teachers. They needed to concentrate more when working with two categories of students at the same time. More time had to be spent on the preparation and development of courses. Teachers felt overloaded with pedagogical and administrative tasks as no new staff were added to the department with the introduction of the DME. They were tired of working overtime.

After the lectures, the distance students did not have an opportunity to ask teachers any individual questions without exposure on the public e-space. The interactivity of personal electronic communication is experienced as being rather poor. This problem is well recognised for international distance programmes (Hudson, Hudson, \& Steel, 2006). Students from different cultural contexts show varying degrees of ease with discussing in public and disturbing teachers with their questions.

Thus, distance education means in many courses that the students experience pedagogical distance to the instructors. Using Moore's words (1997), it could be interpreted as "transactional distance," which refers to the separation of learners and teachers not only in geographical space 
but also in psychological and communications space, leading to potential misunderstandings between the inputs of the instructor and those of the learner. Teachers also agree that students perform better when they work in personal and face-to-face contact with the teacher, but the distance students never have a chance to meet their teachers.

\section{Conclusions}

In general, the pedagogy of the DME programme is characterised by a teacher-centric approach with mainly one-way communication, the delivery of materials from teachers to students. The level of interaction among the students enrolled on the program around the world (particularly in African countries) and with the teachers in Sweden remains rather ineffective. Increasing numbers of DME students did not lead to new staff positions at the department. The Swedish government provides the university with 75,000SEK (about 10,000USD) per year for each student (who has enrolled and successfully finished the year, and the department gets one third of this sum directly after a student has registered) in the field of engineering education. Thus, economic resources are available, but money was not converted into "tools for teaching," i.e., pedagogical resources. This makes the mediation process of teaching/learning on the DME rather ineffective.

The practical component of the programme is also weak. It is possible to question what type of knowledge future engineers can gain by watching computer-displayed lectures or video films of laboratory work and study visits. The organisation of hands-on practical activities is a serious challenge in the distance mode of an engineering programme. Practical collaborative activity provides opportunities to acquire the valuable skills of problem solving and cooperative group work, which are very important for modern engineers. Thus, an essential feature of engineering training, i.e., students' engagement in practical collaborative activities, appears to be unsuccessful in the DME. The results of this investigation lead us to believe that the different study contexts should result in different but parallel course syllabi: the campus programme could include the usual laboratory practicum and field visits, while the distance programme could place a stronger emphasis on empirical projects adapted to local needs in addition to virtual laboratory exercises.

It is possible to conclude that skills such as web communication, time keeping, and progress monitoring are not easy to acquire for students who are studying outside Sweden. Greater purposeful action from the programme management is required in this direction, for example a preparatory "zero-course" can be designed particularly with the aim of distance students developing skills in managing technology, studying, and self-monitoring. The DME programme teachers also need an introduction to teaching Internet-based courses for learners with different cultural backgrounds. They should become aware of the differences in social norms and traditions that exist in different cultural contexts, in particular those related to shared study and communication models. These measures can potentially improve the motivation and performance of distance students in the programme.

In conclusion, activity theory suggests that all practice needs to be analysed through the lens of historical development. We have to see for example how the use of tools unfolds over time. From 
this perspective, it is possible to conclude that the DME has been in a steady process of developmental change. The teachers acquired the necessary skills of using technology; the study material became available on the Internet platform; and the administrative and organisational tools were placed in action. The programme is in progress! However, teachers need more knowledge about the modern methodology of distance education, more time for self-monitoring and reflection on their pedagogical actions, and additional professional support for the challenging task of teaching distance and on-campus students simultaneously. 


\section{References}

Bates, T., \& Poole, G. (2003). Effective teaching with technology in higher education: Foundations for success. San Francisco: Jossey-Bass.

Bhattacharya, B. (2008). Engineering education in India - the role of ICT. Innovations in Education and Teaching International. 45(2), 93-101.

Casey, D. (2008). A journey to legitimacy: The historical development of distance education through technology. TechTrends: Linking Research and Practice to Improve Learning, 52(2), 45-51.

Collis, B., \& Margaryan, A. (2004). Applying activity theory to computer supported collaborative learning and work-based activities in corporate settings. Educational Technology Research and Development, 52(4), 38-52.

Conole, G., \& Oliver, M. (Eds.) (2007). Contemporary perspectives in e-learning research: Themes, methods and impact on practice. London: Routledge.

European Commission (2008). An updated strategic framework for European cooperation in education and training. Brussels, 16.12.2008. Retrieved Feb, 2009, from http://ec.europa.eu/education/news/news1108_en.htm.

Hudson, B., Hudson, A., \& Steel, J. (2006).Orchestrating interdependence in an international online learning community. British Journal of Educational Technology. 37(5),733-748.

Högskoleverket (2008). E-learning quality: Aspects and criteria for evaluation of e-learning in higher education. The Swedish National Agency for Higher Education. Högskoleverkets rapportserie 2008:11 R.

Kaptelinin, V., \& Nardi B. A. (2006). Acting with technology: Activity theory and interaction design. Cambridge, MA: MIT Press.

Kuleshov, G.G. (2008). Computerized education: What is behind the attractive curtain? In M. Iskander (Ed.), Innovative techniques in instruction technology, e-learning, e-assessment, and education. Bridgeport, CT, USA: Springer.

Leont'ev, A.N. (1981). The problem of activity in psychology. In J.Wertsch (Ed.), The concept of activity in Soviet psychology (pp. 7-71). NY: M.E.Sharpe Inc.

London, H., \& Draper, M. (2008). The silent revolution in higher education. Academic Questions, 21(2), 221-225.

Lowes, S. (2008). Online teaching and classroom change: The trans-classroom teacher in the age 
of the Internet. INNOVATE: Journal of Online Education, 4(3).

Moore, M. (1997). Theory of transactional distance. In D. Keegan (Ed.), Theoretical principles of distance education (pp. 22-38). London: Routledge. Retrieved Feb, 2009, from http://www.aged.tamu.edu/research/readings/Distance/1997MooreTransDistance.pdf

Ritchie J., Spencer, L., \& O’Connor, W. (2008). Carrying out qualitative analysis. In J. Ritchie and J. Lewis (Eds.), Qualitative research practice: A guide for social science students and researchers. London: Sage.

Vygotsky, L.S. (1978). Mind and society. (M. Cole, V. John-Steiner, S. Scribner, \& E. Souberman, Eds. \& Trans.). Cambridge, MA: Harvard University Press.
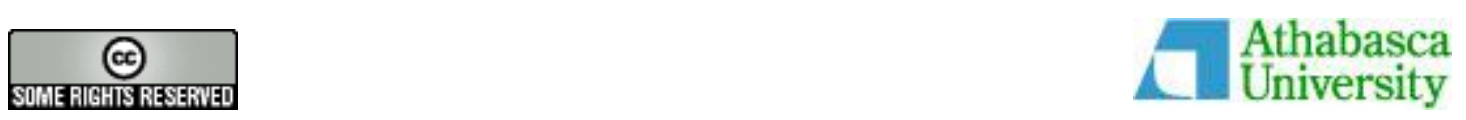

\footnotetext{
${ }^{\mathrm{i}}$ For anonymity reasons the name and abbreviation of the programme have been changed.
} 
June - 2009

\title{
Questions of Culture in Distance Learning: A Research Review
}

\author{
Sedef Uzuner \\ State University of New York at Albany, USA
}

\begin{abstract}
This paper reviews past research that focused on questions of culture in distance learning. Of specific interest are the studies that examined the influence of culture on students' learning and engagement in asynchronous learning networks (ALNs). The purpose of this review is three-fold: to present the state of knowledge concerning the questions of culture in distance learning, to highlight important methodological issues that past research has left unresolved, and to provide practical insights into teaching culturally and linguistically diverse online communities of learners. For these purposes, 27 studies are examined and the findings are reported under the following two categories: What do studies focusing on questions of culture in distance learning tell us? What implications do they suggest for practice and future research? Also, the paper provides methodological insights for researchers who wish to investigate the cultural dimensions of distance learning in future studies.
\end{abstract}

Keywords: Asynchronous learning networks; culture; online learning; distance learning

\section{Introduction}

This paper will provide a definition of culture and use it to examine the research literature on distance learning. In particular, it will demonstrate how cultural factors interact with and influence students' learning and engagement in asynchronous learning networks (ALNs), networks for anytime and anywhere learning via computer communications technologies (Hiltz \& Goldman, 2005). The intent is to raise awareness about the cultural factors that may affect ALN learning and to provide guidance for practice and future research.

This paper views distance learning as a process that is sensitive to social, cultural, and contextual factors (Warschauer, 1998; Wegerif, 1998). Considering the cultural dimension as a crucial element in the effectiveness of ALNs, the paper supports and elaborates on the idea that successful ALN learning is not only dependent on optimal uses of available technologies, teachers' pedagogical-content knowledge, and students' motivation level, it is also dependent on the cultural (mental) representations learners and teachers bring to the learning situation. 


\section{Culture Defined}

Culture is a complex term to define precisely. As such, it has a long and complicated history. In most disciplines, the historical tendency has been to connect culture to nationality and ethnic origin. Grounded in the influential work of Hofstede (1980), the inclination has been to assume national groups as having the same patterns of thought, action, and values.

More recently, however, culture has been seen as an entity that transcends ethnic and national boundaries. Viewed from this perspective, culture encompasses "the patterns shaped by ethnicity, religion, socio-economic status, geography, profession, ideology, gender, and lifestyle" (Branch, 1993, p. 7). This more recent definition of culture embraces the idea that every person and human group is both cultural and multicultural.

For the purposes of this review, culture will be defined as acquired behaviors, perspectives, and values characteristic of a particular group or community.

\section{Overview and Problem Statement}

Traditional learning environments may become sites of struggle for teachers and learners when there is a collision of different cultures. More often than not, it is difficult for the teacher to accommodate each and every student's culture. Therefore, the students are expected "to step out of their own culture and temporarily enter into the culture of the instructor" (Moore, 2006, p. 1). Within this process, problems arise if the instructor's pedagogical values are not compatible with students' assumptions about how teaching should be done.

Basing teaching on one set of values, namely the dominant values, in culturally diverse settings usually results in what Gramsci (1971) called "cultural hegemony," a phenomenon that refers to the ways in which assumptions of a group/person achieve dominance and are viewed as commonsense understandings or interests that serve for all. Several scholars have remarked on the issue of cultural hegemony in traditional classrooms and have proposed theories advocating incorporation of multiple cultures in school curricula. Such theories include, but are not limited to, "culturally relevant pedagogy" (Ladson-Billings, 1995), "culturally responsive teaching" (Gay, 2000), "culturally sensitive instruction" (Boyer, 1993), and "multicultural instruction" (Saldana \& Waxman, 1996). These are valuable contributions that provide useful frameworks for understanding and dealing with issues of culture in traditional multicultural classrooms.

For the purposes of this review, the overarching questions become these: Does cultural hegemony also exist in distance education? Do conflicts resulting from cultural differences transfer from the traditional classroom to the distance learning environment? If so, how do teachers and students navigate different cultures of learning in these environments? These are the kinds of questions that need specific attention if our aim is to improve distance learning. 
In a highly comprehensive meta-analysis, Zhao, Lei, Yan, Lai, and Tan (2005) identified the factors impacting the effectiveness of distance education. Their analysis consisted of 423 empirical studies that compared face-to-face education to distance education. In the end, Zhao et al. (2005) concluded that "distance education in essence is still education [...] The factors found to have an impact on the effectiveness of distance education are also factors that would affect the effectiveness of face-to-face education" (p. 1865). In view of this finding, it is hypothesized that distance learning environments are by no means immune to the problems arising from cultural differences. In fact, these environments may even be more prone to cultural conflicts than traditional classrooms as instructors in these settings not only interact with students who have removed themselves from their native culture, but they also interact with students who remain "physically and socially within the different culture, a culture that is foreign to, and mostly unknown, to the teacher" (Moore, 2006, p. 1).

\section{Methodology}

The review was guided by the following question: What research evidence do we have on how culture influences students' distance learning experiences? For the purposes of this paper, students' distance learning experiences will be operationalized as their learning and engagement in ALNs.

The search for empirical articles focusing on the issues of culture in distance learning was conducted in three stages. First, significant electronic databases for education research (such as EBSCO, ERIC, Education Full Text, and PsycINFO) were searched. The following key words were used separately or in combination during this search: culture, online learning, distance education, cultural factors, multicultural, asynchronous learning networks, and e-learning. The second stage involved examination of the reference lists of the articles located in the electronic databases. Third, tables of contents of refereed open access electronic journals that are specifically concerned with distance education and ALNs were scrutinized for additional works. Since the focus was on data-based studies, conceptual articles that include discussions on how to promote cultural sensitivity in ALNs were discarded (e.g., Bates, 2001; Bentley, Tinney, \& Chia, 2005; Chen, Mashadi, Ang, \& Harkrider, 1999; Collis, 1999; Malbran \& Villar, 2001; McLoughlin, 1999; Smith \& Ayers, 2006; Wilson, 2001).

The search revealed 27 studies, two of which were dissertations. Based on methodology, these works were sorted into three categories: qualitative studies, quantitative studies, and mixed method studies, which used both qualitative and quantitative approaches to collect and analyze data.

The audience of this paper should keep in mind two important factors. First, the compilation of studies is influenced by the author's resource availability. Although every effort is made to make the literature presented here fully inclusive, works that are not abstracted in primary academic indexes (such as EBSCO, ERIC, Education Full Text, and PsycINFO) or are not peer reviewed open access electronic journals have been excluded. Nevertheless, despite having a small database, this review is important at this juncture in the field of distance education because it will 
allow designers, instructors, and researchers to understand the influences of culture in ALNs and to identify potential paths for future research.

Second, the author's distance learning and teaching experiences in the United States may have influenced this review. As such, some of the ideas may reflect a North American perspective. However, the cultural diversity reflected in the selected studies makes the recommendations in the remainder of this paper applicable to all culturally diverse distance learning environments.

\section{Findings}

The findings of the review will be reported under the following categories:

- What do studies focusing on questions of culture in distance learning tell us?

- What implications do they suggest for practice?

- What implications do they suggest for future research?

The review will also provide methodological insights for researchers who wish to investigate the cultural dimensions of distance learning in future studies.

\section{What do Studies Focusing on Questions of Culture in Distance Learning Tell Us?}

\section{Qualitative studies.}

Of the 27 studies reviewed, 12 were qualitative. Among these, some focused on particular national groups' ALN experiences. For example, Thompson and $\mathrm{Ku}$ (2005) explored seven Chinese graduate students' online learning experiences in an American university. One of the key findings of this study was that the participants were less critical and opinionated in online discussions than their US peers. Thompson and $\mathrm{Ku}$ attributed this finding to Hofstede's (1980) view that "Chinese culture is highly collective and feminine and tends to value group effort, harmony, affection, compassion and emotionality" (p. 43). The study also revealed the participants' frustration with the following issues in ALNs: not getting immediate feedback from the instructor, inability to understand specific cultural references in online discussions, and lack of face-to-face communication.

Tu (2001) and Zhao and McDougall (2000) also looked at Chinese online learners. Tu examined the impact of social context on Chinese graduate students' online interactions in ALNs in the U.S., and Zhao and McDougall explored Chinese graduate students' experiences and attitudes toward online learning in a Canadian university. Specifically, Tu's study emphasized the importance of social context in Chinese culture and showed how reliance on non-linguistic cues is tied to the way Chinese students interacted in ALNs. In Zhao and McDougall's study, cultural factors that were found to hinder six Chinese students' engagement in ALNs were their 
conservative, modest, and face-saving cultural traits and their unfamiliarity with the disciplinary cultures of education in Canada.

Another qualitative study that looked at a particular national group's ALN experiences was AlHarthi's (2005) study of six Arab students pursuing graduate degrees in the US. During in-depth interviews, these students expressed that they were at first scared and anxious about taking online courses because they equated online learning with independent learning, a finding reflecting Arab culture's high uncertainty avoidance (Hofstede, 1991). Students also reported that they intentionally participated less in online discussions than their American peers because they viewed eagerness to participate as "showing off or trying to appear smart" (p.9), a finding reflecting the importance of modesty in Arab culture. Other cultural factors that interfered with the students' successful ALN learning were found to be feelings of shame originating from Arab culture's social restrictions on the interactions between genders and communication difficulties with instructors arising from students' fear of confrontation with authority figures.

Rather than focusing on one particular nation, some studies investigated the distance learning experiences of various cultural groups. For example, Goodfellow, Lea, Gonzalez, and Mason (2001) focused on non-English speaking adults undertaking graduate level course work at a UKbased higher education institution. They found that these students' unfamiliarity with the linguistic and academic culture of the UK negatively impacted their success and academic performance. Shattuck (2005) studied Asian and Middle Eastern students taking distance education courses delivered by an American university, and Walker-Fernandez (1999) investigated non-American graduate students' experiences in an American distance education program while they were situated within their local cultures. These two studies found that cultural differences hinder students' communication and success in ALNs, causing them to experience feelings of isolation, alienation, and "dissonance out of conflict with the dominant educational culture" (Shattuck, 2005, p. 186).

Three studies (Morse, 2003; Gouthro, 2004; Biesenbach-Lucas, 2003) examined cross-cultural differences between two or more national/cultural groups. Morse (2003) compared the ALN experiences of students from the US, the UK, Australia, and New Zealand (the low context cultural group) to the experiences of students from Pakistan, the People's Republic of China, the Republic of China, Singapore, Sri Lanka, and Thailand (the high context cultural group). Morse found the low context group to be "outwardly oriented" in their computer-mediated communications $(\mathrm{CMC})$, meaning that these students valued the time afforded by CMC to reflect on other people's opinions. On the other hand, he found the high context participants to be more "inwardly oriented," meaning these students valued the time afforded by CMC to think more about their own contributions. This study also revealed that students from high context cultures viewed the lack of face-to-face contact with faculty and peers as a challenge to their ability to learn and form social relationships, whereas low context participants did not believe that the lack of face-to-face contact impacted their learning abilities positively or negatively.

Gouthro (2004) investigated Jamaican and Canadian women's distance learning experiences in a graduate level adult education program. Although findings of this study were interpreted mainly 
from a gender perspective, a significant cultural issue emerged: both groups' cultural expectations regarding women's roles in the home did limit their learning, participation, and engagement in ALNs. In light of this finding, Gouthro wrote, "distance educators teaching in higher education need to be aware of the complex circumstances in which women learners come to participate, and be attentive to power issues around gender and culture in the classroom and in the homeplace" (p. 459).

Biesenbach-Lucas (2003) examined the attitudes and behaviors of American and non-American students, who were mainly from Asian cultures, toward asynchronous discussions that were incorporated into two graduate level teacher training courses at an American university. The results revealed that both groups perceived online discussions to be beneficial for social interaction and learning. These discussions were especially found to provide non-American students with spaces where they could "explore issues at their own pace, examine topics from various angles until they felt they had reached an understanding of material not presented in their native language" (p. 31). An interesting finding that emerged from this study was that both American and non-American students avoided expressing disagreement with others and their posts "did not include the kind of reflection that showed critical evaluation and synthesis of information" (p.33). Biesenbach-Lucas made the point that perhaps two factors were at play in non-American students' avoidance of disagreement: they may consider challenging and criticizing other's ideas culturally inappropriate, and/or they may "not know how to express disagreement appropriately in English" (p. 37).

Of the studies focusing on culture Fang's (2007) study was unique because it investigated the impact of multiple levels of cultures (such as national culture, ethnic culture, and cyber culture) on students' ALN experiences. Twenty Singaporean Chinese engineering students were the focus of this study. The purpose was to understand how different levels of culture influenced what these students perceived as useful, enjoyable, and effective in a predominantly online program. The results, based on individual and group interviews, were as follows: Influenced by their national culture, which values achievement and success, the students cared less for fun and exciting activities and valued tasks that led to achievement in learning. Influenced by their ethnic (Chinese) culture, which stresses learning from an authority figure, the students preferred teacher feedback to peer feedback. Lastly, influenced by their cyber culture, the students appreciated the convenience, flexibility, and social benefits of ALNs.

The last study in this category was Rogers, Graham, and Mayes' (2007) study, which looked at the issue of culture in ALNs from the perspective of instructional designers. Through interviews with 12 professionals involved in the design of online courses delivered cross-culturally, Rogers et al. (2007) found that instructional designers' or instructors' awareness of the potential differences between cultures does not necessarily mean this knowledge is integrated into the design of online courses. 


\section{Quantitative studies.}

Of the 27 studies reviewed, seven were quantitative in nature, using survey methodology. Below, these studies and their key findings will be discussed briefly.

Smith, Coldwell, Smith, and Murphy's (2005) survey research explored the similarities and differences between Australian and Chinese undergraduate students' engagement in online discussions. The findings indicated that compared to their Australian peers, Chinese students were less engaged in critical thinking in their posts. Smith et al. (2005) noted that "the lower number of intellectual postings may not indicate that these students had less to say, but that they were constrained in saying it, possibly further compounded by the fact that the discussion was in English" (p. 131). This study also found that Chinese students displayed a higher level of anxiety in ALNs than their Australian counterparts over issues such as course requirements and assessment, and they showed a strong need for transparency in course structure. This finding echoed another survey report by Smith and Smith (1999), which indicated that Chinese heritage students tend to display more anxiety than Australian students in terms of their general approaches to learning.

Anakwe and Christensen (1999) investigated whether differences arising from individualistic and collectivistic cultural orientations impacted 424 undergraduate and graduate students' perceptions of distance learning in two American universities. The results showed distance learning to be more compatible with individualists' motives and ways of interacting. A similar study was also conducted by Tapanes, Smith, and White (2009). Based on survey data obtained from 40 online students from two American universities, this study found students from collectivistic cultures to be less motivated to participate in ALNs than those from individualistic cultures.

In another survey-based research project, Smith and Smith (2000) studied the differences among Malaysian-Chinese, Singaporean, and Hong Kong first year undergraduate students taking distance courses from an Australian university. Significant differences were found among these three groups. For example, Malaysian-Chinese and Singaporean students were found to be equally dependent on structured instruction, but both groups differed in terms of their learning orientations. While Singaporean students demonstrated deep level learning, Malaysian-Chinese students showed a tendency for more surface and less organized forms of learning in ALNs. Compared to these two groups, Hong Kong students demonstrated less dependence on structure, but they showed a higher fear of failure. As was the case with Singaporean students, Hong Kong students demonstrated deep level learning. Based on these findings, Smith and Smith (2000) concluded that culture does impact various national groups' learning behavior in ALNs.

Lim (2004) used surveys to compare 236 undergraduate and graduate students' online learning motivation by country. Students enrolled in online courses at four Korean universities $(N=95)$ and an American university $(N=141)$ were the participants. The findings were that regardless of the country affiliation, all students considered course relevancy (belief that a particular course matches a student's needs) as the most important motivational factor in their online learning. The differences between the two groups were that while American students indicated they "prefer 
voicing personal opinions during class, enjoy learning and enroll in classes to obtain a sense of belonging," Korean students expressed their tendency to "avoid voicing their opinions and keep passive and quiet during class as they are influenced by the authoritarian classroom context of Asian culture" (169-170). These findings supported Lim's contention that cultural orientation influences national groups' learning motivation in ALNs.

Hannon and D'Netto (2007) surveyed Australian and non-Australian/international students to find out how linguistic and cultural backgrounds impacted their engagement in ALNs. The students surveyed were undergraduate and graduate students $(N=241)$ taking business classes at a large Australian university. The findings revealed that international students differed from Australian students in terms of their perceptions of and satisfaction with their ALN experiences. Specifically, international students experienced more challenges with technological aspects of online learning and more isolation in ALNs than their Australian peers.

\section{Mixed method studies.}

Of the 27 studies reviewed, eight employed mixed-methods, using both qualitative and quantitative approaches to collect and analyze data. The key findings of these studies will be discussed below.

Through surveys and focus group interviews, $\mathrm{Ku}$ and Lohr (2003) studied 23 graduate students' (18 American, 2 Chinese, and 3 Taiwanese) perceptions and attitudes towards their first ALN experiences in the U.S. Some of these students indicated that they felt uncomfortable with the nonlinear nature of their online course and its emphasis on peer feedback. This finding was attributed to the uncertainty avoidance dimension of Asian culture as described by Hoftede (1991). The study also found that Chinese and Taiwanese students "liked the idea of building an online community among peers and instructors" (p. 100), a finding reflecting the collectivistfemininity attributes of their culture.

Using surveys and focus group interviews, Gunawardena, Nolla, Wilson, Lopez-Islas, RamirezAngel, and Rosa (2001) examined Mexican and American students' perceptions of online group process and development. Fifty American and 50 Mexican students who were enrolled in distance education programs in their respective local contexts participated in this study. Framed within theories of group development, diversity, and culture, this cross-cultural study found strong evidence showing the influence of students' national culture on their online learning behaviors. For example, compared to their American peers, Mexican students showed higher tendencies for affection, compassion, and emotion in online group processes, a finding that reflects the importance of care and affection in Mexican culture (Hosftede, 1980).

Selinger (2004) investigated the implementation of a global e-learning program, which is based on Western learning theories, in countries such as Denmark, France, Germany, Hungary, Italy, Poland, Spain, Sweden, South Africa, United Arab Emirates and the UK. Data from surveys and interviews with 300 students and 100 instructors from these countries provided support for Edmundson's (2009) claim that "e-learning courses are cultural artifacts, embedded with the 
cultural values, preferences, characteristics, and nuances of the culture that designed them, and inherently creating challenges for learners from other cultures" (p. 42). Emphasizing the importance of cultural context in learning and thinking, Selinger's study highlighted the importance of training local instructors so they can make a course that is developed in another country (predominantly in the US) culturally and pedagogically relevant to students in their local contexts.

Wang (2007) conducted a cross-cultural study to investigate the differences among Chinese, Korean, and American students in terms of their motivation to participate in online discussions, perceptions of online team work, and comfort level in approaching their online instructors. Participants in this study were students from universities across the US, China, and South Korea, and data were drawn predominantly from online surveys. The findings revealed that students' cultural identity has a significant impact on their participation in and perceptions of ALNs. Specifically, course requirement was found to be the major factor behind Korean and Chinese students' participation in online discussions and activities. American students, on the other hand, indicated that they participated in online discussions because they enjoyed connecting with their peers. All three cultural groups preferred asynchronous discussions to synchronous ones. Wang (2007) attributed Korean and Chinese students' preference for asynchronous communication to an Asian cultural trait, "think more, talk less, and think it through before speaking" (p. 303). Although all three cultural groups found individual work boring and challenging, mixed results were found regarding their perceptions of online team work. Among the three groups, Korean students were found to be the least comfortable with online collaborative work. The study also showed that American students tended to communicate more with their instructors because they perceived them as equals, whereas Korean and Chinese students reported low levels of comfort in approaching their instructors. Wang (2007) attributed this finding to Asian culture's embodiment of power distance.

Liang and McQueen (2000) examined the impact of e-mail interaction on the learning outcomes of 18 culturally diverse adult learners from China, Fiji, Hong Kong, Korea, New Zealand, the Philippines, South Africa, Taiwan, and the US. Data from questionnaires, observations, and interviews revealed that Western students were more open to the idea of learning from peers online and perceived peer interaction to be beneficial intellectually, affectively, and interpersonally. On the other hand, Asian students valued teacher input more than peer input and perceived online peer-to-peer interaction to be beneficial only when it assisted their learning.

Kim and Bonk's (2002) cross-cultural study examined the differences in Finnish, Korean, and American undergraduate pre-service teachers' online collaborative behaviors. Qualitative and quantitative content analysis of three asynchronous web-based conferences revealed that each group exhibited distinct behaviors in ALNs. For example, both Finnish and American students were task-oriented, but they differed in the way they participated in asynchronous discussions. In their communications, Finnish students were concerned with theory and demonstrated a higher level of reflection, while American students were concerned less with theory and more with practice. Korean students, on the other hand, were contextually-driven and demonstrated the highest level of social interaction behaviors among the groups studied. 
Chen, Hsu, and Caropreso (2006) investigated the influence of culture on 15 graduate students' (10 American and 5 Taiwanese) social learning behaviors during online collaboration. Qualitative and quantitative content analysis of students' online messages in discussion forums were supplemented with data from an attitude survey. The results revealed culture-based differences in both groups' online collaboration and communication patterns. For example, American students preferred individualistic division of labor in collaborative assignments and possessed communication patterns that were short and content-driven. Taiwanese students, on the other hand, displayed group-based behaviors and were more inclined to produce long messages that included emotional expressions and numerous references to their personal contexts. More importantly, perhaps, this research indicated how cultural differences at times create tensions between culturally diverse student groups while working together online. For example, Taiwanese students interpreted American students' fast-paced responses as a sign of aggressiveness, and American students viewed Taiwanese students' delayed participation in discussions as a sign of passivity and weakness.

The final study in this category is Bing and Ai-Ping's (2008) study, which examined the influence of national culture on learners' asynchronous interactions in two distance education institutions, one in China and the other in Malaysia. Using qualitative and quantitative content analysis, the researchers divided students' interactions into five categories (social, procedural, expository, explanatory, and cognitive) and explained group differences by using Hofstede's (1991) cultural dimensions. The results revealed that Malaysian learners had a higher degree of individualism and lower degree of masculinity and power distance compared to their Chinese peers. Consistent with other study findings (Smith et al., 2005; Smith \& Smith, 1999) Chinese learners were found to display a high degree of uncertainty avoidance. As Bing and Ai-Ping wrote, "they wanted to be certain of the exact scope of assessments and preferred a more structured way of learning" (p. 333). One common feature in both groups' interactions was that the cognitive dimension, which is associated with higher order thinking, was the least dominant dimension.

In sum, despite the flaws inherent in their design or execution (methodological weaknesses of these studies will be described in a later section of this review), the studies summarized above provide a strong research base on the cultural dimensions of learning in ALNs.

\section{What Implications do these Studies Suggest for Practice?}

Some papers reviewed above provided explicit recommendations for practice, while others did not. Nonetheless, a broad yet incomplete list of recommendations emerged from this review. These recommendations are described below.

1. Some studies (e.g., Al-Harthi, 2005; Bing \& Ai-Ping, 2008; Smith et al., 2005; Smith \& Smith, 1999; Wang, 2007) showed that learners from strong uncertainty avoidance cultures are threatened by learning situations that are unstructured and unclear. They expect formal rules to guide their behavior. For example, Smith and Smith (1999) found that Chinese students display a strong need for "structured programs of instruction where 
the logic of that structure is transparent to the student" (p. 77). In a similar vein, when discussing the factors impacting Korean and Chinese students' participation in ALNs, Wang wrote: "the 'rules' for online participation were unclear. Both Chinese and Korean students, who rarely spoke in traditional classrooms, felt lost when they were expected to speak online. They wondered if there were any rules and rituals for them to follow" ( $\mathrm{p}$. 304). To alleviate such student anxieties, online instructors should make their course structure transparent by setting clear expectations for participation, assignments, learning activities, team work, grading, submission dates, and assessment.

2. Influenced by cultural traditions that discourage the "nail that sticks up," some students tend to show passive presence in ALNs. For example, Taiwanese participants in Chen, Hsu, and Caropreso's (2006) study “appeared to be passive toward interacting with group members, while U.S. students appeared actively engaged and energetic” (p. 23). Similarly, Zhao and McDougall (2008) found that some of the Chinese learners participating in their study "hesitated to ask questions and some even gave up on a discussion or contributed fewer messages when their opinions conflicted with those of other participants" (p. 72). Last but not least, Liang and McQueen's (2000) study demonstrated that Asian students "tend to hold back their thoughts when they perceive the teacher or majority of the learning peers will not favorably receive messages that are contrary to what they want to hear" (p. 28). These findings indicate that in distance learning contexts (such as the North American distance learning contexts) where active participation in discussions is highly valued, instructors should make specific efforts to promote critique and divergence and encourage students to create a safe space where opinions, experiences, beliefs, and knowledge can be shared.

3. Morse's (2003) and Hannon and D'Netto's study (2007) drew attention to the fact that the skills and experiences students bring to the distance learning environment are highly influenced by their cultural backgrounds. Therefore, instructors should be cognizant of variations in students' experience and learning styles and at the outset of the course remind learners that learning activities in ALNs may be different from what the learners are accustomed to. It is also equally important that instructors model the target behavior or learning outcome expected from the students. For example, in distance education environments such as the American one, critical reflection is highly valued. The instructors in these contexts should not assume that all students are familiar with reflection processes. In fact, as Biesenbach-Lucas's (2003) and Thompson and Ku's (2005) studies show, challenging and criticizing others' ideas may not be considered culturally appropriate in some cultural groups.

4. Tu (2001), Kim and Bonk (2002), Morse (2003), and Ku and Lohr (2003) showed that social presence is the key for the success of students from context dependent cultures. To improve the likelihood of such learners' success, Thompson and $\mathrm{Ku}(2005, \mathrm{p}$. 45) made the following recommendations for online instructors:

a. Get to know the students. Encourage students to send their pictures and post their background information and interests online. 
b. Encourage students to communicate with each other both online and offline. For example, exchange phone numbers, meet in person, use email, fax, the discussion board, and the chat room.

c. Encourage face-to-face interactions or meetings with classmates and instructors when possible.

5. Anakwe and Christensen (1999) found that "relationship building is foremost" for students from collectivist cultures (p. 240). This finding has significant implications for online instructors who emphasize collaborative work in their courses. One implication is that online instructors should allow sufficient time to develop relationships prior to engaging learners in collaborative activities (Liang \& McQueen, 2000). In addition, they should allow learners to work in small groups, encourage diversity in those groups (Thompson \& Ku, 2005; Wang \& Reeves, 2007), and always monitor the nature and scope of team work (Wang, 2007).

6. Wang's (2007) and Al-Harthi's (2005) studies illustrated how students from large power index cultures (Hofstede, 1991) are intimidated by the thought of approaching their instructors. In line with this finding, some of the authors whose works are included in this review recommended that online instructors pay attention to power issues, position themselves as equal to students (Wang, 2007), and be available for consultation and guidance (Smith et al, 2005).

7. When knowledge is embedded in the dominant culture, learners who are foreign to that culture lose their motivation to understand it. The frustration felt by a Chinese student in Thompson and Ku's (2005) study as a result of being unable to understand the cultural references used by her American peers in online discussions is a case in point. To avoid situations like this one, online instructors should provide background information when specific cultural references are used in ALNs.

8. Liang and McQueen (2000), Fang (2007), and Thompson and Ku (2005) found that students from Asian cultures, who see instructors as authority figures, value teacher feedback more than peer feedback and get frustrated when they do not see teacher presence in ALNs. For example, Hong, a Chinese student from Thompson and Ku's (2005) study stated:

It is like students are exploring an unknown territory in a forest. The instructor eventually comes out and leads us to the right path. Because we think the teacher is an authority figure, we want to know what his thoughts are instead of discussing among ourselves blindly. (p. 42)

These findings suggest that online instructors should integrate feedback into the peer review processes and increase the amount of individual teacher feedback students receive.

9. Last but not least, Shattuck (2005) found that "constructivist-based pedagogy couched in the highly interactive communication world can be a lonely place for an international online learner whose cultural experiences are different than the dominant educational cultures" (p. 186). This finding logically leads us to conclude that online instructors 
should not simply implement "best practices," which are born out of dominant educational cultures, in their courses without knowing the needs of their learners. As Selinger (2004) noted, instructors' roles and decisions are pivotal in making ALN learning successful for students. Therefore, to ensure that these decisions improve culturally diverse groups' ALN experiences, online instructors need to effectively conduct needs assessments and engage in an ongoing process of re-constructing their teaching approaches based on the results of these assessments.

\section{What Implications does this Review Suggest for Future Research?}

Although research focusing on the impact of culture on ALN learning has increased in the past decade, there are several gaps in the literature.

First, there is a dearth of studies looking at the questions of culture in ALNs among domestic diversity cultures. For example, what are the experiences of African American, Latino-American, and/or Asian-American students taking distance learning courses in the U.S.? Empirical attention to the interaction between learners from dominant and diversity cultures would reveal useful insights in understanding the complexity of student learning in ALNs. Studies of this sort will enrich our knowledge base as to how different populations of students representing the dominant and diversity cultures both resemble and contrast with one another in distance learning environments.

Second, the vast majority of research tends to surround Asian learners and their ALN experiences. More studies looking at the influences of culture on students from other cultures, such as German, French, Hungarian, Polish, Turkish, Greek, Iranian, Indian, etc, are needed. Research into these, so far under-represented, groups will provide instructors with important insights.

Lastly, in most cultural studies included in this review, there was a tendency to lump students into one category without paying attention to their individual differences. This problem is also echoed by Gunawardena et al. (2001) who wrote the following:

Individual differences in cultural groups need to be accounted for so that we do not subscribe to the fallacy of homogeneity (that terms such as "American" connote international sameness), or the fallacy of monolithic identity (the assumption that individuals in groups have no differential identities) (p. 117).

In future studies, attention to this distinction would likely prove fruitful in understanding the complexity of ALN learning as it will prevent researchers from generating fixed conceptualizations of various groups' cultural characteristics.

\section{Methodological Insights}

The papers discussed in this review provide useful insights into the cultural dimensions of student learning in ALNs. Overall, their strength lies in their exploratory nature and focus on pragmatic considerations. However, a major weakness of these studies is that most of them did not follow 
rigorous designs or analyses. A discussion of the theoretical and methodological weaknesses of these studies follows below.

The review herein supports Patton's (2002) contention that “there are no perfect research designs. There are always trade-offs" (p.223). Therefore, the goal in this section is not to isolate particular studies, point out flaws in their design and conduct, or undermine their conclusions. Rather, the intent of the following discussion is to provide methodological insights for researchers who plan future studies on cultural factors impacting student learning in ALNs.

Let us start with qualitative studies. While such studies enriched our knowledge of the cultural issues impacting ALNs, most fell short of meeting the conventional standards of qualitative research designs. For example, few had a solid foundation in theories. The ones that did make use of theories, however, relied on the same, existing theoretical models (such as Edward Hall's and Geert Hoftede's cultural constructs) to explain students' culture-bounded behaviors in ALNs. In future qualitative studies, researchers should provide theoretical underpinnings for their work, and in so doing they should break theoretical boundaries and engage in creative application of concepts from different disciplines.

Anfara, Brown, and Mangione (2002) recommend that qualitative researchers "account for and disclose all aspects of the research process" (p. 28). They highlight analytic openness as key to conducting methodologically sound qualitative research. When we look at the qualitative studies reviewed above, however, we find that only a handful of researchers provided detailed explanations of the inner workings of their research process. For example, in most papers, no mention was made of how themes and categories were developed, what verification processes were used to confirm validity, or how triangulation was achieved. Moreover, almost all of the qualitative studies relied on interviews, yet none provided the readers with information about what questions were asked in the interview protocols. Lastly, none of the qualitative studies included in this review addressed researcher bias, and only a few provided methodological justifications regarding the sampling approaches used. It is important that researchers attend to these issues and make the inner workings of the overall research process public in future qualitative reports.

In addition to the qualitative works, some of the studies included in this review employed quantitative or mixed method (qualitative and quantitative) approaches. Studies of this type mainly relied on survey methodology, but only a few succeeded in following a rigorous survey research design. Overall, eight weaknesses were identifiable: 1) inadequate sampling size that compromised generalization to larger populations; 2) minimal description of the sampling approaches, the defining boundaries of the population, and the criteria of inclusion and exclusion of the sampling frame; 3) lack of hypotheses and/or definitions of the independent and dependent variables; 4) minimal or no information about the survey instrument, pre-testing, and piloting; 5) minimal or no information about the initial size of the sample and the final percentage that responded to the surveys; 6) inadequate descriptions of data collection and analysis procedures; 7) inadequate coverage of the literature; and 8) over-reliance on cross-sectional surveys. 


\section{Discussion and Conclusions}

Empirical works reviewed in this paper provide useful insights into the influences of culture on students' ALN experiences. Despite their varying contexts and focus, it is possible to identify common threads running through them. Notable in particular among these studies is an emphasis on the idea that culture is inseparable from distance learning and teaching. Researchers express broad agreement that the diverse cultural assumptions students bring to ALNs concerning how teaching and learning should be done bring about conflicts, disagreements, and frustrations. Not surprisingly, the issues dealt with in these studies resemble those faced by traditional classroom teachers who teach culturally and linguistically diverse students. This validates Zhao et al.'s (2005) conclusion that "distance education in essence is still education [...] The factors found to have an impact on the effectiveness of distance education are also factors that would affect the effectiveness of face-to-face education" (p. 1865).

Another point that emerges from these studies is their emphasis on practical issues. The studies support a multicultural perspective on the aims and conduct of distance education and identify the ways in which teaching in ALNs can best be done to enhance several different cultural groups' learning. Specific recommendations that emerged from these studies were described earlier. On such practical matters, it is fair to argue that those recommendations would be good not only for international or multicultural students but also for everyone engaged in distance learning. Recognizing this fact leads us to conclude that good practices for culturally diverse online learning environments are good practices for others where teachers and students are operating within the same culture and space.

Finally, the reviewed studies point to the need to recognize the diversity within online communities of learners. Researchers express broad agreement that online instructors should be sensitive to cultural issues, become aware of the variations in students' learning strategies, and avoid adopting the "one size fits all" approach when viewing the process of learning for their students in ALNs. It can be argued that within the process of becoming aware of the needs of students from other cultures, online instructors can also become aware of the diverse needs of students from their own culture. This heightened sensitivity will benefit students in general.

Clearly, the limited number of studies $(N=27)$ located in available databases and online open access journals may be indicative of the fact that cultural dimensions of ALNs are a relatively new field of study, one in which important insights have yet to be discovered. Continued research that is grounded in sound methodology is certainly needed to improve our understanding of it.

\section{Acknowledgements}

The author would like to thank Jason Smith, Dr. Peter Shea from SUNY Albany, and two anonymous reviewers for their insightful comments, and she is especially grateful to Terry Anderson for his invaluable editorial guidance. 


\section{References}

Al-Harthi, A. S. (2005). Distance higher education experiences of Arab Gulf students in the United States: A cultural perspective. International Review of Research in Open and Distance Learning, 6(3), 1-14.

Anakwe, U. P., \& Christensen, E. W. (1999). Distance learning and cultural diversity: Potential users' perspective. The International Journal of Organizational Analysis, 7(3), 224-243.

Anfara, V. A., Brown, K. M., \& Mangione, T. L. (2002). Qualitative analysis on stage: Making the research process more public. Educational Researcher, 31(7), 28-38.

Bates, T. (2001). International distance education: Cultural and ethical issues. Distance Education, 22(1), 122-136.

Bentley, J. P. H., Tinney, M. V., \& Chia, B. H. (2005). Intercultural internet-based learning: Know your audience and what it values. Educational Technology Research \& Development, 53(2), 117-127.

Biesenbach-Lucas, S. (2003). Asynchronous discussion groups in teacher training classes: Perceptions of native and non-native students. Journal of Asynchronous Learning Networks, 7(3), 24-46.

Bing, W., \& Ai-Ping, T. (2008). The influence of national culture toward learners' interaction in the online learning environment: A comparative analysis of Shanghai TV University (China) and Wawasan Open University (Malaysia). The Quarterly Review of Distance Education, 9(3), 327-339.

Boyer, J. B. (1993). Culturally sensitive instruction: An essential component of education for diversity. Catalyst for Change, 22, 5-8.

Branch, R. M. (1997). Educational technology frameworks that facilitate culturally pluralistic instruction. Educational Technology, 37, 38-41.

Chen, S., Hsu, C., \& Caropreso, E. J. (2006). Cross-cultural collaborative online learning: When the West meets the East. International Journal of Technology in Teaching and Learning, 2(1), 17-35.

Chen, A., Mashhadi, A., Ang, D., \& Harkrider, N. (1999). Cultural issues in the design of technology-enhanced learning systems. British Journal of Educational Technology, $30(3), 217-230$.

Collis, B. (1999). Designing for differences: cultural issues in the design of WWW-based coursesupport sites. British Journal of Educational Technology, 30(3), 201-215. 
Edmundson, A. (2009). Culturally accessible e-learning: An overdue global business imperative. Retrieved May 15, 2009, from http://www.astd.org/LC/2009/0509_edmundson.htm

Fang, L. (2007). Perceiving the useful, enjoyable, and effective: A case study of the e-learning experience of tertiary students in Singapore. Educational Media International, 44(3), 237-253.

Gay, G. (2000). Culturally responsive teaching: Theory, research, \& practice. New York: Teachers College Press.

Goodfellow, R., Lea, M., Gonzales, F., \& Mason, R. (2001). Opportunity and e-quality: Intercultural and linguistic issues in global online learning. Distance Education, 22(1) 6584.

Gouthro, P. A. (2004). Assessing power issues in Canadian and Jamaican women's experiences in learning via distance in higher education. Teaching in Higher Education, 9(4), 449461.

Gramsci, A. (1971). Selections from the prison notebooks. London: Lawrence and Wishart.

Gunawardena, C. N., Nolla, A. C., Wilson, P. L., Lopez-Islas, J. R., Ramirez-Angel, N., \& Megchun-Alpizar, R. M. (2001). A cross-cultural study of group process and development in online conferences. Distance Education, 22(1), 85-121.

Hannon, J., \& D’Neto, B. (2007). Cultural diversity online: Student engagement with learning technologies. International Journal of Educational Management, 21(5), 418-432.

Hiltz, S. R., \& Goldman, R. (2005). What are asynchronous learning networks? In S. R. Hiltz and R. Goldman (Eds), Learning together online: Research on asynchronous learning networks (pp. 3-18). Mahwah, NJ: Lawrence Erlbaum.

Hofstede, G. (1991). Cultures and organizations: Software of the mind. London: McGraw-Hill.

Hofstede, G. (1980). Culture's consequences: International differences in work-related values. Beverly Hills, CA: Sage Publications.

Kim, K. J., \& Bonk, C. J. (2002). Cross-cultural comparisons of online collaboration among preservice teachers in Finland, Korea, and the United States. Journal of Computer-Mediated Communication, 8(1).

Ku, H. Y., \& Lohr, L. L. (2003). A case study of Chinese students' attitudes toward their first online learning experience. Educational Technology Research and Development, 51(3), 95-102. 
Ladson-Billings, G. (1995). Toward a theory of culturally relevant pedagogy. American Educational Research Journal, 32(3), 465-491.

Liang, A., \& McQueen, R., J. (2000). Computer assisted adult interactive learning in a multicultural environment. Adult Learning, 11(1), 26-29.

Lim, D. H. (2004). Cross cultural differences in online learning motivation. Educational Media International, 41(2), 163-175.

Malbran, M. C., \& Villar, C. M. (2001). Incorporating cultural relevance into online courses: The case of VirtualMente. Distance Education, 22(1), 168-174.

McLoughlin, C. (1999). Culturally responsive technology use: Developing an online community of learners. British Journal of Educational Technology, 30(3), 231-243.

Moore, M. (2006). Editorial. The American Journal of Distance Education. 20(1), 1-5.

Morse, K. (2003). Does one size fit all? Exploring asynchronous learning in a multicultural environment. Journal of Asynchronous Learning Networks, 7(1), 37-55.

Patton, M. Q. (2002). Qualitative research and evaluation methods. Thousand Oaks, CA: Sage Publications.

Rogers, P. C., Graham, C. R., \& Mayes, C. T. (2007). Cultural competence and instructional design: Exploration research into the delivery of online instruction cross-culturally. Educational Technology Research and Development, 55(2), 197-217.

Saldana, D.C., \& Waxman, H. (1996). The integration of multicultural education in urban middle level schools. Current Issues in Middle Level Education, 5, 9-29.

Selinger, M. (2004). Cultural and pedagogical implications of a global e-learning programme. Cambridge Journal of Education, 34(2), 223-239.

Shattuck, K. (2005). Cultures meeting cultures in online distance education: Perceptions of international adult learners of the impact of culture when taking online distance education courses designed and delivered by an American University. Unpublished doctoral dissertation, The Pennsylvania State University, University Park.

Smith, D. R., \& Ayers, D. F. (2006). Culturally responsive pedagogy and online learning: Implications for the globalized community college. Community College Journal of Research and Practice, 30, 401-415.

Smith, P.J., Coldwell, J., Smith, S. N., \& Murphy, K. L. (2005). Learning through computer- 
mediated communication: A comparison of Australian and Chinese heritage students. Innovations in Education and Teaching International, 42(2), 123-134.

Smith, S. N., \& Smith, P. J. (2000). Implications for distance education in the study approaches of different Chinese national groups. The Journal of Distance Education, 15(2), 71-84.

Smith, P. J., \& Smith, S. N. (1999). Differences between Chinese and Australian students: Some implications for distance educators. Distance Education, 20(1), 64-80.

Tapanes, M. A., Smith, G. G., \& White, J. A. (2009). Cultural diversity in online learning: A study of the perceived effects of dissonance in levels of individualism/collectivism and tolerance of ambiguity. The Internet and Higher Education, 12, 26-34.

Thompson, L., \& Ku, H. (2005). Chinese graduate students' experiences and attitudes toward online learning. Educational Media International, 42(1), 33-47.

Tu, C. (2001). How Chinese perceive social presence: An examination of interaction in online learning environment. Educational Media International, 38(1), 45-60.

Walker-Fernandez, S. E. (1999). Toward understanding the study experiences of culturally sensitive graduate students in American distance education programs. Unpublished doctoral dissertation, Florida International University, Miami.

Wang, M. (2007) Designing online courses that effectively engage learners from diverse cultural backgrounds. British Journal of Educational Technology, 38(2), 294-311.

Warschauer, M. (1998). Online learning in sociocultural context. Anthropology \& Education Quarterly, 29(1), 68-88.

Wegerif, R. (1998). The social dimension of asynchronous learning networks. Journal of Asynchronous Learning Networks, 2(1), 34-49.

Wilson, M. S. (2001). Cultural considerations in online instruction and learning. Distance Education, 22(1), 52-64.

Zhao, N., \& McDougall, D. (2008). Cultural influences on Chinese students' asynchronous online learning in a Canadian university. Journal of Distance Education, 22(2), 59-80.

Zhao, Y., Lei, J., Yan, B., Lai, C., \& Tan, H. S. (2005) What makes the difference? A practical analysis of research on the effectiveness of distance education. Teachers College Record, 107(8), 1836-1884.

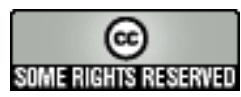


June - 2009

\title{
The Retention of Experienced Faculty in Online Distance Education Programs: Understanding Factors that Impact their Involvement
}

\author{
Tim Green \\ California State University, Fullerton, USA \\ Jeffery Alejandro and Abbie H. Brown \\ East Carolina University
}

\begin{abstract}
The study sought to determine factors that affect faculty decisions regarding their involvement in teaching online distance education courses. A survey was administered to online distance education faculty across the United States to determine those factors that encourage or discourage them from continuing to teach online courses. The factors were examined and reported from the standpoint of each of four faculty groups: (1) tenured, (2) tenure-track, (3) full-time nontenured/fixed term, and (4) part-time/adjunct. From the survey responses $(N=135)$, a list of retention strategies that university administrators may use for retention of online distance education faculty are offered.
\end{abstract}

Keywords: Online distance education administration; faculty retention; strategies for retaining faculty

\section{Introduction}

Over the past five years, the Sloan Consortium has published an annual report focusing on the state of online learning in U.S. higher education. The most recent published report, Online Nation: Five Years of Growth in Online Learning, describes data received from 2,535 institutions $(4,491$ degree-granting institutions open to the public were surveyed). The institutions were asked to respond to questions regarding the number of students enrolled in online learning at their institution, the courses or programs these students were enrolled in, and the barriers that prohibited widespread adoption of online learning at their institution. Based on data collected, more than two-thirds of the institutions reported having some form of online offerings, with the majority of the institutions providing programs that are offered fully online. The number of students in fall 2006 taking at least one online course represented almost 20 percent of all students enrolled at these institutions, which is an increase of $10.1 \%$ since 2002 (Allan \& Seaman, 2007). These numbers indicate that future growth in online learning in the U.S. is likely 
to continue significantly in the years to come. It appears that this growth is being planned for, or at least considered, by a number of higher education institutions.

As institutions consider and plan, a variety of issues must be addressed if their online programs are to be successful. One major issue is faculty turnover, particularly among part-time, adjunct faculty. Faculty turnover is costly. This cost can involve course adaptation and redevelopment, faculty training, and increased staff support (Pferdehirt, Smith, \& Al-Ashakr, 2005) In addition to being detrimental to an institution's budget, faculty turnover can also be damaging to its reputation. Institutions, therefore, should be proactive in developing a system focused on retaining high quality distance education faculty (Pferdehirt, Smith, \& Al-Ashakr). Before an institution is capable of developing an effective distance education faculty retention system, factors that impact faculty participation in distance education must first be understood.

\section{Theoretical Framework}

A significant body of literature exists that theorizes and reports research on motivating factors, discouraging factors, and encouraging factors influencing faculty involvement in the teaching of online distance education courses. The literature review provided in this section is by no means an exhaustive examination of the body of literature; however, the literature reviewed does provide a detailed summary of prior studies focusing on motivating factors, discouraging factors, and encouraging factors that influence faculty to teach online distance education courses.

\section{Motivating Factors}

Some of the motivating factors listed in the research (Andersen, 2004; Hiltz, Kim, \& Shea, 2006; Keeten, 2000; Schnitzer \& Crosby, 2003; Theall, 1999; Townsend \& Hauss, 2002) are flexible scheduling, opportunity to experiment with new pedagogy, computing skill level and opportunity to learn new technology, natural curiosity, marketability of skills, opportunity to share knowledge, and career development. Other motivators include university sponsored incentives and policies (Gannon-Cook \& Ley, 2004; Moore \& Anderson, 2003).

Many faculty members are motivated to teach distance education courses because of the various incentives that they receive for doing so. According to Moore and Anderson (2003), "incentives that have been identified with respect to distance education appear to be of three major types: (1) situational aspects or characteristics of the work environment that facilitate participation, (2) inducements offered by the institution expressly to entice faculty to participate, and (3) intrinsic rewards returned for participation" (p. 557). Situational aspects or characteristics may include availability of technology training and assistance, departmental commitment to distance education, and/or a well-developed support system. Inducements offered by the institution may include increase in salary, promotion credit, and/or release time. Intrinsic rewards may include personal/professional growth, career advancement, personal challenge, and/or personal satisfaction for a job well done. 
In regards to situational aspects, Theall (1999) identified eight basic characteristics of campus culture that motivate faculty to teach: (1) a high level of administrative commitment and support; (2) faculty involvement, shared values, and a sense of ownership; (3) a broader definition of scholarship; (4) teaching demonstration or pedagogical colloquium as part of the hiring process; (5) frequent interaction, collaboration, and community among faculty; (6) a faculty development program or campus teaching center; (7) supportive and effective department chairs; and (8) a rigorous evaluation of teaching that is connected to tenure and promotion decisions. GannonCook and Ley's (2004) review of prior research showed that university policies that create positive, motivating conditions for faculty participation and that eliminate inhibitors could sustain and stimulate faculty participation in distance education. They found three leading motivators of distance education faculty in most studies: (1) personal motivation to use technology, (2) ability to reach new audiences, and (3) presence of strong technical and administrative support. Faculty who sense a serious commitment to quality from their institution will have a strong personal investment in the distance education program's future (Allan \& Seaman, 2007). Faculty members are motivated to participate when they see how their institutions value distance education, how distance education benefits their careers, and how teaching via distance fits their lives.

As for inducements, faculty wants to know what the personal rewards may be. Full-time, parttime, and adjunct faculty members are all involved in online teaching, with adjunct faculty becoming more involved in teaching in higher education settings (Schnitzer \& Crosby, 2003). Townsend and Hauss (2002) found that two of the main reasons adjunct instructors teach distance education courses were to gain teaching experience and for additional income. This was supported when Gannon-Cook and Ley (2004) examined prior research studies and found that most listed the presence of monetary reward systems as an inducement offered by institutions to recruit distance education faculty. Shea (2007) reports that part-time faculty members may be more inclined to teach online because it accommodates other life needs, potentially provides more free time for other professional activities, and reduces commuting time. Andersen (2004) found tenure-track faculty more likely to teach distance education courses if they know their efforts will be counted towards tenure. Seldom will faculty participate in activities that take time and resources away from furthering their careers, especially when trying to get tenured at an institution. Schifter (2000b) found that faculty compensation is an important factor in faculty motivation. Full-time instructors who participate in distance education are sometimes compensated with release time, overload pay, new computer or laptop, travel funds, or access to a teaching assistant.

As mentioned previously, intrinsic rewards may include personal growth and the satisfaction gained from a job well done. Ko and Rossen (2003) wrote that some faculty teach distance education courses because they seek a heightened awareness of teaching and a connection to a global community of educators. They desire to help further the advancement of knowledge and society as a whole. Some faculty members teach distance education courses for the students. McKenzie et al. (2000) determined that some faculty migrate to distance education because of their wish to interact with students more frequently and because students had asked consistently for courses to be offered online. This was later confirmed by Belcheir and Cucek (2002), who 
found that faculty was more likely to participate in online classes if they could see that students would benefit from them. The motivating factor here was an opportunity for faculty to share knowledge and expand their field of study.

\section{Discouraging Factors}

Disincentives cited within the professional literature (Belcheir \& Cucek, 2002; Bower, 2001; Brown, 2003; Giannoni \& Tesone, 2003; Moore \& Anderson, 2003; Passmore, 2000; Schweber, Kelley, \& Orr, 1998; Sumrall, 2002) included the following: the time and effort teaching online requires (compared to face-to-face courses); the lack of financial compensation in comparison to work performed; the lack of institutional support; the lack of experience with online teaching; the lack of recognition for efforts made in online teaching; and the lack of sufficient technical training.

Sumrall (2002) found that one of the primary obstacles for faculty participation in distance education is the lack of fit with university missions and goals (institutional fit). The absence of institutional fit often leads to a lack of institutional support. Keeton (2002) discovered that institutions that failed to convince faculty that the technology is reliable and that the quality is at least equal to the traditional methods, that do not provide faculty with adequate time to develop and maintain distance education courses, and that do not establish a clear vision of distance education were not likely to recruit quality faculty to teach in their distance education programs.

Shea (2007) reported that the number of times an instructor has taught online has an impact on their interest in continuing to do so. Less experienced instructors were reticent to engage in online teaching due to feeling under-prepared in terms of familiarity with online pedagogy and having fewer opportunities to observe online teaching modeled by others. Issues of compensation were also an issue among less experienced instructors.

Another reason that faculty is sometimes reluctant to participate in distance education is because they feel their return on investment is questionable, especially with respect to tenure and promotion (Passmore, 2000; Shea, 2007). Faculty at four-year institutions also indicated that online teaching can be confusing and that the time necessary to revise online courses may not be available.

The literature further suggests that faculty may opt not to teach distance education courses because they do not receive adequate compensation, release time, materials, and equipment to offer quality distance education courses (Bower, 2001; Schifter 2000a, b). Faculty with higher computer skills may also be less inclined to teach online due to their feeling that they received inadequate compensation and/or recognition for the task (Shea, 2007).

\section{Encouraging Factors}

The proposed retention strategies mentioned in the literature (Fredrickson et al., 2000; Schweber, Kelley, \& Orr, 1998) included continuous training, mentoring, opportunities for distance 
education faculty to collaborate with campus faculty, and assimilation into the university community. Faculty will stay if they feel welcomed, wanted, and needed.

Gaillard-Kenney (2006) suggests that after institutions hire adjunct faculty, they should schedule an orientation to help the adjuncts feel part of the organization. Following the orientation process, provisions should be made for subsequent faculty development opportunities. These things need to be done in order to prevent the adjunct faculty from feeling isolated and to ensure quality of teaching. Also, adjuncts should be integrated into the institution. One way to accomplish this is to offer adjuncts opportunities to interact with full-time faculty members. Adjunct faculty members should be provided with opportunities for collaboration in order to facilitate scholarly exchanges and the building of a teaching community. Also, a mentoring program should be established to further assimilate adjuncts into the institution's culture.

According to Schweber, Kelley, and Orr (1998), one way to retain distance education faculty is to provide them with continuous training in the form of workshops. The workshop topics should be varied (i.e., Authorware, online course development, course management systems, computer literacy). Training should be at no cost to the faculty and faculty should receive a stipend for each workshop that they complete. Keeton (2002) advises distance education administrators to do the following: (1) convince faculty that the technology is reliable and the quality is at least equal to the traditional methods, (2) provide time to develop and maintain distance education courses, (3) examine and evaluate distance education, (4) establish peer models within departments, and (5) establish a clear vision of distance education.

One way to establish peer models is through mentoring. Mentoring is sometimes seen as a quality control tool. Such is the case when a more experienced faculty member observes and assists another faculty member in migrating their course from face-to-face to online. Their chief objective is to make sure the new course format meets certain standards. Aside from its role as a quality control tool, mentoring can be a sign of a university's commitment to ongoing professional development for its faculty (Mandernach et al., 2005). This can be a useful retention strategy. Mentoring is a way to assimilate new faculty into university culture and to make them feel welcomed. Also, it allows seasoned faculty to share their skills with novices and to enhance personal self-satisfaction (Parker, 2003). A mentoring strategy can thus help to retain both the new and the established faculty member.

\section{Research Method and Participants}

To determine more specifically which factors have the greatest impact on faculty with regard to their approach to teaching online, the authors developed and administered a survey to a sample of online distance educators across the United States.

\section{Participants}

The sample for this study comes from the population of faculty active in online distance education. The sample was drawn from members of the Distance Education Online Symposium 
listserv as well as from online distance education faculty members who currently teach or who have taught at East Carolina University and the California State University, Fullerton. It is difficult to ascertain the exact number of faculty the survey reached due to the survey being sent to a listserv; despite this, we can say that the survey reached at least 500 faculty members (including the lists from East Carolina University and California State University, Fullerton). The study sample was selected based on its members being actively engaged in teaching online distance education courses.

\section{Data Collection Protocol}

Based on the review of the literature, a survey was designed to identify those factors critical to the retention of online distance education faculty. Participants were asked to respond to a series of closed and open-ended questions that were designed to collect background information as well as to rate 10 statements about motivating factors, 11 statements about discouraging factors, and seven statements about encouraging factors. The ratings were as follows: strongly agree, agree, neutral, disagree, and strongly disagree. Following each set of statements, participants were asked to indicate which of the factors in the set impacted their decision to teach distance education courses the most. Participants were also prompted to list additional factors not specifically stated in the survey.

Prior to the distribution of the survey, four distance education experts reviewed the instrument (two faculty members, a distance education administrator, and an instructional designer). Based on the reviewers' suggestions, minor changes were made to the instrument. For ease of distribution and data collection, the survey was posted online. After reviewing several web-based survey tools, Perseus Survey Solutions software was selected for its ease of use and data collection capabilities. Because all survey participants were experienced distance educators, it was felt that an online survey would provide a relatively easy and reliable method of response.

\section{Data Collection and Analysis Procedures}

A link to the online survey was distributed through email to solicit participation. Included in the email was a message describing the purpose of the study and the importance of participating in it; also, there was a statement to assure the respondents of confidentiality. Two weeks after the initial emailing, a follow-up email was sent to the Distance Education Online Symposium listserv reminding members about the survey. After the survey link had been open for 30 days, the responses were downloaded and data analysis began. Descriptive statistics were calculated and then examined for trends.

\section{Respondent Profile}

The survey invitation elicited 135 completed surveys from the participant population. The respondents represented 23 different universities. They were somewhat evenly divided among the four faculty groups: (1) adjunct/part-time, 28.15\%; (2) full-time non-tenured, 22.96\%; (3) tenure- 
track, 25.93\%; and (4) tenured, 22.96\%. Most had been teaching distance education courses for 13 years $(52.59 \%)$, followed by $34.81 \%$ for $4-6$ years, $6.67 \%$ for $7-9$ years, and $5.93 \%$ for 10 or more years. Forty percent of the group taught only distance education courses, while $60 \%$ taught both distance education and face-to-face courses.

\section{Results and Findings}

This section is organized according to the various faculty groups that make up the participants who were surveyed: all faculty, adjunct/part time, full-time non-tenured, and tenured.

\section{All Faculty}

As a whole, faculty members are motivated to teach online distance education courses for the following reasons: flexible working conditions (82.22\%), opportunity to use technology (71.11\%), opportunity to share knowledge with others (70.37\%), intellectual challenge $(67.41 \%)$, career development/advancement (58.52\%), and opportunity to gain teaching experience (54.81\%). A majority (54.07\%) of the respondents cited that their concerns about time commitment might discourage them from teaching distance education courses. Numerous respondents listed the lack of sufficient financial compensation in comparison to workload (48.89\%), concerns about workload (48.15\%), and lack of institutional support $(43.70 \%)$ as possible discouraging factors. Factors that most respondents stated would encourage them to continuing teaching distance education courses are the following: continuous training provided by the university $(73.33 \%)$, fair financial compensation in comparison to workload $(72.59 \%)$, increased institutional support $(71.85 \%)$, opportunity to assist with course/program development $(71.85 \%)$, and mentoring from veteran distance education instructors $(51.85 \%)$.

\section{Adjunct/Part-Time Faculty}

Adjunct/part-time faculty as a group is similar to the other groups in that they are motivated by the flexible working conditions $(97.37 \%)$, the opportunity to share knowledge with others (89.47\%), the opportunity to use technology (86.84\%), the opportunity to gain teaching experience $(78.95 \%)$, the opportunity for career development/advancement $(71.05 \%)$ and the intellectual challenge $(71.05 \%)$. Unlike the other groups, however, adjunct/part-time faculty members are motivated by the possibility of increasing personal income $(78.95 \%)$ and a sense of loyalty to the university (52.63\%). Based on their responses, adjunct/part-time faculty members are discouraged by the lack of sufficient financial compensation in comparison to workload $(50.00 \%)$ and by concerns about the quality of students $(50.00 \%)$. While this group indicated that they are encouraged by all the factors listed on the survey, they were especially motivated by fair financial compensation in comparison to workload (89.47\%), increased institutional support (81.58\%), and the opportunity to assist with course/program development (81.58\%). 


\section{Full-Time Non-Tenured Faculty}

When it comes to motivating factors, the full-time non-tenured faculty is no different from the other groups. Most are motivated by flexible working conditions (83.87\%), the opportunity to use technology $(80.65 \%)$, the opportunity to share knowledge with others $(77.42 \%)$, the intellectual challenge (74.19\%), the opportunity for career development/advancement (67.74\%), and the opportunity to gain teaching experience $(58.06 \%)$. In regard to discouraging factors, the full-time non-tenured faculty is also similar to the other groups. Their concerns about workload $(54.84 \%)$ and their concerns about time commitment (51.61\%) are the factors that are most likely to discourage them from teaching distance education courses. Most full-time non-tenured faculty members are encouraged to continuing teaching by the following factors: opportunity to assist with course/program development $(80.65 \%)$, continuous training provided by the university (64.52\%), fair financial compensation in comparison to workload $(61.29 \%)$, and increased institutional support (58.06\%).

\section{Tenure-Track Faculty}

The factors that motivate most tenure-track faculty are flexible working conditions $(77.14 \%)$, intellectual challenge (62.86\%), opportunity to share knowledge with others $(57.14 \%)$, and career development/advancement opportunities (54.29\%). Unlike adjunct/part-time and full-time nontenured faculty groups, less than half of the tenure-track faculty is motivated by gaining additional teaching experience $(48.57 \%$ ) or by the opportunity to use technology (48.57\%). Like the other groups, over half of the tenure-track faculty can be discouraged by their concerns about workload (51.43\%). It appears that the tenure-track faculty group is highly encouraged by continuous training provided by the university (77.14\%), increased institutional support (71.43\%), fair financial compensation in comparison to workload (68.57\%), and opportunities to assist with course/program development $(62.86 \%)$. Few cited being encouraged by additional opportunities to interact with the full university community $(28.57 \%)$.

\section{Tenured Faculty}

Many tenured faculty members are motivated by the intellectual challenge $(70.97 \%)$, followed by the opportunity to use technology (67.74\%), the flexible working conditions $(67.74 \%)$, and the opportunity to share knowledge with others $(54.84 \%)$. Most of the tenured faculty cited a lack of sufficient financial compensation in comparison to workload (58.06\%), concerns about time commitment $(51.61 \%)$, and concerns about quality of students $(51.61 \%)$ as factors that would discourage them from teaching distance education courses in the future. Also, most cited the lack of personal connection with the university $(51.61 \%)$ as a discouraging factor. They were the only group to do so. As with the other groups, most of the tenured faculty agreed that continuous training provided by the university $(77.42 \%)$, increased institutional support $(74.19 \%)$, fair financial compensation in comparison to workload (67.74\%), and opportunities to assist with course/program development (61.29\%) would encourage them to continue teaching distance education courses. 


\section{Summary}

\section{All Faculty}

Qualified and experienced faculty members are an important resource for online distance education programs. Universities must make a concerted effort to retain them. This research study found that online distance education faculty as a whole are highly motivated by situational incentives, such as flexible working conditions and the opportunity to use technology. They are also motivated by intrinsic rewards, such as the opportunity to share knowledge with others, the intellectual challenge, their career development/advancement, and the opportunity to gain teaching experience. The major factor that might discourage them from teaching distance education courses is their concern about time commitment. Based on these factors, some possible retention strategies may include the provision of continuous training, of mentoring from veteran distance education instructors, and of opportunities to assist with course/program development. Because most faculty members are motivated by flexible working conditions, they should be allowed to have some say about their course load and schedule. The findings of this study support the findings of other studies regarding motivating factors for online distance education instructors.

\section{Adjunct/Part-Time Faculty}

The motivating factors that set the adjunct/part-time faculty apart from the other groups were increased personal income and a sense of loyalty to the university. They and the full-time nontenured faculty were the only two groups to note that they want to gain additional teaching experience. This group wants to feel that they are a vital part of the university. Like the other groups studied, their responses expressed a concern about the lack of sufficient financial compensation in comparison to workload. The adjunct/part-time faculty also cited that their concerns about the quality of students might discourage them. Possible retention strategies for this group are fair compensation plans, long-term teaching contracts, orientation programs, mentoring programs, and opportunities to assist with course/program development.

\section{Full-Time Non-Tenured Faculty}

Like the other groups, full-time non-tenured faculty members are motivated by flexible working conditions, the opportunity to use technology, the opportunity to share knowledge with others, the intellectual challenge, their career development/advancement, and the opportunity to gain teaching experience. Their chief concerns are workload and time commitment. The retention strategies that could encourage them to keep teaching via distance education are opportunities to assist with course/program development, continuous training, fair financial compensation, and increased institutional support. 


\section{Tenure-Track Faculty: Untenured}

The factors that motivate most tenure-track faculty are mainly intrinsic rewards. They are motivated by flexible working conditions, intellectual challenge, opportunity to share knowledge with others, and career development/advancement opportunities. Unlike adjunct/part-time and full-time non-tenured faculty groups, less than half of the tenure-track faculty is motivated by gaining additional teaching experience or the opportunity to use technology. Like the other groups, over half of the tenure-track faculty can be discouraged by their concerns about workload. Providing them with continuous training, increased institutional support, fair financial compensation, and opportunities to assist with course/program development may retain most tenure-track faculty.

\section{Tenured Faculty}

Like the tenure-track faculty, most tenured faculty members are motivated by intrinsic rewards. They like the intellectual challenge, flexible working conditions, and opportunity to share knowledge with others. Tenured faculty can be discouraged by the lack of sufficient financial compensation in comparison to the workload as well as by concerns about time commitment and about the quality of students. They were the only group to indicate the lack of personal connection with the university as a discouraging factor. As with all the other groups, the suggested retention strategies for tenured faculty are continuous training, increased institutional support, fair financial compensation, and opportunities to assist with course/program development. An additional retention strategy for this group may be the implementation of an online faculty community.

\section{Implications and Future Directions}

As mentioned earlier, a significant portion (69\%) of traditional and non-traditional colleges and universities in the United States believe that student demand for online courses and programs is continuing to grow (Allan \& Seaman, 2007). Almost all institutions (83\%) currently offering online distance education expect their enrollments to continue to increase (Allan \& Seaman). With this continued demand, the need to retain experienced faculty to teach these courses is paramount. Institutions will have to develop a systematic plan for recruiting, hiring, and developing online distance education faculty. To be successful, there must be a commitment to educational quality as well as a commitment from all levels of an institution.

Based on the survey results, the following strategies are recommended as part of an overall system to develop and retain experienced faculty.

1. Provide an institutional support system that includes the following: 
- $\quad$ Training for all levels of online distance education instructors from the beginners to veteran distance educators who are interested in continuing their professional development. It is important not to forget the veteran distance educators. Keeping training opportunities available to this group will help them stay 'fresh' and let them know they are being considered and valued. Many institutions have faculty development centers that can provide this type of training.

- Assistance in course development. This includes the overall instructional design of an entire course to the development of instructional media. Faculty may not have the expertise and/or the desire to create effective instructional media. Instructional designers and media developers can help faculty to develop and use instructional media that meets the needs of their students.

- Mentors for beginning online distance educators. A process needs to be in place where veteran distance educators serve as mentors to provide guidance and support on various issues. An important element of this process is course observation-a veteran distance educator visiting his or her mentee to provide feedback. This process is similar to on-campus relationships where senior faculty members are asked to observe junior faculty as they are teaching and to provide feedback.

2. Faculty should be compensated at a level that they feel is fair based on the perceived (and often real) increased workload associated with developing and teaching an online distance education course. This is especially important for adjunct faculty who are able to easily move to another institution because there is no on-going relationship. This strategy leads directly to the next strategy, which is to consider providing veteran (successful) adjunct faculty with a year-long or multiyear commitment. This can help adjunct faculty feel valued and thus more committed to continue teaching at a particular institution.

3. Determine how online distance education courses fit into the retention and promotion process for full-time tenure-track faculty. One extremely important element is to ensure that student evaluation instruments for distance education courses are developed thoughtfully and that data is collected carefully. Course facilitation and course technology are two separate issues. Faculty should only be evaluated based on how well they facilitated the course, not on whether a particular course management system worked efficiently (which often is not within the control of a faculty member).

4. Ensure that online distance education students are adequately supported. Faculty should be able to focus on teaching and not have to be the frontline support for students facing technical issues. When faculty have to deal with frontline support issues (e.g. technical issues with course management systems) it detracts from the time spent facilitating a course. Faculty should also be supported when they experience technical issues.

5. Develop a sense of community with online distance education instructors. It is important to help instructors (especially adjunct instructors who may only teach at a distance) feel connected to the university. Regular communication with online distance education faculty is a must. Their input should be sought on various issues regarding online courses and programs. A system should be in place where online faculty can communicate and share ideas with other online faculty at the institution. This can be accomplished through a variety of Internet-based tools (e.g., listserv, blog, discussion board). 
While the authors believe the study results help confirm (and expand) the results from similar studies, which themselves provide a reasonable basis for understanding the factors critical to the retention of experienced online distance educators (especially adjunct faculty), there is a need to conduct additional research in this area. Given more time and greater resources, the survey, or a similar one, might be made available to a larger pool of participants by expanding the invitation to include educators who may not subscribe to the DEOS listserv or who may not teach at East Carolina University or California State University, Fullerton. An expansion of the data gathered through an additional survey would allow additional elements to be identified, such as gender of faculty participants, university enrollment, online distance education enrollment, and technology resources. These data could then be used to conduct more robust statistical analyses. Furthermore, with a larger sample, statistical comparisons of the various subgroups would be more robust and helpful in making stronger generalizations. Finally, interviews with individuals or focus group studies addressing the same or similar factors as those addressed in the survey may provide greater insight into those factors that affect educators' approaches to teaching in an online distance education environment. 
The Retention of Experienced Faculty in Online Distance Education Programs: Understanding Factors that Impact their Involvement - Green, Alejandro, and Brown

\section{References}

Allan, E., \& Seaman, J. (2007). Online nation: Five years of growth in online learning. Needham, MA: The Sloan Consortium. Retrieved December 21, 2007, from http://www.sloan-c.org/publications/survey/pdf/online nation.pdf

Andersen, D. (Ed.) (2004). Digital scholarship in the tenure, promotion, and review process. Armonk, NY: M.E. Sharpe.

Belcheir, M., \& Cucek, M.(2002). Faculty perceptions of teaching distance education courses. Research Report: 2002. Boise, ID: Boise State University. (ERIC Document Reproduction Service No. ED 480925)

Bower, B. (2001). Distance education: Facing the faculty challenge. The Online Journal of Distance Learning Administration, 6(2). Retrieved November 23, 2006, from http://www.westga.edu/ distance/ojdla/summer42/bower42.html

Brown, D. (2003). Developing faculty to use technology. Boston, MA: Anker Publishing Company.

Fredrickson, E., Pickett, A., Shea, P., Pelz, W., \& Swan, K. (2000). Factors influencing faculty satisfaction with asynchronous teaching and learning in the SUNY learning network. Journal of Asynchronous Learning Networks, 4(3). Retrieved November 1, 2007, from http://www.alnresearch.org/Data_Files/articles/full_text/fs-fredericksen.htm

Gannon-Cook, R., \& Ley, K. (2004, October 20). What's driving faculty participation in distance education? Paper presented at the 27th Annual Meeting of the Association for Educational Communications and Technology, Chicago, IL.

Giannoni, D., \& Tesone, D. (2003). What academic administrators should know to attract senior level faculty members to online learning environments. Online Journal of Distance Education Administration, 6(1). Retrieved October 21, 2007, from http://www.westga.edu/ distance/ojdla/spring61/giannoni61.htm

Hiltz, S. R., Kim, E., \& Shea, P. (2006). Faculty motivators and demotivators for teaching online: Results of focus group interviews at one university. Proceedings of the 40th Annual Hawaii International Conference on System Sciences.

Keeton, C. (2000). Institutional structures that influence faculty to participate in distance education. Dissertation Abstracts International, 61(10), 3840A. (UMI No. AAT 9993226)

Ko, S., \& Rossen, S. (2003). Teaching online: A practical guide. Boston, MA: Houghton Mifflin. 
Mandernach, B., Donnelli, E., Dailey, A., \& Schulte, M. (2005). A faculty evaluation model for online instructors: Mentoring and evaluation in the online classroom. Online Journal of Distance Learning Administration, 8(3). Retrieved October 21, 2007, from http://www.westga.edu/ distance/ojdla/fall83/mandernach83.htm

McKenzie, B., Mims, N., Bennett, E., \& Waugh, M. (Winter, 2000). Needs, concerns and practices of online instructors. Online Journal of Distance Learning Administration, 3(3). $\begin{array}{llll}\text { Retrieved October } & \text { 1, 2007, from }\end{array}$ http://www.westga.edu/ distance/ojdla/fall33/mckenzie33.html

Moore, G., \& Anderson, W. (Eds) (2003). Handbook of distance education. Mahwah, NJ: Lawrence Erlbaum Associates.

Parker, A. (2003). Motivation and incentives for distance faculty. Online Journal of Distance Learning Administration, 6(3). Retrieved November 12, 2006, from http://www.westga.edu/ distance/ojdla/fall63/parker63.htm

Passmore, D. (2000). Impediments to adoption of web-based course delivery among university faculty. ALN Magazine, 4(2). Retrieved November 30, 2006, from http://www.sloanc.org/publications/magazine/v4n2/passmore.asp

Pferdehirt, W., Smith, T., \& Al-Ashkar, K. (2005). The University of Wisconsin-Madison's Master of Engineering in Professional Practice (MEPP) program: The road to quality online graduate engineering education. Journal of Asynchronous Learning Networks, 9(2). Retrieved

September 28, 2006, from http://www.sloanc.org/publications/jaln/v9n2/pdf/v9n2_pferdehirt.pdf

Schifter, C. (2000a). Compensation models in distance education. The Online Journal of Distance Learning Administration, 3(1). Retrieved November 19, 2006, from http://www.westga.edu/ distance/schifter31.html

Schifter, C. (2000b). Factors influencing faculty participation in distance education: A factor analysis. Education at a Distance, 13(1). Retrieved November 19, 2006, from http://www.usdla.org/html/journal/JAN00_Issue/Factors.htm

Schnitzer, M., \& Crosby, L. (2003). Recruitment and development of online adjunct instructors. The Online Journal of Distance Learning Administration. Retrieved December 21, 2007, from http://www.westga.edu/ distance/ojdla/summer62/crosby_schnitzer62.html

Schweber, C., Kelley, K., \& Orr, G. (1998, August). Training and retaining faculty for online courses: Challenges and strategies. Paper presented at the Annual Conference on Distance Teaching and Learning, Madison, WI. 
Shea, P. (2007). Bridges and barriers to teaching online college courses: A study of experienced online faculty in thirty-six colleges. Journal of Asynchronous Learning Networks, 11(2). Retrieved February 18, 2008, from http://www.sloanc.org/publications/jaln/v11n2/pdf/v11n2_shea.pdf

Sumrall, J. (2002). Factors which influence faculty attitudes and perceptions of distance education in analytical subject areas. Dissertation Abstracts International, 65(06), 2081A. (UMI No. 3135309)

Theall, M. (Ed.) (Summer, 1999). Motivation from within: Approaches for encouraging faculty and students to excel. New Directions for Teaching and Learning, 78. San Francisco, CA: Jossey Bass.

Townsend, R., \& Hauss, M. (2002). The 2002 AHA-OAH survey of part-time and adjunct faculty. Perspectives Online. Retrieved October 6, 2006, from http://www.historians.org/perspectives/issues/2002/0210/0210aha3.cfm.
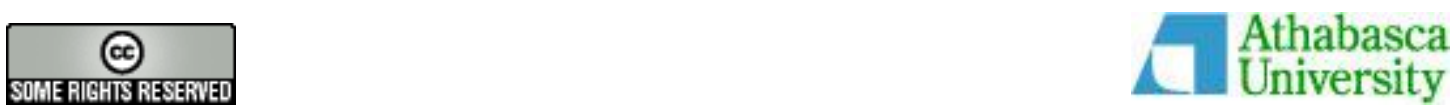
June - 2009

\title{
Technical Evaluation Report
}

\section{Appropriate Distance Education Media in the Philippines and Mongolia}

\author{
Brenda McDonald \\ Centre for Distance Education, Athabasca University, Alberta
}

\begin{abstract}
Recent educational projects in the Philippines and Mongolia have revealed effective educational delivery methods as well as necessary changes to ensure DE access for as many learners as possible. A project initiated by Canada's International Development Research Centre (IDRC) has stressed the value of DE delivery through cellular phone technology. As the cell phone becomes increasingly available in Mongolia and the Philippines, its use to deliver education promises to compensate for the relative lack of Internet access in these countries. The IDRC project illustrates how appropriate distance education methods in Asian countries will assist in economic and social development.
\end{abstract}

Keywords: Mobile learning; cell-phone; appropriate technology; Asian distance education

\section{Current Filipino and Mongolian Initiatives}

As Sir Francis Bacon wrote, "Knowledge is power." When people have knowledge, they are able to participate in the development of their countries and they cease to be bystanders on the world stage. For this purpose, countries such as Mongolia and the Philippines are motivated to offer their citizens effective, affordable, and appropriate means to access distance education (DE). These two countries have participated in recent projects to determine the best way to deliver DE to urban and rural learners who typically cannot afford it. This report discusses the results and formal evaluations of these projects and of other current initiatives designed to improve DE access. Only by examining the outcomes of such initiatives can stakeholders identify the most useful methods and move ahead with appropriate decisions.

\section{Nonformal Distance Education in the Philippines}

A recent project illustrating the context and problems of distance education in the Philippines was Project WASH (Water, Sanitation and Hygiene for All), initiated in 2004. Sponsored by the International Development Research Centre, the Molave Development Foundation Inc. (MDFI) 
embarked on a project entitled Technology-Supported Distance Education and Training in Water, Hygiene and Sanitation (the Philippines) (Ramos et al., 2007). The project's purpose was to expose urban slums and rural areas in the Philippines to basic hygiene practices through informal DE, using a variety of formats including popular comic book styles. To this reviewer, a nurse, the importance of such hygiene education cannot be underestimated because even a simple, informal educational initiative can change the lives of people living in inaccessible communities.

The project was conducted in a remote community on Mindanao, one of the Philippine islands. The community is isolated, with one road connecting it to other parts of the island. The community had the necessary technological equipment, such as computers, printers, and scanners, as well as Internet access via dial-up connections, but this access was limited because the telephone service was not available consistently. For this reason, materials were provided in alternative formats - online and CD-ROM. Content was divided into six modules containing topics related to hygiene and sanitation practices that are relevant to the communities. The design was simple, and assistance was provided to first-time computer users to access the materials and to participate in the project. Technical support was also provided. Results were determined through pre- and post-testing of the community participants' levels of knowledge. In addition, focus groups were conducted (Ramos et al., 2007).

The communities reacted positively to these innovations:

Most of the focus group discussion participants expressed the view that the modules on water, sanitation, and hygiene had a positive effect on their knowledge and attitudes in terms of personal hygiene, eating habits, drinking water, and personal protection. Most participants wanted to share the knowledge acquired from the modules with their families and neighbors, and encourage others to learn WASH through ICT. (Ramos, et al., 2007, p. 222)

The WASH project in the Philippines illustrated that simple, nonformal, media-based education is an effective way to educate people about health and hygiene practices. However, was the project realistic and sustainable? Can other communities in the Philippines and Asia mimic what was achieved, and can the program be delivered cost-effectively? These issues were discussed as the project wrapped up, and the following conclusions were reached:

(1) Up-to-date technical support is needed to ensure that these units run efficiently.

(2) With communities dispersed across 7,100 islands in the country, and with little or no advanced telecommunications infrastructure in many areas, best-laid plans can falter and appropriate technologies must be sought. (Ramos et al., 2007, p. 226)

The first conclusion raises questions about whether technical support is cost-effective for providers and whether governments can provide such assistance for this form of education. The second conclusion indicates the most serious problem identified by the project. In a later section, this report will describe an appropriate cellular technology that is emerging in the Philippines to deliver DE to widely dispersed communities. 


\section{Nonformal Distance Education in Mongolia}

Although one of Asia's least developed nations, Mongolia is experiencing early success in the use of DE for urban and rural training; in fact, it has been determined that the delivery of education in Mongolia cannot be sustained without it (Amarsaikhan et al., 2009). It is imperative for Mongolia to examine effective and efficient ways to deliver education to its population and to maintain its current UNESCO Literacy Prize winning levels of literacy advancement. DE is a viable solution to the problems of educational access in Mongolia (Amarsaikhan et al., 2009).

DE methods in Mongolia urgently need development, however. Traditionally, DE has been exclusively print-based, but other methods of delivery should be explored, such as radio and television, in order to compensate for the lack of Internet access in rural areas. Amarsaikhan et al. (2009) report recent focus groups that indicated public interest in the development of TV-based learning resources. Students also recommended the use of FM radio as a DE delivery method, and wide accessibility to and usage of FM radio makes this a real possibility. Western communities have relied heavily on the radio for education and communication since the 1940's, and it makes sense to broadcast DE lectures from radio stations in countries such as Mongolia where radio is a primary medium.

The Mongolian report makes no reference to using the Internet as a means for effective DE delivery, a decision that reminds us of the Internet's perceived lack of relevance in many developing regions. Another recent study, however, emphasises that the possibility of online methods is being examined carefully. From 2005-08, the PANdora network of Asian DE researchers conducted a study to evaluate the use of online learning management systems (LMS) in Mongolia and other Asian countries. The study revealed the following:

A clear advantage of an LMS in Asian education would be the ability to operate efficiently over low-speed Internet connections (but) even this feature is of little use to the majority of DE students in Asia who lack Internet access in any form. (In Mongolia) this is a major problem... (Batpurev \& Buyandelger, 2009, p. 8687)

Clearly, Mongolia is one of the Asian countries that must explore avenues for DE other than Internet-based systems.

\section{Exploring New Technologies}

Educators in the Philippines and Mongolia are exploring technologies for DE delivery that go beyond the online methods that are prevalent elsewhere. Both countries are interested in the opportunities of mobile education (m-learning) and the potential use of mobile devices such as the cell phone. The use of cellular technology throughout Mongolia and the Philippines indicates the commitment to mobile devices of their governments and of the public (Ramos et al., 2009). The MDFI, whose WASH project was discussed above, has led a series of IDRC-funded projects 
in the two countries to explore the DE implications of Short Messaging Systems (SMS). Known as the MIND project, this initiative examined the socio-economic and gender issues that motivate or hinder cell phone subscribers in using SMS for nonformal distance education.

MIND (Mobile Technology Initiative for Nonformal Distance Education) involved establishing an SMS learning system using a GMS data terminal, SMS software, and support facilities for teachers and students. Support materials were distributed as printed text and audio CDs, following which the students used the cell phone to submit assignments and to respond to quizzes that assessed their learning levels. The results indicated that cell phone DE delivery fit well into the participants' daily schedule. Male and female participants learned the content, took the quizzes efficiently, and submitted the necessary assignments to their tutors via this innovative method (Ramos \& Triñona, 2009).

Accessibility and affordability were the main perceived benefits of this project. Students felt that SMS learning was more beneficial than other costlier forms of education. "Learning through SMS has more value for money because of the added benefit of not having to travel and of being able to learn from their homes or workplaces" (Ramos \& Triñona, 2009, p. 249). Access to education is a major hurdle for people in countries such as Mongolia and the Philippines; thus, accessible and cost-effective education for large numbers of people offers appealing future directions.

In each of these countries, the potential of DE using SMS methods is remarkable. SMS has the ability to overcome geographical limitations and has proved in these studies to be a cost-effective means of DE delivery. The simple cell phone can be used to deliver educational material and information to vast populations in both the developed and developing worlds, and it is important that full advantage be taken of this new educational technology by educators and governments. However, tutors must be given the necessary tools and training for such programmes to be successful. Many educators interviewed for this project expressed concerns about the level of preparation for DE delivery that they receive (Amarsaikhan et al., 2009).

\section{Conclusions}

The studies above indicated that students and teachers alike recognise the need for greater and more appropriate technological support for DE. The development of a wide range of usable course materials is the only way DE will serve an increasing number of users. New ideas are emerging in lesser developed countries such as Mongolia and the Philippines to overcome infrastructure and training challenges. The accessibility and cost effectiveness of DE delivery are issues that need to be addressed because the use of cell phone technology for the delivery of education is an exciting alternative not only for the Philippines and Mongolia but for the world. Cell phones are now available to over half the world's population; they have outstripped the number of landline telephones. Does the future of the cell phone include greater provision of educational services in vendors' packages? If the challenges of m-learning can be solved, it will become a vital force for $\mathrm{DE}$ in developing countries and in remote areas of developed countries. 


\section{References}

Amarsaikhan D., Oyun S., \& Zhang, W. (2009, in press). Distance education policy and practice in Mongolia. In J. Baggaley \& T. Belawati (Eds.), Distance education technology in Asia. New Delhi: Sage India.

Bacon, Francis (Sir). The Quotation Page. Retrieved from: http://www.quotationspage.com/quotes/Sir_Francis_Bacon/

Batpurev, B., \& Buyandelger, B. (2009, in press). Online learning management systems. In T. Belawati \& J. Baggaley (Eds.), The PANdora distance education guidebook. New Delhi: Sage India.

Ramos, A., Nangit, G., Ranga, A., \& Triñona, J. (2007). ICT-Enabled distance education in community development in the Philippines. Distance Education, 28(2), 21.

Ramos, A.J., \& Triñona, J. (2009, in press). Mobile technology in nonformal distance education. In J. Baggaley \& T. Belawati (Eds.), Distance education technology in Asia. New Delhi: Sage India. 
June - 2009

\title{
Technical Evaluation Report
}

\section{Distance Education in China and India: Collectivism and Connectivism}

\author{
Deborah Joy Carter \\ University of British Columbia, Okanagan, Canada
}

\begin{abstract}
In the last decade, China and India have seen large increases in their literacy and graduation rates and an increasing emphasis on distance education and training initiatives. They are examples of nations in which economic and technological initiatives have been aligned in order to produce outcomes that ensure the population will thrive in the $21^{\text {st }}$ century. However, no country can simply equip its distance education system with updated technologies and expect to be fully prepared for $21^{\text {st }}$ century economic challenges. This report outlines the consonances and dissonances of distance education (DE) in China and India and the policy alignments required for its stable development.
\end{abstract}

Keywords: Distance education policy; China; India; economical alignment; technology; collectivism; connectivism

\section{Introduction}

Independence must begin at the bottom. Thus every village will be a republic ... having full powers. It follows, therefore, that every village has to be selfsustained and capable of managing its affairs. Thus, ultimately, it is the individual who is the unit... In this structure composed of innumerable villages, there will be ever-widening, never-ascending circles. Life will not be a pyramid with the apex sustained by the bottom. (Mahatma Gandhi, 1946)

The agricultural term 'monoculture' refers to the practice of growing one crop over a wide area deemed inferior due to soil conditions, short growing seasons, and other factors. The uniform crops yield greater harvests and prosperity in the short term, but a single variable can destroy the entire community's social, economic, cultural, and political sustainability. Non-agricultural disciplines have adapted this term to describe a situation in which a single entity sanctions one solution for a seemingly ubiquitous circumstance (Blackmore, 1999; Reimann, 2008). For example, Geer (2003) defined Microsoft's global dominance in technology as a monoculture. His 
concerns were not couched in the usual cross-platform debate of PC versus Mac; rather, he pointed to a flaw that could destroy businesses and governments utilising this monoculture security mediocrity (Udell, 2004). Once a hacker 'opens the door' to one virtual data warehouse in the Microsoft community, all warehouses become accessible, independent of their physical time and space. Geer further postulated that the individual business or government is accountable to other community members to remain vigilant in relation to this flaw, which is created by the single, shared integrated pattern.

If Geer's warning is justified, the Microsoft monoculture will cease to cause convergence among users and will lead to user divergence. Since Microsoft has not provided a wide range of solutions for a variety of global needs, the monoculture is already becoming an open-source polyculture in which community members champion solutions based on specific needs. If community dialogue is facilitated and the members' solutions are widely distributed for analysis and synthesis, their global contribution will become greater than the sum of their parts. Then, as community dialogue serves as a feedback loop to Microsoft, the changes generated will positively affect future policies based on the global community's needs. By connecting the collective of individual needs to Microsoft, its future policy and decisions become more relevant to all stakeholders.

A similar situation could occur in the development of distance education (DE) in the major developing powers of China and India because the governments of both nations have taken a generally monocultural approach to developing educational initiatives for their populations. In the current report, the levels of technological consonance and dissonance in these two sets of national policy are reviewed, and a global flaw is discussed that may jeopardise the sustainability and convergence of their distance education (DE) initiatives.

\section{Distance Education Policies in China and India}

\section{Consonance}

When global interconnectedness was in its infancy, developed countries took the lead in defining DE development, largely in relation to Internet access. Until recently, the DE approaches of China and India have emulated the traditional teacher-centred pedagogies and have provided asynchronous educational tools for learners through correspondence, TV, radio and the Internet. The two countries have begun to add the latest DE multimedia to their methodology, including synchronous communication methods between teachers and students. Today, China and India have the most extensive networks of open universities and DE institutions in the world, which provide a continuum of education from kindergarten to higher education and a nontraditional holistic view that supports lifelong learning and remediation strategies for adult learners. Their adult learners include full-time urban workers and rural and farming communities. Furthermore, their agendas anticipate an era of future employment opportunities and economic sustainability that is based on support for teacher development and professionalism.

While China stimulates its economy through education initiatives largely independent of the rest of the world, India enters into international partnerships, for example in the areas of workplace 
learning and the teaching of English in evening classes (The Economist, 2008; Jamtsho et al., 2009). In India, parents regard their children's education as more important than their own, and they view education as an opportunity to improve the family's economic status, especially if it includes the study of English (Crichton \& Childs, 2008; Chen, Wang, \& Chen, 2009; Jamtsho et al., 2009). Both countries actively use a far broader range of DE technologies than is used in the West. The significant effects on their communities have already been broad and deep (Chen, Wang, \& Chen, 2009; Jamtsho et al., 2009).

\section{Dissonance}

DE developments in China and India differ owing to diverse patterns of population density. China's western region, similar to Canada's north, is sparsely populated. These are the most isolated and poorest areas requiring the greatest government assistance to attract teaching professionals and to maintain Internet, TV, and radio access for educational initiatives. India's population distribution resembles that of the United States, with more urbanisation and fewer isolated areas. This distribution attracts more private industry solutions across the country and distributes government spending more evenly although not necessarily more equitably. An economic difference between these two patterns is that the poorer regions in China are likely to experience more impact than the poorer Indian regions if their governments reduce economical support for educational development.

\section{A Flaw: Collectivism without Connectivism}

Although the ongoing costs of maintaining educational infrastructures remain fixed, government spending is inevitably tied to some form of economic prediction. Any leakage in the collective or any chance occurrence can lead to the collapse of both policy and practice. Such leakage occurs, for example, when international students fail to return to their own countries after graduating abroad. The largest proportion of international students in Canada is from China and India. The Survey of Earned Doctorates (King et al., 2006) has indicated that $72 \%$ of international doctoral students intend to remain in Canada upon completion of their studies. The ripple effect of this decision is complex, with an immediate loss for the home countries of the research and development advantages the students have gained in their studies. Similar losses of benefit occur when students graduate from higher education institutions in their own countries and leave for better career opportunities abroad. In the 1990s, for example, India experienced almost universal emigration of their graduating computer sciences students; however, as career opportunities have multiplied in India, their graduates have tended to stay. Clearly, governmental attempts to harmonise industry and education are fragile (World Bank, 2000).

The long-term effects of national disasters can also destabilise development. A historical example of such devastation was the Great Irish Famine (1845-49), in which single variant potato crops were lost due to blight (Gkotzaridis, 2006). Similarly, in 1959-61, China endured a famine in which over 20 million people are thought to have died. The famine had lasting effects on the health and economic growth of the country. The sharp drop in Chinese grain harvests in 1958 created a similar flaw in the monoculture created by the nation's agricultural collectivisation 
programme. The superior communication technologies available in China today could generate massive immigration and a very different demographic, political, and cultural landscape from that of the past and present (Chen \& Zhou, 2007).

These examples demonstrate the difficulty of predicting the economic and educational future of a nation. As interconnectivity spreads globally, individuals become more empowered and the predictability of outcomes for individual countries diminishes. To counter this problem and to enhance education and economic viability, a nation may attempt to create an integrated information environment of student and worker data systems, as in the European Union (EU) (Euroactiv.com, 2008). The EU has defined common standards for education and shared processes and services, which facilitate interoperability between countries. It updates accountability measures and systems to include outcome measures that reach beyond the scope of a single country, while investigating dynamic and integrated technology infrastructures across multiple borders. It is piloting projects for ePortfolio systems to create personal digital archives for students and workers while augmenting teacher training. Despite these positive initiatives, the EU's membership continues to experience negative economic growth, and the EU's ability to anticipate the educational consequences of the shifting global economy remains elusive.

\section{Four Themes}

From these examples, four themes emerge. Firstly, the human aspect of education is a key component in the successful alignment of economic and educational initiatives. The need for the development and maintenance of human relationships is essential in social and cognitive development, assessment practices, and learning styles (Crichton \& Childs, 2008). Secondly, connected feedback loops between the teaching-learning environment and government should drive curriculum development in centralised educational initiatives that are aligned with economic policy. Otherwise, courses become generic products that do not meet the needs of learners or industry; the teacher's role is relegated to that of gatekeeper rather than of a respected professional; and programme administration becomes unruly (Chen, Wang, \& Chen, 2009). Thirdly, the underlying tenets of communal learning need to be respected in computer-based instruction so that learning can be effective and relevant. Such courses must recognise the importance of allowing participants in different areas to experience learning in various ways, to be actively engaged in the process of acquiring new, pertinent knowledge, and to express their learning according to their strengths, experiences, and goals. Two successful examples in this respect are the community learning centres developed in poverty-stricken areas of China by Tsinghua University and the village information centres of Pondicherry, India (Chen, Wang, \& Chen, 2009; Larson \& Murray, 2008).

The final emerging theme is that change in DE is not driven only by available technologies but also by the winds of political and economic change, which determine the maintenance of technology usage. Changes in DE require analysis that differentiates between cutting-edge and merely trendy policies and practices. Change must not be for the sake of change; rather, it must be contemplated in the light of its potential impact on individuals and communities of practice. For lifelong learners, it is important to maintain, if not increase, information technology literacy 
and to find ways of applying information technologies that maximize each DE community's strengths and abilities, whether their members reside in western China, urban India, or northern Canada (Baggaley, 1999).

\section{Conclusion}

Since the early $20^{\text {th }}$ century, the governments of China and India have maintained national policies to ensure that their vast populations, each numbering over a billion people and together representing approximately one-third of the world's population, are educated for the $21^{\text {st }}$ century. As well as aligning their educational policies and their economies, they have created high priorities for technological immersion and global interconnectedness. Owing to incongruent population density and poverty levels, both governments have invested in diverse technologies and have implemented several generations of DE nationwide. Both have directly attributed increases in the literacy rates of urban and rural districts to these policies and action plans.

Past success does not predict future solvency in a global economy, however, as the current global downturn is demonstrating. In 1908, Henry Ford perfected the moving assembly line on which workers became 'one part' experts (HenryFord.org, 2009). By retooling his factory, Ford became an automotive leader. A century later, the Ford Company faces government bailouts, factory closings, and redundancies. Nations such as China and India cannot simply retool their DE systems with updated technologies and expect to be fully prepared for $21^{\text {st }}$ century challenges. As demonstrated in the case of the Microsoft monoculture, it is the vigilance of the polycultural community that generates just-in-time learning and solutions when unexpected events attack the global system.

Too often new educational initiatives are introduced with great fanfare. However, in many cases, without proper guidance, appropriate communication systems, and careful policy alignment, they flounder. The challenge is to design a higher education system that meets the diversity of teachers and learners, provides individual versus collective learning preferences, and seeks flexibility in multiple modes (Bonk \& Graham, 2006). A further responsibility is to provide evaluation and feedback in stages so that the results of global changes can be anticipated, and ripple effects in one area do not create a tsunami in another, thus potentially destroying a nation's social, economic, cultural, and political sustainability. 


\section{References}

Baggaley, J. (1999). The impact of information technology on national and transnational education. In S. Bond \& J. P. Lemasson (Eds.), A new world of knowledge: Canadian universities and globalization (pp. 183-199). Ottawa: AUCC/CIDE/IDRC.

Blackmore, J. (1999). Troubling women: Feminism, leadership and educational change. Buckingham: Open University Press.

Bonk, C., \& Graham, C. (2006). Furture directions of blended learning in higher education and workplace learning centres. In C. Bonk \& C. Graham (Eds.), The handbook of blended learning: Global perspectives, local designs. San Franscisco: Pfieffer.

Chen, L., Wang, N., \& Chen, H. (2009, in press). E-learning in Chinese schools and unversities. In J. Baggaley \& T. Belawati (Eds.), Distance education technology in Asia. New Delhi: Sage. Retrieved from www.pandora-asia.org/downloads/Book-2/PANdora-book2_v6Chap4.pdf

Chen, Y., \& Zhou, L. (2007). The long-term health and economic consequences of the 1959-1961 famine in China. Jounal of Health Economics 26(4), pp. 659-681.

Crichton, S., \& Childs, E. (2008). Looking forward: stories of practice. In Education for a digital world: Advice, guidelines, and effective practice from around the globe. Vancouver: BCcampus and Commonwealth of Learning.

The Economist (2008). Dr. Keynes's Chinese patient. Vol. 389 (8606), November 15.

Euroactiv.com (2008). Lifelong Learning. Retrieved from: www.euractiv.com/en/education/lifelong-learning/article-117516

Gandhi, M. (1946). Article in Harijan. Cited by Varughese, S. (2002). Retrieved from www.lifepositive.com/spirit/masters/mahatma-gandhi/gandhi.asp

Geer, D. (2003). CyberInsecurity: The cost of monopoly. Retrieved from cryptome.info/0001/cyberinsecurity.htm

Gkotzaridis, E. (2006). Trials of Irish history: Genesis and evolution, 1938-2000. London: Routledge.

HenryFord.org (2009). The life of Henry Ford. Retrieved from www.hfmgv.org/EXHIBITS/hf/default.asp\#fmc

Jamtsho, S., Rinchen, S., Khan, Z., Sangi, N., Ahmed, S., \& Samaranayake, V. (2009, in press). Accessibility, acceptance and effects of distance education in South Asia. In J. Baggaley, 
\& T. Belawati (Eds.), Distance education technology in Asia. New Delhi: Sage. Retrieved from www.pandora-asia.org/downloads/Book-2/PANdora-book2 v6Chap2.pdf

King, D., Eisl-Culkin, J., \& Desjardins, L. (2007). Doctoral graduates in Canada: Findings from the Survey of Earned Doctorates, 2004/2005. Retrieved from www.statcan.gc.ca/pub/81595-m/81-595-m2008069-eng.htm

Larson, R. C., \& Murray, M. E. (2008). Learning as a tool for poverty reduction and economic development: A focus on China and Mexico. Journal of Science Education and Technology, 17(2), 175-196.

Reimann, P. (2008). Communities of practice. In H. Adelsberger, P. Kinshuk, J. Pawlowski et al. (Eds.), Handbook on information technologies for education and training. Verlag Heidelberg: Springer.

Udell, J. (2004). Accountability on demand. InfoWorld, 26(38), p. 36.

World Bank (2000). Higher education in developing countries: Peril or promise. Washington, DC.

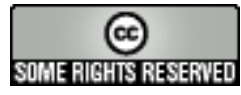

